Cochrane Database Syst Rev. Author manuscript; available in PMC 2016 June 09.

Published in final edited form as:

Cochrane Database Syst Rev. ; (2): CD008722. doi:10.1002/14651858.CD008722.pub2.

\title{
Interventions to enhance adherence to dietary advice for preventing and managing chronic diseases in adults
}

\author{
Sophie Desroches ${ }^{1,2}$, Annie Lapointe ${ }^{1,2}$, Stéphane Ratté ${ }^{1}$, Karine Gravel$^{2}$, France Légaré $^{3}$, \\ and Stéphane Turcotte ${ }^{1}$ \\ ${ }^{1}$ Centre de recherche du Centre hospitalier universitaire de Québec (CHUQ), St-François \\ d'Assise Hôpital, Québec, Canada \\ 2Département des sciences des aliments et de nutrition, Université Laval, Québec, Canada \\ ${ }^{3}$ Département de médecine familiale et d'urgence, Université Laval, Québec, Canada
}

\section{Abstract}

Background-It has been recognized that poor adherence can be a serious risk to the health and wellbeing of patients, and greater adherence to dietary advice is a critical component in preventing and managing chronic diseases.

Objectives-To assess the effects of interventions for enhancing adherence to dietary advice for preventing and managing chronic diseases in adults.

Search methods-We searched the following electronic databases up to 29 September 2010: The Cochrane Library (issue 9 2010), PubMed, EMBASE (Embase.com), CINAHL (Ebsco) and PsycINFO (PsycNET) with no language restrictions. We also reviewed: a) recent years of relevant conferences, symposium and colloquium proceedings and abstracts; b) web-based registries of clinical trials; and c) the bibliographies of included studies.

Selection criteria-We included randomized controlled trials that evaluated interventions enhancing adherence to dietary advice for preventing and managing chronic diseases in adults.

Contact address: Sophie Desroches, sophie.desroches@fsaa.ulaval.ca.

*Indicates the major publication for the study

\section{CONTRIBUTIONS OF AUTHORS}

SD coordinated and contributed to all stages of the review.

AL performed the search strategy, identified eligible studies, extracted data, performed analysis and interpreted result and wrote the first draft of the review.

ST assisted with statistical analyses, contributed to the writing of the review.

SR developed the search strategy, contributed to the writing of the review.

$\mathrm{KG}$ contributed to the protocol development and to the writing of the review.

FL contributed to the protocol development and to the writing of the review.

\section{DECLARATIONS OF INTEREST}

None known.

DIFFERENCES BETWEEN PROTOCOL AND REVIEW

The protocol was published in 2010 (Desroches 2010).

Types of interventions: Multiple interventions are now defined as those with two or more interventions.

Pubmed search strategy: Food habit*[TIAB] or Feeding behaviour*[TIAB] or Eating behaviour*[TIAB] were added to the Pubmed search strategy.

Assessment of reporting biases: publication bias using funnel plot was not explored since multiple adherence outcome measures were reported in several studies and could not be pooled together. 
Studies were eligible if the primary outcome was the client's adherence to dietary advice. We defined 'client' as an adult participating in a chronic disease prevention or chronic disease management study involving dietary advice.

Data collection and analysis-Two review authors independently assessed the eligibility of the studies. They also assessed the risk of bias and extracted data using a modified version of the Cochrane Consumers and Communication Review Group data extraction template. Any discrepancies in judgement were resolved by discussion and consensus, or with a third review author. Because the studies differed widely with respect to interventions, measures of diet adherence, dietary advice, nature of the chronic diseases and duration of interventions and followup, we conducted a qualitative analysis. We classified included studies according to the function of the intervention and present results in a narrative table using vote counting for each category of intervention.

Main results-We included 38 studies involving 9445 participants. Among studies that measured diet adherence outcomes between an intervention group and a control/usual care group, 32 out of 123 diet adherence outcomes favoured the intervention group, 4 favoured the control group whereas 62 had no significant difference between groups (assessment was impossible for 25 diet adherence outcomes since data and/or statistical analyses needed for comparison between groups were not provided). Interventions shown to improve at least one diet adherence outcome are: telephone follow-up, video, contract, feedback, nutritional tools and more complex interventions including multiple interventions. However, these interventions also shown no difference in some diet adherence outcomes compared to a control/usual care group making inconclusive results about the most effective intervention to enhance dietary advice. The majority of studies reporting a diet adherence outcome favouring the intervention group compared to the control/usual care group in the short-term also reported no significant effect at later time points. Studies investigating interventions such as a group session, individual session, reminders, restriction and behaviour change techniques reported no diet adherence outcome showing a statistically significant difference favouring the intervention group. Finally, studies were generally of short duration and low quality, and adherence measures varied widely.

Authors' conclusions-There is a need for further, long-term, good-quality studies using more standardized and validated measures of adherence to identify the interventions that should be used in practice to enhance adherence to dietary advice in the context of a variety of chronic diseases.

\section{PLAIN LANGUAGE SUMMARY}

\section{Interventions to enhance adherence to dietary advice for preventing and managing chronic diseases in adults}

Chronic diseases are the leading cause of mortality worldwide. Although the adoption of a healthy diet is recognized as an important component for their prevention and management, many individuals at risk of or having chronic diseases do not adhere to recommended dietary advice. The methods used to facilitate changes in dietary habits through dietary advice (defined in this review as 'interventions') could improve adherence of clients to dietary advice. Therefore, we reviewed trials of interventions aiming to enhance adherence to dietary advice for preventing and managing chronic diseases in adults. 
We identified 38 studies involving 9445 participants examining several types of interventions for enhancing adherence to dietary advice for preventing and managing many chronic diseases. The main chronic diseases involved were cardiovascular diseases, diabetes, hypertension, and renal diseases. Interventions shown to improve at least one diet adherence outcome are: telephone follow-up, video, contract, feedback, nutritional tools and more complex interventions including multiple interventions. However, these interventions also showed no difference in some diet adherence outcomes compared to a control/usual care group making the results inconclusive about the most effective intervention to enhance dietary advice. Interestingly, all studies including clients with renal diseases reported at least one diet adherence outcome showing a statistically significant difference favouring the intervention group, no matter which intervention was provided. The majority of studies reporting a diet adherence outcome favouring the intervention group compared to the control/usual care group in the short-term also reported no significant effect at later time points. Studies investigating interventions such as a group session, individual session, reminders, restriction and behaviour change techniques reported no diet adherence outcome showing a statistically significant difference favouring the intervention group. Finally, interventions were generally of short duration, studies used different methods for measuring adherence and the quality of the studies was generally low.

\section{BACKGROUND}

\section{Description of the condition}

Chronic diseases are defined as diseases of long duration that have generally a slow progression (WHO 2008). The most common chronic diseases include diabetes, cardiovascular diseases (CVD), cancers, asthma, chronic obstructive pulmonary diseases (COPD), arthritis, obesity and renal failure. Considering that chronic diseases are the leading cause of death and disability and account for $60 \%$ of all deaths worldwide (WHO 2008), the Department of Chronic Disease and Health Promotion of the World Health Organization (WHO) emphasizes the importance of preventing and managing chronic diseases and their risk factors (WHO 2010). Some health conditions have been found to be risk factors, for example, patients with the metabolic syndrome have an increased risk of developing CVD (Mottillo 2010). Similarly, women with a previous history of gestational diabetes have an increased risk of developing type II diabetes (Bellamy 2009). These risk factors may be targeted in interventions aiming to prevent chronic diseases.

Evidence from epidemiologic, experimental and clinical studies has demonstrated a strong relationship between dietary patterns or nutrient intakes, and prevention and management of chronic diseases including diabetes (Champagne 2009), CVD (Lavie 2009), and obesity (Kennedy 2004). Several authoritative health agencies have recommended the adoption of a healthy diet as the cornerstone in preventing and/or managing chronic diseases such as CVD (Lichtenstein 2006), diabetes (Bantle 2008) and cancer (Kushi 2006). For example, lifestyle interventions including dietary changes were shown to reduce the incidence of diabetes by $58 \%$ compared to a control group in individuals at high risk in two large randomized controlled trials (RCTs): the Finnish Diabetes Prevention study (Lindstrom 2003) and the Diabetes Prevention Program (Knowler 2002). In line with this, dietitians and other health 
professionals provide people with dietary advice designed to improve their nutritional intake (Baldwin 2011).

The concept of 'adherence' recognizes the patient's right to choose whether or not to follow advice, and implies a patient's active participation in the treatment regimen (Cohen 2009). For chronic disease management including medication and lifestyle changes, non-adherence rates are estimated to be between 50\% and 80\% (WHO 2003). Thus, poor adherence can be a serious threat to patients' health and wellbeing (DiMatteo 2002), and also carries an economic burden (DiMatteo 2004a). Adherence is particularly important in the context of chronic diseases requiring long-term therapy and a number of permanent rather than temporary changes in lifestyle behaviours, such as diet, physical activity and smoking (WHO 2003). The extent to which risk-reduction interventions proved to be as effective in research settings as in individuals' real-life settings depends on the patient's adherence to treatment advice. In that regard, results from an RCT assessing adherence to and effectiveness of four popular diets (Atkins, Zone, Weight Watchers, and Ornish) revealed that level of adherence to dietary advice, rather than the type of diet, was the key determinant of greater weight loss and CVD risk factor reductions (Dansinger 2005). Whether the number of intervention goals that an individual has to reach influences adherence was also addressed in a secondary analysis of the PREMIER study (Young 2009). In this RCT that tested the effects of two multicomponent lifestyle interventions on blood pressure control, the authors reported that individuals with the most physical activity and dietary behaviour goals to achieve reached the most goals (Young 2009).

Measurement of adherence to prescribed dietary advice typically involves: 1) assessment of what the client eats through self-reported methods (e.g. 24-hour recall, food records, food frequency questionnaires, diet history); and 2) determination of the degree to which the diet approximates the recommended dietary plan (e.g. difference between clients' recommended macronutrient goals and their self-reported intake). Although sparsely used, more objective measures of adherence to diets also exist (e.g. 24-hour urinary sodium excretion to assess adherence to a low sodium diet (Chung 2008)). However, there is no gold standard for the accurate determination of dietary intake. Self-report of energy intake is a characteristic inherent to nutrition-related topics and is found to be underestimated compared to objective measures such as resting energy expenditure assessed by indirect calorimetry (Asbeck 2002). Underreporting energy intake has been observed more frequently in women versus men, (Johnson 1994), in older versus young (Huang 2005), and in obese versus normal weight individuals (Briefel 1997). Although self-report measures are often regarded as susceptible to bias (e.g. over reliance on memory; report error related to meal composition or portion sizes; daily dietary variability; social desirability) (Kumanyika 2000; Wilson 2005) they are a direct, simple and inexpensive method (DiMatteo 2004b), and are readily available for use in practice. Self-report measures can be improved and validated by using multiple measures of adherence and controlling statistically for bias or by using constructs such as body weight, blood pressure or plasma cholesterol concentrations (Hebert 2001; DiMatteo 2004b). 


\section{Description of the intervention}

Adherence to dietary advice has been shown to vary according to gender (Chung 2006), socio-economic status (Reid 1984) and ethnicity (Natarajan 2009). Moreover, numerous barriers to client adherence in health care have been identified. Among them are complexity of treatment plan, and clients' knowledge of disease and understanding of the importance of treatment in its control and in preventing adverse outcomes (Makaryus 2005; Harmon 2006; Robinson 2008). According to a WHO report, "interventions for removing barriers to adherence must become a central component of efforts to improve population health worldwide" (WHO 2003). Although non-adherence is often attributed to clients who are viewed as "non cooperative", "non compliant" and "unable to follow instructions" (Kapur 2008), it is increasingly recognized that health professionals may help their clients overcome barriers to adherence (Harmon 2006) by improving how they approach their clients' problems, how they provide advice, and how they involve their clients in treatment decision making. Although there is a wide diversity of interventions for enhancing adherence to dietary advice, their underlying aim is to prompt change to facilitate the adoption of recommended dietary behaviours.

\section{How the intervention might work}

Behaviour change theories have proved useful for explaining health-related behaviours, including dietary behaviours. They attempt to identify the determinants that will contribute to predict the adoption of a specific behaviour, and which should be taken into account when developing a behaviour change intervention, such as a method for providing dietary advice. Several models or theories to predict behaviour change can be used in health-related interventions, such as the Health Belief Model (Rosenstock 1974), the Theory of Planned Behaviour (Ajzen 1991), the Theory of Reasoned Action (Fishbein 1981) and the Social Cognitive Theory (Bandura 1986). More recently, Michie 2011 proposed a framework, the COM-B system, which includes three principal interrelated components of the determination of a behaviour: 1) the motivation (the direct brain process leading to a behaviour), 2) the capability (the individual's psychological and physical capacity to engage a behaviour) and 3 ) the opportunity (the factors that lie outside the individual that make the behaviour possible or not) (Michie 2011). The authors also developed a system for characterizing behaviour change interventions and their components in order to facilitate the identification of the effective behaviour change interventions and the implementation of evidence-based practice in this area. According to this system, behaviour change interventions can be classified as nine intervention functions: education, persuasion, incentivisation, coercion, training, restriction, environmental restructuring, modelling and enablement (Michie 2011). These theories or models focus on different determinants or combinations of determinants of the behaviours which could be helpful for developing interventions for enhancing adherence to dietary advice.

\section{Why it is important to do this review}

As greater adherence to dietary advice is a critical component in preventing and managing chronic diseases, research is needed to identify the characteristics of interventions that will result in a better agreement between health professionals' evidence-based dietary advice, 
and their clients' eating patterns. Despite growing recognition that non-adherence to dietary advice is a barrier to getting new nutrition knowledge into practice, previous knowledge syntheses have provided decision makers and knowledge users with little practical guidance on the development of useable interventions for enhancing adherence to dietary advice. Studies have reported on interventions designed to enhance adherence to dietary advice by overcoming barriers to adherence. Although some studies have reported positive effects of interventions to enhance adherence to dietary advice, no systematic review specifically assesses dietary interventions that lead to sustained dietary changes or that refer to a wide array of chronic diseases. Haynes 2008 summarized the results of RCTs of interventions to help clients adhere to prescriptions for medications for medical problems, and excluded interventions targeting dietary advice. Bosch-Capblanch 2007 systematically reviewed the effects of contracts between clients and health professionals for improving clients' adherence to treatment, prevention and health promotion activities. Although this review is relevant to our review, it reported only the effect of contracts (as opposed to other interventions), and was not specific to dietary advice. Several non-Cochrane reviews may overlap with our review, but these are not systematic (Brownell 1995b; Brownell 1995a; Burke 1997; Newell 2000; Fappa 2008) and/or are related to only one health condition and not specifically targeting dietary advice (Burke 1997; Newell 2000; Fappa 2008).

This review will improve the knowledge base for adherence to dietary advice; a topic of immense importance for dietetics practice that will also be relevant to clients, and other health professionals.

\section{OBJECTIVES}

To assess the effects of interventions for enhancing adherence to dietary advice for preventing and managing chronic diseases in adults.

\section{METHODS}

\section{Criteria for considering studies for this review}

Types of studies-Randomized controlled trials (RCTs) including cluster RCTs. Because interventions for enhancing adherence to dietary advice aim to initiate dietary changes, a cross-over design in which each client received all interventions could induce a carry-over effect. Therefore, we excluded studies including a cross-over design.

Types of participants-Clients, aged 18 years and over, in real-life settings. We define 'client' as an adult participating in a chronic disease prevention or chronic disease management study involving dietary advice. We included clients who had a diet relatedchronic disease (e.g. obesity, cardiovascular disease, renal failure, hypertension) or at least one risk factor for a chronic disease (e.g. overweight, hyper-lipidaemia). We included family or non-family caregivers such as wife/husband or individual living with the client and involved in meal planning and preparation. We also included studies involving health professionals delivering dietary advice. 
Types of interventions-We included studies assessing the effects of a single intervention or multiple interventions involving chronic disease prevention and management, on adherence to dietary advice. 'Intervention' was defined as the method used to facilitate changes in dietary habits through dietary advice. To structure the presentation of results, we grouped interventions according to the intervention functions of the behaviour change wheel developed by Michie and colleagues (Michie 2011). Therefore, we classified interventions to enhance adherence to dietary advice as:

- $\quad$ Education (increasing knowledge or understanding);

- Persuasion (using communication to induce positive or negative feelings or stimulate action);

- Incentivisation (creating expectation of reward);

- $\quad$ Coercion (creating expectation of punishment or cost);

- $\quad$ Training (imparting skills);

- Restriction (using rules to reduce the opportunity to engage in the target behaviour);

- Environmental restructuring (changing the physical or social context);

- $\quad$ Modelling (providing an example for people to aspire to or imitate);

- $\quad$ Enablement (increasing means/reducing barriers to increase capability or opportunity);

- $\quad$ Multiple (combination of two or more different interventions).

We included studies making the following comparisons:

- $\quad$ Single intervention for enhancing adherence to dietary advice versus no intervention (control) or a reference standard of care (usual care);

- $\quad$ Single intervention for enhancing adherence to dietary advice versus single or multiple interventions with a similar purpose (to enhance adherence to dietary advice);

- Multiple interventions for enhancing adherence to dietary advice versus no intervention (control) or a reference standard of care (usual care);

- Multiple interventions for enhancing adherence to dietary advice versus single or multiple interventions for enhancing adherence to dietary advice.

The term 'reference standard of care' refers to the usual dietary intervention performed to address a specific health condition. For example, in Amato 1990 two approaches were used with patients who were severely obese using the same dietary advice: 1) weight loss advice versus 2) weight loss advice combined with psychotherapy. The approach with weight loss advice was the reference standard of care while the approach with weight loss advice combined with psychotherapy was the intervention for enhancing adherence to dietary advice. Furthermore, only studies comparing interventions with the same dietary advice component (e.g. increase consumption of fruits and vegetables, decrease fat intake) but 
differing in terms of the method for changing dietary habits through dietary advice (e.g. education (counselling and follow-up with health professional, educational tools)) were included. We excluded studies assessing adherence to dietary advice for which interventions were not a method for facilitating changes in dietary habits through dietary advice (e.g. medication for weight loss, exercise, etc.). We excluded studies that aimed primarily to evaluate the effects of an experimental diet or a food plan on health outcomes, and for which adherence was monitored as a secondary outcome to justify, for example, the validity of the results, as these interventions were not designed for enhancing adherence to dietary advice. We only included studies including food-based dietary advice and representing real-life conditions. Therefore, we excluded studies involving the provision of meals, food items or dietary supplements (e.g. vitamin, mineral, omega-3 fatty acid).

\section{Types of outcome measures}

\section{Primary outcomes}

- $\quad$ Client adherence to dietary advice (e.g. biochemical measures within acceptable limits, mean dietary intake, proportion of clients achieving the dietary advice). We included studies reporting adherence to dietary advice as a primary outcome, namely those clearly mentioning a measurement of diet adherence in the title or the objective of the study and/or those reporting the proportion of patients adhering to dietary advice. We excluded studies reporting mean dietary intake without specifically assessing adherence to dietary advice.

\section{Secondary outcomes}

- Process measures: e.g. attendance at or participation in individual counselling or group sessions, number of completed food records returned to research coordinators, client or family or non-family caregivers' satisfaction with the dietary or counselling approaches, health professionals' skills in performing the experimental interventions or their satisfaction with the counselling approach.

- $\quad$ Client-based health or behaviour outcomes: e.g. blood pressure; plasma cholesterol concentration; plasma glucose concentration; body weight; relief of symptoms; smoking; physical activity; blood glucose monitoring.

- Organisational outcomes: e.g. cost; time; resources required by client, family or non-family caregivers, or healthcare professionals.

- Harms or secondary effects: e.g. confusion regarding new eating patterns; feelings of lack of confidence or skills in preparing meals; unhappiness at loss of traditional meals.

\section{Search methods for identification of studies}

Electronic searches-We conducted a systematic search, using 29 September 2010 as the cut-off date, in the following electronic databases:

- $\quad$ The Cochrane Library, issue 92010 (via Wiley);

- $\quad$ PubMed; 
- $\quad$ EMBASE (Embase.com);

- $\quad$ CINAHL (Ebsco);

- $\quad$ PsycINFO (PsycNet).

We present detailed search strategies in Appendix 1; Appendix 2; Appendix 3; Appendix 4; Appendix 5. There were no language restrictions and all databases were searched from their start date.

Searching other resources-We conducted additional searches for unpublished studies through grey literature:

- $\quad$ Recent years of relevant conference, symposium and colloquium proceedings and abstracts:

- $\quad$ 2009-10 Scientific sessions of the American Diabetes Association;

- $\quad$ 2009-10 Scientific sessions of the American Heart Association;

- $\quad$ 2009-10 Food and Nutrition Conference and Expo of the American Dietetic Association;

- $\quad 2010$ Canadian Diabetes Association/Canadian Society of Endocrinology and Metabolism Professional Conference and Annual Meeting;

- 2009 International Diabetes Federation World Diabetes Congress North America;

- 2009-10 Dietitians of Canada National Conference;

- $\quad$ 2009-10 Obesity Society Annual Scientific Meeting;

- 2009-10 Experimental Biology Meeting;

- $\quad$ 2009-10 Canadian Nutrition Society;

- Web-based registries of clinical trials (US National Institutes of Health, The National Library of Medicine, Current Controlled Trials);

- $\quad$ Bibliographies of included studies;

- Contact with experts in the field to request details of any other known studies.

\section{Data collection and analysis}

Selection of studies-Two review authors independently assessed the eligibility of papers identified by the search strategy. All titles and abstracts were screened according to pre-established inclusion criteria (see Criteria for considering studies for this review). We retrieved full text copies of papers judged to be potentially relevant to the review. Disagreements were resolved by discussion between the two review authors, and when consensus was not reached, with a third review author. We attempted to contact authors to obtain further details of papers containing insufficient information to make a decision about 
eligibility. If no response was provided, we sent up to two reminders and, when possible, also contacted one co-author. We contacted 81 authors of whom 67 provided a response.

Data extraction and management-Two review authors performed the data extraction independently from all included studies using a modified version of the Cochrane Consumers and Communication Review Group data extraction template (CCCRG 2010). In addition to the standard form derived from the data extraction template of the Cochrane Consumers and Communication Review Group, other relevant information was extracted including:

- $\quad$ Food-based dietary advice;

- $\quad$ Rationale underlying the dietary advice (e.g. clinical practice guidelines, other evidence-based sources);

- $\quad$ Adherence assessment method (proportion of clients achieving the dietary advice, biochemical measures);

- Description of the intervention (eg. education, persuasion, training).

Any discrepancies in judgement were resolved by discussion and consensus, or with a third review author. Where information was missing, we contacted the corresponding author. If no answer was provided, we sent up to two reminders and, when possible, also contacted one co-author. We contacted 38 authors of included studies, of whom 22 provided a response.

Assessment of risk of bias in included studies-Two review authors assessed and reported on the risk of bias of included RCTs in terms of the following individual elements that affect risk of bias:

- $\quad$ Random sequence generation;

- $\quad$ Allocation concealment;

- $\quad$ Blinding - clients, providers and outcome assessors;

- $\quad$ Incomplete outcome data;

- $\quad$ Selective reporting;

- $\quad$ Other bias.

Each of the risk of bias items was assessed as 'low risk of bias', 'high risk of bias' and 'unclear risk' based on the study reports and/or additional information provided by the study authors. Any discrepancies in judgement were resolved by discussion and consensus, or with a third review author.

Measures of treatment effect-The table Characteristics of included studies includes descriptions of study design, setting, country, chronic disease, type of participants (age, sex, ethnicity), sample size, intervention(s) and/or control/usual care, measurement of diet adherence, dietary advice, drop-out rate and providers. Sample size is presented as the number of randomized clients, or when the authors did not report it, as the number of 
completers. Drop-out rate is presented as reported or as calculated when the authors did not report it.

Since the included studies addressed a wide range of interventions, measures of diet adherence, dietary advice, nature of chronic diseases, and duration of interventions and follow-up, it was impossible to perform meta-analyses. For this reason, we could not apply all the methods outlined in the protocol (Desroches 2010) but present these in Appendix 6 for application in future updates of the review. To facilitate the presentation of results, two authors independently classified included studies according to the function of the intervention (Michie 2011). Any discrepancies in judgement were resolved by discussion and consensus, or with a third review author. The method(s) for facilitating changes in dietary habits through dietary advice used in the intervention group and differing from the method(s) used in the comparative group (control, usual care or other intervention group) was (were) defined as the intervention and was (were) classified according to different categories of interventions (education, persuasion, incentivisation, coercion, training, restriction, environmental restructuring, modelling, enablement and multiple). Representing each category of interventions, eight additional tables (Additional tables) summarize narratively the number of studies and participants per intervention, the effect on diet adherence and the quality of evidence (GRADE) (Higgins 2011). In case of discrepancies between the results provided by the authors and the risk ratio (RR) or the standardized mean difference (SMD) calculated using Review Manager 5 ('RevMan') software (RevMan 2012), we selected the results provided by RevMan to complete the Additional tables. Some studies assessed and therefore reported multiple diet adherence outcomes (e.g. adherence to fiber intake and adherence to cholesterol-restricted diet) and/or evaluated diet adherence outcome(s) at different times (e.g. one month, three months, six months). Consequently, we used vote counting, that is we reported the number of diet adherence outcomes favouring the intervention out of the total number of diet adherence outcomes reported, regardless of the statistical significance or size of their results (Higgins 2011), to assess studies that reported diet adherence outcomes between an intervention group and a control/usual care group. Studies are described in more than one category of intervention if they investigated more than one intervention (Baraz 2010; Cummings 1981; Hsueh 2007; Jones 1986; Kendall 1987; Logan 2010; Mahler 1999; McCulloch 1983). Only studies that compared an intervention with a control/usual care group were included in these Additional tables.

We used RevMan to create forest plots when diet adherence outcomes provided raw and complete data (means and standard deviations for continuous data, and number of events and number of total observations for dichotomous data). We analyzed dichotomous data by determining the RR and 95\% confidence intervals. We analyzed continuous data by determining the SMD of the intervention and the control groups in each study with 95\% confidence intervals. Only studies comparing a single or multiple intervention group with a control/usual care group were included in forest plots. We used mean differences between pre-post intervention to calculate SMD. When these data were not known, and that baseline data were available for the two groups, we corrected the standard effect size by calculating the difference between pre- and post-intervention values. The pooled estimates standard deviation was used to calculate the standard deviation of this difference. When no baseline data were reported, groups were considered to be similar before the intervention. Outcomes 
with data including covariate-adjusted means or imputed means were not analysed with forest plots. For these studies, we presented the qualitative data as reported by the study authors. Some elevated SMDs could represent a high diet adherence (e.g. fruit, vegetable and fiber intakes) whereas some elevated SMDs could represent a low diet adherence (e.g. energy, fat and sodium intakes). Therefore, to correct for difference in the direction of the scale in forest plots, means of the intervention and the control groups were multiplied by -1 for outcomes where elevated SMD represented a high diet adherence (e.g. fruit, vegetable and fiber intakes). When authors did not report statistical analyses, we used data to calculate the SMD or the RR in RevMan in order to compare differences in outcomes between groups.

Assessment of heterogeneity-We did not explore heterogeneity due to the wide range of interventions, measures of diet adherence, dietary advice, nature of chronic diseases, and duration of interventions and follow-up addressed in included studies.

Consumer participation-The Cochrane Consumers and Communication Review Group's editorial process for the protocol (Desroches 2010) and the review involved two anonymous consumer referees. We also sought additional feedback throughout the review process from representatives of the Dietitians of Canada to ensure that important issues for health professionals were addressed.

\section{RESULTS}

\section{Description of studies}

See: Characteristics of included studies; Characteristics of excluded studies; Characteristics of studies awaiting classification; Characteristics of ongoing studies.

Results of the search-From the searches, we identified 5183 potentially-relevant publications after duplicates were removed. From these, we excluded 4786 publications after examining the titles and abstracts, and we retrieved 398 full-texts of potentially-relevant publications. From these, 42 publications (describing 38 unique studies) met our inclusion criteria and were considered as eligible. We classified a further 5 publications (describing 6 studies) as ongoing studies (see Characteristics of ongoing studies), and 20 publications as studies awaiting classification (See Characteristics of studies awaiting classification) (see Figure 1, Study Flow Diagram).

Included studies-Three included studies were described in more than one publication. First, Jiang's PhD thesis was published later in an electronic journal (Jiang 2004). Similarly, Chow's PhD thesis was published later in an electronic journal (Wong 2010). Miller 1988, Miller 1989 and Miller 1990 (Miller 1988) all described the same study and reported results for diet adherence at 30 and 60 days, 1 year and 2 years, respectively. We refer to this study as Miller 1988. Therefore we included 38 studies reported in 42 publications (See Characteristics of included studies).

All included studies were RCTs. Only one of them used cluster randomisation (Wood 2008).

Location, setting and duration: Studies were conducted in the following countries: 


\begin{tabular}{|l|l|l|}
\hline Country & Number of studies & Studies \\
\hline United States of America & 14 & $\begin{array}{l}\text { Aldarondo 1999; Beasley 2008; Becker 1998; Cummings } \\
\text { Ken1; Gans 1994; Gill 2010; Hsueh 2007; Hyman 2007; } \\
\text { Racelis 1997; Scisney-Matlock 2006 }\end{array}$ \\
\hline United Kingdom & 7 & $\begin{array}{l}\text { Bennett 1986; French 2008; Grace 1996; Jones 1986; } \\
\text { Logan 2010; McCulloch 1983; Morey 2008 }\end{array}$ \\
\hline China & 5 & $\begin{array}{l}\text { Chen 2006; Chiu 2010; Jiang 2004; Wong 2010; Zhao } \\
\text { 2004 }\end{array}$ \\
\hline Canada & 4 & Arcand 2005; Conrad 2000; Gucciardi 2007; Ryan 2002 \\
\hline Brazil & 1 & Assuncao 2010 \\
\hline Iran & 1 & Baraz 2010 \\
\hline The Netherlands & 1 & Blanson 2009 \\
\hline Finland & 1 & Laitinen 1993 \\
\hline Norway & 1 & Meland 1994 \\
\hline South Africa & 1 & Stewart 2005 \\
\hline Taiwan & 1 & Tsay 2003 \\
\hline $\begin{array}{l}\text { Multiple (France, Italy, Poland, } \\
\text { Spain, Sweden, United Kingdom, } \\
\text { Denmark and the Netherlands) }\end{array}$ & 1 & Wood 2008 \\
\hline
\end{tabular}

All included studies were directed towards clients and none of them was directed towards family or non-family caregivers or health professionals.

An outpatient setting was reported in the majority of the included studies $(\mathrm{n}=31)$. Four studies were carried out in a research center setting (Beasley 2008; Blanson 2009; Hsueh 2007; Micco 2007) while one study (Gans 1994) included two settings (workplace and community). In two studies, the setting could not be identified (Aldarondo 1999; Bennett 1986).

Nineteen studies evaluated diet adherence to dietary advice over a period of less than 6 months (Aldarondo 1999; Arcand 2005; Baraz 2010; Beasley 2008; Bennett 1986; Blanson 2009; Chen 2006; Chiu 2010; Cummings 1981; Gans 1994; Gill 2010; Grace 1996; Gucciardi 2007; Jones 1986; Mahler 1999; Meland 1994; Scisney-Matlock 2006; Wong 2010; Zhao 2004), nine studies had a duration between 6 and 12 months (Assuncao 2010; Conrad 2000; Hsueh 2007; Jiang 2004; Kendall 1987; McCulloch 1983; Ryan 2002; Stewart 2005; Tsay 2003), while only 10 studies evaluated diet adherence to dietary advice over a 12-month period or more (Becker 1998; French 2008; Hyman 2007; Laitinen 1993; Logan 2010; Micco 2007; Miller 1988; Morey 2008; Racelis 1998; Wood 2008).

Clients: The 38 studies included in this review involved 9445 clients. The range in the number of clients in each study varied from 7 to 5405 (median $=83$ ). Only 13 of the 38 studies provided a power calculation (Aldarondo 1999; Assuncao 2010; Beasley 2008; Chiu 2010; French 2008; Hyman 2007; Jiang 2004; Meland 1994; Stewart 2005; Tsay 2003; Wong 2010; Wood 2008; Zhao 2004) and among them, 10 studies recruited the number of 
clients according to their power analysis (Aldarondo 1999; Assuncao 2010; Beasley 2008; French 2008; Jiang 2004; Meland 1994; Stewart 2005; Tsay 2003; Wong 2010; Zhao 2004).

Prevention of chronic diseases: Five studies included clients receiving dietary advice for the prevention of chronic diseases, such as clients with a high risk of CVD (clients having dyslipidaemia (Gans 1994; Grace 1996), siblings of individuals with coronary heart diseases (Becker 1998)) and overweight clients (Blanson 2009; Jones 1986).

Management of chronic diseases: Twenty-seven included studies addressed dietary advice for chronic disease management. Eight studies included clients receiving dietary advice for the management of CVD (heart failure (Arcand 2005), coronary heart disease (Logan 2010; Zhao 2004), coronary artery disease (Conrad 2000; Mahler 1999), peripheral artery disease (Racelis 1998), angina pectoris and myocardial infarction (Jiang 2004; Miller 1988)); six studies involved the management of diabetes (French 2008; Gucciardi 2007; Kendall 1987; Laitinen 1993; McCulloch 1983; Ryan 2002); five studies involved the management of hypertension (Chiu 2010; Hyman 2007; Meland 1994; Scisney-Matlock 2006; Stewart 2005); six studies addressed the management of renal failure (Baraz 2010; Chen 2006; Cummings 1981; Morey 2008; Tsay 2003; Wong 2010); one study addressed the management of obesity (Aldarondo 1999): and one study addressed the management of irritable bowel syndrome (Hsueh 2007).

Prevention and management of chronic diseases: Six studies included clients receiving dietary advice for both the prevention and the management of chronic diseases. One study was conducted with clients with coronary heart disease and clients with a high risk of developing CVD (Wood 2008). The remaining five studies included overweight and obese clients (Assuncao 2010; Beasley 2008; Bennett 1986; Gill 2010; Micco 2007).

Interventions: Included studies assessed interventions in the following categories:

Education: Nine studies offered nutrition counselling and follow-up with a health professional through telephone follow-up (Chiu 2010; Cummings 1981; Racelis 1998; Stewart 2005), group sessions (Gill 2010; Jones 1986) or individual sessions with a dietitian (Jones 1986; Micco 2007) or a nurse (Hsueh 2007). Moreover, four studies used educational tools to provide dietary advice such as video (Baraz 2010; Mahler 1999; McCulloch 1983) or booklet (Kendall 1987).

Persuasion: Two studies used reminders (Gans 1994; Ryan 2002).

Incentivisation: One study used contracts with rewards (Cummings 1981).

Training: Three studies used feedback (Beasley 2008; French 2008; Meland 1994).

Restriction: Only one study compared an immediate versus an incremental reduction of fat intake (Conrad 2000). 
Modelling: Seven studies used nutritional tools such as menus, exchange list and portion size examples in order to enhance diet adherence ( Assuncao 2010; Chen 2006; Grace 1996; Kendall 1987; Logan 2010; McCulloch 1983; Scisney-Matlock 2006).

Enablement: Three studies used one or more behaviour change techniques, including barrier identification/problem solving (Aldarondo 1999; Bennett 1986; Logan 2010), goal setting (Logan 2010), self-talk (defined as use of self-instruction and self-encouragement to support action by Abraham and Michie (Abraham 2008)) (Aldarondo 1999; Bennett 1986) and teaching to use prompts/cues (defined as teaching the person to identify environmental cues that can be used to remind them to perform a dietary behaviour by Abraham and Michie (Abraham 2008)) (Bennett 1986).

Multiple: This category includes 18 studies using a combination of two or more different interventions (Arcand 2005; Baraz 2010; Becker 1998; Blanson 2009; Cummings 1981; Gucciardi 2007; Hsueh 2007; Hyman 2007; Jiang 2004; Jones 1986; Laitinen 1993; Mahler 1999; Miller 1988; Morey 2008; Tsay 2003; Wong 2010; Wood 2008; Zhao 2004).

Outcomes: Twenty-eight studies compared two groups (Aldarondo 1999; Arcand 2005; Assuncao 2010; Baraz 2010; Beasley 2008; Becker 1998; Blanson 2009; Chen 2006; Chiu 2010; Conrad 2000; Gill 2010; Grace 1996; Gucciardi 2007; Hsueh 2007; Kendall 1987; Jiang 2004; Laitinen 1993; Logan 2010; Meland 1994; Micco 2007; Miller 1988; Morey 2008; Racelis 1998; Scisney-Matlock 2006; Stewart 2005; Tsay 2003; Wong 2010; Zhao 2004), six studies compared three groups (Bennett 1986; French 2008; Hyman 2007; Mahler 1999; McCulloch 1983; Ryan 2002) and four studies compared four groups (Cummings 1981; Gans 1994; Jones 1986; Wood 2008). Twenty-five studies assessed a single diet adherence outcome (Arcand 2005; Beasley 2008; Becker 1998; Bennett 1986; Blanson 2009; Chen 2006; Chiu 2010; Conrad 2000; Gans 1994; Gill 2010; Gucciardi 2007; Hyman 2007; Jiang 2004; Jones 1986; Logan 2010; Mahler 1999; McCulloch 1983; Meland 1994; Micco 2007; Miller 1988; Morey 2008; Racelis 1998; Scisney-Matlock 2006; Tsay 2003; Zhao 2004) while 13 studies assessed multiple diet adherence outcomes (Aldarondo 1999; Assuncao 2010; Baraz 2010; Cummings 1981; French 2008; Grace 1996; Hsueh 2007; Kendall 1987; Laitinen 1993; Ryan 2002; Stewart 2005; Wong 2010; Wood 2008). Twenty studies assessed diet adherence outcome(s) once (Aldarondo 1999; Arcand 2005; Assuncao 2010; Baraz 2010; Beasley 2008; Becker 1998; Bennett 1986; Blanson 2009; Chen 2006; Chiu 2010; Conrad 2000; French 2008; Gans 1994; Gill 2010; Grace 1996; Gucciardi 2007; Jones 1986; McCulloch 1983; Racelis 1998; Wood 2008), 13 studies assessed diet adherence outcome (s) twice (Cummings 1981; Hsueh 2007; Hyman 2007; Jiang 2004; Kendall 1987; Laitinen 1993; Logan 2010; Mahler 1999; Meland 1994; Micco 2007; Stewart 2005; Wong 2010; Zhao 2004) while 5 studies assessed diet adherence outcome (s) 3 or more times (Miller 1988; Morey 2008; Ryan 2002; Scisney-Matlock 2006; Tsay 2003). Consequently, 32 studies compared diet adherence outcomes between an intervention group and a control/ usual care group, and 9 studies compared two intervention groups.

Excluded studies-As described in the Characteristics of excluded studies table, reasons for exclusion included: no measure of adherence outcome; not the same dietary advice 
component in groups; not a randomized controlled trial; provision of meals, food, items or dietary supplements; not involving clients with or at risk of chronic diseases; intervention not intended to improve diet adherence; not a real-life setting; clients were under the age of 18; and study did not involve a nutritional intervention.

\section{Risk of bias in included studies}

As described in the Characteristics of included studies, eight risk of bias criteria were applied to each study (random sequence generation, allocation concealment, blinding: clients, providers and outcome assessors, incomplete outcome data, selective reporting and other bias). Two studies were rated as low risk on 4 of the 8 criteria (Gucciardi 2007; Zhao 2004), 8 studies were low risk on 3 criteria (Aldarondo 1999; French 2008; Jiang 2004; Meland 1994; Morey 2008; Scisney-Matlock 2006; Stewart 2005; Tsay 2003), 11 studies were rated as low risk on 2 criteria (Arcand 2005; Assuncao 2010; Baraz 2010; Chen 2006; Cummings 1981; Kendall 1987; Laitinen 1993; Logan 2010; Mahler 1999; Ryan 2002; Wong 2010), 11 studies were rated as low risk on one criterion (Beasley 2008; Becker 1998; Bennett 1986; Blanson 2009; Chiu 2010; Conrad 2000; Gill 2010, Hsueh 2007; McCulloch 1983; Miller 1988; Racelis 1998) and six studies were not rated low risk for any criteria (Gans 1994; Grace 1996; Hyman 2007; Jones 1986; Micco 2007; Wood 2008) (see Figure 2).

Allocation-The allocation sequence was adequately generated in the majority of studies $(\mathrm{n}=26)$. Twelve studies did not report sufficient information to determine this risk of bias (Blanson 2009; Conrad 2000; Gans 1994; Grace 1996; Hyman 2007; Jones 1986; McCulloch 1983; Micco 2007; Miller 1988; Racelis 1998; Tsay 2003; Wood 2008).

The allocation was adequately concealed only in seven studies (Assuncao 2010; Jiang 2004; Laitinen 1993; Mahler 1999; Meland 1994; Stewart 2005; Zhao 2004) while nine studies reported an inadequate allocation (Aldarondo 1999; Baraz 2010; Beasley 2008; Bennett 1986; Cummings 1981; Gucciardi 2007; Kendall 1987; Logan 2010; Miller 1988). The majority of the studies $(n=22)$ did not describe the allocation concealment in sufficient detail to permit evaluation.

Blinding-The majority of the interventions provided to clients were difficult to blind for clients, providers and outcomes assessors. Therefore, only three studies (Aldarondo 1999; Blanson 2009; Scisney-Matlock 2006), two studies (Gucciardi 2007; Tsay 2003) and six studies (French 2008; Gucciardi 2007; Jiang 2004; Kendall 1987; Stewart 2005; Zhao 2004) respectively blinded clients, providers and outcome assessors.

Incomplete outcome data-Twelve studies adequately addressed incomplete outcome data (Aldarondo 1999; Arcand 2005; Baraz 2010; Chen 2006; Conrad 2000; McCulloch 1983; Meland 1994; Morey 2008; Racelis 1998; Ryan 2002; Tsay 2003; Zhao 2004) whereas 17 studies did not (Assuncao 2010; Beasley 2008; Becker 1998; Bennett 1986; Blanson 2009; Cummings 1981; Gucciardi 2007; Hyman 2007; Jiang 2004; Jones 1986; Kendall 1987; Laitinen 1993; Logan 2010; Miller 1988; Stewart 2005; Wong 2010; Wood 2008). The principal reason for the incomplete outcome data bias was that missing outcomes 
are enough to induce clinically-relevant bias in the observed effect estimate. Nine studies reported insufficient information to permit an evaluation of this criterion (Chiu 2010; French 2008; Gans 1994; Gill 2010, Grace 1996; Hsueh 2007; Mahler 1999; Micco 2007; ScisneyMatlock 2006).

Selective reporting-Study protocols were available for only one study and all of the study's pre-specified outcomes that were of interest in the study were reported in the prespecified way. Therefore, only this study ( French 2008) was free of suggestion of selective outcome reporting. Eighteen studies incompletely reported some outcomes of interest (Aldarondo 1999; Assuncao 2010; Becker 1998; Conrad 2000; Grace 1996; Hyman 2007; Jiang 2004; Kendall 1987; Laitinen 1993; Meland 1994; Micco 2007; Miller 1988; Morey 2008; Racelis 1998; Ryan 2002; Stewart 2005; Wong 2010; Wood 2008) whereas others provided insufficient information to address this criterion $(n=19)$.

Other potential sources of bias-Eight studies (Cummings 1981; Gucciardi 2007; Logan 2010; Miller 1988; Morey 2008; Scisney-Matlock 2006; Tsay 2003; Wong 2010) appeared free of other potential sources of bias, whereas 13 studies had at least one important risk of bias such as a baseline imbalance between groups which was not taken into consideration in statistical analyses, a diet adherence not clearly defined, a diet adherence assessed by a non-validated self-reporting method, a potential conflict of interest or a potential intervener effect (Assuncao 2010; Beasley 2008; Becker 1998; Chiu 2010; Conrad 2000; French 2008; Gans 1994; Grace 1996; Hsueh 2007; Hyman 2007; Ryan 2002; Stewart 2005; Zhao 2004). Other studies did not report sufficient information to assess other potential sources of bias $(n=17)$.

\section{Effects of interventions}

Included studies differed widely according to interventions provided, measures of diet adherence, dietary advice, nature of the chronic diseases and duration of interventions and follow-up. Therefore, data were not pooled statistically. Instead, we present a qualitative analysis described in a narrative table using vote counting for each category of interventions (see Additional tables). We also created forest plots for outcomes from studies comparing a single or multiple intervention group with a control/usual care group (see Figure 3; Figure 4; Figure 5). Among the 32 studies that measured diet adherence outcomes between an intervention group and a control/usual care group, 32 out of 123 diet adherence outcomes favoured the intervention group, 4 favoured the control group whereas 62 had no significant difference between groups. This result was impossible to assess for 25 diet adherence outcomes as data and/or statistical analyses needed for comparison between groups were not provided (Additional tables).

Education-See Table 1.

\section{Counselling and follow-up with health professional}

Telephone follow-up: Chiu 2010 assessed the effects of telephone follow-up on: adherence to a sodium-restricted diet; fat intake and fruit and vegetable intake, in clients with hypertension. The authors reported no differences in diet adherence between the intervention 
group and the control group at eight weeks. However, a greater decrease in systolic and diastolic blood pressure was observed in the intervention group compared to the control group as well as a greater increase in exercise adherence.

One study (Cummings 1981) reported significantly higher adherence to a potassiumrestricted diet and fluid-restricted diet at six weeks in clients with renal failure who received telephone follow-up, compared to clients in the control group. However, these differences were no longer significant at three months. This study also compared clients with renal failure receiving telephone follow-up with clients writing a formal agreement (contract) and with clients writing a contract with the involvement of a family member or friend, but found no differences in adherence to a potassium- and fluid-restricted diet at three months between groups.

Racelis 1998 assessed the effects of telephone follow-up on adherence to diet in clients with peripheral artery disease. The authors indicated that no significant difference was noted between the intervention and the control groups.

Stewart 2005 also evaluated the effects of telephone follow-up on adherence to a sodiumrestricted diet in clients with hypertension. The authors reported that a higher proportion of clients adhered to the sodium-restricted diet at 24 weeks in the intervention group compared to the control group, but the difference was no longer significant at 36 weeks. No differences were found in systolic and diastolic blood pressure between groups. The authors also noted no difference in non-adherence to alcohol intake at 24 and 36 weeks between groups.

Among studies using a control/usual care group, three out of ten diet adherence outcomes favoured the intervention group compared to control group and seven diet adherence outcomes had no significant difference between groups (see Table 1). However, these three diet adherence outcomes favouring the intervention group were no longer significant at a later time point.

Group sessions: Gill 2010 evaluated the effects of group sessions in overweight-obese college women on adherence to the Dietary Approaches to Stop Hypertension (DASH) diet. However, the authors did not report measures of diet adherence for the intervention and the control groups, making comparison between groups impossible. Jones 1986 compared an intervention using group sessions (GS) with three other groups for overweight clients: group sessions with a dietitian combined with a leaflet providing advice to reduce exposure to food cues (GS + cues); individual sessions with a dietitian (IS); individual sessions with a dietitian combined with a leaflet providing advice to reduce exposure to food cues (IS + cues). Adherence to diet at 16 weeks was assessed but no significant difference between groups was found. The SMD for weight loss was calculated using RevMan software (RevMan 2012) and no significant difference was found between groups at 16 weeks (vs 1 SMD -0.24 (95\% CI -1.22 to 0.75$)$; vs 2 SMD -0.03 (95\% CI - 0.94 to 0.88); vs 3 SMD -0.55 (95\% CI -1.55 to 0.46$)$.

Overall, these studies did not allow us to draw conclusions on the effect of group sessions on diet adherence outcomes (see Table 1). 
Individual sessions with a dietitian: To assess the effects of a 16-week intervention promoting individual sessions with a dietitian (IS), Jones 1986 compared this intervention in overweight clients with three others: group sessions with a dietitian (GS);2) group sessions with a dietitian combined with a leaflet providing advice to reduce exposure to food cues (GS + cues); 3) individual sessions with a dietitian combined with a leaflet providing advice to reduce exposure to food cues (IS + cues). Adherence to diet at 16 weeks was assessed but no significant difference was found between groups. The SMD for weight loss was calculated using RevMan 2012 and no significant difference between groups was found at 16 weeks (vs 1 SMD 0.23 (95\% CI -0.46 to 0.93 ); vs $2=\operatorname{SMD} 0.30$ (95\% CI -0.69 to $1.08)$; vs 3 SMD 0.59 (95\% CI -0.35 to 1.52$)$.

Another study (Micco 2007) evaluated the effects of individual sessions with a dietitian in overweight-obese clients on diet adherence. The authors assessed diet adherence but they did not report measures for the intervention and the control groups, making the comparison between groups impossible. The authors reported no weight loss difference between groups at 12 months.

Overall, these studies did not allow us to draw conclusions on the effect of individual sessions with a dietitian on diet adherence outcomes (see Table 1).

Individual sessions with a nurse: Hsueh 2007 compared a single intervention comprising individual sessions with a nurse, on adherence to dietary advice to increase fiber, vegetable and fruit intakes in clients with irritable bowel syndrome, with a multiple intervention comprised of individual sessions with a nurse alternating with telephone follow-up. The authors reported no difference in the proportion of high-compliant clients for fiber, vegetable and fruit intakes between groups at three months and six months.

\section{Educational tools}

Video: One study (Baraz 2010) compared a single intervention using a video as an educational tool with a multiple intervention using a booklet as educational tool, combined with group sessions in clients with chronic end-stage renal disease. The authors did not report the proportion of clients classified as adherent to diet for both groups, making a comparison between groups impossible. The risk ratio (RR) for the proportion of clients who adhered to the diet and fluid-restricted diet was calculated using RevMan and no difference was found between groups at two months for diet (RR 0.48 (95\% CI 0.17 to $1.35)$ ) and fluid-restricted diet (RR 0.81 (95\% CI 0.25 to 2.57)).

Mahler 1999 evaluated the effects of a video as an educational tool on adherence to a cholesterol and saturated fat-restricted diet in clients with coronary artery disease. Adherence to a cholesterol and saturated fat-restricted diet was significantly higher in the intervention group compared to the control group at one month but this difference was no longer significant at three months. The authors also compared the intervention with another intervention using a video as an educational tool combined with relapse prevention/coping planning, and found no difference between groups. Another study (McCulloch 1983) reported a significant difference in day-to-day consistency in carbohydrate intake in clients with insulin dependent diabetes receiving an intervention using a video as an educational 
tool, compared to the usual care group at six months. Moreover, glycated haemoglobin $\left(\mathrm{HbA}_{1 c}\right)$ was significantly lower in the intervention group than in the usual care group at six months. The authors also compared the intervention with another intervention using nutritional tool and no difference between groups was noted.

Among studies using a control/usual care group, two out of three diet adherence outcomes favoured the intervention group compared to the control/usual care group and one diet adherence outcome had no significant difference between groups (see Table 1). However, one out of two diet adherence outcomes favouring the intervention group was no longer significant at a later time point.

Booklet: Kendall 1987 compared an intervention using a booklet as an educational tool with an intervention using exchange lists as a nutritional tool in clients with non-insulindependent diabetes. No difference between groups was reported for adherence to energy, protein, vitamin $\mathrm{A}$, vitamin $\mathrm{C}$, thiamine, riboflavin, niacin, calcium, phosphorus, iron and zinc intakes at three and six months. Moreover, there was no difference between groups for health outcomes such as systolic and diastolic blood pressure, weight, plasma glucose, $\mathrm{HbA}_{1 c}$, serum cholesterol, low-density lipoprotein (LDL)-cholesterol, high-density lipoprotein (HDL)-cholesterol and serum triglycerides at six months.

Persuasion: See Table 2.

Reminders: Gans 1994 compared three interventions using reminders with a usual care group in clients with elevated blood cholesterol: 1) clients received the reminder, 2) physicians received a reminder postcard which they could mail to the clients, 3) clients received the reminder in addition to the physicians who received a reminder postcard which they could mail to the clients. The authors reported no difference in the proportion of clients that adhered to diet in any of these groups compared to the usual care group at three months, and no difference between groups for the compliance to lifestyle recommendations at three months.

Another study (Ryan 2002) compared two interventions using knowledge and self-care practices as reminders with a control group in clients with type II diabetes: 1) reminders provided to clients at two weeks, three months and six months, 2) reminders provided to clients at three months and six months. The authors reported adherence to frequency of meals and snacks combined for all three groups, making comparison between groups impossible. Overall, the studies used reminders for patients and physicians (Gans 1994) or for patients (Ryan 2002) to enhance adherence to dietary advice. Among studies using a control/usual care group, three out of 19 diet adherence outcomes had no significant difference between groups. It was impossible to assess this result for 16 diet adherence outcomes since data and/or statistical analyses needed for comparison between groups were not provided (see Table 2).

Incentivisation: See Table 3. 
Contracts with rewards: One study (Cummings 1981) reported significantly higher adherence to a potassium-restricted diet and to a fluid-restricted diet at six weeks in clients with renal failure who wrote a behavioural contract, compared to clients in the control group (see Table 3). However, these differences were no longer significant at three months (see Table 3). This study also compared clients with renal failure writing a contract with clients receiving telephone follow-up and with clients writing a contract with the involvement of a family member or friend but no difference was noted in adherence to the potassiumrestricted diet and fluid-restricted diet at six weeks and three months between groups.

Training: See Table 4.

Feedback: Beasley 2008 reported a higher adherence to energy, fat, saturated fat and cholesterol intakes in overweight-obese clients in the intervention group using feedback based on self-monitoring using an electronic food diary compared to the control group. However, no difference in weight loss was observed between groups.

French 2008 compared two interventions using feedback based on self-monitoring of blood glucose with a usual care group in clients with type II diabetes: 1) less intensive intervention, 2) most intensive intervention. Adherence to general and specific diet at 12 months was greater in the control group compared to both intervention groups.

Another study (Meland 1994) assessed the effects of feedback using self-monitoring of urine chloride concentration on adherence to a sodium-restricted diet in clients with hypertension. No difference was reported in adherence to the sodium-restricted diet or in blood pressure between the intervention group and the control group at one and three months.

In this category, three studies used feedback based on self-monitoring using an electronic food diary (Beasley 2008), blood glucose (French 2008) and urine chloride concentration (Meland 1994). Among studies using a control/usual care group, one out of seven diet adherence outcomes favoured the intervention group compared to the control/usual care group, four favoured the control group whereas two had no significant difference between groups (see Table 4).

\section{Restriction: See Table 5 .}

Conrad 2000 assessed the effects of an intervention proposing an incremental reduction in fat to a goal of $10 \%$ of energy intake compared to an intervention proposing an immediate reduction in fat to a goal of $10 \%$ of energy intake in clients with coronary artery disease. The authors did not compare adherence to fat intake advice between groups. Therefore, we calculated the SMD for adherence to the very low fat diet using RevMan 2012 and found no differences between groups at seven months (SMD -1.88 (95\% CI -4.00 to 0.23 )) (see also Table 5).

Modelling: See Table 6.

Nutritional tools: Assuncao 2010 assessed the effects of nutritional tools such as portion size examples and food lists on diet adherence in overweight-obese clients using an 
intention-to-treat analysis. Authors reported a significant enhancement of adherence to sodium and sweet food intake goals at six months in clients in the intervention group compared with those receiving usual care. However, a discrepancy was found between the results provided by the authors and the SMD calculated using RevMan which showed no difference for adherence to sweet food intake at six months between groups. No difference was found between groups for adherence to recommended energy, protein, fat, carbohydrate, cholesterol, fiber, fruit and vegetable intakes (see Analysis 1.1). An increase in physical leisure activity as well as a decrease in fasting glucose were reported in the intervention compared to the usual care group at six months, whereas no difference between groups was observed for weight loss, blood pressure and lipid profile.

Chen 2006 reported a higher proportion of intervention-group clients with renal failure reaching the target for protein intake at one month using menu suggestions, exchange lists and portion sizes as nutritional tools compared to the control group.

Grace 1996 evaluated the effects of nutritional tools such as an additional package containing low-fat cooking methods and low-fat recipe adaptation on adherence to energy and fat intakes in clients with hyperlipidaemia. The authors reported a higher reduction in percentage of fat intake in the intervention group compared to the control group. However, they reported no difference for energy change between the intervention and the control groups at 12 weeks (see also Analysis 1.1).

Kendall 1987 compared an intervention using exchange lists as a nutritional tool with an intervention using a booklet as an educational tool in clients with non-insulin-dependent diabetes. No difference between groups was reported for adherence to energy, protein, vitamin $\mathrm{A}$, vitamin $\mathrm{C}$, thiamine, riboflavin, niacin, calcium, phosphorus, iron and zinc intakes at three and six months. Moreover, there was no difference between groups for health outcomes such as systolic and diastolic blood pressure, weight, plasma glucose, $\mathrm{HbA}_{1 c}$, serum cholesterol, LDL-cholesterol, HDL-cholesterol and serum triglycerides at six months.

One study (Logan 2010) compared an intervention using recipes and meal plans with an intervention using barrier identification/problem solving and goal setting in clients with coronary heart disease. The authors reported no difference between groups for adherence to the Mediterranean diet at 6 and 12 months.

Another study (McCulloch 1983) reported no difference in day-to-day consistency in carbohydrate intake in clients with insulin-dependent diabetes following an intervention using exchange lists and lunch time with health professionals as nutritional tools, compared to usual care group. However, $\mathrm{HbA}_{1 c}$ was significantly lower in the intervention group at 9 months compared to the control group. The authors also compared the intervention with another intervention using a video as an educational tool and found no difference between groups.

Scisney-Matlock 2006 evaluated the effects of wheels and bar charts displaying Cognitive Representations of the DASH diet as a nutritional tool on adherence to the DASH diet in 
clients with hypertension compared to a control group. The authors reported results grouped for both groups, making comparison between groups impossible.

To summarize the interventions in this category: two studies included portion sizes (Assuncao 2010; Chen 2006), three studies used menu suggestions and recipes (Chen 2006; Grace 1996; Logan 2010), three studies included exchange lists (Chen 2006; Kendall 1987; McCulloch 1983), one study used an additional package containing low-fat cooking methods (Grace 1996), one study used lunch time with health professionals (McCulloch 1983), and one study used wheels and bar charts displaying Cognitive Representations of the DASH diet (Scisney-Matlock 2006) as nutritional tools in their intervention.

Among studies using a control/usual care group, 3 out of 17 diet adherence outcomes favoured the intervention group and 11 diet adherence outcomes had no significant difference between groups. It was impossible to assess this result for three diet adherence outcomes as data and/or statistical analyses needed for comparison between groups were not provided (Table 6).

Enablement: See Table 7.

Behaviour change techniques: Aldarondo 1999 reported no difference in adherence to energy, fat and saturated fat intake at 14 weeks between the intervention group using barrier identification/problem solving and self-talk compared to the control group in obese clients.

Another study (Bennett 1986) compared three interventions using behavioural change techniques in overweight-obese clients: 1) teaching clients to use prompts/cues, 2) self-talk, 3) barrier identification/problem solving. The authors reported that clients in the intervention group using food cues adhered more closely to energy intake goals than those in the two other groups between baseline and 15 weeks.

One study (Logan 2010) compared an intervention using barrier identification/problem solving and goal setting with an intervention using recipes and meal plans as nutritional tools in clients with coronary heart disease. The authors reported no difference between groups for adherence to the Mediterranean diet at 6 and 12 months.

Overall, in this category: three studies used behavioural change techniques such as barrier identification/problem solving and self-talk (Aldarondo 1999), teaching clients to use prompts/cues, self-talk and barrier identification/problem solving (Bennett 1986) and barrier identification/problem solving and goal setting (Logan 2010).

Only one study used a control group and three out of three diet adherence outcomes had no difference between groups (see Table 7).

Multiple interventions: See Table 8.

Arcand 2005 evaluated the effects of individual sessions with a dietitian combined with goal setting, on adherence to a sodium-restricted diet in clients with heart failure. The authors did not compare adherence to the sodium-restricted diet nor blood pressure between groups. 
Therefore, we calculated the SMD for adherence to the sodium-restricted diet and blood pressure using RevMan, and found no difference between groups for sodium-restricted diet (see also Analysis 2.1), systolic blood pressure (SMD-0.30 (95\% CI -0.88 to 0.27 )) and diastolic blood pressure (SMD -0.53 (95\% CI -1.11 to 0.05$)$ ).

One study (Baraz 2010) compared a multiple intervention using a booklet as educational tool combined with group sessions, with a single intervention using a video as an educational tool, in clients with chronic end-stage renal disease. The authors did not report the proportion of clients classified as adherent to diet for both groups, making comparison between groups impossible. Therefore, we calculated the RR for the proportion of clients who adhered to the diet and fluid-restricted diet at two months, using RevMan, and found no difference between groups.

Using an intention-to-treat analysis, Becker 1998 reported no difference in the proportion of clients at risk of coronary heart disease who received telephone follow-up combined with a barrier identification/problem solving intervention for adherence to a fat-restricted diet at two years, compared to clients in the usual care group. Moreover, no difference was found for LDL-cholesterol, HDL-cholesterol and triglyceride levels at two years between groups.

Blanson 2009 evaluated the effects of self-monitoring using a computer assistant combined with feedback using motivational interviewing in overweight clients. They reported no significant difference in adherence to diet at 28 days between the intervention and the control groups.

Cummings 1981 reported a significantly higher adherence to a fluid-restricted diet at six weeks in clients with renal failure asked to write a formal agreement (contract) with the involvement of a family member or friend, compared to clients in the control group. However, these differences were no longer significant at three months. This study also compared clients writing a formal agreement (contract) with the involvement of a family member or friend, with clients writing a contract, and with clients who received telephone follow-up, but no differences in adherence to a potassium- and fluid-restricted diet at three months were found between groups.

In type II diabetes clients, the comparison of an intervention using group sessions and nutritional tools combined with barrier identification/problem solving versus control (Gucciardi 2007) showed a higher adherence to dietary advice in the intervention group at three months. However, the authors reported no difference in $\mathrm{HbA}_{1 c}$ between the groups at three months (see also Analysis 2.1). Hsueh 2007 compared a multiple intervention comprising individual sessions with a nurse alternating with telephone follow-up on adherence to fiber, vegetable and fruit intakes in clients with irritable bowel syndrome, with a single intervention comprising individual sessions with a nurse. The authors reported no difference in the proportion of high-compliant clients for fiber, vegetable and fruit intakes between groups at three and six months. To assess the effectiveness of an intervention using telephone follow-up combined with motivational interviewing, Hyman 2007 compared two interventions in clients with hypertension with a usual care group: 1) simultaneous behaviour change (stop smoking, reduce dietary sodium level and increase physical activity); 
2) sequential behaviour change (stop smoking, then reduce dietary sodium levels and finally increase physical activity). A higher proportion of clients adhered to the sodium-restricted diet in the simultaneous group, compared to the sequential intervention and the usual care group at six months, but no difference was observed at 18 months. No difference was reported for blood pressure between groups (see also Analysis 2.2).

Jiang 2004 assessed the effects of an intervention using individual sessions with a nurse and telephone follow-up combined with goal setting, on adherence to the Adult Treatment Panel (ATP) step II diet (hypocholesteraemic diet) in clients with angina pectoris or myocardial infarction. Using an intention-to-treat analysis, the authors reported better adherence to the step II diet in the intervention group compared to the usual care group at three and six months. At three months, triglyceride, total cholesterol, LDL-cholesterol levels and blood pressure decreased significantly more in the intervention group than the usual care group, while no difference was noted for HDL-cholesterol and body weight. At six months, only the differences in triglyceride, total cholesterol and LDL-cholesterol levels remained significant.

Jones 1986 compared four interventions in overweight clients: group sessions with a dietitian (GS); group sessions with a dietitian combined with a leaflet providing advice to reduce exposure to food cues (GS + cues); individual sessions with a dietitian (IS); individual sessions with a dietitian combined with a leaflet providing advice to reduce exposure to food cues (IS + cues). The authors found no significant difference between groups for adherence to diet, as well as for weight loss, at 16 weeks.

Laitinen 1993 evaluated the effects of individual sessions with a dietitian and nutritional tools combined with goal setting, on adherence to total fat, saturated fat, unsaturated fat, carbohydrate, fiber and cholesterol advice in clients with non-insulin-dependent diabetes. Although the authors reported no differences for total, saturated and unsaturated fat intake at three months, there was a higher proportion of clients who adhered to total and saturated fat intake recommendations in the intervention group compared to the usual care group at 15 months, whereas a higher proportion of clients adhered to unsaturated fat in the usual care group at 15 months. However, a discrepancy was found between the results provided by the authors and the RR calculated using RevMan which revealed no difference for adherence in total fat and unsaturated fat at 15 months between groups. Fasting blood glucose and $\mathrm{HbA}_{1 c}$ decreased significantly more in the intervention group at 15 months than in the control group, while no difference was noted for body weight, total cholesterol and HDL-cholesterol levels. From data provided by the authors, we used RevMan to calculate the SMD for the proportion of clients who adhered to carbohydrate, fiber and cholesterol intakes, and found no differences between groups at 3 and 15 months (see also Analysis 2.2).

Mahler 1999 assessed the effects of a video as educational tool combined with relapse prevention/coping planning on adherence to a cholesterol- and saturated fat-restricted diet in clients with coronary artery disease. Adherence to a cholesterol- and saturated fat-restricted diet was significantly higher in the intervention group compared to the control group at one month, but this difference was no longer significant at three months. The authors also 
compared the intervention with another intervention using a video as an educational tool, and found no difference between groups.

Miller 1988 evaluated the effects of individual sessions with a dietitian combined with barrier identification/problem solving and goal setting in clients with myocardial infarction. While no difference was found at 30 days, 60 days and 1 year, the authors reported a significant difference in adherence to diet at 2 years between the intervention and the control groups.

Morey 2008 compared an intervention including individual sessions with a nurse, a booklet as educational tool and reminders combined with motivational interviewing intervention with a control group. They reported a higher proportion of clients with end-stage kidney disease adhering to a phosphate-restricted diet at three months in the intervention group compared to the control group. Data for adherence to the phosphate-restricted diet at 6 and 12 months were not reported (see also Analysis 2.2).

A multiple intervention (Tsay 2003) including self-monitoring in a diary and feedback combined with stress management and goal setting in clients with end-stage renal disease showed a significant group main effect in adherence to a fluid-restricted diet when baseline mean weight gains were applied as covariate. From data provided by the authors, we used RevMan to calculate the SMD for adherence to a fluid-restricted diet at 1 month, 3 months and 6 months, respectively. No difference was found between groups at one month but adherence to a fluid-restricted diet at three months and six months was significantly higher in the intervention group compared to the control group (see also Analysis 2.1).

Wong 2010 reported a difference in the degree of non-adherence to diet at seven weeks in clients with renal failure who received telephone follow-up combined with goal setting compared to clients in the control group. However, a discrepancy was found between the results provided by the authors and the SMD calculated using RevMan which revealed no difference for the degree of non-adherence to diet at seven weeks between groups. No difference was found between groups for the degree of non-adherence to diet at 13 weeks and for the number of days of non-adherence to diet, as well as non-adherence to fluid restriction (degree and days) at 7 and 13 weeks (see also Analysis 2.1).

Wood 2008 studied two populations: clients with coronary heart disease and clients at high risk of the disease. In clients with coronary heart disease, the authors reported a higher proportion of clients achieving the target for saturated fat, oily fish and fruit and vegetable intakes at one year in the intervention group (individual sessions with a nurse combined with motivational interviewing) compared to the usual care group. No difference was observed in adherence to fish consumption advice between groups. However, a discrepancy was found between the results provided by the authors and the RR calculated using RevMan which revealed a higher proportion of clients achieving the target for fish intake in the intervention group. A higher proportion of clients achieved the target for blood pressure in the intervention group compared to the usual care group, while no difference was found for body weight, and total and LDL-cholesterol levels. In clients at high risk of coronary heart disease, a higher proportion of clients achieving the target of fruit and vegetable intakes was 
reported at one year in the intervention group, while no difference was observed in adherence to recommended fish and oily fish intakes between groups. However, a discrepancy was found between the results provided by the authors and the RR calculated using RevMan which revealed a higher proportion of clients achieving the target for oily fish and fish intake in the intervention group. A higher proportion of clients also achieved the target for blood pressure and body weight in the intervention group compared to the usual care group while no difference was found for total and LDL-cholesterol levels (see also Analysis 2.2).

One study (Zhao 2004) evaluating the effects of telephone follow-up as well as individual sessions with a dietitian combined with goal setting in clients with coronary heart disease reported a higher proportion of clients with high adherence to diet in the intervention group compared to the usual care group at 4 and 12 weeks (see also Analysis 2.2).

Overall, in this category, 13 studies combined an educational intervention with another intervention such as an enablement intervention (Arcand 2005; Becker 1998; Gucciardi 2007; Hyman 2007; Jones 1986, Mahler 1999; Miller 1988; Wong 2010; Wood 2008; Zhao 2004), modelling and enablement interventions (Laitinen 1993), persuasion and enablement interventions (Morey 2008), and two educational interventions with enablement interventions (Jiang 2004). Two studies combined two different educational interventions (Baraz 2010; Hsueh 2007). One study combined a training intervention with an enablement intervention (Blanson 2009) and one study combined two enablement interventions and a training intervention (Tsay 2003). One study combined an incentivisation with a persuasion intervention (Cummings 1981).

In this category, among studies using a control/usual care group, 21 out of 56 diet adherence outcomes favoured the intervention group whereas 32 diet adherence outcomes had no significant difference between groups. It was impossible to assess this result for three diet adherence outcomes as data and/or statistical analyses needed for comparison between groups were not provided (Table 8). However, 4 out of 21 diet adherence outcomes favouring the intervention group was no longer significant at a later time point.

\section{DISCUSSION}

\section{Summary of main results}

This review included 38 studies investigating the effects of interventions enhancing adherence to dietary advice for preventing and managing chronic diseases in adults. Studies reporting at least one diet adherence outcome showing statistically significant differences favouring the intervention group included the following interventions: telephone follow-up, video, contract, feedback, nutritional tools and multiple interventions. However, these interventions also showed no difference in some diet adherence outcomes compared to a control/usual care group. Moreover, the included studies differed widely according to interventions provided, measures of diet adherence, dietary advice, nature of the chronic diseases and duration of interventions and follow-up. 
The majority of these studies were conducted in United States of America. Cardiovascular disease, diabetes, hypertension, and renal diseases were the most frequently studied chronic diseases. The adoption of a healthy diet is recommended as a prevention or management strategy for each of these chronic diseases (Lichtenstein 2006; Bantle 2008; Kopple 2001). Interestingly, all studies including clients with renal diseases reported at least one diet adherence outcome showing a statistically significant difference favouring the intervention group, no matter which intervention was provided. Only 10 of the 38 included studies evaluated diet adherence to dietary advice over a 12-month period (Becker 1998; French 2008; Hyman 2007; Laitinen 1993; Logan 2010; Micco 2007; Miller 1988; Morey 2008; Racelis 1998; Wood 2008). Among those 10 studies, only three studies showed at least one statistically significant difference in diet adherence outcomes favouring the intervention group over a 12-month period.

A broad range of interventions, all related to the method for changing dietary habits through dietary advice, was covered in this review, including education (telephone follow-up, group sessions, individual sessions with a dietitian or a nurse, and educational tools (video or booklet)), persuasion (reminders), incentivisation (contracts with rewards), training (feedback), restriction, modelling (nutritional tools) and enablement (behaviour change techniques). However, the majority of studies included a combination of two or more different interventions.

This review included studies comparing one or more intervention group(s) with one control/ usual care group, but also studies comparing two or more intervention groups to each other. However, only comparisons made between an intervention group and a control/usual care group allowed the evaluation of the effect of the intervention alone on adherence to dietary advice. Therefore, among studies that measured diet adherence outcomes between an intervention group and a control/usual care group, 32 out of 123 diet adherence outcomes favoured the intervention group. More specifically, studies reporting at least one diet adherence outcome showing statistically significant differences favouring the intervention group included the following interventions: telephone follow-up ( 3 out of 10 diet adherence outcomes), video ( 2 out of 3 diet adherence outcomes), contract ( 2 out of 4 diet adherence outcomes), feedback ( 1 out of 7 diet adherence outcomes), nutritional tools ( 3 out of 17 diet adherence outcomes) and multiple interventions (21 out of 56 diet adherence outcomes). Studies investigating interventions such as a group session, individual session, reminders, restriction and behaviour change techniques reported no diet adherence outcome showing a statistically significant difference favouring the intervention group. However, these results should be interpreted with caution as several studies evaluated two or more diet adherence outcomes. Among those, most of the studies showing a statistically significant difference favouring the intervention group for diet adherence outcome(s) also showed no significant differences between groups for other diet adherence outcome(s) (Assuncao 2010; Cummings 1981; Grace 1996; Hyman 2007; Laitinen 1993; Mahler 1999; McCulloch 1983; Miller 1988; Stewart 2005; Tsay 2003). For example, Laitinen 1993 assessed the effects of a multiple intervention and reported better adherence to saturated fat intake at 15 months in the intervention group whereas no differences were observed for adherence to intake of total, saturated or unsaturated fat carbohydrate, fiber or cholesterol between the intervention group and the control group at either 3 or 15 months. In addition, where studies measured 
outcomes at multiple time points, the majority of studies reporting a diet adherence outcome favouring the intervention group compared to the control/usual care group in the short-term also reported no significant effect at later time points. Interestingly, the majority of studies involving multiple interventions reported positive results on adherence to dietary advice. However, because multiple components within these interventions acted as co-interventions, it may have introduced confounding effects. Therefore, drawing conclusions about whether the interventions enhanced adherence to dietary advice is very difficult.

\section{Overall completeness and applicability of evidence}

Although we included a substantial number of studies covering a broad range of chronic diseases and interventions, very few studies assessing a specific chronic disease condition evaluated the same intervention. In addition, measures of adherence and dietary advice varied widely across studies.

This review assessed the effects on adherence related to the intervention alone since only the intervention, related to the method for facilitating changes in dietary habits through dietary advice, differed between the intervention group and the control/usual care group. Comparisons between two or more intervention groups were also reported. However, comparisons between multiple interventions were all different. In order to isolate the effects of the intervention, both clients in the intervention group and the control/usual care group received the same dietary advice related to their chronic disease condition. This situation could explain why adherence to dietary advice in the control/usual care group increased in some studies. However, factors other than the intervention provided could have affected adherence to dietary advice. For example, clients' intrinsic characteristics such as an elevated level of self-efficacy (Mishali 2011; Aljasem 2001) as well as few perceived barriers (Walsh 2011) are associated with better dietary adherence in clients with chronic diseases. Some studies also reported that the client's stage of change based on the Transtheoretical Model predicted long-term changes in dietary behaviours (Mochari 2010; Blissmer 2010). Therefore, confounding factors should be taken into consideration in studies evaluating adherence to dietary advice.

In this review, secondary outcomes related directly to the chronic disease condition (e.g. $\mathrm{HbA}_{1 c}$ and/or blood glucose in clients with diabetes, weight for clients with obesity) were reported. Few studies reported other secondary outcomes such as process measures, services outcomes and harms or secondary effects, making interpretation about these secondary outcomes impossible. Fourteen studies comparing an intervention group with a control/usual care group also reported clinical and/or biochemical outcome(s) in addition to adherence to dietary advice. Among those, six reported improvement in at least one chronic diseaserelated clinical or biochemical outcome in the intervention group. As mentioned earlier, these results should be interpreted with caution as several studies evaluated two or more clinical and/or biochemical outcomes.

Seventeen studies provided advice in order to induce changes other than diet such as physical activity, medication compliance, smoking cessation and blood glucose monitoring. All of these studies independently assessed adherence to dietary advice, but because those studies varied widely according to interventions provided and nature of the chronic diseases, 
we cannot conclude that adherence to dietary advice is improved when multifaceted interventions are provided.

\section{Quality of the evidence}

Despite a high number of included studies $(\mathrm{n}=38)$, these studies varied widely according to interventions provided, measures of diet adherence, dietary advice, nature of the chronic diseases and duration of interventions and follow-up. The numbers of clients included in the review is impressive (9445), but the range of number of clients in each study was wide, varying from 7 to 5405 clients. Only 13 of the 38 included studies provided a power calculation (Aldarondo 1999; Assuncao 2010; Beasley 2008; Chiu 2010; French 2008; Hyman 2007; Jiang 2004; Meland 1994; Stewart 2005; Tsay 2003; Wong 2010; Wood 2008; Zhao 2004) and among them, 10 studies recruited the number of clients according to their power analysis (Aldarondo 1999; Assuncao 2010; Beasley 2008; French 2008; Jiang 2004; Meland 1994; Stewart 2005; Tsay 2003; Wong 2010; Zhao 2004).

While an elevated drop-out rate could be considered as an indirect measure of nonadherence, such as in studies of pharmaceutical interventions where participants who withdraw no longer have access to medication, it cannot be assumed that clients dropping out of dietary intervention studies are non-adherent to dietary advice. Most studies included in this review had a low drop-out rate. In fact, 19 studies reported a drop-out rate lower than $20 \%$ ( 9 of those had no drop-out). Nine studies had a drop-out rate of between $20 \%$ and $30 \%$ and only five studies had a drop-out rate over $30 \%$. It was impossible to calculate the dropout rate for six studies (Gans 1994; Gill 2010; Hsueh 2007; Jones 1986; Mahler 1999; McCulloch 1983). One study (Wood 2008) reported adherence for two populations, which explains why the total number of included studies adds up to 39 , and not 38 .

The majority of included studies were of poor methodological quality and/or poorly reported risk of bias elements. All included studies met less than five of the eight criteria of risk of bias (see Assessment of risk of bias in included studies). Among those eight criteria, three of them evaluated respectively the blinding of clients, providers and outcome assessors. Very few included studies met these criteria because blinding in the context of delivering a nutritional intervention is very difficult to achieve, even impossible in some designs. Unlike most pharmaceutical designs using placebo, both clients and providers from nutritional studies usually know which intervention is delivered.

A major challenge in the measurement of diet adherence is the correct estimation of dietary intake, as no method for accurate determination of dietary intake has been developed yet. In this review, 31 studies used self-reported measures of diet adherence while 6 studies assessed diet adherence using objective measures. Objective measures included serum micronutrients (e.g. potassium, sodium, phosphate) and interdialytic weight gain to evaluate respectively adherence to diet and to fluid-restricted diet in clients with renal diseases, and urinary electrolytes excretion (sodium, chloride) to evaluate adherence to a sodium-restricted diet in clients with hypertension. Those methods have been validated and are usually more reliable than self-reported measures. However, the assessment of many food and nutrient intakes cannot always be performed by objective measures, especially when dietary advice targets food groups (e.g. fruit and vegetables) rather than a specific nutrient (e.g. sodium). 
The Academy of Nutrition and Dietetics states that "total diet or overall pattern of food eaten is the most important focus of a healthful eating style" (JADA 2007). Consequently, most studies providing dietary advice focusing on a global healthy diet rather than a specific nutrient used self-reported methods such as dietary tools (e.g. food records, food frequency questionnaires and validated diet questionnaires or scales). Misreporting of dietary intake is a major issue and has been related to body mass index, age, sex, socio-economic status and education (Poslusna 2009). In addition, other sources of misreporting have been identified such as memory relapses, misrepresentation of portion size consumed, social desirability and daily dietary variability (Kumanyika 2000; Wilson 2005). Therefore, establishing validity and reliability of dietary tools is crucial in order to avoid inconsistent estimates of dietary intake leading to a high risk of bias. In this review, only 14 studies of 32 stated that the selfreported measures of diet adherence had been validated and/or shown to be reliable, suggesting that adherence to dietary advice in those studies could be biased. To gain a thorough understanding of adherence to dietary advice, both self-report and objective measures of adherence are needed. While objective measures provide information on food intake only, self-report measures also provide useful information on the circumstances of non-adherence. The latter is important for clinicians to understand the reasons why the client is non-adherent (which may include the clinicians' lack of behavioral skills) and to promote a collaborative relationship that considers clients' values and preferences. More research is therefore needed to both develop standardized and validated self-report adherence measures and to identify more robust and objective measures of adherence to dietary advice.

\section{Potential biases in the review process}

Strengths of this review include the fact that we contacted many study authors during the data extraction process to gather additional information. The main reason was that some authors did not adequately describe the intervention provided in the intervention group and/or in the control/usual care group, in the published report. Additional information we received allowed us to better classify the included studies according to the intervention provided.

As expected, a limitation of this review is the definition of adherence to dietary advice. Adherence to dietary advice is a wide concept and includes many different measures including self-reported measures which are not always comparable. Accordingly, in this review, some included studies assessed adherence to dietary advice by reporting the proportion of clients achieving the dietary recommendations. However, the majority of included studies evaluated adherence to dietary advice by comparing the mean dietary intake between groups. These different ways to measure adherence to dietary advice suggest that there is a need to develop standardized and validated tools to assess adherence to dietary advice.

In this review, we only included studies clearly mentioning a measure of adherence to dietary advice in the title or the objective of the study and/or those reporting the proportion of clients adhering to dietary advice. Therefore, we excluded all studies reporting mean dietary intake between groups without specifically assessing adherence to dietary advice as a primary outcome. Despite an extensive search in standard databases as well as in the grey 
literature, we cannot exclude the possibility that we missed some studies measuring adherence to dietary advice if those studies were not indexed in bibliographic databases as reporting adherence or compliance.

We categorized interventions according to Michie et al (Michie 2011) intervention functions to simplify and structure the presentation of results and not to provide insights about which intervention function was most effective for enhancing adherence to dietary advice.

Although two review authors assigned the interventions to the categories through consensus, the assignment was arbitrary and we cannot exclude the fact that others may have assigned interventions to other categories. However, it must be emphasized that the process did not interfere with the interpretation of results.

\section{Agreements and disagreements with other studies or reviews}

Few systematic reviews evaluated clients' adherence to recommendations in the context of preventing and/or managing chronic diseases. Among systematic reviews reporting the effectiveness of interventions to enhance adherence to dietary advice, none assessed the same criteria as this review, making comparisons difficult. For example, two systematic reviews included other components in the assessment of adherence in addition to diet, such as physical activity and medication (Matteson 2010; Greaves 2011). The evaluation of diet adherence alone for those studies was therefore impossible. Fappa et al (Fappa 2008) performed a non-systematic review on lifestyle interventions for enhancing adherence to diet and exercise in the management of the metabolic syndrome. However, dietary advice provided in the majority of included studies differed between the intervention and the control groups. Consequently, the effects of the intervention could not be isolated.

Burke 1997 conducted a non-systematic review of successful strategies to increase adherence to dietary advice in the context of CVD prevention. Among eleven included studies, interventions found to be effective to improve adherence to nutritional therapy were behavioural skill training, spouse support and self-efficacy enhancement.

Our results are consistent with those of Brownell and colleagues (Brownell 1995b) who performed an overview of studies with diet adherence data. They reported inconsistencies in methods and had difficulty interpreting results because of the broad variation of diseases covered and interventions provided. Similarly, Newell et al (Newell 2000) performed a nonsystematic review of strategies for improving cardiovascular client compliance to nonpharmacologic treatments. No strong evidence was reported for the enhancement of dietary regime, and studies included were assessed as fair quality in term of study design. Those conclusions underline the fact that further good-quality studies assessing adherence to dietary advice for preventing and managing chronic diseases should be performed.

\section{AUTHORS' CONCLUSIONS}

\section{Implications for practice}

Non-adherence to dietary advice represents one of the barriers to getting nutrition knowledge into practice, thereby potentially hampering the prevention of the onset or progression of many chronic diseases and ultimately, improved population well-being and 
health. This Cochrane review aimed to summarize, categorize and compare the effects of interventions for enhancing adherence to dietary advice for preventing and managing chronic diseases in adults. Some interventions such as telephone follow-up, video, contract, feedback and nutritional tools demonstrated a mixed effect on diet adherence as they showed some diet adherence outcomes favouring the intervention group compared to the control/ usual care group but also no difference in some diet adherence outcomes between groups. Moreover, included studies differed widely according to interventions provided, measures of diet adherence, dietary advice, nature of the chronic diseases and duration of interventions and follow-up, making assessment of intervention versus intervention rather challenging. Therefore, this systematic review cannot draw firm conclusions from comparisons between interventions, but rather identifies a number of potentially-beneficial interventions that can be used in practice (telephone follow-up, video, contract, feedback and nutritional tools). Also, while the majority of multiple interventions have demonstrated a positive effect on diet adherence compared to a control/usual care group, none of the included studies assessed the same combination of interventions, making impossible the identification of the optimal combination of interventions to enhance adherence to dietary advice. Consequently, researchers, decision makers, health professionals and consumers remain with little practical guidance with regard to the best intervention for enhancing adherence to dietary advice. However, it may be argued that in health care, there is often no unique best option for either treatment or process of care, as these options may be influenced by clients' preferences and values. Although longer-term, well-designed RCTs using improved methods for measuring diet adherence are needed, results of this systematic review provide options for both health professionals and consumers that may be used in practice. Interventions shown to be beneficial compared to a control/usual care group could be used depending on clients' preferences, lifestyle and values, health professionals' communication skills, and organisational context.

\section{Implications for research}

Evidence of the role of a healthy diet and/or specific nutrient intakes on the prevention and management of chronic diseases is well recognized. Further studies are now essential to refine methods for providing dietary advice and improve diet adherence in the context of chronic diseases. Several gaps in knowledge have been identified in this review regarding the effectiveness of interventions to enhance adherence to dietary advice for preventing and managing chronic diseases in adults:

- $\quad$ Further good quality studies should be designed to minimize bias and to have an adequate sample size to detect significant differences between groups;

- $\quad$ Further studies with a long-term duration, namely more than 12 months, and a follow-up evaluation are needed;

- Further research should be designed with a comparison between an intervention group and a control/usual care group both providing the same dietary advice to capture the effect of the intervention only, without confounding factors;

- Further studies need to define clearly the term 'adherence' and describe the intervention in detail. Moreover, there is a need to develop standardized and 
validated self-report tools and robust objective measures (e.g. biomarkers) to assess adherence to dietary advice;

- Further studies should investigate the factors contributing to clients' nonadherence to dietary advice in order to develop interventions to overcome barriers. These factors include psychosocial and environmental determinants, but also biological factors affecting food intake;

- $\quad$ Moreover, perspectives from health professionals and clients about the interventions enhancing adherence to dietary advice should be studied with the aim of identifying those that are most implementable in practice and adaptable to local contexts (Desroches 2011).

\section{Acknowledgments}

We thank the staff and editors of the Cochrane Consumers and Communication Review Group, especially Professor Adrian Edwards (Contact Editor for this review), Dr Megan Prictor (Managing Editor), Dr Sophie Hill (Coordinating Editor) and Mr John Kis-Rigo (Trials Search Coordinator). We also thank Dr Anik Giguere for her assistance with systematic review methods, Jayne Thirsk for her comments on the review and Narimane Toureche, Sarah-Maude Deschênes, Catherine Laramée, Vincent Hao May, Annabelle Fortier and Nadine Tremblay for their assistance with the selection of studies and/or data extraction and/or tables conception. Finally, we thank XiaoQiang Wang, Sumi Ross, Annette Bluemle, Amélie Trépanier, Sonia Pomerleau, Claire Glenton and Docent Suzana Nikolovska who assisted with translating publications from languages other than English (Chinese, Japanese, German, Spanish, Danish and Norwegian and Serbian).

\section{SOURCES OF SUPPORT}

Internal sources

- $\quad$ No sources of support supplied

External sources

- Canadian Institutes of Health Research, Canada.

Salary of Annie Lapointe

\section{References}

\section{References to studies included in this review}

Aldarondo 1999 \{published and unpublished data\}. Aldarondo, F. PhD thesis. Vol. 60. University of Indiana; US: 1999. Adherence among individuals in an exercise, nutrition, and weight loss program. ProQuest Information \& Learning

Arcand 2005 \{published and unpublished data\}. Arcand JA, Brazel S, Joliffe C, Choleva M, Berkoff F, Allard JP, et al. Education by a dietitian in patients with heart failure results in improved adherence with a sodium-restricted diet: a randomized trial. American Heart Journal. 2005; 150:716.

Assuncao 2010 \{published and unpublished data\}. Assuncao MC, Gigante DP, Cardoso MA, Sartorelli DS, Santos IS. Randomized, controlled trial promotes physical activity and reduces consumption of sweets and sodium among overweight and obese adults. Nutrition Research. 2010; 30:541-9. [PubMed: 20851308]

Baraz 2010 \{published and unpublished data\}. Baraz S, Parvardeh S, Mohammadi E, Broumand B. Dietary and fluid compliance: an educational intervention for patients having haemodialysis. Journal of Advanced Nursing. 2010; 66:60-8. [PubMed: 20423436]

Beasley 2008 \{published and unpublished data\}. Beasley JM, Riley WT, Davis A, Singh J. Evaluation of a PDA-based dietary assessment and intervention program: a randomized controlled trial. Journal of the American College of Nutrition. 2008; 27:280-6. [PubMed: 18689560] 
Becker 1998 \{published data only\}. Becker DM, Raqueno JV, Yook RM, Kral BG, Blumenthal RS, Moy TF, et al. Nurse-mediated cholesterol management compared with enhanced primary care in siblings of individuals with premature coronary disease. Archives of Internal Medicine. 1998; 158:1533-9. [PubMed: 9679794]

Bennett 1986 \{published and unpublished data\}. Bennett GA. Cognitive rehearsal in the treatment of obesity: a comparison against cue avoidance and social pressure. Addictive Behaviors. 1986; 11:225-37. [PubMed: 3739810]

Blanson 2009 \{published and unpublished data\}. Blanson Henkemans OA, van der Boog PJ, Lindenberg J, van der Mast CA, Neerincx MA, Zwetsloot-Schonk BJ. An online lifestyle diary with a persuasive computer assistant providing feedback on self-management. Technology and Health Care. 2009; 17:253-67. [PubMed: 19641261]

Chen 2006 \{published data only\}. Chen W, Lu XH, Wang T. Menu suggestion: an effective way to improve dietary compliance in peritoneal dialysis patients. Journal of Renal Nutrition. 2006; 16:132-6. [PubMed: 16567269]

Chiu 2010 \{published data only\}. Chiu CW, Wong FK. Effects of 8 weeks sustained follow-up after a nurse consultation on hypertension: a randomised trial. International Journal of Nursing Studies. 2010; 47:1374-82. [PubMed: 20413121]

Conrad 2000 \{published data only\}. Conrad BC, Glanville NT, Raine-Travers KD. Adherence to a very low fat diet for cardiac rehabilitation patients. Canadian Journal of Dietetic Practice and Research. 2000; 61:193-5. [PubMed: 11844410]

Cummings 1981 \{published and unpublished data\}. Cummings KM, Becker MH, Kirscht JP, Levin NW. Intervention strategies to improve compliance with medical regimens by ambulatory hemodialysis patients. Journal of Behavioral Medicine. 1981; 4:111-27. [PubMed: 7288877]

French 2008 \{published data only\}. French DP, Wade AN, Yudkin P, Neil HA, Kinmonth AL, Farmer AJ. Self-monitoring of blood glucose changed non-insulin-treated Type 2 diabetes patients' beliefs about diabetes and self-monitoring in a randomized trial. Diabetic Medicine. 2008; 25:1218-28. [PubMed: 19046201]

Gans 1994\{published data only\}. Gans KM, Lapane KL, Lasater TM, Carleton RA. Effects of intervention on compliance to referral and lifestyle recommendations given at cholesterol screening programs. American Journal of Preventive Medicine. 1994; 10:275-82. [PubMed: 7848670]

Gill 2010 \{published and unpublished data\}. Gill CE, Cook EA, Smith CL, Domos CA, Delmonico MJ, Lofgren IE. Dietary Approaches to Stop Hypertension diet compliance decreases coronary heart disease risk in overweight and obese college-aged women. Journal of the American Dietetic Association. 2010; 110:A-116.

Grace 1996 \{published and unpublished data\}. Grace C, Summerbell C. Does provision of additional dietary information affect actual or only reported compliance to a low-fat diet over 12 weeks in hyperlipidaemic individuals? Report of a pilot study. Journal of Human Nutrition and Dietetics. 1996; 9:303-7.

Gucciardi 2007 ppublished and unpublished data\}. Gucciardi E, Demelo M, Lee RN, Grace SL. Assessment of two culturally competent diabetes education methods: individual versus individual plus group education in Canadian Portuguese adults with type 2 diabetes. Ethnicity and Health. 2007; 12:163-87. [PubMed: 17364900]

Hsueh 2007 \{published data only\}. Hsueh, H. PhD thesis. University of Washington; 2007. Compliance with dietary recommendations in adults with irritable bowel syndrome.

Hyman 2007 \{published data only\}. Hyman DJ, Pavlik VN, Taylor WC, Goodrick GK, Moye L. Simultaneous vs sequential counseling for multiple behavior change. Archives of Internal Medicine. 2007; 167:1152-8. [PubMed: 17563023]

Jiang 2004\{published and unpublished data\}. Jiang, X. The effect of a nurse-led cardiac rehabilitation programme on patients with coronary heart disease in Chengdu, China (PhD thesis). The Hong Kong Polytechnic University. Hong Kong Polytechnic University (People's Republic of China); 2004. Jiang X, Sit JW, Wong TK. A nurse-led cardiac rehabilitation programme improves health behaviours and cardiac physiological risk parameters: evidence from Chengdu, China. Health Technology Assessment. 2007; 16:1886-97. 
Jones 1986 \{published data only\}. Jones SE, Owens HM, Bennett GA. Does behaviour therapy work for dietitians? An experimental evaluation of the effects of three procedures in a weight reduction clinic. Human Nutrition: Applied Nutrition. 1986; 40:272-81. [PubMed: 3759500]

Kendall 1987 \{published and unpublished data\}. Kendall PA, Jansen CM, Sjogren DD, Jansen GR. A comparison of nutrient-based and exchange-group methods of diet instruction for patients with noninsulin-dependent diabetes. Annals of Surgery. 1987; 45:625-37.

Laitinen 1993 \{published and unpublished data\}. Laitinen JH, Ahola IE, Sarkkinen ES, Winberg RL, Harmaakorpi-Iivonen PA, Uusitupa MI. Impact of intensified dietary therapy on energy and nutrient intakes and fatty acid composition of serum lipids in patients with recently diagnosed non-insulin-dependent diabetes mellitus. Journal of the American Dietetic Association. 1993; 93:276-83. [PubMed: 8382712]

Logan 2010 \{published and unpublished data\}. Logan KJ, Woodside JV, Young IS, McKinley MC, Perkins-Porras L, McKeown PP. Adoption and maintenance of a Mediterranean diet in patients with coronary heart disease from a Northern European population: a pilot randomised trial of different methods of delivering Mediterranean diet advice. Journal of Human and Dietetics. 2010; 23:30-7.

Mahler 1999\{published and unpublished data\}. Mahler HI, Kulik JA, Tarazi RY. Effects of a videotape information intervention at discharge on diet and exercise compliance after coronary bypass surgery. Journal of Cardiopulmonary Rehabilitation. 1999; 19:170-7. [PubMed: 10361648]

McCulloch 1983 \{published data only\}. McCulloch DK, Mitchell RD, Ambler J, Tattersall RB. Influence of imaginative teaching of diet on compliance and metabolic control in insulin dependent diabetes. British Medical Journal. 1983; 287:1858-61. [PubMed: 6423045]

Meland 1994\{published and unpublished data\}. Meland E, Laerum E, Ulvik RJ. Salt restriction in hypertension: the effect of dietary advice and self monitoring of chloride concentration in urine. Scandinavian Journal of Clinical and Laboratory Investigation. 1994; 54:399-404. [PubMed: 7997845]

Micco 2007 \{published data only\}. Micco N, Gold B, Buzzell P, Leonard H, Pintauro S, Harvey-Berino J. Minimal in-person support as an adjunct to internet obesity treatment. Annals of Behavioral Medicine. 2007; 33:49-56. [PubMed: 17291170]

Miller 1988\{published data only\}. Miller P, Wikoff R, Garrett MJ, McMahon M, Smith T. Regimen compliance two years after myocardial infarction. Nursing Research. 1990; 39:333-6. [PubMed: 2092306] Miller P, Wikoff R, McMahon M, Garrett MJ, Ringel K. Influence of a nursing intervention on regimen adherence and societal adjustments postmyocardial infarction. Nursing Research. 1988; 37:297-302. [PubMed: 3047691] Miller P, Wikoff R, McMahon M, Garrett MJ, Ringel K, Collura D, et al. Personal adjustments and regimen compliance 1 year after myocardial infarction. Heart and Lung. 1989; 18:339-46. [PubMed: 2745106]

Morey 2008 \{published data only\}. Morey B, Walker R, Davenport A. More dietetic time, better outcome? A randomized prospective study investigating the effect of more dietetic time on phosphate control in end-stage kidney failure haemodialysis patients. Nephron Clinical Practice. 2008; 109:c173-80. DOI: 10.1159/000145462 [PubMed: 18663331]

Racelis 1998 \{published data only\}. Racelis MC, Lombardo K, Verdin J. Impact of telephone reinforcement of risk reduction education on patient compliance. Journal of Vascular Nursing. 1998; 16:16-20. [PubMed: 9764028]

Ryan 2002 \{published and unpublished data\}. Ryan EA, Todd KR, Estey A, Cook B, Pick M. Diabetes education evaluation: a prospective outcome study. Canadian Journal of Diabetes. 2002; 26:1139.

Scisney-Matlock 2006\{published data only\}. Scisney-Matlock M, Glazewki L, McClerking C, Kachorek L. Development and evaluation of DASH diet tailored messages for hypertension treatment. Applied Nursing Research. 2006; 19:78-87. [PubMed: 16728291]

Stewart 2005 \{published and unpublished data\}. Stewart A, Noakes T, Eales C, Shepard K, Becker P, Veriawa Y. Adherence to cardiovascular risk factor modification in patients with hypertension. Cardiovascular Journal of South Africa. 2005; 16:102-7. [PubMed: 15915277]

Tsay 2003 \{published data only\}. Tsay SL. Self-efficacy training for patients with end-stage renal disease. Journal of Advanced Nursing. 2003; 43:370-5. [PubMed: 12887355] 
Wong 2010 published and unpublished data\}. Chow, SKY. The effects of a nurse-led case management programme on patients undergoing peritoneal dialysis: a randomized controlled trial (PhD thesis). The Hong Kong Polytechnic University; 2006. Wong FK, Chow SK, Chan TM. Evaluation of a nurseled disease management programme for chronic kidney disease: a randomized controlled trial. International Journal of Nursing Studies. 2010; 47:268-78. [PubMed: 19651405]

Wood 2008 \{published data only\}. Wood DA, Kotseva K, Connolly S, Jennings C, Mead A, Jones J, et al. Nurse-coordinated multidisciplinary, family-based cardiovascular disease prevention programme (EUROACTION) for patients with coronary heart disease and asymptomatic individuals at high risk of cardiovascular disease: a paired, cluster-randomised controlled trial. The Lancet. 2008; 371:1999-2012.

Zhao 2004 \{published data only\}. Zhao, Y. PhD thesis. Hong Kong Polytechnic University (People's Republic of China); 2004. Effects of a discharge planning intervention for elderly patients with coronary heart disease in Tianjin, China: a randomized controlled trial.

\section{References to studies excluded from this review}

Abramson 1980 \{published data only\}. Abramson R, Garg M, Cioffari A, Rotman PA. An evaluation of behavioral techniques reinforced with an anorectic drug in a double-blind weight loss study. Journal of Clinical Psychiatry. 1980; 41:234-7. [PubMed: 6993445]

Agras 1996\{published data only\}. Agras WS, Berkowitz RI, Arnow BA, Telch CF, Marnell M, Henderson J, et al. Maintenance following a very-low-calorie diet. Journal of Consulting and Clinical Psychology. 1996; 64:610-3. [PubMed: 8698956]

Ammerman 2003 \{published data only\}. Ammerman AS, Keyserling TC, Atwood JR, Hosking JD, Zayed H, Krasny C. A randomized controlled trial of a public health nurse directed treatment program for rural patients with high blood cholesterol. Preventive Medicine. 2003; 36:340-51. [PubMed: 12634025]

Arnaud-Battandier 1999\{published data only\}. Arnaud-Battandier F, Lauque S, Paintin M, Mansourian R, Vellas B, Guigoz Y. MNA and nutritional intervention. Nestlé Nutrition Workshop Series Clinical and Performance Programme. 1999; 1:131-8. discussion 138-40. [PubMed: 11490589]

Ashurst 2003 \{published data only\}. de Ashurst IB, Dobbie H. A randomized controlled trial of an educational intervention to improve phosphate levels in hemodialysis patients. Journal of Renal Nutrition. 2003; 13:267-74. [PubMed: 14566763]

Atwood 1992 \{published data only\}. Atwood JR, Aickin M, Giordano L, Benedict J, Bell M, Ritenbaugh $\mathrm{C}$, et al. The effectiveness of adherence intervention in a colon cancer prevention field trial. Preventive Medicine. 1992; 21:637-53. [PubMed: 1332022]

Babamoto 2009 \{published data only\}. Babamoto KS, Sey KA, Camilleri AJ, Karlan VJ, Catalasan J, Morisky DE. Improving diabetes care and health measures among hispanics using community health workers: results from a randomized controlled trial. Health Education and Behavior. 2009; 36:113-26. [PubMed: 19188371]

Basler 1982\{published data only\}. Basler HD, Brinkmeier U, Buser K, Haehn KD, Molders-Kober R. Psychological group treatment of essential hypertension in general practice. British Journal of Clinical Psychology. 1982; 21(Pt 4):295-302. [PubMed: 6756521]

Baum 1991 \{published data only\}. Baum JG, Clark HB, Sandler J. Preventing relapse in obesity through posttreatment maintenance systems: comparing the relative efficacy of two levels of therapist support. Journal of Behavioral Medicine. 1991; 14:287-302. [PubMed: 1875405]

Befort 2008\{published data only\}. Befort CA, Nollen N, Ellerbeck EF, Sullivan DK, Thomas JL, Ahluwalia JS. Motivational interviewing fails to improve outcomes of a behavioral weight loss program for obese African American women: a pilot randomized trial. Journal of Behavioral Medicine. 2008; 31:367-77. [PubMed: 18587639]

Berra 2007 \{published data only\}. Berra K, Ma J, Klieman L, Hyde S, Monti V, Guardado A, et al. Implementing cardiac risk-factor case management: lessons learned in a county health system. Critical Patway in Cardiology. 2007:173-9.

Berteus 2008 \{published data only\}. Berteus Forslund H, Klingstrom S, Hagberg H, Londahl M, Torgerson JS, Lindroos AK. Should snacks be recommended in obesity treatment? A 1-year 
randomized clinical trial. European Journal of Clinical Nutrition. 2008; 62:1308-17. [PubMed: 17700649]

Bertram 1990\{published data only\}. Bertram SR, Venter I, Stewart RI. Weight loss in obese women: exercise v dietary education. South African Medical Journal. 1990; 78:15-8. [PubMed: 2363076]

Boeka 2010\{published data only\}. Boeka AG, Prentice-Dunn S, Lokken KL. Psychosocial predictors of intentions to comply with bariatric surgery guidelines. Psychology, Health and Medicine. 2010; 15:188-97.

Borg 2002 \{published data only\}. Borg P, Kukkonen-Harjula K, Fogelholm M, Pasanen M. Effects of walking or resistance training on weight loss maintenance in obese, middle-aged men: a randomized trial. International Journal of Obesity. 2002; 26:676-83. [PubMed: 12032753]

Bosworth 2008 \{published data only\}. Bosworth HB, Olsen MK, Neary A, Orr M, Grubber J, Svetkey L, et al. Take Control of Your Blood Pressure (TCYB) study: a multifactorial tailored behavioral and educational intervention for achieving blood pressure control. Patient Education and Counseling. 2008; 70:338-47. [PubMed: 18164894]

Brekke 2003 \{published data only\}. Brekke HK, Jansson PA, Mansson JE, Lenner RA. Lifestyle changes can be achieved through counseling and follow-up in first-degree relatives of patients with type 2 diabetes. Journal of the American Dietetic Association. 2003; 103:835-43. [PubMed: 12830021]

Brekke 2005a\{published data only\}. Brekke HK, Lenner RA, Taskinen MR, Mansson JE, Funahashi T, Matsuzawa Y, et al. Lifestyle modification improves risk factors in type 2 diabetes relatives. Diabetes Research and Clinical Practice. 2005; 68:18-28. [PubMed: 15811562]

Brekke 2005b \{published data only\}. Brekke HK, Jansson PA, Lenner RA. Long-term (1- and 2-year) effects of lifestyle intervention in type 2 diabetes relatives. Diabetes Research and Clinical Practice. 2005; 70:225-34. [PubMed: 15885845]

Brekke 2009\{published data only\}. Brekke HK, Sunesson A, Lenner RA. Unannounced telephone interviews: a useful and positively received tool in the reinforcement of lifestyle intervention. Patient Preference and Adherence. 2009; 3:357-62. [PubMed: 20054441]

Broekhuizen 2010\{published data only\}. Broekhuizen K, van Poppel MN, Koppes LL, Brug J, van Mechelen W. A tailored lifestyle intervention to reduce the cardiovascular disease risk of individuals with Familial Hypercholesterolemia (FH): design of the PRO-FIT randomised controlled trial. BMC Public Health. 2010; 10:69. [PubMed: 20156339]

Bruckert 2008 \{published data only\}. Bruckert E, Giral P, Paillard F, Ferrieres J, Schlienger JL, Renucci JF, et al. Effect of an educational program (PEGASE) on cardiovascular risk in hypercholesterolaemic patients. Cardiovascular Drugs and Therapy. 2008; 22:495-505. [PubMed: 18830810]

Burke 2005 \{published and unpublished data\}. Burke LE, Dunbar-Jacob J, Orchard TJ, Sereika SM. Improving adherence to a cholesterol-lowering diet: a behavioral intervention study. Patient Education and Counseling. 2005; 57:134-42. [PubMed: 15797163]

Burke 2006a \{published data only\}. Burke LE, Sereika S, Choo J, Warziski M, Music E, Styn M, et al. Ancillary study to the PREFER trial: a descriptive study of participants' patterns of selfmonitoring--rationale, design and preliminary experiences. Contemporary Clinical Trials. 2006; 27:23-33. [PubMed: 16311076]

Burke 2006b \{published data only\}. Burke LE, Choo J, Music E, Warziski M, Styn MA, Kim Y, et al. PREFER study: a randomized clinical trial testing treatment preference and two dietary options in behavioral weight management: rationale, design and baseline characteristics. Contemporary Clinical Trials. 2006; 27:34-48. [PubMed: 16233990]

Burke 2007 published data only\}. Burke LE, Hudson AG, Warziski MT, Styn MA, Music E, Elci OU, et al. Effects of a vegetarian diet and treatment preference on biochemical and dietary variables in overweight and obese adults: a randomized clinical trial. American Journal of Clinical Nutrition. 2007; 86:588-96. [PubMed: 17823421]

Burke 2008 \{published data only\}. Burke LE, Sereika SM, Music E, Warziski M, Styn MA, Stone A. Using instrumented paper diaries to document self-monitoring patterns in weight loss. Contemporary Clinical Trials. 2008; 29:182-93. [PubMed: 17702667] 
Burke 2010 \{published data only\}. Burke LE, Conroy MB, Sereika SM, Elci OU, Styn MA, Acharya $\mathrm{SD}$, et al. The effect of electronic self-monitoring on weight loss and dietary intake: a randomized behavioral weight loss trial. Obesity. 2010; 19(2):338-44. [PubMed: 20847736]

Burkett 1990 \{published data only\}. Burkett PA, Southard DR, Herbert WG, Walberg J. Frequent cholesterol feedback as an aid in lowering cholesterol levels. Journal of Cardiopulmonary Rehabilitation. 1990:141-6.

Campbell 1984\{published data only\}. Campbell DF, Dixon JK, Sanderford LD, Denicola MA. Relaxation: its effect on the nutritional status and performance status of clients with cancer. Journal of the American Dietetic Association. 1984; 84:201-4. [PubMed: 6363490]

Campbell 1990\{published and unpublished data\}. Campbell LV, Barth R, Gosper JK, Jupp JJ, Simons LA, Chisholm DJ. Impact of intensive educational approach to dietary change in NIDDM. Diabetes Care. 1990; 13:841-7. [PubMed: 2209318]

Campbell 1998\{published data only\}. Campbell NC, Ritchie LD, Thain J, Deans HG, Rawles JM, Squair JL. Secondary prevention in coronary heart disease: a randomised trial of nurse led clinics in primary care. Heart. 1998; 80:447-52. [PubMed: 9930042]

Cangiano 1991 \{published data only\}. Cangiano C, Ceci F, Cairella M, Cascino A, Del Ben M, Laviano A, et al. Effects of 5-hydroxytryptophan on eating behavior and adherence to dietary prescriptions in obese adult subjects. Advances in Experimental Medicine and Biology. 1991; 294:591-3. [PubMed: 1722953]

Cangiano 1992\{published data only\}. Cangiano C, Ceci F, Cascino A, Del Ben M, Laviano A, Muscaritoli M, et al. Eating behavior and adherence to dietary prescriptions in obese adult subjects treated with 5-hydroxytryptophan. American Journal of Clinical Nutrition. 1992; 56:863-7. [PubMed: 1384305]

Cangiano 1998 \{published data only\}. Cangiano C, Laviano A, Del Ben M, Preziosa I, Angelico F, Cascino A, et al. Effects of oral 5-hydroxy-tryptophan on energy intake and macronutrient selection in non-insulin dependent diabetic patients. International Journal of Obesity. 1998; 22:648-54. [PubMed: 9705024]

Carels 2005 \{published data only\}. Carels RA, Darby LA, Douglass OM, Cacciapaglia HM, Rydin S. Education on the glycemic index of foods fails to improve treatment outcomes in a behavioral weight loss program. Eating Behaviors. 2005; 6:145-50. [PubMed: 15598601]

Carels 2005a\{published data only\}. Carels RA, Darby LA, Rydin S, Douglass OM, Cacciapaglia HM, O'Brien WH. The relationship between self-monitoring, outcome expectancies, difficulties with eating and exercise, and physical activity and weight loss treatment outcomes. Annals of Behavioral Medicine. 2005; 30:182-90. [PubMed: 16336069]

Carson 1988 \{published data only\}. Carson MA, Hathaway A, Tuohey JP, McKay BM. The effect of a relaxation technique on coronary risk factors. Behavioral Medicine. 1988; 14:71-7. [PubMed: 3289645]

Casebeer 1999 \{published data only\}. Casebeer LL, Klapow JC, Centor RM, Stafford MA, Renk1 LA, Mallinger AP, et al. An intervention to increase physicians' use of adherence-enhancing strategies in managing hypercholesterolemic patients. Academic Medicine. 1999; 74:1334-9. [PubMed: 10619013]

Cegala 2000 \{published data only\}. Cegala DJ, Marinelli T, Post D. The effects of patient communication skills training on compliance. Archives of Family Medicine. 2000; 9:57-64. [PubMed: 10664643]

Chang 2009\{published data only\}. Chang MW, Brown R, Nitzke S. Participant recruitment and retention in a pilot program to prevent weight gain in low-income overweight and obese mothers. BMC Public Health. 2009; 9:424. [PubMed: 19930587]

Cheyette 2007 \{published data only\}. Cheyette C. Weight no more: a randomised controlled trial for people with type 2 diabetes on insulin therapy. Practical Diabetes International. 2007:450-6.

Chlebowski 1993 \{published data only\}. Chlebowski RT, Blackburn GL, Buzzard IM, Rose DP, Martino S, Khandekar JD, et al. Adherence to a dietary fat intake reduction program in postmenopausal women receiving therapy for early breast cancer. The Women's Intervention Nutrition Study. Journal of Clinical Oncology. 1993; 11:2072-80. [PubMed: 8229121] 
Costa 2008 \{published data only\}. Costa e Silva R, Pellanda L, Portal V, Maciel P, Furquim A, Schaan B. Transdisciplinary approach to the follow-up of patients after myocardial infarction. Clinics. 2008; 63:489-96. [PubMed: 18719760]

Darlington 1986\{published data only\}. Darlington LG, Ramsey NW, Mansfield JR. Placebocontrolled, blind study of dietary manipulation therapy in rheumatoid arthritis. The Lancet. 1986; $1: 236-8$.

Davidson 1996 \{published data only\}. Davidson MH, Kong JC, Drennan KB, Story K, Anderson GH. Efficacy of the National Cholesterol Education Program Step I diet. A randomized trial incorporating quick-service foods. Archives of Internal Medicine. 1996; 156:305-12. [PubMed: 8572841]

Dechamps 2009\{published data only\}. Dechamps A, Gatta B, Bourdel-Marchasson I, Tabarin A, Roger P. Pilot study of a 10-week multidisciplinary Tai Chi intervention in sedentary obese women. Clinical Journal of Sport Medicine. 2009; 19:49-53. [PubMed: 19124984]

Del 2009 \{published data only\}. Del Corral P, Chandler-Laney PC, Casazza K, Gower BA, Hunter GR. Effect of dietary adherence with or without exercise on weight loss: a mechanistic approach to a global problem. The Journal of Clinical Endocrinology and Metabolism. 2009; 94:1602-7. [PubMed: 19258409]

Demark-Wahnefried 2006 \{published data only\}. Demark-Wahnefried W, Clipp EC, Morey MC, Pieper CF, Sloane R, Snyder DC, et al. Lifestyle intervention development study to improve physical function in older adults with cancer: Outcomes from project LEAD. Journal of Clinical Oncology. 2006:3465-73. [PubMed: 16849763]

Dennis 2001 ppublished data only\}. Dennis KE, Tomoyasu N, McCrone SH, Goldberg AP, Bunyard L, Qi BB. Self-efficacy targeted treatments for weight loss in postmenopausal women. An International Journal. 2001; 15:259-76.

De Zwaan 2005 \{published data only\}. De Zwaan M, Mitchell JE, Crosby RD, Mussell MP, Raymond NC, Specker SM, et al. Short-term cognitive behavioral treatment does not improve outcome of a comprehensive very-low-calorie diet program in obese women with binge eating disorder. Behavior Therapy. 2005:89-99.

Digenio 2009 \{published data only\}. Digenio AG, Mancuso JP, Gerber RA, Dvorak RV. Comparison of methods for delivering a lifestyle modification program for obese patients: a randomized trial. Annals of Internal Medicine. 2009; 150:255-62. [PubMed: 19221377]

Domenech 1995 \{published data only\}. Domenech MI, Assad D, Mazzei ME, Kronsbein P, Gagliardino JJ. Evaluation of the effectiveness of an ambulatory teaching/treatment programme for non-insulin dependent (type 2) diabetic patients. Acta Diabetologica. 1995; 32:143-7. [PubMed: 8590781]

Donnelly 2003 \{published data only\}. Donnelly JE, Kirk EP, Jacobsen DJ, Hill JO, Sullivan DK, Johnson SL. Effects of 16 mo of verified, supervised aerobic exercise on macronutrient intake in overweight men and women: the Midwest Exercise Trial. American Journal of Clinical Nutrition. 2003; 78:950-6. [PubMed: 14594781]

Dyson 1997 \{published data only\}. Dyson PA, Hammersley MS, Morris RJ, Holman RR, Turner RC. The Fasting Hyperglycaemia Study: II. Randomized controlled trial of reinforced healthy-living advice in subjects with increased but not diabetic fasting plasma glucose. Metabolism. 1997; 46:50-5. [PubMed: 9439560]

Eriksson 2009 \{published data only\}. Eriksson MK, Franks PW, Eliasson M. A 3-year randomized trial of lifestyle intervention for cardiovascular risk reduction in the primary care setting: the Swedish Bjorknas study. PLOS ONE. 2009; 4:e5195. [PubMed: 19365563]

Evers 1987 \{published data only\}. Evers SE, Bass M, Donner A, McWhinney IR. Lack of impact of salt restriction advice on hypertensive patients. Preventive Medicine. 1987; 16:213-20. [PubMed: 3588562]

Farmer 2009 \{published data only\}. Farmer AJ, Wade AN, French DP, Simon J, Yudkin P, Gray A, et al. Blood glucose self-monitoring in type 2 diabetes: a randomised controlled trial. Health Technology Assessment. 2009; 13:iii-iv. ix-xi, 1-50.

Fehily 1991 \{published data only\}. Fehily AM, Vaughan-Williams E, Shiels K, Williams AH, Horner M, Bingham G. Factors influencing compliance with dietary advice: the Diet and Reinfarction Trial (DART). Journal of Human Nutrition and Dietetics. 1991:33-42. 
Ferrante 2010 \{published data only\}. Ferrante D, Varini S, Macchia A, Soifer S, Badra R, Nul D, et al. Long-term results after a telephone intervention in chronic heart failure: DIAL (Randomized Trial of Phone Intervention in Chronic Heart Failure) follow-up. Journal of the American College of Cardiology. 2010; 56:372-8. [PubMed: 20650358]

Fitzgibbon 2005 \{published data only\}. Fitzgibbon ML, Stolley MR, Schiffer L, Sanchez-Johnsen LA, Wells AM, Dyer A. A combined breast health/weight loss intervention for Black women. Preventive Medicine. 2005; 40:373-83. [PubMed: 15530590]

Forget 1990\{published data only\}. Forget D, Caranhac G, Quillot MJ, Besnier MO. Compliance with very low protein diet and ketoanalogues in chronic renal failure. The French Multicentric Trial IRCCA. Contributions to Nephrology. 1990; 81:79-86. [PubMed: 2093515]

Forli 2001 \{published data only\}. Forli L, Bjortuft O, Vatn M, Kofstad J, Boe J. A study of intensified dietary support in underweight candidates for lung transplantation. Annals of Nutrition and Metabolism. 2001; 45:159-68. [PubMed: 11463999]

Forrester 2010 \{published data only\}. Forrester DL, Britton J, Lewis SA, Pogson Z, Antoniak M, Pacey SJ, et al. Impact of adopting low sodium diet on biomarkers of inflammation and coagulation: a randomised controlled trial. Journal of Nephrology. 2010; 23:49-54. [PubMed: 20091486]

Fox 1996\{published data only\}. Fox AA, Thompson JL, Butterfield GE, Gylfadottir U, Moynihan S, Spiller G. Effects of diet and exercise on common cardiovascular disease risk factors in moderately obese older women. The American Journal of Clinical Nutrition. 1996; 63:225-33. [PubMed: 8561064]

Frohling 1990 \{published data only\}. Frohling PT, Kaschube I, Vetter K, Knabich E, Lindenau K, Schmicker R. Dietary compliance in the GDR trial. Contributions to Nephrology. 1990; 81:8794. [PubMed: 2093516]

Frost 2007 published data only\}. Frost G, Masters K, King C, Kelly M, Hasan U, Heavens P, et al. A new method of energy prescription to improve weight loss. Journal of Human and Dietetics. 2007; 20:152-6.

Fuchs 1993 \{published data only\}. Fuchs Z, Viskoper JR, Drexler I, Nitzan H, Lubin F, Berlin S, et al. Comprehensive individualised nonpharmacological treatment programme for hypertension in physician-nurse clinics: two year follow-up. Journal of Human Hypertension. 1993; 7:585-91. [PubMed: 8114054]

Glasgow 2003 \{published data only\}. Glasgow RE, Boles SM, McKay HG, Feil EG, Barrera M Jr. The D-Net diabetes self-management program: long-term implementation, outcomes, and generalization results. Preventive Medicine. 2003; 36:410-9. [PubMed: 12649049]

* Gorin 2010 \{published and unpublished data\}. Gorin, A., Raynor, H., Fava, J., Maguire, K., Robichaud, E., Trautvetter, J., Crane, M., Wing, RR. Randomized control trial of a comprehensive home environment-focused weight loss program for adults: 18 month results. Obesity Society Annual Scientific Meeting; 2010; p. 95-ORGorin, AA., Raynor, HA., Fava, J., Maguire, K., Robichaud, E., Trautvetter, J., et al. Randomised controlled trial of a comprehensive home environment-focused weight loss program for adults; Health Psychology; 2012 Feb 6. E pub ahead of print

Grancelli 2003\{published data only\}. Grancelli H, Varini S, Ferrante D, Schwartzman R, Zambrano C, Soifer S, et al. Randomized Trial of Telephone Intervention in Chronic Heart Failure (DIAL): study design and preliminary observations. Journal of Cardiac Failure. 2003; 9:172-9. [PubMed: 12815566]

Greene 1977 \{published data only\}. Greene LR. Effects of verbal evaluation feedback and interpersonal distance on behavioral compliance. Journal of Counseling Psychology. 1977; $24: 10-4$.

Hakala 1993 \{published data only\}. Hakala P, Karvetti RL, Ronnemaa T. Group vs. individual weight reduction programmes in the treatment of severe obesity: a five year follow-up study. International Journal of Obesity. 1993; 17:97-102. [PubMed: 8384171]

Hartwell 1986\{published data only\}. Hartwell SL, Kaplan RM, Wallace JP. Comparison of behavioral interventions for control of Type II diabetes mellitus. Behavior Therapy. 1986; 17:447-61.

Harvey-Berino 2004\{published data only\}. Harvey-Berino J, Pintauro S, Buzzell P, Gold EC. Effect of internet support on the long-term maintenance of weight loss. Obesity Research. 2004; 12:320-9. [PubMed: 14981225] 
Harvey-Berino 2009 \{published data only\}. Harvey Berino J, West D, Krukowski R, Prewitt E, VanBiervliet A, Ashikaga T, et al. Internet delivered behavioral obesity treatment. Preventive Medicine. 2010; 51(2):123-8. [PubMed: 20478333] Harvey-Berino J, West D, Prewitt TE, VanBiervliet A, Ashikaga T. Internet delivered behavioral obesity treatment. Obesity Research. 2009; 17:S77.

Hebert 2001 \{published data only\}. Hebert JR, Ebbeling CB, Olendzki BC, Hurley TG, Ma Y, Saal N, et al. Change in women's diet and body mass following intensive intervention for early-stage breast cancer. Journal of the American Dietetic Association. 2001; 101:421-31. [PubMed: 11320947]

Henkin 2000 \{published data only\}. Henkin Y, Shai I, Zuk R, Brickner D, Zuilli I, Neumann L, et al. Dietary treatment of hypercholesterolemia: do dietitians do it better? A randomized, controlled trial. American Journal of Medicine. 2000; 109:549-55. [PubMed: 11063956]

Heraief 1985 \{published data only\}. Heraief E, Burckhardt P, Wurtman JJ, Wurtman RJ. Tryptophan administration may enhance weight loss by some moderately obese patients on a protein-sparing modified fast (PSMF) diet. International Journal of Eating Disorders. 1985:281-92.

Hyman 1998 \{published data only\}. Hyman DJ, Ho KS, Dunn JK, Simons-Morton D. Dietary intervention for cholesterol reduction in public clinic patients. American Journal of Preventive Medicine. 1998; 15:139-45. [PubMed: 9713670]

Jolly 1998 \{published data only\}. Jolly K, Bradley F, Sharp S, Smith H, Mant D. Follow-up care in general practice of patients with myocardial infarction or angina pectoris: initial results of the SHIP trial. Southampton Heart Integrated Care Project. Family Practice. 1998; 15:548-55. [PubMed: 10078796]

Jolly 2007 published data only\}. Jolly K, Taylor R, Lip GY, Greenfield S, Raftery J, Mant J, et al. The Birmingham Rehabilitation Uptake Maximisation Study (BRUM). Home-based compared with hospital-based cardiac rehabilitation in a multi-ethnic population: cost-effectiveness and patient adherence. Health Technology Assessment. 2007; 11:1-118.

Jones 2003 \{published data only\}. Jones H, Edwards L, Vallis TM, Ruggiero L, Rossi SR, Rossi JS, et al. Changes in diabetes self-care behaviors make a difference in glycemic control: the Diabetes Stages of Change (DiSC) study. Diabetes Care. 2003:732-7. [PubMed: 12610030]

Jula 1990 \{published data only\}. Jula A, Ronnemaa T, Rastas M, Karvetti RL, Maki J. Long-term nonpharmacological treatment for mild to moderate hypertension. Journal of Internal Medicine. 1990; 227:413-21. [PubMed: 2191071]

Kaiman 2000 \{published data only\}. Kaiman DS, Colker CM, Swain MA, Torina GC, Shi Q. A randomized, double-blind, placebo-controlled study of 3-acetyl-7-oxo-dehydroepiandrosterone in healthy overweight adults. Current Therapeutic Research. 2000; 61:435-42.

Kalodner 1991 \{published data only\}. Kalodner CR, DeLucia JL. The individual and combined effects of cognitive therapy and nutrition education as additions to a behavior modification program for weight loss. Addictive Behaviors. 1991; 16:255-63. [PubMed: 1776542]

Kalter-Leibovici 2010 \{published data only\}. Kalter-Leibovici O, Younis-Zeidan N, Atamna A, Lubin F, Alpert G, Chetrit A, et al. Lifestyle intervention in obese Arab women: a randomized controlled trial. Archives of Internal Medicine. 2010; 170:970-6. [PubMed: 20548010]

Kattelmann 2009 \{published data only\}. Kattelmann KK, Conti K, Ren C. The medicine wheel nutrition intervention: a diabetes education study with the Cheyenne River Sioux Tribe. Journal of the American Dietetic Association. 2009; 109:1532-9. [PubMed: 19699832]

Khoo 2007 published data only\}. Khoo CK, Vickery CJ, Forsyth N, Vinall NS, Eyre-Brook IA. A prospective randomized controlled trial of multimodal perioperative management protocol in patients undergoing elective colorectal resection for cancer. Annals of Surgery. 2007; 245:86772. [PubMed: 17522511]

Kim 2006\{published data only\}. Kim SH, Lee SJ, Kang ES, Kang S, Hur KY, Lee HJ, et al. Effects of lifestyle modification on metabolic parameters and carotid intima-media thickness in patients with type 2 diabetes mellitus. Metabolism Clinical and Experimental. 2006; 55:1053-9. [PubMed: 16839841]

Kirkman 1994 \{published data only\}. Kirkman MS, Weinberger M, Landsman PB, Samsa GP, Shortliffe EA, Simel DL, et al. A telephone-delivered intervention for patients with NIDDM. Effect on coronary risk factors. Diabetes Care. 1994; 17:840-6. [PubMed: 7956628] 
Koelewijn-van Loon 2009 \{published and unpublished data\}. Koelewijn-van Loon MS, van der Weijden T, van Steenkiste B, Ronda G, Winkens B, Severens JL, et al. Involving patients in cardiovascular risk management with nurse-led clinics: a cluster randomized controlled trial. Canadian Medical Association Journal. 2009; 181:E267-74. [PubMed: 19948811]

Korhonen 1983 \{published data only\}. Korhonen T, Huttunen JK, Aro A, Hentinen M, Ihalainen O, Majander $\mathrm{H}$, et al. A controlled trial on the effects of patient education in the treatment of insulindependent diabetes. Diabetes Care. 1983; 6:256-61. [PubMed: 6347578]

Korhonen 2003 \{published data only\}. Korhonen M, Kastarinen M, Uusitupa M, Puska P, Nissinen A. The effect of intensified diet counseling on the diet of hypertensive subjects in primary health care: a 2-year open randomized controlled trial of lifestyle intervention against hypertension in eastern Finland. Preventive Medicine. 2003; 36:8-16. [PubMed: 12473420]

Krier 1999\{published data only\}. Krier BP, Parker RD, Grayson D, Byrd G. Effect of diabetes education on glucose control. Journal of the Louisiana State Medical Society. 1999; 151:86-92. [PubMed: 11280842]

Kumanyika 1993 \{published data only\}. Kumanyika SK, Hebert PR, Cutler JA, Lasser VI, Sugars CP, Steffen-Batey L, et al. Feasibility and efficacy of sodium reduction in the Trials of Hypertension Prevention, phase I. Trials of Hypertension Prevention Collaborative Research Group. Hypertension. 1993; 22:502-12. [PubMed: 8406655]

Lampman 1977 \{published data only\}. Lampman RM, Santinga JT, Hodge MF, Block WD, Flora JD Jr, Bassett DR. Comparative effects of physical training and diet in normalizing serum lipids in men with Type IV hyperlipoproteinemia. Circulation. 1977; 55:652-9. [PubMed: 189952]

Laws 2004 \{published data only\}. Laws R. A new evidence-based model for weight management in primary care: the Counterweight Programme. Journal of Human Nutrition and Dietetics. 2004; 17:191-208. [PubMed: 15139891]

Leermakers 1999\{published data only\}. Leermakers EA, Perri MG, Shigaki CL, Fuller PR. Effects of exercise-focused versus weight-focused maintenance programs on the management of obesity. Addictive Behaviors. 1999; 24:219-27. [PubMed: 10336103]

Lesley 2007 published data only\}. Lesley ML. Social problem solving training for African Americans: effects on dietary problem solving skill and DASH diet-related behavior change. Patient Education and Counseling. 2007; 65:137-46. [PubMed: 16950591]

Lindahl 2009\{published data only\}. Lindahl B, Nilssön TK, Borch-Johnsen K, Røder ME, Söderberg $\mathrm{S}$, Widman L, et al. A randomized lifestyle intervention with 5-year follow-up in subjects with impaired glucose tolerance: pronounced short-term impact but long-term adherence problems: erratum. Scandinavian Journal of Public Health. 2009; 37:443.

Locatelli 1990 \{published data only\}. Locatelli F. Dietary compliance in patients with chronic renal failure: experience in a northern Italy trial. Contributions to Nephrology. 1990; 81:102-6. [PubMed: 2093485]

Lopez 2006\{published data only\}. Lopez Cabezas C, Falces Salvador C, Cubi Quadrada D, Arnau Bartes A, Ylla Bore M, Muro Perea N, et al. Randomized clinical trial of a postdischarge pharmaceutical care program vs regular follow-up in patients with heart failure. Farmacia Hospitalaria. 2006; 30:328-42. [PubMed: 17298190]

Manchanda 2000 \{published data only\}. Manchanda SC, Narang R, Reddy KS, Sachdeva U, Prabhakaran D, Dharmanand S, et al. Retardation of coronary atherosclerosis with yoga lifestyle intervention. Journal of Association of Physicians of India. 2000; 48:687-94. [PubMed: 11273502]

Mathus-Vliegen 1993 \{published data only\}. Mathus-Vliegen LM, Res AM. Dexfenfluramine influences dietary compliance and eating behavior, but dietary instruction may overrule its effect on food selection in obese subjects. Journal of American Dietetic Association. 1993; 93:1163-5.

McCarron 1998 \{published data only\}. McCarron DA, Oparil S, Resnick LM, Chait A, Haynes RB, Kris-Etherton $\mathrm{P}$, et al. Comprehensive nutrition plan improves cardiovascular risk factors in essential hypertension. American Journal of Hypertension. 1998; 11:31-40. [PubMed: 9504447]

McConnon 2007 \{published data only\}. McConnon A, Kirk SF, Cockroft JE, Harvey EL, Greenwood DC, Thomas JD, et al. The Internet for weight control in an obese sample: results of a randomised controlled trial. BMC Health Services Research. 2007; 7:206. [PubMed: 18093289] 
McConnon 2009 \{published data only\}. McConnon A, Kirk SF, Ransley JK. Process evaluation of an internet-based resource for weight control: use and views of an obese sample. Journal of Nutrition Education and Behavior. 2009; 41:261-7. [PubMed: 19508931]

Melchionda 2006 \{published data only\}. Melchionda N, Forlani G, La Rovere L, Argnani P, Trevisani F, Zocchi D, et al. Disease management of the metabolic syndrome in a community: study design and process analysis on baseline data. Metabolic Syndrome and Related Disorders. 2006; 4(1):716. [PubMed: 18370765]

Melin 2003 \{published data only\}. Melin I, Karlstrom B, Lappalainen R, Berglund L, Mohsen R, Vessby B. A programme of behaviour modification and nutrition counselling in the treatment of obesity: a randomised 2-y clinical trial. International Journal of Obesity. 2003; 27:1127-35. [PubMed: 12917721]

Metz 1997 \{published data only\}. Metz JA, Kris-Etherton PM, Morris CD, Mustad VA, Stern JS, Oparil S, et al. Dietary compliance and cardiovascular risk reduction with a prepared meal plan compared with a self-selected diet. American Journal of Clinical Nutrition. 1997; 66:373-85. [PubMed: 9250117]

Metz 2000 \{published data only\}. Metz JA, Stern JS, Kris-Etherton P, Reusser ME, Morris CD, Hatton DC, et al. A randomized trial of improved weight loss with a prepared meal plan in overweight and obese patients: impact on cardiovascular risk reduction. Archives of Internal Medicine. 2000; 160:2150-8. [PubMed: 10904458]

Mhurchu 1998\{published data only\}. Mhurchu CN, Margetts BM, Speller V. Randomized clinical trial comparing the effectiveness of two dietary interventions for patients with hyperlipidaemia. Clinical Science. 1998; 95:479-87. [PubMed: 9748424]

Milas 1995 \{published data only\}. Milas NC, Nowalk MP, Akpele L, Castaldo L, Coyne T, Doroshenko $\mathrm{L}$, et al. Factors associated with adherence to the dietary protein intervention in the Modification of Diet in Renal Disease Study. Journal of the American Dietetic Association. 1995; 95:1295300. [PubMed: 7594126]

Miller 2009\{published data only\}. Miller CK, Gutshcall MD, Mitchell DC. Change in food choices following a glycemic load intervention in adults with type 2 diabetes. Journal of the American Dietetic Association. 2009; 109:319-24. [PubMed: 19167961]

Morgan 2009 \{published data only\}. Morgan PJ, Lubans DR, Collins CE, Warren JM, Callister R. The SHED-IT randomized controlled trial: evaluation of an Internet-based weight-loss program for men. Obesity. 2009; 17:2025-32. [PubMed: 19343018]

Nir 2004 \{published data only\}. Nir Z, Zolotogorsky Z, Sugarman H. Structured nursing intervention versus routine rehabilitation after stroke. American Journal of Physical Medicine and Rehabilitation. 2004; 83:522-9. [PubMed: 15213476]

Nugent 1984\{published data only\}. Nugent CA, Carnahan JE, Sheehan ET, Myers C. Salt restriction in hypertensive patients. Comparison of advice, education, and group management. Archives of Internal Medicine. 1984; 144:1415-7. [PubMed: 6732403]

Oldroyd 2006 \{published data only\}. Oldroyd JC, Unwin NC, White M, Mathers JC, Alberti KG. Randomised controlled trial evaluating lifestyle interventions in people with impaired glucose tolerance. Diabetes Research and Clinical Practice. 2006; 72:117-27. [PubMed: 16297488]

Ornish 1998 \{published data only\}. Ornish D, Scherwitz LW, Billings JH, Brown SE, Gould KL, Merritt TA, et al. Intensive lifestyle changes for reversal of coronary heart disease. Journal of the American Medical Association. 1998; 280:2001-7. [PubMed: 9863851]

Pater 2000\{published data only\}. Pater C, Ditlef Jacobsen C, Rollag A, Sandvik L, Erikssen J, Karin Kogstad E. Design of a randomized controlled trial of comprehensive rehabilitation in patients with myocardial infarction, stabilized acute coronary syndrome, percutaneous transluminal coronary angioplasty or coronary artery bypass grafting: Akershus Comprehensive Cardiac Rehabilitation Trial (the CORE Study). Current Controlled Trials in Cardiovascular Medicine. 2000; 1:177-83. [PubMed: 11714435]

Pettman 2008 \{published data only\}. Pettman TL, Misan GM, Owen K, Warren K, Coates AM, Buckley JD, et al. Self-management for obesity and cardio-metabolic fitness: description and evaluation of the lifestyle modification program of a randomised controlled trial. International Journal of Behavioral Nutrition and Physical Activity. 2008; 5:53.doi: 10.1186/1479-5868-5-53 [PubMed: 18954466] 
Pierce 1997 \{published data only\}. Pierce JP, Faerber S, Wright FA, Newman V, Flatt SW, Kealey S, et al. Feasibility of a randomized trial of a high-vegetable diet to prevent breast cancer recurrence. Nutrition and Cancer. 1997; 28:282-8. [PubMed: 9343838]

Pierce 2002 \{published data only\}. Pierce JP, Faerber S, Wright FA, Rock CL, Newman V, Flatt SW, et al. A randomized trial of the effect of a plant-based dietary pattern on additional breast cancer events and survival: the Women's Healthy Eating and Living (WHEL) Study. Controlled Clinical Trials. 2002; 23:728-56. [PubMed: 12505249]

Pierce 2007 \{published data only\}. Pierce JP, Newman VA, Natarajan L, Flatt SW, Al-Delaimy WK, Caan BJ, et al. Telephone counseling helps maintain long-term adherence to a high-vegetable dietary pattern. The Journal of Nutrition. 2007; 137:2291-6. [PubMed: 17885013]

Pijls 2000\{published data only\}. Pijls LT, de Vries H, van Eijk JT, Donker AJ. Adherence to protein restriction in patients with type 2 diabetes mellitus: a randomized trial. European Journal of Clinical Nutrition. 2000; 54:347-52. [PubMed: 10745287]

Pringle 1993 \{published data only\}. Pringle M, Stewart-Evans C, Coupland C, Williams I, Allison S, Sterland J. Influences on control in diabetes mellitus: patient, doctor, practice, or delivery of care? BMJ. 1993; 306:630-4. [PubMed: 8461816]

Rabkin 1983\{published data only\}. Rabkin SW, Boyko E, Wilson A, Streja DA. A randomized clinical trial comparing behavior modification and individual counseling in the nutritional therapy of noninsulin-dependent diabetes mellitus: comparison of the effect on blood sugar, body weight, and serum lipids. Diabetes Care. 1983; 6:50-6. [PubMed: 6341015]

Racette 1995 \{published data only\}. Racette SB, Schoeller DA, Kushner RF, Neil KM. Exercise enhances dietary compliance during moderate energy restriction in obese women. The American Journal of Clinical Nutrition. 1995; 62:345-9. [PubMed: 7625341]

Rallidis 2009\{published data only\}. Rallidis LS, Lekakis J, Kolomvotsou A, Zampelas A, Vamvakou G, Efstathiou S, et al. Close adherence to a Mediterranean diet improves endothelial function in subjects with abdominal obesity. The American Journal of Clinical Nutrition. 2009; 90:263-8. [PubMed: 19515732]

Rhew 2007 published data only\}. Rhew I, Yasui Y, Sorensen B, Ulrich CM, Neuhouser ML, Tworoger SS, et al. Effects of an exercise intervention on other health behaviors in overweight/obese postmenopausal women. Contemporary Clinical Trials. 2007; 28:472-81. [PubMed: 17287149]

Rimmer 2000 \{published data only\}. Rimmer JH, Braunschweig C, Silverman K, Riley B, Creviston T, Nicola T. Effects of a short-term health promotion intervention for a predominantly AfricanAmerican group of stroke survivors. American Journal of Preventive Medicine. 2000; 18:332-8. [PubMed: 10788737]

Robertson 1992 \{published data only\}. Robertson I, Phillips A, Mant D, Thorogood M, Fowler G, Fuller A, et al. Motivational effect of cholesterol measurement in general practice health checks. British Journal of General Practice. 1992; 42:469-72. [PubMed: 1472394]

Rosman 1989\{published data only\}. Rosman JB, Langer K, Brandl M, Piers-Becht TP, van der Hem GK, ter Wee PM, et al. Protein-restricted diets in chronic renal failure: a four year follow-up shows limited indications. Kidney International. 1989; 27:S96-102. [PubMed: 2636680]

Rosman 1990 \{published data only\}. Rosman JB, Donker-Willenborg MA. Dietary compliance and its assessment in the Groningen trial on protein restriction in renal failure. Contributions to Nephrology. 1990; 81:95-101. [PubMed: 2093518]

Roumen 2008 \{published data only\}. Roumen C, Corpeleijn E, Feskens EJ, Mensink M, Saris WH, Blaak EE. Impact of 3-year lifestyle intervention on postprandial glucose metabolism: the SLIM study. Diabetic Medicine. 2008; 25:597-605. [PubMed: 18445174]

Sadur 1999 \{published data only\}. Sadur CN, Moline N, Costa M, Michalik D, Mendlowitz D, Roller $\mathrm{S}$, et al. Diabetes management in a health maintenance organization. Efficacy of care management using cluster visits. Diabetes Care. 1999; 22:2011-7. [PubMed: 10587835]

Sartorio 2003 \{published data only\}. Sartorio A, Lafortuna CL, Marinone PG, Tavani A, La Vecchia C, Bosetti C. Short-term effects of two integrated, non-pharmacological body weight reduction programs on coronary heart disease risk factors in young obese patients. Diabetes, Nutrition \& Metabolism. 2003; 16:262-5. 
Schapira 1991 \{published data only\}. Schapira DV, Kumar NB, Lyman GH, Baile WF. The effect of duration of intervention and locus of control on dietary change. American Journal of Preventive Medicine. 1991; 7:341-7. [PubMed: 1790041]

Sevick 2008 \{published and unpublished data\}. Sevick MA, Zickmund S, Korytkowski M, Piraino B, Sereika S, Mihalko S, et al. Design, feasibility, and acceptability of an intervention using personal digital assistant-based self-monitoring in managing type 2 diabetes. Contemporary Clinical Trials. 2008; 29:396-409. [PubMed: 17997364]

Shaw-Stuart 2000 \{published data only\}. Shaw-Stuart NJ, Stuart A. The effect of an educational patient compliance program on serum phosphate levels in patients receiving hemodialysis. Journal of Renal Nutrition. 2000; 10:80-4. [PubMed: 10757820]

Singh 1991 \{published data only\}. Singh RB, Rastogi SS, Sircar AR, Mehta PJ, Sharma KK. Dietary strategies for risk-factor modification to prevent cardiovascular diseases. Nutrition. 1991; 7:210 4. [PubMed: 1666320]

Singh 1992 \{published data only\}. Singh RB, Rastogi SS, Verma R, Bolaki L, Singh R. An Indian experiment with nutritional modulation in acute myocardial infarction. American Journal of Cardiology. 1992; 69:879-85. [PubMed: 1550016]

Sisk 2006 \{published data only\}. Sisk JE, Hebert PL, Horowitz CR, McLaughlin MA, Wang JJ, Chassin MR. Effects of nurse management on the quality of heart failure care in minority communities: a randomized trial. Annals of Internal Medicine. 2006; 145:273-83. [PubMed: 16908918]

Smith 1997 \{published data only\}. Smith DE, Heckemeyer CM, Kratt PP, Mason DA. Motivational interviewing to improve adherence to a behavioral weight-control program for older obese women with NIDDM. A pilot study. Diabetes Care. 1997; 20:52-4. [PubMed: 9028693]

Sone 2010 \{published data only\}. Sone H, Tanaka S, Iimuro S, Oida K, Yamasaki Y, Oikawa S, et al. Long-term lifestyle intervention lowers the incidence of stroke in Japanese patients with type 2 diabetes: a nationwide multicentre randomised controlled trial (the Japan Diabetes Complications Study). Diabetologia. 2010; 53:419-28. [PubMed: 20054522]

Southard 2003 \{published data only\}. Southard BH, Southard DR, Nuckolls J. Clinical trial of an Internet-based case management system for secondary prevention of heart disease. Journal of Cardiopulmonary Rehabilitation. 2003; 23:341-8. [PubMed: 14512778]

Sperduto 1986 \{published data only\}. Sperduto WA, Thompson HS, O'Brien RM. The effect of target behavior monitoring on weight loss and completion rate in a behavior modification program for weight reduction. Addictive Behaviors. 1986:337-40. [PubMed: 3739819]

Thoolen 2009\{published data only\}. Thoolen BJ, de Ridder D, Bensing J, Gorter K, Rutten G. Beyond good intentions: The role of proactive coping in achieving sustained behavioural change in the context of diabetes management. Psychology and Health. 2009; 24:237-54. [PubMed: 20204991]

Tilley 1997 \{published data only\}. Tilley BC, Vernon SW, Glanz K, Myers R, Sanders K, Lu M, et al. Worksite cancer screening and nutrition intervention for high-risk auto workers: design and baseline findings of the Next Step Trial. Preventive Medicine. 1997; 26:227-35. [PubMed: 9085392]

Toobert 1998 \{published data only\}. Toobert DJ, Glasgow RE, Nettekoven LA, Brown JE. Behavioral and psychosocial effects of intensive lifestyle management for women with coronary heart disease. Patient Education and Counseling. 1998; 35:177-88. [PubMed: 9887850]

Toobert 2000 \{published data only\}. Toobert DJ, Glasgow RE, Radcliffe JL. Physiologic and related behavioral outcomes from the Women's Lifestyle Heart Trial. Annals of Behavioral Medicine. 2000; 22:1-9. [PubMed: 10892523]

Torgerson 1999 \{published data only\}. Torgerson JS, Agren L, Sjostrom L. Effects on body weight of strict or liberal adherence to an initial period of VLCD treatment. A randomised, one-year clinical trial of obese subjects. International Journal of Obesity. 1999; 23:190-7. [PubMed: 10078855]

Tsang 2001 \{published data only\}. Tsang MW, Mok M, Kam G, Jung M, Tang A, Chan U, et al. Improvement in diabetes control with a monitoring system based on a hand-held, touch-screen electronic diary. Journal of Telemedicine and Telecare. 2001; 7:47-50. 
Vale 2003 \{published and unpublished data\}. Vale MJ, Jelinek MV, Best JD, Dart AM, Grigg LE, Hare DL, et al. Coaching patients On Achieving Cardiovascular Health (COACH): a multicenter randomized trial in patients with coronary heart disease. Archives of Internal Medicine. 2003; 163:2775-83. [PubMed: 14662633]

van der Weijden 1998 \{published data only\}. van der Weijden T, Grol RPTM, Schouten BJ, Knottnerus JA. Barriers to working according to cholesterol guidelines: A randomized controlled trial on implementation of national guidelines in 20 general practices. European Journal of Public Health. 1998; 8(2):113-8.

van Gool 2006\{published data only\}. van Gool CH, Penninx BW, Kempen GI, Miller GD, van Eijk JT, Pahor M, et al. Determinants of high and low attendance to diet and exercise interventions among overweight and obese older adults. Results from the arthritis, diet, and activity promotion trial. Contemporary Clinical Trials. 2006; 27:227-37. [PubMed: 16387555]

Verges 1998 \{published data only\}. Verges BL, Patois-Verges B, Cohen M, Casillas JM. Comprehensive cardiac rehabilitation improves the control of dyslipidemia in secondary prevention. European Journal of Public Health. 1998; 18:408-15.

Voils 2009\{published data only\}. Voils CI, Yancy WS Jr, Kovac S, Coffman CJ, Weinberger M, Oddone EZ, et al. Study protocol: Couples Partnering for Lipid Enhancing Strategies (CouPLES) - a randomized, controlled trial. Trials. 2009; 10:10. [PubMed: 19200384]

von Gruenigen 2008 \{published data only\}. von Gruenigen VE, Courneya KS, Gibbons HE, Kavanagh MB, Waggoner SE, Lerner E. Feasibility and effectiveness of a lifestyle intervention program in obese endometrial cancer patients: a randomized trial. Gynecologic Oncology. 2008; 109:19-26. [PubMed: 18243282]

Wadden 1997 \{published data only\}. Wadden TA, Berkowitz RI, Vogt RA, Steen SN, Stunkard AJ, Foster GD. Lifestyle modification in the pharmacologic treatment of obesity: a pilot investigation of a potential primary care approach. Obesity Research. 1997; 5:218-26. [PubMed: 9192396]

Wadden 2009 \{published data only\}. Wadden TA, West DS, Neiberg RH, Wing RR, Ryan DH, Johnson $\mathrm{KC}$, et al. One-year weight losses in the Look AHEAD study: factors associated with success. Obesity. 2009; 17:713-22. [PubMed: 19180071]

Webber 2010 \{published data only \}. Webber KH, Tate DF, Ward DS, Bowling JM. Motivation and its relationship to adherence to self-monitoring and weight loss in a 16-week Internet behavioral weight loss intervention. Journal of Nutrition Education and Behavior. 2010; 42:161-7. [PubMed: 20138583]

Wing 1986\{published data only\}. Wing RR, Epstein LH, Nowalk MP, Scott N, Koeske R, Hagg S. Does self-monitoring of blood glucose levels improve dietary compliance for obese patients with type II diabetes? The American Journal of Medicine. 1986; 81:830-6. [PubMed: 3535493]

Wing 1996\{published data only\}. Wing RR, Jeffery RW, Hellerstedt WL, Burton LR. Effect of frequent phone contacts and optional food provision on maintenance of weight loss. Annals of Behavioral Medicine. 1996; 18:172-6. [PubMed: 24203769]

Wing 1999 \{published data only\}. Wing RR, Jeffery RW. Benefits of recruiting participants with friends and increasing social support for weight loss and maintenance. Journal of Consulting and Clinical Psychology. 1999; 67:132-8. [PubMed: 10028217]

Wing 2003 \{published data only\}. Wing RR, Jeffery RW. Prescribed "breaks" as a means to disrupt weight control efforts. Obesity Research. 2003; 11:287-91. [PubMed: 12582226]

Witmer 2004 \{published data only\}. Witmer JM, Hensel MR, Holck PS, Ammerman AS, Will JC. Heart disease prevention for Alaska Native women: a review of pilot study findings. Journal of Women's Health. 2004; 13:569-78.

Wright 1981 \{published data only\}. Wright J, Wood B, Hale G. Evaluation of group versus individual nutrition education in overweight patients with myocardial infarction. Australia and New Zealand Journal of Medicine. 1981; 11:497-501.

Zismer 1982 \{published data only\}. Zismer DK, Gillum RF, Johnson CA, Becerra J, Johnson TH. Improving hypertension control in a private medical practice. Archives of Internal Medicine. 1982; 142:297-9. [PubMed: 7059257] 


\section{References to studies awaiting assessment}

Aldous 2009 \{published data only\}. Aldous D, Firth W. Impact of a nutrition intervention with applied motivational interviewing and behavior change techniques in the Community Cardiovascular Hearts in Motion (CCHIM) program-preliminary findings. Canadian Foundation for Dietetic Research; Showcase of Dietetic Research in Canada. 2009:18.

Amato 1990 \{published data only\}. Amato S, Colajanni E, Averna MR, Barbagallo CM, Lo Cascio ML, Traina G, et al. Diet and psychological therapy in a group of severely obese patients. Minerva Endocrinologica. 1990; 15:219-21. [PubMed: 2101441]

Clark 2004 \{published data only\}. Marie, Clark, Hampson Sarah, E., Lorraine, Avery, Robert, Simpson. Effects of a tailored lifestyle self-management intervention in patients with Type 2 diabetes. British Journal of Health Psychology. 2004; 9:365-79. [PubMed: 15296683]

Contel 1993 \{published data only\}. Contel JC, Adell A, Álvarez S, Baulies T, Campamà I, Gómez I, et al. Food-meter glass: usefulness to promote the compliance with the diet in primary care consultations. Annals de Medicina. 1993; 212

Duncan 2001 \{published data only\}. Duncan K, Pozehl B, Rosado K. The effects of behavioral feedback on adherence to dietary sodium intake for patients with congestive heart failure. Journal of Cardiopulmonary Rehabilitation. 2001:304.

Fernández López 2007 published data only\}. Fernández López L, Guerrero Llamas L, Gutiérrez Villaplana JM, Estrada Reventos D, Casal Garcia MC, Andugar Hernández J, et al. Mixed intervention programme on compliance and quality of life in hypertensive patients [Spanish]. Revista de la Sociedad Española de Enfermería Nefrológica. 2007; 10:7-13.

Firth 2009 \{published data only\}. Firth W, Pancura B. Can a web-based, self-monitoring wellness program augment outcomes and lead to sustained weight management and exercise ability at one year after completing a community cardiac rehabilitation program? Canadian Foundation for Dietetic Research; Showcase of Dietetic Research in Canada. 2004:19.

González 1987 \{published data only\}. González CA, Forés D, Avilés A, Argimón JM, Boada JM, Cubí $\mathrm{R}$, et al. Efficacy of a self-control method for the compliance with low-salt diet. Atención Primaria. 1987:258-62.

Hauner 2006 \{published data only\}. Hauner H. An intense nutritional training program for obese patients with type 2 diabetes mellitus: a randomised controlled two-year intervention study. Current Controlled Trials. 2006

Kim 2003 \{published data only\}. Kim HS, Oh JA. Adherence to diabetes control recommendations: impact of nurse telephone calls. Journal of Advanced Nursing. 2003; 44:256-61. [PubMed: 14641395]

Koprucki 2010 \{published and unpublished data\}. Koprucki M, Piraino B, Bender F, Snetselaar L, Hall B, Stark S, et al. RCT of Personal Digital Assistant (PDA) supported dietary intervention to reduce sodium intake in PD. American Journal of Kidney Diseases. 2010; 55:A72.

Lin 2007 published data only\}. Lin PH, Appel LJ, Funk K, Craddick S, Chen C, Elmer P, et al. The PREMIER intervention helps participants follow the Dietary Approaches to Stop Hypertension dietary pattern and the current Dietary Reference Intakes recommendations. Obesity. 2007; 107:1541-51.

Martínez-Marcos 1999\{published data only\}. Martínez Marcos M, Domínguez Bidagor J, Sempere Jorda R, Benito MJ, Rodríguez Martín R, Rapp Fernández P, et al. Evaluation of a nursing intervention for improving self-care of patients with diabetes [Spanish]. Metas de Enfermería. $1999 ; 2: 45-51$.

Mayeux 2004 \{published data only\}. Mayeux RL, Grim JA, Duffy JK, Kwong WY, Connella KR. Is survival skills diet education using Aramark's nutrition concepts@ as effective as traditional diet education? Journal of American Dietetic Association. 2004:36.

Mensink 2003 \{published data only\}. Mensink M, Blaak EE, Corpeleijn E, Saris WH, de Bruin TW, Feskens EJ. Lifestyle intervention according to general recommendations improves glucose tolerance. Obesity Research. 2003; 11:1588-96. [PubMed: 14694225]

Paisey 2005 \{published and unpublished data\}. Paisey R. Group education randomisation trial of type II diabetes practice care or continued group education. Current Controlled Trials. 2005 
Simpson 2010 \{published and unpublished data\}. Simpson S. A randomised controlled trial of a 12month multi-component intervention versus a less intensive version on study participants' maintenance of weight loss. Current Controlled Trials. 2010

Song 2009 \{published data only\}. Song MS, Kim HS. Intensive management program to improve glycosylated hemoglobin levels and adherence to diet in patients with type 2 diabetes. Applied Nursing Research. 2009; 22:42-7. [PubMed: 19171294]

Stollar 1993 \{published data only\}. Stollar, C., Scherch, L., Adler, S., Kusek, J., Caggiula, A. Patterns of patient dietary compliance in the modification of diet in renal disease (MDRD) study, Phase III. 12th International Congress of Nephrology; 1993 June 13-18; Jerusalem, Israel. 1993. p. 609

Wedman 1987\{published data only\}. Wedman B, Kahan RS. Diabetes graphic aids used in counseling improve patient compliance. Journal of the American Dietetic Association. 1987; 87:1672-4. [PubMed: 2445804]

\section{References to ongoing studies}

Feldman 2009\{published and unpublished data\}. Feldman PH, McDonald MV, Mongoven JM, Peng TR, Gerber LM, Pezzin LE. Home-based blood pressure interventions for blacks. Circulation Cardiovascular Quality and Outcomes. 2009; 2:241-8. [PubMed: 20031844]

Griva 2010 \{published and unpublished data\}. Griva K. The effectiveness of a self-management intervention to improve outcomes in prevalent haemodialysis patients: a randomised controlled trial. Current Controlled Trials. 2010

Jansink 2006\{published and unpublished data\}. Jansink R, Braspenning J, van der Weijden T, Niessen L, Elwyn G, Grol R. Nurse-led motivational interviewing to change the lifestyle of patients with type 2 diabetes (MILD-project): protocol for a cluster, randomized, controlled trial on implementing lifestyle recommendations. BMC Health Services Research. 2009; 9:19. [PubMed: 19183462] Jansink RME. Motivational interview by practice nurses to improve lifestyle adherence in patients with type 2 diabetes. Current Controlled Trials. 2006

Ma 2009 \{published data only\}. Ma J, King AC, Wilson SR, Xiao L, Stafford RS. Evaluation of lifestyle interventions to treat elevated cardiometabolic risk in primary care (E-LITE): a randomized controlled trial. BMC Family Practice. 2009; 10:71. [PubMed: 19909549]

Sher 2002 \{published data only\}. Sher TG, Bellg AJ, Braun L, Domas A, Rosenson R, Canar WJ. Partners for Life: a theoretical approach to developing an intervention for cardiac risk reduction. Health Education Research. 2002; 17:597-605. [PubMed: 12408204]

\section{Additional references}

Abraham 2008. Abraham C, Michie S. A taxonomy of behavior change techniques used in interventions. Health Psychology. 2008; 27(3):379-87. [PubMed: 18624603]

Ajzen 1991. Ajzen I. The theory of planned behavior. Organizational Behavior and Human Decision Processes. 1991; 50:179-211.

Aljasem 2001. Aljasem LI, Peyrot M, Wissow L, Rubin RR. The impact of barriers and self-efficacy on self-care behaviors in type 2 diabetes. Diabetes Education. 2001; 27(3):393-404.

Asbeck 2002. Asbeck I, Mast M, Bierwag A, Westenhofer J, Acheson KJ, Muller MJ. Severe underreporting of energy intake in normal weight subjects: use of an appropriate standard and relation to restrained eating. Public Health Nutrition. 2002; 5:683-90. [PubMed: 12372163]

Baldwin 2011. Baldwin C, Weekes CE. Dietary advice with or without oral nutritional supplements for disease-related malnutrition in adults. Cochrane Database of Systematic Reviews. 2011; (9)doi: 10.1002/14651858.CD002008.pub4

Bandura 1986. Bandura, A. Social Foundations of Thought and Action: A Social Cognitive Theory. Englewood Cliffs, N.J: Prentice Hall; 1986.

Bantle 2008. Bantle JP, Wylie-Rosett J, Albright AL, Apovian CM, Clark NG, Franz MJ, et al. Nutrition recommendations and interventions for diabetes: a position statement of the American Diabetes Association. Diabetes Care. 2008; 31(Suppl 1):S61-78. [PubMed: 18165339] 
Bellamy 2009. Bellamy L, Casas JP, Hingorani AD, Williams D. Type 2 diabetes mellitus after gestational diabetes: a systematic review and meta-analysis. Lancet. 2009; 373:1773-9. [PubMed: 19465232]

Blissmer 2010. Blissmer B, Prochaska JO, Velicer WF, Redding CA, Rossi JS, Greene GW, et al. Common factors predicting long-term changes in multiple health behaviors. Journal of Health Psychology. 2010; 15(2):205-14. [PubMed: 20207664]

Bosch-Capblanch 2007. Bosch-Capblanch X, Abba K, Prictor M, Garner P. Contracts between patients and healthcare practitioners for improving patients' adherence to treatment, prevention and health promotion activities. Cochrane Database of Systematic Reviews. 2007; (2)doi: 10.1002/14651858.CD004808.pub3

S Briefel 1997. Briefel RR, Sempos CT, McDowell MA, Chien S, Alaimo K. Dietary methods research in the third National Health and Nutrition Examination Survey: underreporting of energy intake. American Journal of Clinical Nutrition. 1997; 65:1203S-9. [PubMed: 9094923]

Brownell 1995a. Brownell KD, Cohen LR. Adherence to dietary regimens. 1: An overview of research. Behavioral Medicine. 1995; 20:149-54. [PubMed: 7620226]

Brownell 1995b. Brownell KD, Cohen LR. Adherence to dietary regimens. 2: Components of effective interventions. Behavioral Medicine. 1995; 20:155-64. [PubMed: 7620227]

Burke 1997. Burke LE, Dunbar-Jacob JM, Hill MN. Compliance with cardiovascular disease prevention strategies: a review of the research. Annals of Behavioral Medicine. 1997; 19:239-63. [PubMed: 9603699]

CCCRG 2010. Cochrane Consumers and Communication Review Group. Data collection checklist. 2010. Available from http://www.latrobe.edu.au/chcp/cochrane/resources.html

Champagne 2009. Champagne CM. The usefulness of a Mediterranean-based diet in individuals with type 2 diabetes. Current Diabetes Reports. 2009; 9:389-95. [PubMed: 19793509]

Chung 2006. Chung ML, Moser DK, Lennie TA, Worrall-Carter L, Bentley B, Trupp R, et al. Gender differences in adherence to the sodium-restricted diet in patients with heart failure. Journal of Cardiac Failure. 2006; 12:628-34. [PubMed: 17045182]

Chung 2008. Chung ML, Lennie TA, de Jong M, Wu JR, Riegel B, Moser DK. Patients differ in their ability to self-monitor adherence to a low-sodium diet versus medication. Journal of Cardiac Failure. 2008; 14:114-20. [PubMed: 18325457]

Cohen 2009. Cohen SM. Concept analysis of adherence in the context of cardiovascular risk reduction. Nursind Forum. 2009; 44:25-36.

Dansinger 2005. Dansinger ML, Gleason JA, Griffith JL, Selker HP, Schaefer EJ. Comparison of the Atkins, Ornish, Weight Watchers, and Zone diets for weight loss and heart disease risk reduction: a randomized trial. JAMA. 2005; 293:43-53. [PubMed: 15632335]

Desroches 2011. Desroches S, Lapointe A, Ratté S, Gravel K, Légaré F, Thirsk J. Interventions to enhance adherence to dietary advice for preventing and managing chronic diseases in adults: a study protocol. BMC Public Health. 2011; 11:111. [PubMed: 21329508]

DiMatteo 2002. DiMatteo MR, Giordani PJ, Lepper HS, Croghan TW. Patient adherence and medical treatment outcomes: a meta-analysis. Medical Care. 2002; 40:794-811. [PubMed: 12218770]

DiMatteo 2004a. DiMatteo MR. Variations in patients' adherence to medical recommendations: a quantitative review of 50 years of research. Medical Care. 2004; 42:200-9. [PubMed: 15076819]

DiMatteo 2004b. DiMatteo MR. Evidence-based strategies to foster adherence and improve patient outcomes. Journal of the American Academy of Physician Assistants. 2004; 17:18-21.

Fappa 2008. Fappa E, Yannakoulia M, Pitsavos C, Skoumas I, Valourdou S, Stefanadis C. Lifestyle intervention in the management of metabolic syndrome: could we improve adherence issues? Nutrition. 2008; 24:286-91. [PubMed: 18201869]

Fishbein 1981. Fishbein, M., Ijzen, I. Attitudes and voting behaviour: an application of the theory of reasoned action. In: Stephenson, GM., Davis, JM., editors. Progress in Applied Social Psychology. London: Wiley; 1981. p. 95-125.

Gamble 2005. Gamble C, Hollis S. Uncertainty method improved on best-worst case analysis in a binary meta-analysis. Journal of Clinical Epidemiology. 2005; 58(6):579-88. [PubMed: 15878471] 
Greaves 2011. Greaves CJ, Sheppard KE, Abraham C, Hardeman W, Roden M, Evans PH, et al. Systematic review of reviews of intervention components associated with increased effectiveness in dietary and physical activity interventions. BMC Public Health. 2011; 11:119. [PubMed: 21333011]

Harmon 2006. Harmon G, Lefante J, Krousel-Wood M. Overcoming barriers: the role of providers in improving patient adherence to antihypertensive medications. Current Opinion in Cardiology. 2006; 21:310-5. [PubMed: 16755199]

Haynes 2008. Haynes RB, Ackloo E, Sahota N, McDonald HP, Yao X. Interventions for enhancing medication adherence. Cochrane Database of Systematic Reviews. 2008; (2)doi: 10.1002/14651858.CD000011.pub3

Higgins 2011. Higgins, JPT., Green, S. Cochrane Handbook for Systematic Reviews of Interventions. The Cochrane Collaboration; 2011. Version 5.1.0 [updated March 2011]Available from www.cochrane-handbook.org

Huang 2005. Huang TT, Roberts SB, Howarth NC, McCrory MA. Effect of screening out implausible energy intake reports on relationships between diet and BMI. Obesity Research. 2005; 13:120517. [PubMed: 16076990]

JADA 2007. Nitzke S, Freeland-Graves J. American Dietetic Association. Position of the American Dietetic Association: total diet approach to communicating food and nutrition information. Journal of American Dietetic Association. 2007; 107(7):1224-32.

Johnson 1994. Johnson RK, Goran MI, Poehlman ET. Correlates of over- and underreporting of energy intake in healthy older men and women. American Journal of Clinical Nutrition. 1994; 59:128690. [PubMed: 8198052]

Kapur 2008. Kapur K, Kapur A, Ramachandran S, Mohan V, Aravind SR, Badgandi M, et al. Barriers to changing dietary behavior. Journal of the Association of Physicians of India. 2008; 56:27-32. [PubMed: 18472496]

Kennedy 2004. Kennedy E. Dietary diversity, diet quality, and body weight regulation. Nutrition Reviews. 2004; 62:S78-81. [PubMed: 15387472]

Knowler 2002. Knowler WC, Barrett-Connor E, Fowler SE, Hamman RF, Lachin JM, Walker EA, et al. Reduction in the incidence of type 2 diabetes with lifestyle intervention or metformin. New England Journal of Medicine. 2002; 346(6):393-403. [PubMed: 11832527]

Kopple 2001. Kopple JD. National Kidney Foundation K/DOQI Work Group. The National Kidney Foundation K/DOQI clinical practice guidelines for dietary protein intake for chronic dialysis patients. American Journal of Kidney Diseases. 2001; 38(4 Suppl 1):S68-73. [PubMed: 11576926]

Kumanyika 2000. Kumanyika SK, Van Horn L, Bowen D, Perri MG, Rolls BJ, Czajkowski SM, et al. Maintenance of dietary behavior change. Health and Psychology. 2000; 19:42-56.

Kushi 2006. Kushi LH, Byers T, Doyle C, Bandera EV, McCullough M, McTiernan A, et al. American Cancer Society Guidelines on Nutrition and Physical Activity for cancer prevention: reducing the risk of cancer with healthy food choices and physical activity. CA: A Cancer Journal of Clinicians. 2006; 56:254-81. quiz 313-4.

Lavie 2009. Lavie CJ, Milani RV, Mehra MR, Ventura HO. Omega-3 polyunsaturated fatty acids and cardiovascular diseases. Journal of the American College of Cardiology. 2009; 54:585-94. [PubMed: 19660687]

Lichtenstein 2006. Lichtenstein AH, Appel LJ, Brands M, Carnethon M, Daniels S, Franch HA, et al. Diet and lifestyle recommendations revision 2006: a scientific statement from the American Heart Association Nutrition Committee. Circulation. 2006; 114:82-96. [PubMed: 16785338]

Lindstrom 2003. Lindstrom J, Louheranta A, Mannelin M, Rastas M, Salminen V, Eriksson J, et al. The Finnish Diabetes Prevention Study (DPS): Lifestyle intervention and 3-year results on diet and physical activity. Diabetes Care. 2003; 26(12):3230-6. [PubMed: 14633807]

Makaryus 2005. Makaryus AN, Friedman EA. Patients' understanding of their treatment plans and diagnosis at discharge. Mayo Clinic Proceedings. 2005; 80:991-4. [PubMed: 16092576]

Matteson 2010. Matteson ML, Russell C. Interventions to improve hemodialysis adherence: a systematic review of randomized-controlled trials. Hemodialysis International. 2010; 14:370-82. [PubMed: 20796047] 
Michie 2011. Michie S, van Stralen MM, West R. The behaviour change wheel: a new method for characterising and designing behaviour change interventions. Implementation Science. 2011; 6:42. [PubMed: 21513547]

Mishali 2011. Mishali M, Omer H, Heymann AD. The importance of measuring self-efficacy in patients with diabetes. Family Practice. 2011; 28(1):82-7. [PubMed: 21047940]

Mochari 2010. Mochari-Greenberger H, Terry MB, Mosca L. Does stage of change modify the effectiveness of an educational intervention to improve diet among family members of hospitalized cardiovascular disease patients? Journal of American Dietetic Association. 2010; 110(7):1027-35.

Mottillo 2010. Mottillo S, Filion KB, Genest J, Joseph L, Pilote L, Poirier P, et al. The metabolic syndrome and cardiovascular risk a systematic review and meta-analysis. Journal of the American College of Cardiology. 2010; 56:1113-32. [PubMed: 20863953]

Natarajan 2009. Natarajan S, Santa Ana EJ, Liao Y, Lipsitz SR, McGee DL. Effect of treatment and adherence on ethnic differences in blood pressure control among adults with hypertension. Annals of Epidemiology. 2009; 19:172-9. [PubMed: 19216999]

Newell 2000. Newell SA, Bowman JA, Cockburn JD. Can compliance with nonpharmacologic treatments for cardiovascular disease be improved? American Journal of Preventive Medicine. 2000; 18:253-61. [PubMed: 10722993]

Poslusna 2009. Poslusna K, Ruprich J, de Vries JH, Jakubikova M, van't Veer P. Misreporting of energy and micronutrient intake estimated by food records and 24 hour recalls, control and adjustment methods in practice. British Journal of Nutrition. 2009; 101(Suppl 2):S73-85. [PubMed: 19594967]

Reid 1984. Reid V, Graham I, Hickey N, Mulcahy R. Factors affecting dietary compliance in coronary patients included in a secondary prevention programme. Human Nutrition Applied Nutrition. 1984; 38:279-87. [PubMed: 6092298]

RevMan 2012. The Nordic Cochrane Centre, The Cochrane Collaboration. Review Manager (RevMan). 5.1. Copenhagen: The Nordic Cochrane Centre, The Cochrane Collaboration; 2012.

Robinson 2008. Robinson JH, Callister LC, Berry JA, Dearing KA. Patient-centered care and adherence: definitions and applications to improve outcomes. Journal of the American Academy Nurse Practitioners. 2008; 20:600-7.

Rosenstock 1974. Rosenstock IM. Historical origins of the Health Belief Model. Health Education Monographs. 1974; 2:328.

Walsh 2011. Walsh E, Lehane E. An exploration of the relationship between adherence with dietary sodium restrictions and health beliefs regarding these restrictions in Irish patients receiving haemodialysis for end-stage renal disease. Journal of Clinical Nursing. 2011; 20(3-4):331-40. [PubMed: 21219516]

WHO 2003. WHO. World Health Organization. Adherence to long-term therapies:evidence for action. 2003. Available from www.who.int

WHO 2008. WHO. World Health Organization. 2008-2013 Action plan for the global strategy for the prevention and control of noncommunicable diseases. 2008. Available from www.who.int/nmh/ publications/9789241597418/en/

WHO 2010. WHO. World Health Organization. Chronic disease and health promotion. 2010. Available from www.who.int/chp/about/en/index.html

Wilson 2005. Wilson KG, Aaron SD, Vandemheen KL, Hebert PC, McKim DA, Fiset V, et al. Evaluation of a decision aid for making choices about intubation and mechanical ventilation in chronic obstructive pulmonary disease. Patient Education and Counseling. 2005; 57:88-95. [PubMed: 15797156]

Young 2009. Young DR, Vollmer WM, King AC, Brown AJ, Stevens VJ, Elmer PJ, et al. Can individuals meet multiple physical activity and dietary behavior goals? American Journal of Health Behavior. 2009; 33:277-86. [PubMed: 19063649] 


\section{References to other published versions of this review}

Desroches 2010. Desroches S, Lapointe A, Ratté S, Gravel K, Légaré F, Njoya MM, et al. Interventions to enhance adherence to dietary advice for preventing and managing chronic diseases in adults. Cochrane Database of Systematic Reviews. 2010; (9)doi: 10.1002/14651858.CD008722

\section{APPENDICES}

\section{Appendix 1. PubMed search strategy}

\#1 Patient compliance[MH:NOEXP]

\#2 Complian*[TIAB] OR Comply*[TIAB] OR Complied[TIAB] OR Adher*[TIAB] OR Noncomplian*[TIAB] OR Nonadher*[TIAB]

\#3 \#1 OR \#2

\#4 Diet[MH]

\#5 Diet therapy[MH]

\#6 Nutrition assessment[MH]

\#7 Food habits[MH]

\#8 Nutrition policy[MH]

\#9 Nutritional requirements[MH]

\#10 Nutrition therapy[MH:NOEXP]

\#11 Diet therapy[SH]

\#12 Diet[TIAB] OR Diets[TIAB] OR Dieta*[TIAB] OR Diete*[TIAB] OR Dieti*[TIAB] OR Nutrition*[TIAB] OR Food habit*[TIAB] OR Feeding behaviour*[TIAB] OR Eating behaviour*[TIAB]

\#13 \#4 OR \#5 OR \#6 OR \#7 OR \#8 OR \#9 OR \#10 OR \#11 OR \#12

\#14 Randomized controlled trial[PT]

\#15 Controlled clinical trial[PT]

\#16 Randomized[TIAB]

\#17 Randomly[TIAB]

\#18 Trial[TIAB]

\#19 Groups[TIAB]

\#20 Placebo[TIAB]

\#21 Drug therapy[SH]

\#22 \#14 OR \#15 OR \#16 OR \#17 OR \#18 OR \#19 OR \#20 OR \#21

\#23 Animals[MH] NOT Humans[MH] 
\#24 (\#3 AND \#13 AND \#22) NOT \#23

\section{Appendix 2. EMBASE search strategy}

\#1 'Patient compliance'/de

\#2 (Complian* OR Comply* OR Complied OR Adher* OR Noncomplian* OR Nonadher*):ti,ab

\#3 \#1 OR \#2

\#4 Diet/exp

\#5 'Diet therapy'/exp

\#6 'Nutritional assessment'/de

\#7 'Feeding behavior'/exp

\#8 'Nutritional requirement'/exp

\#9 \#4 OR \#5 OR \#6 OR \#7 OR \#8

\#10 (Diet* OR Nutrition* OR 'Food habit' OR 'Food habits' OR 'Feeding behavior' OR 'Feeding behaviors' OR 'Eating behavior' OR 'Eating behaviors'):ti,ab

\#11 \#9 OR \#10

\#12 \#3 AND \#11

\#13 'Randomized controlled trial'/de

\#14 'Controlled clinical trial'/de

\#15 'Single blind procedure'/de OR 'Double blind procedure'/de

\#16 'Crossover procedure'/

\#17 Random*:ti,ab

\#18 Placebo*:ti,ab

\#19 $\quad(($ singl* or doubl*) adj (blind* or mask*)):ti,ab

\#20 (crossover or 'cross over' or factorial* or 'latin square'):ti,ab

\#21 (assign* or allocat* or volunteer*):ti,ab

\#22 \#13 OR \#14 OR \#15 OR \#16 OR \#17 OR \#18 OR \#19 OR \#20 OR \#21

\#23 (Animal/OR Nonhuman) NOT Human/

\#24 \#22 NOT \#23

\#25 \#12 AND \#24

\section{Appendix 3. CINAHL search strategy}

S1 MH "Patient Compliance" 
S2 TI (Complian* OR Comply* OR Complied OR Adher* OR Noncomplian* OR Nonadher*) OR AB (Complian* OR Comply* OR Complied OR Adher* OR Noncomplian* OR Nonadher*)

S3 S1 OR S2

S4 MH "Diet+"

S5 MH "Diet therapy+"

S6 MH "Nutritional assessment"

S7 MH "Food habits"

S8 MH "Eating behavior+"

S9 MH "Nutrition policy+"

S10 MH "Nutritional requirement+"

S11 MW "DH"

S12 TI (Diet* OR Nutrition* OR "Food habit*" OR "Feeding behavior*" OR "Eating behavior*") OR AB (Diet* OR Dieti* OR Nutrition* OR "Food habit*" OR "Feeding behavior*" OR "Eating behavior*")

S13 S4 OR S5 OR S6 OR S7 OR S8 OR S9 OR S10 OR S11 OR S12

S14 S2 AND S13

S15 Randomi?ed controlled Trial*

S16 PT "Clinical Trial”

S17 MH "Clinical Trials +"

S18 MH "Random Assignment"

S19 MH "Placebos"

S20 MH "Quantitative studies"

S21 TI (random* OR trial or groups or placebo*) OR AB (random* OR trial or groups or placebo*)

S22 TI (singl* or doubl* or tripl* or trebl*) and TI (blind* or mask*)

S23 AB (singl* or doubl* or tripl* or trebl*) and AB (blind* or mask*)

S24 S15 OR S16 OR S17 OR S18 OR S19 OR S20 OR S21 OR S22 OR S23

S25 S14 AND S24

S26 S25 (Limiters - Exclude Medline records)

\section{Appendix 4. PsycINFO search strategy}

\#1 (complian* or comply* or complied or adher* or noncomplian* or nonadheren*) 
\#2 (diet* or nutrition* or "food habit" or "food habits" or "food intake" or "food intakes" or "eating behavior" or "eating behaviors" OR "feeding behavior" OR "feeding behaviors").

\#3 \#1 AND \#2

\#4 Random*

\#5 Trial* $^{*}$

\#6 Control*

\#7 Placebo*

\#8 ((singl* or doubl* or trebl* or tripl*) and (blind* or mask*))

\#9 "cross over" or crossover or factorial* or "latin square"

\#10 assign* or allocat* or volunteer*

\#11 it = "treatment effectiveness evaluation"

\#12 it = "mental health program evaluation"

\#13 it = "Experimental design"

\#14 \#4 OR \#5 OR \#6 OR \#7 OR \#8 OR \#9 OR \#10 OR \#11 OR \#12 OR \#13

\#15 \#3 AND \#14

\section{Appendix 5. The Cochrane Library search strategy}

\#1 (Complian* OR Comply* OR Complied OR Adher* OR Noncomplian* OR Nonadher*):ti,ab,kw

\#2 (Diet* OR Nutrition* OR "Food habit*" OR "Feeding behavior*" OR "Eating behavior*"):ti,ab,kw

\#3 MeSH descriptor Diet explode all trees

\#4 MeSH descriptor Diet Therapy explode all trees

\#5 \#2 OR \#3 OR \#4

\#6 \#1 AND \#5

\section{Appendix 6. Methods for potential application in future updates of the review}

\section{Unit of analysis issues}

We will meta-analyse cluster RCTs with non-cluster RCTs after inflating the standard errors to account for clustering. If cluster RCTs are included, we will request the intracluster correlation coefficient (ICC) from the study authors. If the ICC is not available, it will be imputed with external estimates obtained from similar studies. The ICC will then be used to calculate the design effect in order to obtain an inflated standard error that accounts for 
clustering by multiplying the standard error of the effect estimate (from an analysis ignoring clustering) by the square root of the design effect. We will also perform sensitivity analyses to assess how sensitive results are to reasonable changes in ICC imputation.

\section{Dealing with missing data}

Where data are missing, we will attempt to contact study authors. We will conduct an intention-to-treat (ITT) analysis where possible; otherwise data will be analysed as reported. Loss to follow-up will be documented and assessed as a source of potential bias. We will perform sensitivity analyses based on consideration of 'best-case' and 'worst-case' scenarios (CCCRG 2010; Gamble 2005). The 'best-case' scenario is that all missing outcomes in the experimental intervention group had good outcomes, and all those missing in the control intervention group had poor outcomes; the 'worst-case' scenario is the reverse.

\section{Assessment of heterogeneity}

Where meta-analysis is possible, we will assess statistical heterogeneity between trials using the $\mathrm{Chi}^{2}$ statistic and $\mathrm{I}^{2}$ statistic. A Chi ${ }^{2} \mathrm{P}$ value of less than 0.10 or an $\mathrm{I}^{2}$ value equal to or more than $50 \%$ will be considered to indicate substantial heterogeneity. If heterogeneity is identified, we will undertake subgroup analysis to investigate its possible source. We will conduct a meta-regression if there are enough studies to assess the effect of the possible sources of heterogeneity.

\section{Data synthesis}

We will group data with respect to participants' health condition (prevention versus management of chronic diseases). We will analyse included studies to determine whether there are studies sufficiently similar in participants' characteristics (e.g. age, gender), study design (RCT, cluster RCT), type of intervention (e.g. directed towards client, family or nonfamily caregiver), environmental setting (e.g. outpatient, workplace, or other community settings), and outcome measurement to allow for a meta-analysis of their combined data. If studies are sufficiently similar, we will conduct meta-analyses using a random-effects model. If studies are too heterogeneous, we will present a descriptive review of included studies using a narrative along with extracted data in tables and figures.

\section{Subgroup analysis and investigation of heterogeneity}

If enough studies are found to justify subgroup analyses, the following subgroups could be investigated using random-effects meta-regression:

- Type of intervention (e.g. directed towards client, family or non-family caregiver); and

- Characteristics of participants (e.g. age, gender, socioeconomic status, immigrant status). 


\section{Sensitivity analysis}

We will conduct a primary analysis with studies which we consider to have a low risk of bias (i.e. those receiving a 'low risk' rating for the criteria of sequence generation and allocation concealment). Sensitivity analyses will also be performed with all included studies in order to show how conclusions might be affected if studies at high risk of bias were appropriate in order to explore the influence of the following factors on effect size:

- $\quad$ excluding unpublished studies;

- $\quad$ excluding studies that do not provide the drop out rate;

- $\quad$ excluding any large studies to establish how they impact on the results;

- $\quad$ excluding studies using the following filters; language of publication, source of funding (industry versus other);

- $\quad$ excluding studies based on weak-evidence advice (e.g. not coming from practice guidelines).

\section{CHARACTERISTICS OF STUDIES}

Characteristics of included studies [ordered by study ID]

\begin{tabular}{|c|c|c|}
\hline \multicolumn{3}{|l|}{ Aldarondo 1999} \\
\hline Methods & \multicolumn{2}{|c|}{ Study design: randomized controlled trial with one intervention group and one control group } \\
\hline Participants & \multicolumn{2}{|c|}{$\begin{array}{l}\text { Setting: not known } \\
\text { Country: United States } \\
\text { Chronic disease: obesity (management) } \\
\text { Type of participants: clients ( } \mathrm{n}=43 \text { ) } \\
\text { Mean age: intervention and control groups (44) } \\
\text { Sex: intervention and control groups (F: } 86 \% \text {, M: 14\%) } \\
\text { Ethnicity: intervention and control groups (37 White, } 3 \text { African American, 1 Latino-Hispanique, } 1 \\
\text { Native-American, 1 Asian American) }\end{array}$} \\
\hline Interventions & \multicolumn{2}{|c|}{$\begin{array}{l}\text { Group 1: single intervention: enablement (behaviour change techniques: barrier identification/ } \\
\text { problem solving, self-talk); } 14 \text { weeks; }(\mathrm{n}=22) \\
\text { Bi-weekly, the intervention took place in small groups during which clients talked about their } \\
\text { specific problems and concerns and created their problem-solving self-instructions with the help of } \\
\text { the group and the therapist. Homework assignments were given to clients to apply problem- } \\
\text { solving self-instruction form regarding eating } \\
\text { Group 2: control (unstructured support group); } 14 \text { weeks; }(\mathrm{n}=21)\end{array}$} \\
\hline Outcomes & \multicolumn{2}{|c|}{$\begin{array}{l}\text { Measurement of diet adherence: adherence to energy, fat and saturated fat intakes assessed by a } \\
\text { three-day food record (baseline, } 14 \text { weeks) }\end{array}$} \\
\hline Notes & \multicolumn{2}{|c|}{$\begin{array}{l}\text { Dietary advice: energy and fat-restricted diet } \\
\text { Drop-out rate: } 0 \% \text { (calculated) } \\
\text { Providers: doctoral students in counselling psychology }\end{array}$} \\
\hline \multicolumn{3}{|l|}{ Risk of bias } \\
\hline Bias & Authors' judgement & Support for judgement \\
\hline $\begin{array}{l}\text { Random } \\
\text { sequence } \\
\text { generation } \\
\text { (selection bias) }\end{array}$ & Low risk & $\begin{array}{l}\text { "Randomization was carried out by drawing names } \\
\text { from a hat" }\end{array}$ \\
\hline $\begin{array}{l}\text { Allocation } \\
\text { concealment } \\
\text { (selection bias) }\end{array}$ & High risk & $\begin{array}{l}\text { "Randomization was carried out by drawing names } \\
\text { from a hat" }\end{array}$ \\
\hline $\begin{array}{l}\text { Blinding } \\
\text { (performance }\end{array}$ & Low risk & $\begin{array}{l}\text { "During the orientation meeting participants were } \\
\text { given detailed information about the study except for }\end{array}$ \\
\hline
\end{tabular}




\begin{tabular}{|c|c|c|}
\hline $\begin{array}{l}\text { bias and } \\
\text { detection bias) } \\
\text { Participants }\end{array}$ & & $\begin{array}{l}\text { the fact that there would be more than one type } \\
\text { of 'healthy lifestyle group' (the CBT group and the } \\
\text { control group) with no further details given" }\end{array}$ \\
\hline $\begin{array}{l}\text { Blinding } \\
\text { (performance } \\
\text { bias and } \\
\text { detection bias) } \\
\text { Providers }\end{array}$ & Unclear risk & This study did not assess this item. \\
\hline $\begin{array}{l}\text { Blinding } \\
\text { (performance } \\
\text { bias and } \\
\text { detection bias) } \\
\text { Outcome } \\
\text { assessors }\end{array}$ & Unclear risk & This study did not assess this item. \\
\hline $\begin{array}{l}\text { Incomplete } \\
\text { outcome data } \\
\text { (attrition bias) } \\
\text { All outcomes }\end{array}$ & Low risk & No missing data. \\
\hline $\begin{array}{l}\text { Selective } \\
\text { reporting } \\
\text { (reporting bias) }\end{array}$ & High risk & $\begin{array}{l}\text { No protocol. Some outcomes are reported } \\
\text { incompletely (diet adherence, weight) }\end{array}$ \\
\hline Other bias & Unclear risk & $\begin{array}{l}\text { Baseline balance between groups. Diet adherence is } \\
\text { assessed by self-reported measure. Validation and } \\
\text { reliability of self-reported diet adherence are not } \\
\text { reported }\end{array}$ \\
\hline \multicolumn{3}{|l|}{ Arcand 2005} \\
\hline Methods & \multicolumn{2}{|c|}{ Study design: randomized controlled trial with one intervention group and one usual care group } \\
\hline Participants & \multicolumn{2}{|c|}{$\begin{array}{l}\text { Setting: outpatient } \\
\text { Country: Canada } \\
\text { Chronic disease: heart failure (management) } \\
\text { Type of participants: clients }(\mathrm{n}=50) \\
\text { Mean age: intervention }(56 \pm 3) \text {, usual care }(61 \pm 3) \\
\text { Sex: intervention (F: } 28 \%, \text { M: } 72 \% \text { ) and usual care (F: } 32 \%, \text { M: } 68 \%) \\
\text { Ethnicity: not known }\end{array}$} \\
\hline Interventions & \multicolumn{2}{|c|}{$\begin{array}{l}\text { Group 1: multiple intervention: individual session with a dietitian + goal setting; } 3 \text { months; }(\mathrm{n}= \\
\text { 25) } \\
\text { An individualized nutrition care plans and goals were developed during a first counselling session } \\
\text { with a dietitian and a second counseling session occurred } 4 \text { to } 6 \text { weeks later } \\
\text { Group 2: usual care (no goal setting and no follow-up counselling session); once; }(\mathrm{n}=25)\end{array}$} \\
\hline Outcomes & \multicolumn{2}{|c|}{$\begin{array}{l}\text { Measurement of diet adherence: adherence to sodium-restricted diet assessed by a three-day food } \\
\text { record (baseline, } 3 \text { months) }\end{array}$} \\
\hline Notes & \multicolumn{2}{|c|}{$\begin{array}{l}\text { Dietary advice: sodium-restricted diet ( } 2 \mathrm{~g} / \text { day }) \\
\text { Drop-out rate: } 6 \% \text { (calculated) } \\
\text { Providers: intervention: dietitian; usual care: clinic nurse }\end{array}$} \\
\hline \multicolumn{3}{|l|}{ Risk of bias } \\
\hline Bias & Authors' judgement & Support for judgement \\
\hline $\begin{array}{l}\text { Random } \\
\text { sequence } \\
\text { generation } \\
\text { (selection bias) }\end{array}$ & Low risk & $\begin{array}{l}\text { Sequence generation using a computer random } \\
\text { number generator }\end{array}$ \\
\hline $\begin{array}{l}\text { Allocation } \\
\text { concealment } \\
\text { (selection bias) }\end{array}$ & Unclear risk & $\begin{array}{l}\text { Allocation concealment is not described explicitly in } \\
\text { the paper }\end{array}$ \\
\hline $\begin{array}{l}\text { Blinding } \\
\text { (performance } \\
\text { bias and } \\
\text { detection bias) } \\
\text { Participants }\end{array}$ & Unclear risk & This study did not assess this item. \\
\hline $\begin{array}{l}\text { Blinding } \\
\text { (performance }\end{array}$ & Unclear risk & This study did not assess this item. \\
\hline
\end{tabular}

Cochrane Database Syst Rev. Author manuscript; available in PMC 2016 June 09. 


\begin{tabular}{|c|c|c|}
\hline $\begin{array}{l}\text { bias and } \\
\text { detection bias) } \\
\text { Providers }\end{array}$ & & \\
\hline $\begin{array}{l}\text { Blinding } \\
\text { (performance } \\
\text { bias and } \\
\text { detection bias) } \\
\text { Outcome } \\
\text { assessors }\end{array}$ & Unclear risk & This study did not assess this item. \\
\hline $\begin{array}{l}\text { Incomplete } \\
\text { outcome data } \\
\text { (attrition bias) } \\
\text { All outcomes }\end{array}$ & Low risk & $\begin{array}{l}\text { Plausible effect size among missing outcomes not } \\
\text { enough to have a clinically-relevant impact on } \\
\text { observed effect size }\end{array}$ \\
\hline $\begin{array}{l}\text { Selective } \\
\text { reporting } \\
\text { (reporting bias) }\end{array}$ & Unclear risk & No protocol. \\
\hline Other bias & Unclear risk & $\begin{array}{l}\text { Baseline balance between groups. Diet adherence is } \\
\text { assessed by self-reported measure. Validation and } \\
\text { reliability of self-reported diet adherence are not } \\
\text { reported }\end{array}$ \\
\hline \multicolumn{3}{|l|}{ Assuncao 2010} \\
\hline Methods & \multicolumn{2}{|c|}{ Study design: randomized controlled trial with one intervention group and one usual care group } \\
\hline Participants & \multicolumn{2}{|c|}{$\begin{array}{l}\text { Setting : outpatient } \\
\text { Country : Brazil } \\
\text { Chronic disease: overweight and obesity (prevention/management) } \\
\text { Type of participants: clients }(\mathrm{n}=241) \\
\text { Mean age: intervention }(41.1) \text {, usual care }(39.6) \\
\text { Sex: intervention }(\mathrm{F}: 90 \%, \mathrm{M}: 10 \%) \text { and usual care }(\mathrm{F}: 87.6 \%, \mathrm{M}: 12.4 \%) \\
\text { Ethnicity: intervention }(82.5 \% \text { White, } 17.5 \% \text { non-White), usual care }(87.6 \% \text { White, } 12.4 \% \text { non- } \\
\text { White) }\end{array}$} \\
\hline Interventions & \multicolumn{2}{|c|}{$\begin{array}{l}\text { Group 1: single intervention: modelling (nutritional tools); } 6 \text { months; }(\mathrm{n}=120) \\
\text { A manual was provided to clients containing photographs illustrating the portion sizes of the } \\
\text { prescribed foods in addition to nutritionally balanced food lists, with calorically equivalent } \\
\text { alternatives, in } 100 \text {-cal portions. During monthly follow-up sessions, additional explanations were } \\
\text { provided regarding the menu and alternative foods } \\
\text { Group 2: usual care (no nutritional tools); } 6 \text { months; }(\mathrm{n}=121)\end{array}$} \\
\hline Outcomes & \multicolumn{2}{|c|}{$\begin{array}{l}\text { Measurement of diet adherence: adherence to advice regarding total energy, protein, fat, } \\
\text { carbohydrate, cholesterol, fiber, sodium, fruit, vegetable and sweet food intakes assessed by a } \\
\text { weekly food consumption questionnaire (baseline, } 6 \text { months) }\end{array}$} \\
\hline Notes & \multicolumn{2}{|c|}{$\begin{array}{l}\text { Dietary advice: energy controlled diet, } 15 \text { to } 30 \% \text { of energy from total fat; } 55 \text { to } 75 \% \text { of energy } \\
\text { from total carbohydrate; } 10 \text { to } 15 \% \text { of energy from protein; up to } 300 \mathrm{mg} / \text { day of cholesterol; up to } \\
5 \mathrm{~g} / \text { day of salt; up to } 25 \mathrm{~g} / \text { day of fiber; at least } 400 \mathrm{~g} / \text { day of fruit and vegetables } \\
\text { Drop-out rate: } 20.3 \% \text { (calculated) } \\
\text { Providers: dietitians }\end{array}$} \\
\hline \multicolumn{3}{|l|}{ Risk of bias } \\
\hline Bias & Authors' judgement & Support for judgement \\
\hline $\begin{array}{l}\text { Random } \\
\text { sequence } \\
\text { generation } \\
\text { (selection bias) }\end{array}$ & Low risk & $\begin{array}{l}\text { Sequence generation referring to a random number } \\
\text { table. }\end{array}$ \\
\hline $\begin{array}{l}\text { Allocation } \\
\text { concealment } \\
\text { (selection bias) }\end{array}$ & Low risk & $\begin{array}{l}\text { Allocation concealment using sequentially } \\
\text { numbered, opaque, sealed envelopes }\end{array}$ \\
\hline $\begin{array}{l}\text { Blinding } \\
\text { (performance } \\
\text { bias and } \\
\text { detection bias) } \\
\text { Participants }\end{array}$ & High risk & $\begin{array}{l}\text { "An unblind, randomised, controlled clinical trial } \\
\text { was (...)" }\end{array}$ \\
\hline $\begin{array}{l}\text { Blinding } \\
\text { (performance } \\
\text { bias and } \\
\text { detection bias) }\end{array}$ & High risk & $\begin{array}{l}\text { "An unblind, randomised, controlled clinical trial } \\
\text { was (...)" }\end{array}$ \\
\hline
\end{tabular}

Cochrane Database Syst Rev. Author manuscript; available in PMC 2016 June 09. 


\begin{tabular}{|c|c|c|}
\hline \multicolumn{3}{|l|}{ Providers } \\
\hline $\begin{array}{l}\text { Blinding } \\
\text { (performance } \\
\text { bias and } \\
\text { detection bias) } \\
\text { Outcome } \\
\text { assessors }\end{array}$ & High risk & $\begin{array}{l}\text { "Except for laboratory tests, all other outcome } \\
\text { indicators were assessed by observers that were } \\
\text { unblind of the status of the study participants" }\end{array}$ \\
\hline $\begin{array}{l}\text { Incomplete } \\
\text { outcome data } \\
\text { (attrition bias) } \\
\text { All outcomes }\end{array}$ & High risk & $\begin{array}{l}\text { Plausible effect size among missing outcomes } \\
\text { enough to have a clinically-relevant impact on } \\
\text { observed effect size }\end{array}$ \\
\hline $\begin{array}{l}\text { Selective } \\
\text { reporting } \\
\text { (reporting bias) }\end{array}$ & High risk & $\begin{array}{l}\text { No protocol. Diet adherence is reported } \\
\text { incompletely. }\end{array}$ \\
\hline Other bias & High risk & $\begin{array}{l}\text { Baseline imbalance between groups (fasting } \\
\text { glucose). Diet adherence is assessed by self-reported } \\
\text { measure (validated food frequency questionnaire) }\end{array}$ \\
\hline \multicolumn{3}{|l|}{ Baraz 2010} \\
\hline Methods & \multicolumn{2}{|c|}{ Study design: randomized controlled trial with two intervention groups } \\
\hline Participants & \multicolumn{2}{|c|}{$\begin{array}{l}\text { Setting: outpatient } \\
\text { Country: Iran } \\
\text { Chronic disease: chronic end-stage renal disease (management) } \\
\text { Type of participants: clients }(\mathrm{n}=63) \\
\text { Mean age: intervention group } 1(35.9 \pm 10.1) \text {, intervention group } 2(33.8 \pm 8.9) \\
\text { Sex: intervention group 1 (F: } 46.9 \%, \text { M: } 53.1 \%) \text { and intervention group } 2 \text { (F: } 48.4 \%, \text { M: } 51.6 \%) \\
\text { Ethnicity: intervention groups (100\% Asian) }\end{array}$} \\
\hline Interventions & \multicolumn{2}{|c|}{$\begin{array}{l}\text { Group 1: multiple intervention: group session + educational tools-booklet; } 2 \text { weeks; }(\mathrm{n}=32) \\
\text { Clients attended two educational sessions. An interactive portion of teaching program was held at } \\
\text { the end of class and clients were encouraged to offer support to each other. Clients also received a } \\
\text { teaching booklet to take home } \\
\text { Group 2: single intervention: education (educational tools-video); } 1 \text { week; }(\mathrm{n}=31) \\
\text { An educational film on a video disc system was shown to each client during two consecutive } \\
\text { dialysis sessions in a week }\end{array}$} \\
\hline Outcomes & \multicolumn{2}{|c|}{$\begin{array}{l}\text { Measurement of diet adherence: adherence to dietary restriction assessed by bimonthly average } \\
\text { values of serum sodium, potassium, calcium, phosphate, albumin, creatinine, uric acid and blood } \\
\text { urea nitrogen (baseline, } 2 \text { months); adherence to fluid-restricted diet assessed by bimonthly } \\
\text { interdialytic weight gain (baseline, } 2 \text { months) }\end{array}$} \\
\hline Notes & \multicolumn{2}{|c|}{$\begin{array}{l}\text { Dietary advice: } 55 \mathrm{~g} / \text { day of oil; } 1.2 \text { to } 1.5 \mathrm{~g} / \mathrm{kg} / \text { day of protein; } 2 \mathrm{~g} / \mathrm{day} \text { of sodium; } 0.5 \text { to } 2 \mathrm{~g} / \text { day of } \\
\text { potassium; } 1 \mathrm{~g} / \text { day of phosphorus; restricted water intake (output } 24 \mathrm{~h}+10 \mathrm{ml} / \mathrm{kg} / \mathrm{day} \text { ) } \\
\text { Drop-out rate: } 0 \% \text { (calculated) } \\
\text { Provider: renal nurse expert }\end{array}$} \\
\hline \multicolumn{3}{|l|}{ Risk of bias } \\
\hline Bias & Authors' judgement & Support for judgement \\
\hline $\begin{array}{l}\text { Random } \\
\text { sequence } \\
\text { generation } \\
\text { (selection bias) }\end{array}$ & Low risk & $\begin{array}{l}\text { "The random allocation was performed using } \\
\text { computer-generated random numbers from } 0 \text { to 99." }\end{array}$ \\
\hline $\begin{array}{l}\text { Allocation } \\
\text { concealment } \\
\text { (selection bias) }\end{array}$ & High risk & $\begin{array}{l}\text { "For an equal allocation to the two groups, we took } \\
\text { odd numbers to indicate group } 1 \text { (oral education) } \\
\text { and even numbers to indicate group } 2 \text { (video } \\
\text { education)." }\end{array}$ \\
\hline $\begin{array}{l}\text { Blinding } \\
\text { (performance } \\
\text { bias and } \\
\text { detection bias) } \\
\text { Participants }\end{array}$ & Unclear risk & This study did not assess this item. \\
\hline $\begin{array}{l}\text { Blinding } \\
\text { (performance } \\
\text { bias and } \\
\text { detection bias) } \\
\text { Providers }\end{array}$ & Unclear risk & This study did not assess this item. \\
\hline
\end{tabular}

Cochrane Database Syst Rev. Author manuscript; available in PMC 2016 June 09. 


\begin{tabular}{|c|c|c|}
\hline $\begin{array}{l}\text { Blinding } \\
\text { (performance } \\
\text { bias and } \\
\text { detection bias) } \\
\text { Outcome } \\
\text { assessors }\end{array}$ & Unclear risk & This study did not assess this item. \\
\hline $\begin{array}{l}\text { Incomplete } \\
\text { outcome data } \\
\text { (attrition bias) } \\
\text { All outcomes }\end{array}$ & Low risk & No missing data. \\
\hline $\begin{array}{l}\text { Selective } \\
\text { reporting } \\
\text { (reporting bias) }\end{array}$ & Unclear risk & No protocol. \\
\hline Other bias & Unclear risk & $\begin{array}{l}\text { Baseline comparisons between groups are not } \\
\text { reported. Diet adherence is assessed by objective } \\
\text { measures }\end{array}$ \\
\hline \multicolumn{3}{|l|}{ Beasley 2008} \\
\hline Methods & \multicolumn{2}{|c|}{ Study design: randomized controlled trial with one intervention group and one control group } \\
\hline Participants & \multicolumn{2}{|c|}{$\begin{array}{l}\text { Setting: research center } \\
\text { Country: United States } \\
\text { Chronic disease: overweight and obesity (prevention/management) } \\
\text { Type of participants: clients }(\mathrm{n}=174) \\
\text { Mean age: intervention }(52 \pm 12) \text {, control }(54 \pm 10) \\
\text { Sex: intervention (F: } 83 \%, \mathrm{M}: 17 \%) \text { and control (F: } 77 \% \text {, M: } 23 \%) \\
\text { Ethnicity: intervention (85\% Caucasian, 10\% Black, } 5 \% \text { Asian), control (83.3\% Caucasian, } \\
16.7 \% \text { Black, 0\% Asian) }\end{array}$} \\
\hline Interventions & \multicolumn{2}{|c|}{$\begin{array}{l}\text { Group 1: single intervention: training (feedback); } 4 \text { weeks; }(\mathrm{n}=89) \\
\text { Clients received a Palm Zire } 21 \text { loaded with the DietMatePro program that displayed personalized } \\
\text { target values for energy based on the Harris-Benedict calculation using National Institutes of } \\
\text { Health }(\mathrm{NIH}) \text { guidelines for weight loss as well as fat, saturated fat, and cholesterol goals based on } \\
\text { Ornish Prevention Diet recommendations. Additional DietMatePro program features to assist in } \\
\text { adhering to the dietary regimen included feedback of comparisons between actual and target intake } \\
\text { by meal and by day as well as recipes and meal plans consistent with the assigned diet } \\
\text { Group 2: control (no feedback); } 4 \text { weeks; }(\mathrm{n}=85) \text {. }\end{array}$} \\
\hline Outcomes & \multicolumn{2}{|c|}{$\begin{array}{l}\text { Measurement of diet adherence: adherence to energy, fat, saturated fat and cholesterol intakes } \\
\text { assessed by a three-day DietMatePro (intervention) or paper-based (control) food diaries and 24-hr } \\
\text { recall (4 weeks) }\end{array}$} \\
\hline Notes & \multicolumn{2}{|c|}{$\begin{array}{l}\text { Dietary advice: Ornish Diet (individualized target of energy level based on the Harris-Benedict } \\
\text { calculation using NIH guidelines for weight loss, } 10 \text { to } 15 \% \text { of energy from fat, up to } 7 \% \text { of } \\
\text { energy from saturated fat and cholesterol less than } 200 \mathrm{mg} / \text { day) } \\
\text { Drop-out rate: } 8.6 \% \text { (calculated) } \\
\text { Provider: research assistant }\end{array}$} \\
\hline \multicolumn{3}{|l|}{ Risk of bias } \\
\hline Bias & Authors' judgement & Support for judgement \\
\hline $\begin{array}{l}\text { Random } \\
\text { sequence } \\
\text { generation } \\
\text { (selection bias) }\end{array}$ & Low risk & $\begin{array}{l}\text { "Participants were then randomly assigned to } \\
\text { receive either the DietMatePro program or the } \\
\text { paper-based food diary as their food recording } \\
\text { method based on a randomization table generated by } \\
\text { the first author." }\end{array}$ \\
\hline $\begin{array}{l}\text { Allocation } \\
\text { concealment } \\
\text { (selection bias) }\end{array}$ & High risk & $\begin{array}{l}\text { Allocation concealment using an open random } \\
\text { allocation schedule (list of random numbers) }\end{array}$ \\
\hline $\begin{array}{l}\text { Blinding } \\
\text { (performance } \\
\text { bias and } \\
\text { detection bias) } \\
\text { Participants }\end{array}$ & Unclear risk & This study did not assess this item. \\
\hline $\begin{array}{l}\text { Blinding } \\
\text { (performance } \\
\text { bias and } \\
\text { detection bias) } \\
\text { Providers }\end{array}$ & Unclear risk & This study did not assess this item. \\
\hline
\end{tabular}

Cochrane Database Syst Rev. Author manuscript; available in PMC 2016 June 09. 


\begin{tabular}{|c|c|c|}
\hline $\begin{array}{l}\text { Blinding } \\
\text { (performance } \\
\text { bias and } \\
\text { detection bias) } \\
\text { Outcome } \\
\text { assessors }\end{array}$ & High risk & $\begin{array}{l}\text { "Research assistants were aware of the participant's } \\
\text { randomization assignment during the assessment." }\end{array}$ \\
\hline $\begin{array}{l}\text { Incomplete } \\
\text { outcome data } \\
\text { (attrition bias) } \\
\text { All outcomes }\end{array}$ & High risk & $\begin{array}{l}\text { The proportion of missing outcomes compared with } \\
\text { observed risk enough to induce clinically relevant } \\
\text { bias in intervention effect estimate }\end{array}$ \\
\hline $\begin{array}{l}\text { Selective } \\
\text { reporting } \\
\text { (reporting bias) }\end{array}$ & Unclear risk & No protocol. \\
\hline Other bias & High risk & $\begin{array}{l}\text { Baseline imbalance between groups (body mass } \\
\text { index). Diet adherence is assessed by self-reported } \\
\text { measures. Validation of Diet-MatePro diary with } \\
\text { paper based diary is reported. Potential conflict of } \\
\text { interest ("All authors were employed at PICS at the } \\
\text { time of the study and PICS is the developer of } \\
\text { DietMatePro") }\end{array}$ \\
\hline \multicolumn{3}{|l|}{ Becker 1998} \\
\hline Methods & \multicolumn{2}{|c|}{ Study design: randomized controlled trial with one intervention group and one usual care group } \\
\hline Participants & \multicolumn{2}{|c|}{$\begin{array}{l}\text { Setting: outpatient } \\
\text { Country: United States } \\
\text { Chronic disease: risk of coronary heart disease (prevention) } \\
\text { Type of participants: clients }(\mathrm{n}=156) \\
\text { Mean age: intervention }(46.1 \pm 7.7) \text {, usual care }(46.9 \pm 6.8) \\
\text { Sex: intervention (F: } 47.6 \%, \text { M: } 52.4 \%) \text { and usual care (F: } 51.4 \%, M: 48.6 \%) \\
\text { Ethnicity: not known }\end{array}$} \\
\hline Interventions & \multicolumn{2}{|c|}{$\begin{array}{l}\text { Group 1: multiple intervention: telephone follow-up + barrier identification/problem solving; } 2 \\
\text { years; }(\mathrm{n}=84) \\
\text { Meetings took place every four months and telephone calls occurred three times a year for lipid } \\
\text { therapy compliance and dietary counselling. Barriers to implementation of diet, pharmacotherapy, } \\
\text { exercise and smoking cessation were discussed. Encounters used standardized prompts that } \\
\text { centered on readiness to change, support systems, and the sociocultural, work, and economic } \\
\text { environment. } \\
\text { Group 2: usual care; duration not known; }(n=72)\end{array}$} \\
\hline Outcomes & \multicolumn{2}{|c|}{$\begin{array}{l}\text { Measurement of diet adherence: adherence to fat-restricted diet assessed by the Block Health } \\
\text { Habits and History Questionnaire food frequency instrument ( } 2 \text { years) }\end{array}$} \\
\hline Notes & \multicolumn{2}{|c|}{$\begin{array}{l}\text { Dietary advice: consumption of less than } 30 \% \text { of total energy from fat and less than } 300 \mathrm{mg} / \mathrm{day} \text { of } \\
\text { cholesterol } \\
\text { Drop-out rate: } 23 \% \\
\text { Providers: nurses and physicians }\end{array}$} \\
\hline \multicolumn{3}{|l|}{ Risk of bias } \\
\hline Bias & Authors' judgement & Support for judgement \\
\hline $\begin{array}{l}\text { Random } \\
\text { sequence } \\
\text { generation } \\
\text { (selection bias) }\end{array}$ & Low risk & $\begin{array}{l}\text { "Randomization was done by family using a } \\
\text { computerized schema" }\end{array}$ \\
\hline $\begin{array}{l}\text { Allocation } \\
\text { concealment } \\
\text { (selection bias) }\end{array}$ & Unclear risk & $\begin{array}{l}\text { "Each family had a number with a corresponding } \\
\text { sealed envelope containing the assignment. The } \\
\text { envelopes were opened after all siblings from the } \\
\text { same family had been screened." }\end{array}$ \\
\hline $\begin{array}{l}\text { Blinding } \\
\text { (performance } \\
\text { bias and } \\
\text { detection bias) } \\
\text { Participants }\end{array}$ & Unclear risk & This study did not assess this item. \\
\hline $\begin{array}{l}\text { Blinding } \\
\text { (performance } \\
\text { bias and } \\
\text { detection bias) }\end{array}$ & Unclear risk & This study did not assess this item. \\
\hline
\end{tabular}

Cochrane Database Syst Rev. Author manuscript; available in PMC 2016 June 09. 


\begin{tabular}{|c|c|c|}
\hline \multicolumn{3}{|l|}{ Providers } \\
\hline $\begin{array}{l}\text { Blinding } \\
\text { (performance } \\
\text { bias and } \\
\text { detection bias) } \\
\text { Outcome } \\
\text { assessors }\end{array}$ & Unclear risk & This study did not assess this item. \\
\hline $\begin{array}{l}\text { Incomplete } \\
\text { outcome data } \\
\text { (attrition bias) } \\
\text { All outcomes }\end{array}$ & High risk & $\begin{array}{l}\text { Imbalance in numbers of missing data between } \\
\text { groups and the proportion of missing outcomes } \\
\text { compared with observed event risk enough to induce } \\
\text { clinically-relevant bias in intervention effect } \\
\text { estimate }\end{array}$ \\
\hline $\begin{array}{l}\text { Selective } \\
\text { reporting } \\
\text { (reporting bias) }\end{array}$ & High risk & $\begin{array}{l}\text { No protocol. Some outcomes are reported } \\
\text { incompletely (weight, total cholesterol, smoking, } \\
\text { physical activity and blood pressure) }\end{array}$ \\
\hline Other bias & High risk & $\begin{array}{l}\text { Baseline imbalance between groups (HDL- } \\
\text { cholesterol). Diet adherence is assessed by self- } \\
\text { reported measures (validated food frequency } \\
\text { questionnaire) }\end{array}$ \\
\hline \multicolumn{3}{|l|}{ Bennett 1986} \\
\hline Methods & \multicolumn{2}{|c|}{ Study design: randomized controlled trial with three intervention groups } \\
\hline Participants & \multicolumn{2}{|c|}{$\begin{array}{l}\text { Setting: not known } \\
\text { Country: United Kingdom } \\
\text { Chronic disease: overweight and obesity (prevention/management) } \\
\text { Type of participants: clients }(\mathrm{n}=53) \\
\text { Mean age: intervention groups }(40) \\
\text { Sex: intervention groups (F: } 100 \%) \\
\text { Ethnicity: intervention groups }(100 \% \text { White) }\end{array}$} \\
\hline Interventions & \multicolumn{2}{|c|}{$\begin{array}{l}\text { Group 1: single intervention: enablement (behaviour change techniques: teach to use prompts/ } \\
\text { cues); } 16 \text { weeks; }(\mathrm{n}=18) \\
\text { The aim was to reduce exposure to food cues by discussion of changes to make in food storage } \\
\text { habits and common target problem. Each session (weeks } 5,6,7,8,9,11 \text { and } 15 \text { ) followed the } \\
\text { same format: a brief review of recent dieting efforts; a central lesson giving specific detailed } \\
\text { advice on ways of reducing contact with food and one area of food management; a discussion of a } \\
\text { specific problem from the point of view of the program as practice in problem solving and a } \\
\text { summary of the content of the session. } \\
\text { Group 2: single intervention: enablement (behaviour change techniques: self-talk); } 16 \text { weeks; (n = } \\
\text { 16) } \\
\text { The aim was to resist overeating by practising self-talk. Each session (weeks } 5,6,7,8,9,11 \text { and } \\
\text { 15) followed the same format: a brief review of recent efforts, a long period of imaginal rehearsal } \\
\text { and a summary of the content of the session. } \\
\text { Group 3: single intervention: enablement (behaviour change techniques: barrier identification/ } \\
\text { problem solving); } 16 \text { weeks; }(\mathrm{n}=19 \text { ) } \\
\text { The aim was to improve self-control ability by reviewing problems encountered and discussing } \\
\text { about adherence to diet }\end{array}$} \\
\hline Outcomes & \multicolumn{2}{|c|}{$\begin{array}{l}\text { Measurement of diet adherence: adherence to energy intake assessed by a daily record (baseline - } \\
3 \text { weeks - } 6 \text { weeks - } 9 \text { weeks - } 12 \text { weeks - } 15 \text { weeks) }\end{array}$} \\
\hline Notes & \multicolumn{2}{|c|}{$\begin{array}{l}\text { Dietary advice: specific quotas of exchanges, representing } 1000 \mathrm{kCal} \text { below expected energy } \\
\text { requirements, with a minimum of } 1000 \mathrm{kCal} \\
\text { Drop-out rate: } 24.5 \% \text { (calculated) } \\
\text { Providers: psychologist and dietitian }\end{array}$} \\
\hline \multicolumn{3}{|l|}{ Risk of bias } \\
\hline Bias & Authors' judgement & Support for judgement \\
\hline $\begin{array}{l}\text { Random } \\
\text { sequence } \\
\text { generation } \\
\text { (selection bias) }\end{array}$ & Low risk & $\begin{array}{l}\text { Sequence generation referring to a random number } \\
\text { table. }\end{array}$ \\
\hline $\begin{array}{l}\text { Allocation } \\
\text { concealment } \\
\text { (selection bias) }\end{array}$ & High risk & $\begin{array}{l}\text { Allocation concealment using an open random } \\
\text { allocation schedule (list of random numbers) }\end{array}$ \\
\hline $\begin{array}{l}\text { Blinding } \\
\text { (performance }\end{array}$ & Unclear risk & This study did not assess this item. \\
\hline
\end{tabular}

Cochrane Database Syst Rev. Author manuscript; available in PMC 2016 June 09. 


\begin{tabular}{|c|c|c|}
\hline $\begin{array}{l}\text { bias and } \\
\text { detection bias) } \\
\text { Participants }\end{array}$ & & \\
\hline $\begin{array}{l}\text { Blinding } \\
\text { (performance } \\
\text { bias and } \\
\text { detection bias) } \\
\text { Providers }\end{array}$ & Unclear risk & This study did not assess this item. \\
\hline $\begin{array}{l}\text { Blinding } \\
\text { (performance } \\
\text { bias and } \\
\text { detection bias) } \\
\text { Outcome } \\
\text { assessors }\end{array}$ & Unclear risk & This study did not assess this item. \\
\hline $\begin{array}{l}\text { Incomplete } \\
\text { outcome data } \\
\text { (attrition bias) } \\
\text { All outcomes }\end{array}$ & High risk & $\begin{array}{l}\text { Plausible effect size among missing outcomes } \\
\text { enough to have a clinically-relevant impact on } \\
\text { observed effect size }\end{array}$ \\
\hline $\begin{array}{l}\text { Selective } \\
\text { reporting } \\
\text { (reporting bias) }\end{array}$ & Unclear risk & No protocol. \\
\hline Other bias & Unclear risk & $\begin{array}{l}\text { Baseline balance between groups. Diet adherence is } \\
\text { assessed by self-reported measure. Validation and } \\
\text { reliability of self-reported diet adherence are not } \\
\text { reported }\end{array}$ \\
\hline \multicolumn{3}{|l|}{ Blanson 2009} \\
\hline Methods & \multicolumn{2}{|c|}{ Study design: randomized controlled trial with one intervention group and one control group } \\
\hline Participants & \multicolumn{2}{|c|}{$\begin{array}{l}\text { Setting: research center } \\
\text { Country: Netherlands } \\
\text { Chronic disease: overweight (prevention) } \\
\text { Type of participants: clients }(\mathrm{n}=191) \\
\text { Mean age: intervention }(44.3 \pm 12.2) \text {, control }(43.0 \pm 11.3) \\
\text { Sex: intervention (F: } 76.9 \%, \mathrm{M}: 23.1 \%) \text { and control (F: } 88.7 \%, \mathrm{M}: 11.3 \%) \\
\text { Ethnicity: not known }\end{array}$} \\
\hline Interventions & \multicolumn{2}{|c|}{$\begin{array}{l}\text { Group 1: multiple intervention: motivational interviewing }+ \text { feedback; } 4 \text { weeks; }(n=97) \\
\text { A computer assistant represented by an animated } i \text { Cat showed different facial expressions and } \\
\text { provided cooperative feedback following principles from the motivational interviewing method. } \\
\text { Group 2: control (no computer assistant); } 4 \text { weeks; }(n=94)\end{array}$} \\
\hline Outcomes & \multicolumn{2}{|c|}{ Measurement of diet adherence: adherence to diet goals assessed by a diary ( 28 days) } \\
\hline Notes & \multicolumn{2}{|c|}{$\begin{array}{l}\text { Dietary advice: one of the following goals: } 20 \text { to } 35 \% \text { of energy from fat; at least two pieces of } \\
\text { fruit and } 150 \text { to } 200 \text { grams of vegetables/day; eat regularly (breakfast, lunch and dinner and a } \\
\text { maximum of two in between snacks) } \\
\text { Drop-out rate: } 81.7 \% \text { (calculated) } \\
\text { Provider: none }\end{array}$} \\
\hline \multicolumn{3}{|l|}{ Risk of bias } \\
\hline Bias & Authors' judgement & Support for judgement \\
\hline $\begin{array}{l}\text { Random } \\
\text { sequence } \\
\text { generation } \\
\text { (selection bias) }\end{array}$ & Unclear risk & $\begin{array}{l}\text { Sequence generation is not described explicitly in } \\
\text { the paper }\end{array}$ \\
\hline $\begin{array}{l}\text { Allocation } \\
\text { concealment } \\
\text { (selection bias) }\end{array}$ & Unclear risk & $\begin{array}{l}\text { Allocation concealment is not described explicitly in } \\
\text { the paper }\end{array}$ \\
\hline $\begin{array}{l}\text { Blinding } \\
\text { (performance } \\
\text { bias and } \\
\text { detection bias) } \\
\text { Participants }\end{array}$ & Low risk & $\begin{array}{l}\text { "The participants were not aware there were two } \\
\text { groups" }\end{array}$ \\
\hline $\begin{array}{l}\text { Blinding } \\
\text { (performance }\end{array}$ & Unclear risk & This study did not assess this item. \\
\hline
\end{tabular}

Cochrane Database Syst Rev. Author manuscript; available in PMC 2016 June 09. 


\begin{tabular}{|c|c|c|}
\hline $\begin{array}{l}\text { bias and } \\
\text { detection bias) } \\
\text { Providers }\end{array}$ & & \\
\hline $\begin{array}{l}\text { Blinding } \\
\text { (performance } \\
\text { bias and } \\
\text { detection bias) } \\
\text { Outcome } \\
\text { assessors }\end{array}$ & Unclear risk & This study did not assess this item. \\
\hline $\begin{array}{l}\text { Incomplete } \\
\text { outcome data } \\
\text { (attrition bias) } \\
\text { All outcomes }\end{array}$ & High risk & $\begin{array}{l}\text { Plausible effect size among missing outcomes } \\
\text { enough to have a clinically-relevant impact on } \\
\text { observed effect size }\end{array}$ \\
\hline $\begin{array}{l}\text { Selective } \\
\text { reporting } \\
\text { (reporting bias) }\end{array}$ & Unclear risk & No protocol \\
\hline Other bias & Unclear risk & $\begin{array}{l}\text { Baseline comparisons between groups are not } \\
\text { reported. Diet adherence is assessed by self-reported } \\
\text { measure. Validation and reliability of self-reported } \\
\text { diet adherence are not reported }\end{array}$ \\
\hline \multicolumn{3}{|l|}{ Chen 2006} \\
\hline Methods & \multicolumn{2}{|c|}{ Study design: randomized controlled trial with one intervention group and one control group } \\
\hline Participants & \multicolumn{2}{|c|}{$\begin{array}{l}\text { Setting: outpatient } \\
\text { Country: China } \\
\text { Chronic disease: renal failure (management) } \\
\text { Type of participants: clients }(\mathrm{n}=70) \\
\text { Mean age: intervention }(57.6 \pm 14.2) \text {, control }(52.9 \pm 14.9) \\
\text { Sex: intervention (F: } 57.1 \%, \text { M: } 42.9 \%) \text { and control (F: } 48.6 \%, \text { M: } 51.4 \%) \\
\text { Ethnicity: not known }\end{array}$} \\
\hline Interventions & \multicolumn{2}{|c|}{$\begin{array}{l}\text { Group 1: single intervention: modelling (nutritional tools); duration not known; }(\mathrm{n}=35) \\
\text { Clients received an individualized menu suggestion based on food preferences and learned how to } \\
\text { make food substitution using an exchange list and portion-sized food aids. } \\
\text { Group 2: control (no menu suggestion); duration not known; }(\mathrm{n}=35)\end{array}$} \\
\hline Outcomes & \multicolumn{2}{|c|}{$\begin{array}{l}\text { Measurement of diet adherence: adherence to protein intake assessed by a three-day food record } \\
\text { (baseline, } 1 \text { month) }\end{array}$} \\
\hline Notes & \multicolumn{2}{|c|}{$\begin{array}{l}\text { Dietary advice: daily protein intake level } 0.8 \text { to } 1.2 \mathrm{~g} / \mathrm{kg} / \mathrm{day} \\
\text { Drop-out rate: } 0 \% \text { (calculated) } \\
\text { Provider: dietitian }\end{array}$} \\
\hline \multicolumn{3}{|l|}{ Risk of bias } \\
\hline Bias & Authors' judgement & Support for judgement \\
\hline $\begin{array}{l}\text { Random } \\
\text { sequence } \\
\text { generation } \\
\text { (selection bias) }\end{array}$ & Low risk & $\begin{array}{l}\text { “(..) all patients were then randomly assigned to } 1 \\
\text { of } 2 \text { groups using random numbers" }\end{array}$ \\
\hline $\begin{array}{l}\text { Allocation } \\
\text { concealment } \\
\text { (selection bias) }\end{array}$ & Unclear risk & $\begin{array}{l}\text { Allocation concealment is not described explicitly in } \\
\text { the paper }\end{array}$ \\
\hline $\begin{array}{l}\text { Blinding } \\
\text { (performance } \\
\text { bias and } \\
\text { detection bias) } \\
\text { Participants }\end{array}$ & Unclear risk & This study did not assess this item. \\
\hline $\begin{array}{l}\text { Blinding } \\
\text { (performance } \\
\text { bias and } \\
\text { detection bias) } \\
\text { Providers }\end{array}$ & Unclear risk & This study did not assess this item. \\
\hline $\begin{array}{l}\text { Blinding } \\
\text { (performance } \\
\text { bias and } \\
\text { detection bias) }\end{array}$ & Unclear risk & This study did not assess this item. \\
\hline
\end{tabular}

Cochrane Database Syst Rev. Author manuscript; available in PMC 2016 June 09. 


\begin{tabular}{|c|c|c|}
\hline \multicolumn{3}{|l|}{$\begin{array}{l}\text { Outcome } \\
\text { assessors }\end{array}$} \\
\hline $\begin{array}{l}\text { Incomplete } \\
\text { outcome data } \\
\text { (attrition bias) } \\
\text { All outcomes }\end{array}$ & Low risk & No missing data. \\
\hline $\begin{array}{l}\text { Selective } \\
\text { reporting } \\
\text { (reporting bias) }\end{array}$ & Unclear risk & No protocol. \\
\hline Other bias & Unclear risk & $\begin{array}{l}\text { Baseline balance between groups. Diet adherence is } \\
\text { assessed by self-reported measure. Validation and } \\
\text { reliability of self-reported diet adherence are not } \\
\text { reported }\end{array}$ \\
\hline \multicolumn{3}{|l|}{ Chiu 2010} \\
\hline Methods & \multicolumn{2}{|c|}{ Study design: randomized controlled trial with one intervention group and one control group } \\
\hline Participants & \multicolumn{2}{|c|}{$\begin{array}{l}\text { Setting: outpatient } \\
\text { Country: China } \\
\text { Chronic disease: hypertension (management) } \\
\text { Type of participants: clients }(\mathrm{n}=63) \\
\text { Mean age: intervention }(53.3 \pm 7.8) \text {, control }(54.4 \pm 7.6) \\
\text { Sex: intervention (F: } 77.4 \%, \text { M: } 22.6 \%) \text { and control (F: } 56.2 \%, \text { M: } 43.8 \%) \\
\text { Ethnicity: not known }\end{array}$} \\
\hline Interventions & \multicolumn{2}{|c|}{$\begin{array}{l}\text { Group 1: single intervention: education (telephone follow-up); } 8 \text { weeks; }(\mathrm{n}=31) \\
\text { A nurse performed a telephone follow-up every two to three weeks during which she reinforced } \\
\text { health self-management behaviours, providing health advice and assessed the need for referrals. } \\
\text { Group 2: control (no telephone follow-up); } 8 \text { weeks; }(n=32)\end{array}$} \\
\hline Outcomes & \multicolumn{2}{|c|}{$\begin{array}{l}\text { Measurement of diet adherence: adherence to sodium-restricted diet, control of fat intake and } \\
\text { adequate fruit and vegetable consumption assessed by a score (baseline, } 8 \text { weeks) }\end{array}$} \\
\hline Notes & \multicolumn{2}{|c|}{$\begin{array}{l}\text { Dietary advice: sodium-restricted diet, fat, fruit and vegetable intakes } \\
\text { Drop-out rate: } 1.6 \% \text { (calculated) } \\
\text { Providers: nurses }\end{array}$} \\
\hline \multicolumn{3}{|l|}{ Risk of bias } \\
\hline Bias & Authors' judgement & Support for judgement \\
\hline $\begin{array}{l}\text { Random } \\
\text { sequence } \\
\text { generation } \\
\text { (selection bias) }\end{array}$ & Low risk & $\begin{array}{l}\text { "Patients (...) were randomised to the study or } \\
\text { control group using sets of computer-generated } \\
\text { random numbers" }\end{array}$ \\
\hline $\begin{array}{l}\text { Allocation } \\
\text { concealment } \\
\text { (selection bias) }\end{array}$ & Unclear risk & $\begin{array}{l}\text { Allocation concealment is not described explicitly in } \\
\text { the paper }\end{array}$ \\
\hline $\begin{array}{l}\text { Blinding } \\
\text { (performance } \\
\text { bias and } \\
\text { detection bias) } \\
\text { Participants }\end{array}$ & Unclear risk & This study did not assess this item. \\
\hline $\begin{array}{l}\text { Blinding } \\
\text { (performance } \\
\text { bias and } \\
\text { detection bias) } \\
\text { Providers }\end{array}$ & Unclear risk & This study did not assess this item. \\
\hline $\begin{array}{l}\text { Blinding } \\
\text { (performance } \\
\text { bias and } \\
\text { detection bias) } \\
\text { Outcome } \\
\text { assessors }\end{array}$ & Unclear risk & $\begin{array}{l}\text { The outcome assessors were blinded for the } \\
\text { satisfaction questionnaire but this study did not } \\
\text { address the blinding for other outcomes }\end{array}$ \\
\hline $\begin{array}{l}\text { Incomplete } \\
\text { outcome data } \\
\text { (attrition bias) } \\
\text { All outcomes }\end{array}$ & Unclear risk & $\begin{array}{l}\text { Insufficient reporting of attrition to permit } \\
\text { judgement. }\end{array}$ \\
\hline
\end{tabular}

Cochrane Database Syst Rev. Author manuscript; available in PMC 2016 June 09. 


\begin{tabular}{|c|c|c|}
\hline $\begin{array}{l}\text { Selective } \\
\text { reporting } \\
\text { (reporting bias) }\end{array}$ & Unclear risk & No protocol \\
\hline Other bias & High risk & $\begin{array}{l}\text { Baseline balance between groups. Diet adherence is } \\
\text { assessed by self-reported measure (validated scale). } \\
\text { An effect of intervener could have influenced results }\end{array}$ \\
\hline \multicolumn{3}{|l|}{ Conrad 2000} \\
\hline Methods & \multicolumn{2}{|c|}{ Study design: randomized controlled trial with one intervention group and one control group } \\
\hline Participants & \multicolumn{2}{|c|}{$\begin{array}{l}\text { Setting: outpatient } \\
\text { Country: Canada } \\
\text { Chronic disease: coronary artery disease (management) } \\
\text { Type of participants: clients }(\mathrm{n}=7) \\
\text { Mean age: not known } \\
\text { Sex: not known } \\
\text { Ethnicity: not known }\end{array}$} \\
\hline Interventions & \multicolumn{2}{|c|}{$\begin{array}{l}\text { Group 1: single intervention: restriction; } 7 \text { months; }(\mathrm{n}=4) \\
\text { INCREMENTAL REDUCTION OF FAT: Meal plan initially targeted intake of } 26 \% \text { to } 30 \% \text { of } \\
\text { energy as fat. At two months, patients were given meal plan targeting } 20 \% \text { fat energy intake. } \\
\text { Finally, at four months they were given meal plan targeting } 10 \% \text { fat energy intake. } \\
\text { Group 2: control; } 7 \text { months; }(\mathrm{n}=3) \\
\text { IMMEDIATE REDUCTION OF FAT: Meal plan consisted to an immediate reduction of fat } \\
\text { energy intake }(10 \%) \text {. The meal plan was reinforced two and four months after the program }\end{array}$} \\
\hline Outcomes & \multicolumn{2}{|c|}{$\begin{array}{l}\text { Measurement of diet adherence: adherence to very low fat diet assessed by a 24-hr recall ( } 7 \\
\text { months) }\end{array}$} \\
\hline Notes & \multicolumn{2}{|l|}{$\begin{array}{l}\text { Dietary advice: } 10 \% \text { of energy from fat } \\
\text { Drop-out rate: } 0 \% \text { (calculated) } \\
\text { Provider: dietitian }\end{array}$} \\
\hline \multicolumn{3}{|l|}{ Risk of bias } \\
\hline Bias & Authors' judgement & Support for judgement \\
\hline $\begin{array}{l}\text { Random } \\
\text { sequence } \\
\text { generation } \\
\text { (selection bias) }\end{array}$ & Unclear risk & $\begin{array}{l}\text { Sequence generation is not described explicitly in } \\
\text { the paper }\end{array}$ \\
\hline $\begin{array}{l}\text { Allocation } \\
\text { concealment } \\
\text { (selection bias) }\end{array}$ & Unclear risk & $\begin{array}{l}\text { Allocation concealment is not described explicitly in } \\
\text { the paper }\end{array}$ \\
\hline $\begin{array}{l}\text { Blinding } \\
\text { (performance } \\
\text { bias and } \\
\text { detection bias) } \\
\text { Participants }\end{array}$ & Unclear risk & This study did not assess this item. \\
\hline $\begin{array}{l}\text { Blinding } \\
\text { (performance } \\
\text { bias and } \\
\text { detection bias) } \\
\text { Providers }\end{array}$ & Unclear risk & This study did not assess this item. \\
\hline $\begin{array}{l}\text { Blinding } \\
\text { (performance } \\
\text { bias and } \\
\text { detection bias) } \\
\text { Outcome } \\
\text { assessors }\end{array}$ & Unclear risk & This study did not assess this item. \\
\hline $\begin{array}{l}\text { Incomplete } \\
\text { outcome data } \\
\text { (attrition bias) } \\
\text { All outcomes }\end{array}$ & Low risk & No missing data. \\
\hline $\begin{array}{l}\text { Selective } \\
\text { reporting } \\
\text { (reporting bias) }\end{array}$ & High risk & No protocol. Diet adherence is not clearly defined. \\
\hline
\end{tabular}




\begin{tabular}{|c|c|c|}
\hline Other bias & High risk & $\begin{array}{l}\text { Baseline comparisons between groups are not } \\
\text { reported. Diet adherence is not clearly defined }\end{array}$ \\
\hline \multicolumn{3}{|l|}{ Cummings 1981} \\
\hline Methods & \multicolumn{2}{|c|}{ Study design: randomized controlled trial with three intervention groups and one control group } \\
\hline Participants & \multicolumn{2}{|c|}{$\begin{array}{l}\text { Setting: outpatient } \\
\text { Country: United States } \\
\text { Chronic disease: renal failure (management) } \\
\text { Type of participants: clients ( }=116) \\
\text { Mean age: intervention and control groups (54.8) } \\
\text { Sex: intervention and control (F: } 46 \%, \text { M: } 54 \%) \\
\text { Ethnicity: intervention and control groups (50\% White) }\end{array}$} \\
\hline Interventions & \multicolumn{2}{|c|}{$\begin{array}{l}\text { Group 1: single intervention: incentivisation (contract with reward); } 6 \text { weeks; }(\mathrm{n}=29) \\
\text { A behavioural contract was formulated and consisted of: identifying a behaviour or set of } \\
\text { behaviours to be targeted for change in the contract; negotiating with the client a timetable for the } \\
\text { accomplishment of the specified behaviours, how should the degree of accomplishment be } \\
\text { evaluated, what rewards would be received for appropriate behaviours, when the client would be } \\
\text { rewarded; writing out a formal agreement which was subsequently signed by both the nurse and } \\
\text { the client; maintaining a record of each client's progress. } \\
\text { Group 2: multiple intervention: Incentivisation (contract with reward) and persuasion (involvement } \\
\text { of a family member or friend) }(\mathrm{n}=29) \\
\text { A behavioural contract was formulated and consisted of: identifying a behaviour or set of } \\
\text { behaviours to be targeted for change in the contract; negotiating with the client a timetable for the } \\
\text { accomplishment of the specified behaviours, how should the degree of accomplishment be } \\
\text { evaluated, what rewards would be received for appropriate behaviours, when the client would be } \\
\text { rewarded; writing out a formal agreement which was subsequently signed by both the nurse and } \\
\text { the client; maintaining a record of each client's progress. Moreover, a third person selected by the } \\
\text { patient participated in the contract agreement along with the patient and the nurse. } \\
\text { Group 3: single intervention: education (telephone follow-up); } 6 \text { weeks; }(\mathrm{n}=29) \\
\text { Weekly, clients were contacted by telephone. Telephone follow-up consisted of: gathering } \\
\text { information from clients regarding problems they might be having in following their treatment } \\
\text { instructions; providing information to clients about such things as the potential negative health } \\
\text { consequences of not adhering to therapy, the benefits to be derived from following treatment } \\
\text { instructions, and things the clients could do to achieve better compliance; providing verbal support } \\
\text { to clients for maintaining proper adherence to treatment } \\
\text { Group } 4 \text { : control (no contract or telephone follow-up); } 6 \text { weeks, }(n=29)\end{array}$} \\
\hline Outcomes & \multicolumn{2}{|c|}{$\begin{array}{l}\text { Measurement of diet adherence: adherence to potassium-restricted diet and fluid-restricted diet } \\
\text { assessed by serum potassium level and weight gain between dialysis treatments (baseline, } 6 \text { weeks, } \\
3 \text { months) }\end{array}$} \\
\hline Notes & \multicolumn{2}{|c|}{$\begin{array}{l}\text { Dietary advice: potassium-restricted diet and fluid-restricted diet } \\
\text { Drop-out rate: } 25 \% \text { (calculated) } \\
\text { Providers: nurses }\end{array}$} \\
\hline \multicolumn{3}{|l|}{ Risk of bias } \\
\hline Bias & Authors' judgement & Support for judgement \\
\hline $\begin{array}{l}\text { Random } \\
\text { sequence } \\
\text { generation } \\
\text { (selection bias) }\end{array}$ & Low risk & $\begin{array}{l}\text { Sequence generation using a computer random } \\
\text { number generator }\end{array}$ \\
\hline $\begin{array}{l}\text { Allocation } \\
\text { concealment } \\
\text { (selection bias) }\end{array}$ & High risk & Allocation concealment using case record number. \\
\hline $\begin{array}{l}\text { Blinding } \\
\text { (performance } \\
\text { bias and } \\
\text { detection bias) } \\
\text { Participants }\end{array}$ & Unclear risk & This study did not assess this item. \\
\hline $\begin{array}{l}\text { Blinding } \\
\text { (performance } \\
\text { bias and } \\
\text { detection bias) } \\
\text { Providers }\end{array}$ & Unclear risk & This study did not assess this item. \\
\hline $\begin{array}{l}\text { Blinding } \\
\text { (performance } \\
\text { bias and } \\
\text { detection bias) }\end{array}$ & Unclear risk & This study did not assess this item. \\
\hline
\end{tabular}

Cochrane Database Syst Rev. Author manuscript; available in PMC 2016 June 09. 


\begin{tabular}{|c|c|c|}
\hline \multicolumn{3}{|l|}{$\begin{array}{l}\text { Outcome } \\
\text { assessors }\end{array}$} \\
\hline $\begin{array}{l}\text { Incomplete } \\
\text { outcome data } \\
\text { (attrition bias) } \\
\text { All outcomes }\end{array}$ & High risk & $\begin{array}{l}\text { Plausible effect size among missing outcomes } \\
\text { enough to have a clinically-relevant impact on } \\
\text { observed effect size }\end{array}$ \\
\hline $\begin{array}{l}\text { Selective } \\
\text { reporting } \\
\text { (reporting bias) }\end{array}$ & Unclear risk & No protocol. \\
\hline Other bias & Low risk & $\begin{array}{l}\text { Baseline imbalance between groups but the authors } \\
\text { adjusted for initial group differences. Diet adherence } \\
\text { is assessed by objective measures }\end{array}$ \\
\hline \multicolumn{3}{|l|}{ French 2008} \\
\hline Methods & \multicolumn{2}{|c|}{ Study design: randomized controlled trial with two intervention groups and one usual care group } \\
\hline Participants & \multicolumn{2}{|c|}{$\begin{array}{l}\text { Setting: outpatient } \\
\text { Country: United Kingdom } \\
\text { Chronic disease: type II diabetes (management) } \\
\text { Type of participants: clients }(\mathrm{n}=453) \\
\text { Mean age: intervention and usual care groups }(65.9 \pm 10) \\
\text { Sex: intervention and usual care groups (F: } 41.3 \%, \mathrm{M}: 58.7 \%) \\
\text { Ethnicity: not known }\end{array}$} \\
\hline Interventions & \multicolumn{2}{|c|}{$\begin{array}{l}\text { Group 1: Single intervention: training (feedback); } 1 \text { year; }(\mathrm{n}=150) \\
\text { LESS INTENSIVE INTERVENTION: clients were asked to use a blood glucose meter to record } \\
\text { three fasting, pre-meal or two hour post meal readings on two days during the week. Treatment } \\
\text { targets of fasting and pre-meal levels were given } \\
\text { Group 2: Single intervention: training (feedback); } 1 \text { year; }(\mathrm{n}=151) \\
\text { MOST INTENSIVE INTERVENTION: clients were asked to use a blood glucose meter to record } \\
\text { three fasting, pre-meal or two hour post meal readings on two days during the week. Treatment } \\
\text { targets of fasting and pre-meal levels were given and clients were trained in interpretation of } \\
\text { results. Clients were also asked to view persistently elevated levels as a prompt to set new goals for } \\
\text { behaviour change. } \\
\text { Group 3: usual care (no feedback); } 1 \text { year; }(\mathrm{n}=152)\end{array}$} \\
\hline Outcomes & \multicolumn{2}{|c|}{$\begin{array}{l}\text { Measurement of diet adherence: adherence to the general diet and the specific diet items } \\
\text { concerning fruit and vegetables as well as high-fat foods assessed by the Summary of Diabetes } \\
\text { Self-Care Activities (baseline, } 12 \text { months) }\end{array}$} \\
\hline Notes & \multicolumn{2}{|c|}{$\begin{array}{l}\text { Dietary advice: not known } \\
\text { Drop-out rate: } 25.2 \% \\
\text { Providers: nurses }\end{array}$} \\
\hline \multicolumn{3}{|l|}{ Risk of bias } \\
\hline Bias & Authors' judgement & Support for judgement \\
\hline $\begin{array}{l}\text { Random } \\
\text { sequence } \\
\text { generation } \\
\text { (selection bias) }\end{array}$ & Low risk & $\begin{array}{l}\text { "(...) using a partial minimisation procedure to } \\
\text { adjust the randomisation probabilities between } \\
\text { groups to balance important covariates (...) using a } \\
\text { computer programme" }\end{array}$ \\
\hline $\begin{array}{l}\text { Allocation } \\
\text { concealment } \\
\text { (selection bias) }\end{array}$ & Unclear risk & $\begin{array}{l}\text { Allocation concealment is not described explicitly in } \\
\text { the paper }\end{array}$ \\
\hline $\begin{array}{l}\text { Blinding } \\
\text { (performance } \\
\text { bias and } \\
\text { detection bias) } \\
\text { Participants }\end{array}$ & Unclear risk & This study did not assess this item. \\
\hline $\begin{array}{l}\text { Blinding } \\
\text { (performance } \\
\text { bias and } \\
\text { detection bias) } \\
\text { Providers }\end{array}$ & Unclear risk & This study did not assess this item. \\
\hline $\begin{array}{l}\text { Blinding } \\
\text { (performance } \\
\text { bias and } \\
\text { detection bias) }\end{array}$ & Low risk & $\begin{array}{l}\text { Questionnaire responses were entered onto computer } \\
\text { by staff unaware of intervention allocation }\end{array}$ \\
\hline
\end{tabular}

Cochrane Database Syst Rev. Author manuscript; available in PMC 2016 June 09. 


\begin{tabular}{|c|c|c|}
\hline \multicolumn{3}{|l|}{$\begin{array}{l}\text { Outcome } \\
\text { assessors }\end{array}$} \\
\hline $\begin{array}{l}\text { Incomplete } \\
\text { outcome data } \\
\text { (attrition bias) } \\
\text { All outcomes }\end{array}$ & Unclear risk & $\begin{array}{l}\text { Insufficient reporting of attrition to permit } \\
\text { judgement. }\end{array}$ \\
\hline $\begin{array}{l}\text { Selective } \\
\text { reporting } \\
\text { (reporting bias) }\end{array}$ & Low risk & $\begin{array}{l}\text { The study protocol is available and all of the study's } \\
\text { pre-specified outcomes that are of interest in the } \\
\text { review have been reported in the pre-specified way }\end{array}$ \\
\hline Other bias & High risk & $\begin{array}{l}\text { Baseline comparisons between groups are not } \\
\text { reported. Diet adherence is assessed by self-reported } \\
\text { measure (SDSCA). The Cronbach's alpha for the } \\
\text { Summary of Diabetes Self-Care Activities (SDSCA) } \\
\text { (specific diet) was low } 0.08\end{array}$ \\
\hline \multicolumn{3}{|l|}{ Gans 1994} \\
\hline Methods & \multicolumn{2}{|c|}{ Study design: randomized controlled trial with three intervention groups and one usual care group } \\
\hline Participants & \multicolumn{2}{|c|}{ 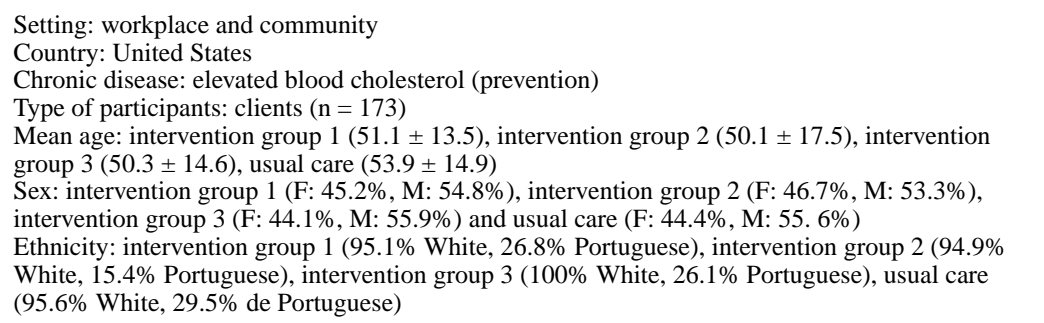 } \\
\hline Interventions & \multicolumn{2}{|c|}{$\begin{array}{l}\text { Group 1: single intervention: persuasion (reminder); once; (completers: } \mathrm{n}=42 \text { ) } \\
\text { Clients received a mailed personalized letter including their blood cholesterol level, a reminder to } \\
\text { see their physician, a list of the specific lifestyle goals, the subject set at the community-based } \\
\text { blood cholesterol Screening, Counseling, Referral Events (SCORE), and a Pawtucket Heart Health } \\
\text { Program magnet for refrigerator. } \\
\text { Group 2: single intervention: persuasion (reminder); once; (completers: } \mathrm{n}=39 \text { ) } \\
\text { Physician received a mailed packet including a letter stating that their patient had been referred on } \\
\text { the basis of their blood cholesterol level and coronary heart disease risk factors. There was a } \\
\text { listing of the lifestyle goals the subject set at the SCORE, National Cholesterol Education Program } \\
\text { (NCEP) guidelines and a reminder postcard (preaddressed to the client) which the physician could } \\
\text { mail to the client. } \\
\text { Group 3: single intervention: persuasion (reminder); once; (completers: } \mathrm{n}=47 \text { ) } \\
\text { Clients received a mailed personalized letter including their blood cholesterol level, a reminder to } \\
\text { see their physician, a list of the specific lifestyle goals, the subject set at the SCORE, and a } \\
\text { Pawtucket Heart Health Program magnet for refrigerator. The physician also received a mailed } \\
\text { packet including a letter setting that their patient had been referred on the basis of their blood } \\
\text { cholesterol level and coronary heart disease risk factors. There was a listing of the lifestyle goals } \\
\text { the subject set at the SCORE, NCEP guidelines and a reminder postcard (preaddressed to the } \\
\text { client) which the physician could mail to the client. } \\
\text { Group 4: usual care (no reminder); once; (completers: } \mathrm{n}=45 \text { ) }\end{array}$} \\
\hline Outcomes & \multicolumn{2}{|c|}{$\begin{array}{l}\text { Measurement of diet adherence: adherence to dietary advice assessed by a telephone questionnaire } \\
\text { (baseline, } 3 \text { months) }\end{array}$} \\
\hline Notes & \multicolumn{2}{|c|}{$\begin{array}{l}\text { Dietary advice: not known } \\
\text { Drop-out rate: not known } \\
\text { Providers: physicians }\end{array}$} \\
\hline \multicolumn{3}{|l|}{ Risk of bias } \\
\hline Bias & Authors' judgement & Support for judgement \\
\hline $\begin{array}{l}\text { Random } \\
\text { sequence } \\
\text { generation } \\
\text { (selection bias) }\end{array}$ & Unclear risk & $\begin{array}{l}\text { Sequence generation is not described explicitly in } \\
\text { the paper }\end{array}$ \\
\hline $\begin{array}{l}\text { Allocation } \\
\text { concealment } \\
\text { (selection bias) }\end{array}$ & Unclear risk & $\begin{array}{l}\text { Allocation concealment is not described explicitly in } \\
\text { the paper }\end{array}$ \\
\hline $\begin{array}{l}\text { Blinding } \\
\text { (performance }\end{array}$ & Unclear risk & This study did not assess this item. \\
\hline
\end{tabular}

Cochrane Database Syst Rev. Author manuscript; available in PMC 2016 June 09. 


\begin{tabular}{|c|c|c|}
\hline $\begin{array}{l}\text { bias and } \\
\text { detection bias) } \\
\text { Participants }\end{array}$ & & \\
\hline $\begin{array}{l}\text { Blinding } \\
\text { (performance } \\
\text { bias and } \\
\text { detection bias) } \\
\text { Providers }\end{array}$ & Unclear risk & This study did not assess this item. \\
\hline $\begin{array}{l}\text { Blinding } \\
\text { (performance } \\
\text { bias and } \\
\text { detection bias) } \\
\text { Outcome } \\
\text { assessors }\end{array}$ & Unclear risk & This study did not assess this item. \\
\hline $\begin{array}{l}\text { Incomplete } \\
\text { outcome data } \\
\text { (attrition bias) } \\
\text { All outcomes }\end{array}$ & Unclear risk & $\begin{array}{l}\text { Insufficient reporting of attrition to permit } \\
\text { judgement. }\end{array}$ \\
\hline $\begin{array}{l}\text { Selective } \\
\text { reporting } \\
\text { (reporting bias) }\end{array}$ & Unclear risk & No protocol. \\
\hline Other bias & High risk & $\begin{array}{l}\text { Baseline balance between groups. Diet adherence is } \\
\text { assessed by self-reported measure. Validation and } \\
\text { reliability of self-reported diet adherence are not } \\
\text { reported. The time interval between SCORE and } \\
\text { survey varied between subject and could influenced } \\
\text { results }\end{array}$ \\
\hline \multicolumn{3}{|l|}{ Gill 2010} \\
\hline Methods & \multicolumn{2}{|c|}{ Study design: randomized controlled trial with one intervention group and one control group } \\
\hline Participants & \multicolumn{2}{|c|}{$\begin{array}{l}\text { Setting: research center } \\
\text { Country: United States } \\
\text { Chronic disease: overweight and obesity (prevention/management) } \\
\text { Type of participants: clients }(\mathrm{n}=64) \\
\text { Mean age: intervention }(19.1 \pm 1.0) \text {, control }(19.1 \pm 1.0) \\
\text { Sex: intervention and control groups (F: } 100 \%) \\
\text { Ethnicity: intervention (70\% White, 10\% African American, 10\% Latina/Hispanic, 10\% Other), } \\
\text { control (66\% White, 17\% African American, 14\% Latina/Hispanic, 3\% Other) }\end{array}$} \\
\hline Interventions & \multicolumn{2}{|c|}{$\begin{array}{l}\text { Group 1: single intervention: education (group sessions); } 8 \text { weeks; }(\mathrm{n}=32) \\
\text { Participants attended a weekly education group sessions run by a dietitian and an exercise } \\
\text { physiologist. } \\
\text { Group 2: control (no education group sessions); } 8 \text { weeks; }(\mathrm{n}=32)\end{array}$} \\
\hline Outcomes & \multicolumn{2}{|c|}{$\begin{array}{l}\text { Measurement of diet adherence: adherence to Dietary Approaches to Stop Hypertension (DASH) } \\
\text { diet assessed by the DASH Diet Index (baseline, } 8 \text { weeks) }\end{array}$} \\
\hline Notes & \multicolumn{2}{|c|}{$\begin{array}{l}\text { Dietary advice: DASH diet and hypocaloric diet } \\
\text { Drop-out rate: not known } \\
\text { Providers: dietitian and exercise physiologist }\end{array}$} \\
\hline \multicolumn{3}{|l|}{ Risk of bias } \\
\hline Bias & Authors' judgement & Support for judgement \\
\hline $\begin{array}{l}\text { Random } \\
\text { sequence } \\
\text { generation } \\
\text { (selection bias) }\end{array}$ & Low risk & $\begin{array}{l}\text { Sequence generation using a computer random } \\
\text { number generator }\end{array}$ \\
\hline $\begin{array}{l}\text { Allocation } \\
\text { concealment } \\
\text { (selection bias) }\end{array}$ & Unclear risk & $\begin{array}{l}\text { Allocation concealment is not described explicitly in } \\
\text { the paper }\end{array}$ \\
\hline $\begin{array}{l}\text { Blinding } \\
\text { (performance } \\
\text { bias and } \\
\text { detection bias) } \\
\text { Participants }\end{array}$ & Unclear risk & This study did not assess this item. \\
\hline
\end{tabular}




\begin{tabular}{|c|c|c|}
\hline $\begin{array}{l}\text { Blinding } \\
\text { (performance } \\
\text { bias and } \\
\text { detection bias) } \\
\text { Providers }\end{array}$ & Unclear risk & This study did not assess this item. \\
\hline $\begin{array}{l}\text { Blinding } \\
\text { (performance } \\
\text { bias and } \\
\text { detection bias) } \\
\text { Outcome } \\
\text { assessors }\end{array}$ & Unclear risk & This study did not assess this item. \\
\hline $\begin{array}{l}\text { Incomplete } \\
\text { outcome data } \\
\text { (attrition bias) } \\
\text { All outcomes }\end{array}$ & Unclear risk & $\begin{array}{l}\text { Insufficient reporting of attrition to permit } \\
\text { judgement. }\end{array}$ \\
\hline $\begin{array}{l}\text { Selective } \\
\text { reporting } \\
\text { (reporting bias) }\end{array}$ & Unclear risk & No protocol. \\
\hline Other bias & Unclear risk & $\begin{array}{l}\text { Baseline balance between groups not reported. Diet } \\
\text { adherence is assessed by self-reported measure. } \\
\text { Validation and reliability of self-reported diet } \\
\text { adherence are not reported }\end{array}$ \\
\hline \multicolumn{3}{|l|}{ Grace 1996} \\
\hline Methods & \multicolumn{2}{|c|}{ Study design: randomized controlled trial with one intervention group and one control group } \\
\hline Participants & \multicolumn{2}{|c|}{$\begin{array}{l}\text { Setting: outpatient } \\
\text { Country: United Kingdom } \\
\text { Chronic disease: hyperlipidaemia (prevention) } \\
\text { Type of participants: clients ( }=13 \text { ) } \\
\text { Mean age: not known } \\
\text { Sex: intervention group (F: } 25 \%, \text { M: } 75 \% \text { ) and control group (F: } 40 \%, \text { M: } 60 \%) \\
\text { Ethnicity: intervention and control groups (100\% Caucasian) }\end{array}$} \\
\hline Interventions & \multicolumn{2}{|c|}{$\begin{array}{l}\text { Group 1: single intervention: modelling (nutritional tools); once; }(\mathrm{n}=8) \\
\text { Clients received standard low-fat dietary advice with an additional package containing details on } \\
\text { improving the practical implementation of a low-fat diet, such as low-fat cooking methods, low-fat } \\
\text { recipe adaptation and eating out on a low-fat diet. } \\
\text { Group 2: control (standard dietary advice with no information package); duration: not known; ( }= \\
\text { 5) }\end{array}$} \\
\hline Outcomes & \multicolumn{2}{|c|}{$\begin{array}{l}\text { Measurement of diet adherence: adherence to total daily energy intake and proportion of energy } \\
\text { from fat assessed by a food-frequency questionnaire (baseline, } 12 \text { weeks) }\end{array}$} \\
\hline Notes & \multicolumn{2}{|c|}{$\begin{array}{l}\text { Dietary advice: low-fat diet } \\
\text { Drop-out rate: } 0 \% \text { (calculated) } \\
\text { Providers: not known }\end{array}$} \\
\hline \multicolumn{3}{|l|}{ Risk of bias } \\
\hline Bias & Authors' judgement & Support for judgement \\
\hline $\begin{array}{l}\text { Random } \\
\text { sequence } \\
\text { generation } \\
\text { (selection bias) }\end{array}$ & Unclear risk & $\begin{array}{l}\text { Sequence generation is not described explicitly in } \\
\text { the paper }\end{array}$ \\
\hline $\begin{array}{l}\text { Allocation } \\
\text { concealment } \\
\text { (selection bias) }\end{array}$ & Unclear risk & $\begin{array}{l}\text { Allocation concealment is not described explicitly in } \\
\text { the paper }\end{array}$ \\
\hline $\begin{array}{l}\text { Blinding } \\
\text { (performance } \\
\text { bias and } \\
\text { detection bias) } \\
\text { Participants }\end{array}$ & Unclear risk & This study did not assess this item. \\
\hline $\begin{array}{l}\text { Blinding } \\
\text { (performance } \\
\text { bias and } \\
\text { detection bias) } \\
\text { Providers }\end{array}$ & Unclear risk & This study did not assess this item. \\
\hline
\end{tabular}

Cochrane Database Syst Rev. Author manuscript; available in PMC 2016 June 09. 


\begin{tabular}{|c|c|c|}
\hline $\begin{array}{l}\text { Blinding } \\
\text { (performance } \\
\text { bias and } \\
\text { detection bias) } \\
\text { Outcome } \\
\text { assessors }\end{array}$ & Unclear risk & This study did not assess this item. \\
\hline $\begin{array}{l}\text { Incomplete } \\
\text { outcome data } \\
\text { (attrition bias) } \\
\text { All outcomes }\end{array}$ & Unclear risk & $\begin{array}{l}\text { Insufficient reporting of attrition to permit } \\
\text { judgement. }\end{array}$ \\
\hline $\begin{array}{l}\text { Selective } \\
\text { reporting } \\
\text { (reporting bias) }\end{array}$ & High risk & $\begin{array}{l}\text { No protocol. Body mass index is reported } \\
\text { incompletely. Diet adherence is not clearly defined }\end{array}$ \\
\hline Other bias & High risk & $\begin{array}{l}\text { Baseline imbalance between groups (\% fat). Diet } \\
\text { adherence is not clearly defined }\end{array}$ \\
\hline \multicolumn{3}{|l|}{ Gucciardi 2007} \\
\hline Methods & \multicolumn{2}{|c|}{ Study design: randomized controlled trial with one intervention and one control group } \\
\hline Participants & \multicolumn{2}{|c|}{$\begin{array}{l}\text { Setting: outpatient } \\
\text { Country: Canada } \\
\text { Chronic disease: type II diabetes (management) } \\
\text { Type of participants: clients }(\mathrm{n}=87) \\
\text { Mean age: intervention }(60.4 \pm 7.9) \text {, control }(59.0 \pm 12.1) \\
\text { Sex: intervention (F: } 68 \%, \text { M: } 32 \% \text { ) and control (F: } 69.4 \%, \text { M: } 30.6 \%) \\
\text { Ethnicity: intervention and control groups (100\% Portuguese) }\end{array}$} \\
\hline Interventions & \multicolumn{2}{|c|}{$\begin{array}{l}\text { Group 1: multiple intervention: group sessions + barrier identification/problem solving + } \\
\text { nutritional tools; } 3 \text { months; }(\mathrm{n}=41) \\
\text { The education intervention lasted } 15 \text { hrs over three consecutive weekdays in which didactic } \\
\text { methods, mutual goal setting, situational problem solving, cognitive reframing and role-playing } \\
\text { methods were used. Some nutritional tools were provided such as food models, kitchen } \\
\text { demonstration, real food samples and food product labels. } \\
\text { Group 2: control; } 3 \text { months; }(\mathrm{n}=46) \\
\text { Clients met the dietitian individually. }\end{array}$} \\
\hline Outcomes & \multicolumn{2}{|c|}{$\begin{array}{l}\text { Measurement of diet adherence: adherence to dietary advice assessed by the Summary of diabetes } \\
\text { Self-care activities Questionnaire (baseline, } 3 \text { months) }\end{array}$} \\
\hline Notes & \multicolumn{2}{|c|}{$\begin{array}{l}\text { Dietary advice: based on an assessment of clients' metabolic profile and on existing comorbidities } \\
\text { such as renal nephropathy or gastrointestinal complications: } 1 \text { ) a limited and consistent intake of } \\
\text { carbohydrates at each meal; 2) an adequate daily intake of fruit and vegetables; 3) a lower intake } \\
\text { of saturated fat; 4) a reduced fat in cooking } \\
\text { Drop-out rate: } 29.9 \% \text { (calculated) } \\
\text { Providers: dietitian, nurse, pharmacist, physiotherapist }\end{array}$} \\
\hline \multicolumn{3}{|l|}{ Risk of bias } \\
\hline Bias & Authors' judgement & Support for judgement \\
\hline $\begin{array}{l}\text { Random } \\
\text { sequence } \\
\text { generation } \\
\text { (selection bias) }\end{array}$ & Low risk & $\begin{array}{l}\text { "Participants were randomly assigned (generated } \\
\text { random number list)..." }\end{array}$ \\
\hline $\begin{array}{l}\text { Allocation } \\
\text { concealment } \\
\text { (selection bias) }\end{array}$ & High risk & $\begin{array}{l}\text { Allocation concealment using an open random } \\
\text { allocation schedule (list of random numbers) }\end{array}$ \\
\hline $\begin{array}{l}\text { Blinding } \\
\text { (performance } \\
\text { bias and } \\
\text { detection bias) } \\
\text { Participants }\end{array}$ & Unclear risk & This study did not assess this item. \\
\hline $\begin{array}{l}\text { Blinding } \\
\text { (performance } \\
\text { bias and } \\
\text { detection bias) } \\
\text { Providers }\end{array}$ & Low risk & $\begin{array}{l}\text { "DEC (Diabetes Education Centre) providers were } \\
\text { also blinded to patients' research participation status } \\
\text { and were caring for all the participants regardless of } \\
\text { the intervention assignment" }\end{array}$ \\
\hline $\begin{array}{l}\text { Blinding } \\
\text { (performance }\end{array}$ & Low risk & $\begin{array}{l}\text { "The research assistants were blinded to } \\
\text { participants' intervention status." }\end{array}$ \\
\hline
\end{tabular}

Cochrane Database Syst Rev. Author manuscript; available in PMC 2016 June 09. 


\begin{tabular}{|c|c|c|}
\hline $\begin{array}{l}\text { bias and } \\
\text { detection bias) } \\
\text { Outcome } \\
\text { assessors }\end{array}$ & & \\
\hline $\begin{array}{l}\text { Incomplete } \\
\text { outcome data } \\
\text { (attrition bias) } \\
\text { All outcomes }\end{array}$ & High risk & $\begin{array}{l}\text { Plausible effect size among missing outcomes } \\
\text { enough to have a clinically-relevant impact on } \\
\text { observed effect size }\end{array}$ \\
\hline $\begin{array}{l}\text { Selective } \\
\text { reporting } \\
\text { (reporting bias) }\end{array}$ & Unclear risk & No protocol. \\
\hline Other bias & Low risk & $\begin{array}{l}\text { Baseline balance between groups. Diet adherence is } \\
\text { assessed by self-reported measure (validated } \\
\text { Summary of Diabetes Self-care Activities } \\
\text { Questionnaire) }\end{array}$ \\
\hline \multicolumn{3}{|l|}{ Hsueh 2007} \\
\hline Methods & \multicolumn{2}{|c|}{ Study design: randomized controlled trial with two intervention groups } \\
\hline Participants & \multicolumn{2}{|c|}{$\begin{array}{l}\text { Setting: research center } \\
\text { Country: United States } \\
\text { Chronic disease: irritable bowel syndrome (management) } \\
\text { Type of participants: clients ( }=81) \\
\text { Mean age: intervention group 1 }(45.8 \pm 14.1) \text {, intervention group } 2(46.1 \pm 14.5) \\
\text { Sex: intervention group 1 (F: } 82.1 \%, \mathrm{M}: 17.9 \%) \text { and intervention group } 2 \text { (F: } 88.1 \%, \mathrm{M}: 11.9 \%) \\
\text { Ethnicity: intervention group 1 (87.2\% White, 0\% African American, 5.1\% Asian/ Indian, 7.7\% } \\
\text { Native American), intervention group 2 (83.3\% White, 4.8\% African American, 9.5\% Asian/ } \\
\text { Indian, 0\% Native American, 2.4\% Unknown) }\end{array}$} \\
\hline Interventions & \multicolumn{2}{|c|}{$\begin{array}{l}\text { Group 1: single intervention: education (individual sessions with a nurse); } 9 \text { weeks; }(\mathrm{n}=\text { not } \\
\text { known) } \\
\text { The intervention included } 9 \text { hours of face-to-face sessions in which the nurse reviewed the } \\
\text { previous homework assignment and discussed how to individualize dietary modifications. } \\
\text { Group 2: multiple intervention: individual sessions with a nurse + telephone follow-up; } 9 \text { weeks; } \\
(\mathrm{n}=\text { not known) } \\
\text { The intervention included two face-to-face sessions, six telephone sessions and one final face-to- } \\
\text { face session in which the nurse reviewed the previous homework assignment and discussed how to } \\
\text { individualize dietary modifications }\end{array}$} \\
\hline Outcomes & \multicolumn{2}{|c|}{$\begin{array}{l}\text { Measurement of diet adherence: adherence to American Dietetic Association recommendations for } \\
\text { fiber intake (more than } 20 \text { g/day) and Food Guide Pyramid for fruit intake (more than } 2 \text { servings/ } \\
\text { day) and vegetable intake (more than } 3 \text { servings /day) assessed by a food-frequency questionnaire } \\
\text { (baseline, } 3 \text { months, } 6 \text { months) }\end{array}$} \\
\hline Notes & \multicolumn{2}{|c|}{$\begin{array}{l}\text { Dietary advice: individualized based on the symptoms: } 25 \mathrm{~g} \text { of fiber/day in constipation- } \\
\text { predominant and } 20 \mathrm{~g} \text { of fiber/day for diarrhoea-predominant } \\
\text { Drop-out rate: not known } \\
\text { Providers: research nurses } \\
\text { A usual care group was included in this study. Since no active treatment was provided in the usual } \\
\text { care group, this group was not described in the Cochrane review }\end{array}$} \\
\hline \multicolumn{3}{|l|}{ Risk of bias } \\
\hline Bias & Authors' judgement & Support for judgement \\
\hline $\begin{array}{l}\text { Random } \\
\text { sequence } \\
\text { generation } \\
\text { (selection bias) }\end{array}$ & Low risk & $\begin{array}{l}\text { “(...) participants were randomly assigned using a } \\
\text { customized computer program (...)" }\end{array}$ \\
\hline $\begin{array}{l}\text { Allocation } \\
\text { concealment } \\
\text { (selection bias) }\end{array}$ & Unclear risk & $\begin{array}{l}\text { Allocation concealment is not described explicitly in } \\
\text { the paper }\end{array}$ \\
\hline $\begin{array}{l}\text { Blinding } \\
\text { (performance } \\
\text { bias and } \\
\text { detection bias) } \\
\text { Participants }\end{array}$ & Unclear risk & This study did not assess this item. \\
\hline $\begin{array}{l}\text { Blinding } \\
\text { (performance } \\
\text { bias and } \\
\text { detection bias) }\end{array}$ & Unclear risk & This study did not assess this item. \\
\hline
\end{tabular}

Cochrane Database Syst Rev. Author manuscript; available in PMC 2016 June 09. 


\begin{tabular}{|c|c|c|}
\hline Providers & & \\
\hline $\begin{array}{l}\text { Blinding } \\
\text { (performance } \\
\text { bias and } \\
\text { detection bias) } \\
\text { Outcome } \\
\text { assessors }\end{array}$ & Unclear risk & This study did not assess this item. \\
\hline $\begin{array}{l}\text { Incomplete } \\
\text { outcome data } \\
\text { (attrition bias) } \\
\text { All outcomes }\end{array}$ & Unclear risk & $\begin{array}{l}\text { Insufficient reporting of attrition to permit } \\
\text { judgement. }\end{array}$ \\
\hline $\begin{array}{l}\text { Selective } \\
\text { reporting } \\
\text { (reporting bias) }\end{array}$ & Unclear risk & No protocol. \\
\hline Other bias & High risk & $\begin{array}{l}\text { Baseline imbalance between groups (fiber, } \\
\text { vegetables and fruit). Diet adherence is assessed by } \\
\text { self-reported measure (validated food frequency } \\
\text { questionnaire) }\end{array}$ \\
\hline \multicolumn{3}{|l|}{ Hyman 2007} \\
\hline Methods & \multicolumn{2}{|c|}{ Study design: randomized controlled trial with two intervention groups and one usual care group } \\
\hline Participants & \multicolumn{2}{|c|}{$\begin{array}{l}\text { Setting: outpatient } \\
\text { Country: United States } \\
\text { Chronic disease: hypertension (management) } \\
\text { Type of participants: clients }(\mathrm{n}=281) \\
\text { Mean age: intervention group } 1(53.9 \pm 5.7) \text {, intervention group } 2(53.4 \pm 5.7) \text {, usual care }(52.7 \\
\pm 6.5) \\
\text { Sex: intervention group } 1(\mathrm{~F}: 65.2 \%, \mathrm{M}: 34.8 \%) \text {, intervention group } 2 \text { (F: } 63.5 \%, \mathrm{M}: 36.5 \%) \text {, usual } \\
\text { care (F: } 73.1 \% \text {, M: } 26.9 \%) \\
\text { Ethnicity: intervention and usual care groups (100\% African American) }\end{array}$} \\
\hline Interventions & \multicolumn{2}{|c|}{$\begin{array}{l}\text { Group 1: multiple intervention: telephone follow-up + motivational interviewing; } 18 \text { months; (n = } \\
\text { 92) } \\
\text { SIMULTANEOUS BEHAVIOUR CHANGE: a brief in-clinic session with a health educator was } \\
\text { provided to clients every six months to review the benefits of the recommended three behavioural } \\
\text { changes (stop smoking, reduce dietary sodium level and increase physical activity), the home- } \\
\text { based, self-help (printed manual, motivational video-tape), instructional materials developed to } \\
\text { facilitate behaviour change and the schedule of telephone counselling session. All three behaviours } \\
\text { were reviewed at each clinic session. There were seven telephone follow-ups between each in- } \\
\text { clinic session. } \\
\text { Group 2: multiple intervention: telephone follow-up + motivational interviewing; } 18 \text { months; (n = } \\
\text { 96) } \\
\text { SEQUENTIAL BEHAVIOUR CHANGE: a brief in-clinic session with a health educator was } \\
\text { provided to clients every six months to review the benefits of the recommended behavioural } \\
\text { change (stop smoking, reduce dietary sodium level and increase physical activity), the home- } \\
\text { based, self-help (printed manual, motivational videotape), instructional materials developed to } \\
\text { facilitate behaviour change and the schedule of telephone counselling session. The protocol } \\
\text { addressed a new behaviour every } 6 \text { months. There were seven motivational interviewing telephone } \\
\text { follow-ups between each in-clinic session. } \\
\text { Group 3: usual care (no telephone follow-up); once; (n = 93) } \\
\text { A brief review of educational materials was provided regarding the three targets behaviours (stop } \\
\text { smoking, reduce dietary sodium level and increase physical activity) }\end{array}$} \\
\hline Outcomes & \multicolumn{2}{|c|}{$\begin{array}{l}\text { Measurement of diet adherence: adherence to sodium-restricted diet assessed by } 24 \text {-hr urine } \\
\text { sodium level }<100 \mathrm{mEq} / \mathrm{l} / \mathrm{day} \text { ) (baseline, } 6 \text { months, } 18 \text { months) }\end{array}$} \\
\hline Notes & \multicolumn{2}{|c|}{$\begin{array}{l}\text { Dietary advice: sodium-restricted diet (less than } 100 \mathrm{mEq} / \mathrm{l} / \mathrm{day} \text { (urinary)) } \\
\text { Drop-out rate: } 20.4 \% \\
\text { Provider: health educator }\end{array}$} \\
\hline \multicolumn{3}{|l|}{ Risk of bias } \\
\hline Bias & Authors' judgement & Support for judgement \\
\hline $\begin{array}{l}\text { Random } \\
\text { sequence } \\
\text { generation } \\
\text { (selection bias) }\end{array}$ & Unclear risk & $\begin{array}{l}\text { Sequence generation is not described explicitly in } \\
\text { the paper }\end{array}$ \\
\hline
\end{tabular}

Cochrane Database Syst Rev. Author manuscript; available in PMC 2016 June 09. 


\begin{tabular}{|c|c|c|}
\hline $\begin{array}{l}\text { Allocation } \\
\text { concealment } \\
\text { (selection bias) }\end{array}$ & Unclear risk & $\begin{array}{l}\text { Allocation concealment is not described explicitly in } \\
\text { the paper }\end{array}$ \\
\hline $\begin{array}{l}\text { Blinding } \\
\text { (performance } \\
\text { bias and } \\
\text { detection bias) } \\
\text { Participants }\end{array}$ & Unclear risk & This study did not assess this item. \\
\hline $\begin{array}{l}\text { Blinding } \\
\text { (performance } \\
\text { bias and } \\
\text { detection bias) } \\
\text { Providers }\end{array}$ & Unclear risk & This study did not assess this item. \\
\hline $\begin{array}{l}\text { Blinding } \\
\text { (performance } \\
\text { bias and } \\
\text { detection bias) } \\
\text { Outcome } \\
\text { assessors }\end{array}$ & Unclear risk & This study did not assess this item. \\
\hline $\begin{array}{l}\text { Incomplete } \\
\text { outcome data } \\
\text { (attrition bias) } \\
\text { All outcomes }\end{array}$ & High risk & $\begin{array}{l}\text { The proportion of missing outcomes compared with } \\
\text { observed event risk enough to have a clinically- } \\
\text { relevant impact on the intervention effect estimate }\end{array}$ \\
\hline $\begin{array}{l}\text { Selective } \\
\text { reporting } \\
\text { (reporting bias) }\end{array}$ & High risk & No protocol. Blood glucose is reported incompletely. \\
\hline Other bias & High risk & $\begin{array}{l}\text { Baseline imbalance between groups (diastolic blood } \\
\text { pressure). Diet adherence is assessed by objective } \\
\text { measure. The order in which the behaviors were } \\
\text { introduced to each participant in the sequential } \\
\text { group was randomized to avoid confounding of } \\
\text { outcomes with patient preferences }\end{array}$ \\
\hline \multicolumn{3}{|l|}{ Jiang 2004} \\
\hline Methods & \multicolumn{2}{|c|}{ Study design: randomized controlled trial with one intervention group and one usual care group } \\
\hline Participants & \multicolumn{2}{|c|}{$\begin{array}{l}\text { Setting: outpatient } \\
\text { Country: China } \\
\text { Chronic disease: angina pectoris or myocardial infarction (management) } \\
\text { Type of participants: clients }(\mathrm{n}=167) \\
\text { Mean age: intervention }(62.1 \pm 7.4) \text {, usual care }(61.4 \pm 7.6) \\
\text { Sex: intervention (F: } 31.3 \%, \text { M: } 68.7 \%) \text { and usual care }(\mathrm{F}: 26.2 \%, \text { M: } 73.8 \%) \\
\text { Ethnicity: intervention and usual care groups (100\% Chinese) }\end{array}$} \\
\hline Interventions & \multicolumn{2}{|c|}{$\begin{array}{l}\text { Group 1: multiple intervention: telephone follow-up + individual session with nurse + goal setting; } \\
12 \text { weeks; }(\mathrm{n}=83 \text { ) } \\
\text { After discharge from the hospital, clients received a weekly home visit during the first three weeks } \\
\text { and alternating home visit and telephone follow-up every other week from week } 4 \text { to } 12 \text {. The } \\
\text { cardiac rehabilitation program consisted of: setting of the goals for walking performance, smoking } \\
\text { cessation, Adult Treatment Panel step II (ATP step II) diet adherence and medication adherence; } \\
\text { setting of the goals for cardiac physiological risk control; clients conducted a goal-directed self- } \\
\text { managed rehabilitative care in medication management, angina management, physical exercise, } \\
\text { dietary management and smoking cessation according to the recommended guidelines on a daily } \\
\text { basis; keeping a log record for tracking progress as well as for self-evaluation and self- } \\
\text { reinforcement. } \\
\text { Group 2: usual care (no cardiac rehabilitation program); duration: not known; }(\mathrm{n}=84)\end{array}$} \\
\hline Outcomes & \multicolumn{2}{|c|}{$\begin{array}{l}\text { Measurement of diet adherence: adherence to ATP step II diet assessed by a 3-day food record } \\
\text { (baseline, } 3 \text { months, } 6 \text { months) }\end{array}$} \\
\hline Notes & \multicolumn{2}{|c|}{$\begin{array}{l}\text { Dietary advice: ATP step II diet ( }<8 \% \text { of total energy from saturated fat and }<250 \mathrm{mg} / \mathrm{d} \text { of } \\
\text { cholesterol) } \\
\text { Drop-out rate: } 15.6 \% \text { (calculated) } \\
\text { Provider: cardiac nurse }\end{array}$} \\
\hline \multicolumn{3}{|l|}{ Risk of bias } \\
\hline Bias & Authors' judgement & Support for judgement \\
\hline
\end{tabular}

Cochrane Database Syst Rev. Author manuscript; available in PMC 2016 June 09. 


\begin{tabular}{|c|c|c|}
\hline $\begin{array}{l}\text { Random } \\
\text { sequence } \\
\text { generation } \\
\text { (selection bias) }\end{array}$ & Low risk & $\begin{array}{l}\text { "(...) randomised assignment of subjects into an } \\
\text { intervention group and a control group according to } \\
\text { a computer-generalized random table" }\end{array}$ \\
\hline $\begin{array}{l}\text { Allocation } \\
\text { concealment } \\
\text { (selection bias) }\end{array}$ & Low risk & Allocation concealment using central allocation. \\
\hline $\begin{array}{l}\text { Blinding } \\
\text { (performance } \\
\text { bias and } \\
\text { detection bias) } \\
\text { Participants }\end{array}$ & Unclear risk & This study did not assess this item. \\
\hline $\begin{array}{l}\text { Blinding } \\
\text { (performance } \\
\text { bias and } \\
\text { detection bias) } \\
\text { Providers }\end{array}$ & Unclear risk & This study did not assess this item. \\
\hline $\begin{array}{l}\text { Blinding } \\
\text { (performance } \\
\text { bias and } \\
\text { detection bias) } \\
\text { Outcome } \\
\text { assessors }\end{array}$ & Low risk & $\begin{array}{l}\text { "They (research assistants) were blinded to patient } \\
\text { group assignment" }\end{array}$ \\
\hline $\begin{array}{l}\text { Incomplete } \\
\text { outcome data } \\
\text { (attrition bias) } \\
\text { All outcomes }\end{array}$ & High risk & $\begin{array}{l}\text { The proportion of missing outcomes compared with } \\
\text { observed event risk enough to have a clinically- } \\
\text { relevant impact on the intervention effect estimate }\end{array}$ \\
\hline $\begin{array}{l}\text { Selective } \\
\text { reporting } \\
\text { (reporting bias) }\end{array}$ & High risk & $\begin{array}{l}\text { No protocol. Smoking cessation is reported } \\
\text { incompletely. }\end{array}$ \\
\hline Other bias & Unclear risk & $\begin{array}{l}\text { Baseline balance between groups. Diet adherence is } \\
\text { assessed by self-reported measure. Validation and } \\
\text { reliability of self-reported diet adherence are not } \\
\text { reported }\end{array}$ \\
\hline \multicolumn{3}{|l|}{ Jones 1986} \\
\hline Methods & \multicolumn{2}{|c|}{ Study design: randomized controlled trial with four intervention groups } \\
\hline Participants & \multicolumn{2}{|l|}{$\begin{array}{l}\text { Setting: outpatient } \\
\text { Country: United Kingdom } \\
\text { Chronic disease: overweight (prevention) } \\
\text { Type of patients: clients }(\mathrm{n}=80) \\
\text { Mean age: intervention groups: } 50.3 \pm 13.5 \\
\text { Sex: intervention groups (F: } 100 \%) \\
\text { Ethnicity: not known }\end{array}$} \\
\hline Interventions & \multicolumn{2}{|c|}{$\begin{array}{l}\text { Group 1: single intervention: education (group sessions); } 16 \text { weeks; }(\mathrm{n}=19) \\
\text { Clients met the dietitian every four weeks in small groups of five to seven clients. } \\
\text { Group 2: multiple intervention: individual sessions with a dietitian + teach to use prompts/cues; } 16 \\
\text { weeks; }(\mathrm{n}=20) \\
\text { Clients saw the dietitian every four weeks individually. Clients were provided with one set of } \\
\text { leaflets on each of their first four visits. These provided specific detailed advice on how to reduce } \\
\text { their exposure to food cues by making a variety of changes in their habits, and were based on the } \\
\text { cue avoidance programme and the food management programme. } \\
\text { Group 3: multiple intervention: group sessions + teach to use prompts/cues; } 16 \text { weeks, }(\mathrm{n}=21) \\
\text { Clients met the dietitian every four weeks in small groups of five to seven clients. Clients were } \\
\text { provided with one set of leaflets on each of their first four visits. These provided specific detailed } \\
\text { advice on how to reduce their exposure to food cues by making a variety of changes in their habits, } \\
\text { and were based on the cue avoidance programme and the food management programme. } \\
\text { Group 4: single intervention: education (individual sessions with a dietitian); } 16 \text { weeks; }(\mathrm{n}=20) \\
\text { Clients met the dietitian individually every four weeks. }\end{array}$} \\
\hline Outcomes & \multicolumn{2}{|c|}{ Measurement of diet adherence: adherence to the diet allowance assessed by a diary ( 16 weeks) } \\
\hline Notes & \multicolumn{2}{|c|}{$\begin{array}{l}\text { Dietary advice: energy levels } 1000 \mathrm{kCal} \text { below expected energy requirements, with a minimum of } \\
1000 \mathrm{kCal} / \mathrm{day} \\
\text { Drop-out rate: not known } \\
\text { Providers: dietitians }\end{array}$} \\
\hline
\end{tabular}

Cochrane Database Syst Rev. Author manuscript; available in PMC 2016 June 09. 


\begin{tabular}{|c|c|c|}
\hline & \multicolumn{2}{|c|}{$\begin{array}{l}\text { Four additional groups were included in this study. Since the clients in these groups did not } \\
\text { complete a diary to assess adherence to dietary advice, these four groups were not described in the } \\
\text { Cochrane review }\end{array}$} \\
\hline \multicolumn{3}{|l|}{ Risk of bias } \\
\hline Bias & Authors' judgement & Support for judgement \\
\hline $\begin{array}{l}\text { Random } \\
\text { sequence } \\
\text { generation } \\
\text { (selection bias) }\end{array}$ & Unclear risk & $\begin{array}{l}\text { Sequence generation is not described explicitly in } \\
\text { the paper }\end{array}$ \\
\hline $\begin{array}{l}\text { Allocation } \\
\text { concealment } \\
\text { (selection bias) }\end{array}$ & Unclear risk & $\begin{array}{l}\text { Allocation concealment is not described explicitly in } \\
\text { the paper }\end{array}$ \\
\hline $\begin{array}{l}\text { Blinding } \\
\text { (performance } \\
\text { bias and } \\
\text { detection bias) } \\
\text { Participants }\end{array}$ & Unclear risk & This study did not assess this item. \\
\hline $\begin{array}{l}\text { Blinding } \\
\text { (performance } \\
\text { bias and } \\
\text { detection bias) } \\
\text { Providers }\end{array}$ & Unclear risk & This study did not assess this item. \\
\hline $\begin{array}{l}\text { Blinding } \\
\text { (performance } \\
\text { bias and } \\
\text { detection bias) } \\
\text { Outcome } \\
\text { assessors }\end{array}$ & Unclear risk & This study did not assess this item. \\
\hline $\begin{array}{l}\text { Incomplete } \\
\text { outcome data } \\
\text { (attrition bias) } \\
\text { All outcomes }\end{array}$ & High risk & $\begin{array}{l}\text { Plausible effect size among missing outcomes } \\
\text { enough to have a clinically-relevant impact on } \\
\text { observed effect size }\end{array}$ \\
\hline $\begin{array}{l}\text { Selective } \\
\text { reporting } \\
\text { (reporting bias) }\end{array}$ & Unclear risk & No protocol. \\
\hline Other bias & Unclear risk & $\begin{array}{l}\text { Baseline comparisons between groups are not } \\
\text { reported. Diet adherence is assessed by self-reported } \\
\text { measure. Validation and reliability of self-reported } \\
\text { diet adherence are not reported }\end{array}$ \\
\hline \multicolumn{3}{|l|}{ Kendall 1987} \\
\hline Methods & \multicolumn{2}{|c|}{ Study design: randomized controlled trial with two intervention groups } \\
\hline Participants & \multicolumn{2}{|c|}{$\begin{array}{l}\text { Setting: outpatient } \\
\text { Country: United States } \\
\text { Chronic disease: non-insulin-dependent diabetes (management) } \\
\text { Type of participants: clients }(\mathrm{n}=83 \text { ) } \\
\text { Mean age: intervention group } 1(56.2 \pm 16.0) \text {, intervention group } 2 \text { (60.2 } \pm 13.8) \\
\text { Sex: intervention group 1 (F: } 66.7 \%, \mathrm{M}: 33.3 \%) \text { and intervention group } 2 \text { (F: } 70.7 \%, \text { M: } 29.3 \% \text { ) } \\
\text { Ethnicity: not known }\end{array}$} \\
\hline Interventions & \multicolumn{2}{|c|}{$\begin{array}{l}\text { Group 1: single intervention: education (educational tools - booklet); } 3 \text { weeks; (completers: } \mathrm{n}= \\
\text { 42) } \\
\text { Clients assisted to three workshops at one week intervals during which a Colorado State } \\
\text { University Diet Guide for Planning Prudent Diet, worksheets for planning and evaluating menus, } \\
\text { leader's guide, and three slide-cassette tape programs on diabetes, using the diet guide and } \\
\text { expanding the diet guide were provided. } \\
\text { Group 2: single intervention: modelling (nutritional tools); } 3 \text { weeks; (completers: } \mathrm{n}=41 \text { ) } \\
\text { Clients assisted to three workshops at one week intervals during which the exchange lists for meal } \\
\text { planning was provided and used as the menu planning and evaluation tool. A slide-cassette tape } \\
\text { program was also used to help teach the exchange lists }\end{array}$} \\
\hline Outcomes & \multicolumn{2}{|c|}{$\begin{array}{l}\text { Measurement of diet adherence: adherence to Recommended Dietary Allowances of the Food and } \\
\text { Nutrition Board (energy, protein, vitamins (A, C, thiamine, riboflavin, niacin), and minerals } \\
\text { (calcium, phosphorus, iron and zinc)) assessed by a three-day food record (baseline, } 3 \text { months, } 6 \\
\text { months) }\end{array}$} \\
\hline
\end{tabular}

Cochrane Database Syst Rev. Author manuscript; available in PMC 2016 June 09. 


\begin{tabular}{|c|c|c|}
\hline Notes & \multicolumn{2}{|c|}{$\begin{array}{l}\text { Dietary advice: prudent diet } \\
\text { Drop-out rate: not known } \\
\text { Providers: dietitian and senior author }\end{array}$} \\
\hline \multicolumn{3}{|l|}{ Risk of bias } \\
\hline Bias & Authors' judgement & Support for judgement \\
\hline $\begin{array}{l}\text { Random } \\
\text { sequence } \\
\text { generation } \\
\text { (selection bias) }\end{array}$ & Low risk & $\begin{array}{l}\text { Sequence generation referring to a random number } \\
\text { table. }\end{array}$ \\
\hline $\begin{array}{l}\text { Allocation } \\
\text { concealment } \\
\text { (selection bias) }\end{array}$ & High risk & $\begin{array}{l}\text { Allocation concealment using an open random } \\
\text { allocation schedule }\end{array}$ \\
\hline $\begin{array}{l}\text { Blinding } \\
\text { (performance } \\
\text { bias and } \\
\text { detection bias) } \\
\text { Participants }\end{array}$ & Unclear risk & This study did not assess this item. \\
\hline $\begin{array}{l}\text { Blinding } \\
\text { (performance } \\
\text { bias and } \\
\text { detection bias) } \\
\text { Providers }\end{array}$ & Unclear risk & This study did not assess this item. \\
\hline $\begin{array}{l}\text { Blinding } \\
\text { (performance } \\
\text { bias and } \\
\text { detection bias) } \\
\text { Outcome } \\
\text { assessors }\end{array}$ & Low risk & $\begin{array}{l}\text { "Food records were reviewed and blind coded for } \\
\text { computer processing and analysis so that data } \\
\text { analyzers were not aware of treatment group" }\end{array}$ \\
\hline $\begin{array}{l}\text { Incomplete } \\
\text { outcome data } \\
\text { (attrition bias) } \\
\text { All outcomes }\end{array}$ & High risk & $\begin{array}{l}\text { Plausible effect size among missing outcomes } \\
\text { enough to have a clinically-relevant impact on } \\
\text { observed effect size }\end{array}$ \\
\hline $\begin{array}{l}\text { Selective } \\
\text { reporting } \\
\text { (reporting bias) }\end{array}$ & High risk & No protocol. Diet adherence is not clearly defined. \\
\hline Other bias & Unclear risk & $\begin{array}{l}\text { Baseline balance between groups. Diet adherence is } \\
\text { assessed by self-reported measure. Validation and } \\
\text { reliability of self-reported diet adherence are not } \\
\text { reported }\end{array}$ \\
\hline \multicolumn{3}{|l|}{ Laitinen 1993} \\
\hline Methods & \multicolumn{2}{|c|}{ Study design: randomized controlled trial with one intervention group and one usual care group } \\
\hline Participants & \multicolumn{2}{|c|}{$\begin{array}{l}\text { Setting: outpatient } \\
\text { Country: Finland } \\
\text { Chronic disease: non-insulin-dependent diabetes (management) } \\
\text { Type of participants: clients }(\mathrm{n}=86) \\
\text { Mean age: intervention (F: } 53.7 \pm 6.3 \text {, M: } 50.7 \pm 7.7) \text {, usual care (F: } 54.4 \pm 6.4, \mathrm{M}: 54.0 \pm 6.6 \text { ) } \\
\text { Sex: intervention (F: } 47.5 \%, \text { M: } 52.5 \% \text { ) and usual care (F: } 39.1 \%, \text { M: } 60.9 \%) \\
\text { Ethnicity: intervention and usual care groups (100\% white) }\end{array}$} \\
\hline Interventions & \multicolumn{2}{|c|}{$\begin{array}{l}\text { Group 1: multiple intervention: individual session with a dietitian }+ \text { nutritional tools }+ \text { goal setting; } \\
12 \text { months; }(\mathrm{n}=40) \\
\text { During each bimonthly visits, the clinical dietitians and the client set one or two clear short-term } \\
\text { goals for dietary change and a goal for weight loss. A food preparation practice was also provided. } \\
\text { Group 2: usual care; duration: not known; }(\mathrm{n}=46)\end{array}$} \\
\hline Outcomes & \multicolumn{2}{|c|}{$\begin{array}{l}\text { Measurement of diet adherence: adherence to total fat, saturated fat, unsaturated fat, } \\
\text { carbohydrates, fiber and cholesterol intake assessed by a three-day food record (baseline, } 3 \\
\text { months, } 15 \text { months) }\end{array}$} \\
\hline Notes & \multicolumn{2}{|c|}{$\begin{array}{l}\text { Dietary advice: restricted energy, fat (especially saturated fatty acid) and dietary cholesterol } \\
\text { intakes, increased unsaturated fatty acid and unrefined carbohydrate intakes and avoided large } \\
\text { amounts of simple carbohydrates } \\
\text { Drop-out rate: } 0 \% \text { (calculated) } \\
\text { Providers: intervention: physician, nurse and clinical dietitian; usual care: physician and nurse }\end{array}$} \\
\hline
\end{tabular}

Cochrane Database Syst Rev. Author manuscript; available in PMC 2016 June 09. 
Risk of bia

\begin{tabular}{|c|c|c|}
\hline Bias & Authors' judgement & Support for judgement \\
\hline $\begin{array}{l}\text { Random } \\
\text { sequence } \\
\text { generation } \\
\text { (selection bias) }\end{array}$ & Low risk & $\begin{array}{l}\text { Sequence generation referring to a random number } \\
\text { table. }\end{array}$ \\
\hline $\begin{array}{l}\text { Allocation } \\
\text { concealment } \\
\text { (selection bias) }\end{array}$ & Low risk & $\begin{array}{l}\text { Allocation concealment using sequentially } \\
\text { numbered, opaque, sealed envelopes }\end{array}$ \\
\hline $\begin{array}{l}\text { Blinding } \\
\text { (performance } \\
\text { bias and } \\
\text { detection bias) } \\
\text { Participants }\end{array}$ & Unclear risk & This study did not assess this item. \\
\hline $\begin{array}{l}\text { Blinding } \\
\text { (performance } \\
\text { bias and } \\
\text { detection bias) } \\
\text { Providers }\end{array}$ & Unclear risk & This study did not assess this item. \\
\hline $\begin{array}{l}\text { Blinding } \\
\text { (performance } \\
\text { bias and } \\
\text { detection bias) } \\
\text { Outcome } \\
\text { assessors }\end{array}$ & Unclear risk & This study did not assess this item. \\
\hline $\begin{array}{l}\text { Incomplete } \\
\text { outcome data } \\
\text { (attrition bias) } \\
\text { All outcomes }\end{array}$ & High risk & $\begin{array}{l}\text { The proportion of missing outcomes compared with } \\
\text { observed risk enough to induce clinically-relevant } \\
\text { bias in intervention effect estimate }\end{array}$ \\
\hline $\begin{array}{l}\text { Selective } \\
\text { reporting } \\
\text { (reporting bias) }\end{array}$ & High risk & $\begin{array}{l}\text { No protocol. Diet adherence is reported } \\
\text { incompletely. }\end{array}$ \\
\hline Other bias & Unclear risk & $\begin{array}{l}\text { Baseline comparisons between groups are not } \\
\text { reported. Diet adherence is assessed by self-reported } \\
\text { measure. Validation and reliability of self-reported } \\
\text { diet adherence are not reported }\end{array}$ \\
\hline \multicolumn{3}{|l|}{ Logan 2010} \\
\hline Methods & \multicolumn{2}{|c|}{ Study design: randomized controlled trial with two intervention groups } \\
\hline Participants & \multicolumn{2}{|c|}{$\begin{array}{l}\text { Setting: outpatient } \\
\text { Country: United Kingdom } \\
\text { Chronic disease: coronary heart disease (management) } \\
\text { Type of participants: clients }(\mathrm{n}=40) \\
\text { Mean age: intervention group } 1(57.7 \pm 7.8) \text {, intervention group } 2(58.0 \pm 9.2) \\
\text { Sex: intervention group 1 (F: } 19 \%, \text { M: } 81 \% \text { ) and intervention group } 2 \text { (F: } 15.8 \%, \mathrm{M}: 84.2 \%) \\
\text { Ethnicity: not known }\end{array}$} \\
\hline Interventions & \multicolumn{2}{|c|}{$\begin{array}{l}\text { Group 1: single intervention: modelling (nutritional tools); } 4 \text { months; }(\mathrm{n}=21) \\
\text { Clients received detailed information regarding the implementation of the Mediterranean diet and } \\
\text { were provided with a diet sheet, which contained detailed advice and information on the } \\
\text { Mediterranean diet, the potential health benefits of the diet, recipe ideas and a sample meal plan. } \\
\text { Then, they received a home visit from the dietitian at week one and at months one, two and four. } \\
\text { Group 2: single intervention: enablement (behavior change techniques: barrier identification/ } \\
\text { problem solving, goal setting); } 4 \text { months; }(\mathrm{n}=19) \\
\text { Interventions were tailored to the individual, with personal specific advice and setting of short-and } \\
\text { long-term goals based on their stage of change measure, which reflected their readiness to adopt a } \\
\text { Mediterranean diet. Clients were provided a diet sheet and also a Help to change booklet, which } \\
\text { contained a list of the common difficulties found when making dietary change, as well as } \\
\text { suggestions for overcoming these. They received a home visit from the dietitian at week one and at } \\
\text { months one, two and four }\end{array}$} \\
\hline Outcomes & \multicolumn{2}{|c|}{$\begin{array}{l}\text { Measurement of diet adherence: adherence to Mediterranean diet assessed by a validated } \\
\text { questionnaire (baseline, } 6 \text { months, } 12 \text { months) }\end{array}$} \\
\hline Notes & \multicolumn{2}{|c|}{$\begin{array}{l}\text { Dietary advice: seven to ten portions of fruit and vegetables/day, more whole grain cereals, more } \\
\text { fish (four portions/week), less meat (approximately once/week), and butter and cream were }\end{array}$} \\
\hline
\end{tabular}

Cochrane Database Syst Rev. Author manuscript; available in PMC 2016 June 09. 


\begin{tabular}{|c|c|c|}
\hline & \multicolumn{2}{|c|}{$\begin{array}{l}\text { replaced with an olive-oil based spread. The oils recommended for salads and food preparation } \\
\text { were olive and rapeseed oils. Moderate alcohol consumption, in the form of wine, was allowed at } \\
\text { meals. Patients were also advised to include unsalted nuts as snacks } \\
\text { Drop-out rate: } 15.5 \% \\
\text { Provider: dietitian } \\
\text { A usual care group was included in this study. Since the Mediterranean diet was not provided in } \\
\text { the usual care group, this group was not described in the Cochrane review }\end{array}$} \\
\hline \multicolumn{3}{|l|}{ Risk of bias } \\
\hline Bias & Authors' judgement & Support for judgement \\
\hline $\begin{array}{l}\text { Random } \\
\text { sequence } \\
\text { generation } \\
\text { (selection bias) }\end{array}$ & Low risk & $\begin{array}{l}\text { "Willing participants }(\mathrm{n}=61) \text { were randomised } \\
\text { (using a block randomisation approach with } \\
\text { computer generated random numbers) ..." }\end{array}$ \\
\hline $\begin{array}{l}\text { Allocation } \\
\text { concealment } \\
\text { (selection bias) }\end{array}$ & High risk & $\begin{array}{l}\text { Allocation concealment using an open random } \\
\text { allocation schedule (list of random numbers) }\end{array}$ \\
\hline $\begin{array}{l}\text { Blinding } \\
\text { (performance } \\
\text { bias and } \\
\text { detection bias) } \\
\text { Participants }\end{array}$ & Unclear risk & This study did not assess this item. \\
\hline $\begin{array}{l}\text { Blinding } \\
\text { (performance } \\
\text { bias and } \\
\text { detection bias) } \\
\text { Providers }\end{array}$ & Unclear risk & This study did not assess this item. \\
\hline $\begin{array}{l}\text { Blinding } \\
\text { (performance } \\
\text { bias and } \\
\text { detection bias) } \\
\text { Outcome } \\
\text { assessors }\end{array}$ & Unclear risk & This study did not assess this item. \\
\hline $\begin{array}{l}\text { Incomplete } \\
\text { outcome data } \\
\text { (attrition bias) } \\
\text { All outcomes }\end{array}$ & High risk & $\begin{array}{l}\text { Plausible effect size among missing outcomes } \\
\text { enough to have a clinically-relevant impact on } \\
\text { observed effect size }\end{array}$ \\
\hline $\begin{array}{l}\text { Selective } \\
\text { reporting } \\
\text { (reporting bias) }\end{array}$ & Unclear risk & No protocol. \\
\hline Other bias & Low risk & $\begin{array}{l}\text { Baseline balance between groups. Diet adherence is } \\
\text { assessed by self-reported measure (validated } \\
\text { questionnaire) }\end{array}$ \\
\hline \multicolumn{3}{|l|}{ Mahler 1999} \\
\hline Methods & \multicolumn{2}{|c|}{ Study design: randomized controlled trial with two intervention groups and one control group } \\
\hline Participants & \multicolumn{2}{|c|}{$\begin{array}{l}\text { Setting: outpatient } \\
\text { Country: United States } \\
\text { Chronic disease: coronary artery disease (management) } \\
\text { Type of participants: clients }(\mathrm{n}=215) \\
\text { Mean age: intervention group 1 }(59.7 \pm 8.5) \text {, intervention group 2: }(63.1 \pm 7.7) \text {, control }(61.1 \\
\pm 8.7) \\
\text { Sex: intervention group } 1(\mathrm{~F}: 14 \%, \mathrm{M}: 86 \%) \text {, intervention group } 2 \text { (F: } 11 \%, \mathrm{M}: 89 \%) \text { and control } \\
\text { (F: } 16 \%, \mathrm{M}: 84 \%) \\
\text { Ethnicity: intervention group 1 }(81.5 \% \text { White, } 1.5 \% \text { Asian, } 13.8 \% \text { Hispanic, } 1.5 \% \text { African } \\
\text { American, } 1.5 \% \text { Other), intervention group } 2(82.7 \% \text { White, } 4 \% \text { Asian, } 10.7 \% \text { Hispanic, } 2.7 \% \\
\text { African American), control (85.3\% White, } 4 \% \text { Asian, } 10.7 \% \text { Hispanic) }\end{array}$} \\
\hline Interventions & \multicolumn{2}{|c|}{$\begin{array}{l}\text { Group 1: single intervention: education (educational tools - video); once; }(\mathrm{n}=65) \\
\text { Mastery tape was made to depict these clients as calm and confident at the time of release, as } \\
\text { making steady progress with no mention of complications during the six months after surgery, and } \\
\text { as adjusting to the recommended exercise and low-fat diet with relative ease. } \\
\text { Group 2: multiple intervention: educational tools-video + relapse prevention/coping planning; } \\
\text { once; ( } \mathrm{n}=75) \\
\text { Coping tape was edited so that the same clients mention concerns they are experiencing about } \\
\text { hospital release and cope with effort but successfully with a variety of difficulties (e.g. heart } \\
\text { rhythm disturbances, fatigue, diet changes) }\end{array}$} \\
\hline
\end{tabular}

Cochrane Database Syst Rev. Author manuscript; available in PMC 2016 June 09. 


\begin{tabular}{|c|c|c|}
\hline & \multicolumn{2}{|c|}{ Group 3:control (no video); once; $(\mathrm{n}=75)$} \\
\hline Outcomes & \multicolumn{2}{|c|}{$\begin{array}{l}\text { Measurement of diet adherence: adherence to cholesterol and saturated fat-restricted diet assessed } \\
\text { by the cholesterol-saturated fat subscale of the Diet Habit Survey ( } 1 \text { month }-3 \text { months) }\end{array}$} \\
\hline Notes & \multicolumn{2}{|c|}{$\begin{array}{l}\text { Dietary advice: low-cholesterol and low-fat diet } \\
\text { Drop-out rate: } 9 \% \\
\text { Provider: cardiothoracic nurse specialist }\end{array}$} \\
\hline \multicolumn{3}{|l|}{ Risk of bias } \\
\hline Bias & Authors' judgement & Support for judgement \\
\hline $\begin{array}{l}\text { Random } \\
\text { sequence } \\
\text { generation } \\
\text { (selection bias) }\end{array}$ & Low risk & $\begin{array}{l}\text { Sequence generation referring to a random number } \\
\text { table. }\end{array}$ \\
\hline $\begin{array}{l}\text { Allocation } \\
\text { concealment } \\
\text { (selection bias) }\end{array}$ & Low risk & $\begin{array}{l}\text { Allocation concealment using sequentially } \\
\text { numbered, opaque, sealed envelopes }\end{array}$ \\
\hline $\begin{array}{l}\text { Blinding } \\
\text { (performance } \\
\text { bias and } \\
\text { detection bias) } \\
\text { Participants }\end{array}$ & Unclear risk & This study did not assess this item. \\
\hline $\begin{array}{l}\text { Blinding } \\
\text { (performance } \\
\text { bias and } \\
\text { detection bias) } \\
\text { Providers }\end{array}$ & Unclear risk & This study did not assess this item. \\
\hline $\begin{array}{l}\text { Blinding } \\
\text { (performance } \\
\text { bias and } \\
\text { detection bias) } \\
\text { Outcome } \\
\text { assessors }\end{array}$ & Unclear risk & This study did not assess this item. \\
\hline $\begin{array}{l}\text { Incomplete } \\
\text { outcome data } \\
\text { (attrition bias) } \\
\text { All outcomes }\end{array}$ & Unclear risk & $\begin{array}{l}\text { Insufficient reporting of attrition to permit } \\
\text { judgement. }\end{array}$ \\
\hline $\begin{array}{l}\text { Selective } \\
\text { reporting } \\
\text { (reporting bias) }\end{array}$ & Unclear risk & No protocol. \\
\hline Other bias & Unclear risk & $\begin{array}{l}\text { Baseline comparisons between groups are not } \\
\text { reported. Diet adherence is assessed by self-reported } \\
\text { measure (validated Diet Habit Survey) }\end{array}$ \\
\hline \multicolumn{3}{|l|}{ McCulloch 1983} \\
\hline Methods & \multicolumn{2}{|c|}{ Study design: randomized controlled trial with two intervention groups and one usual care group } \\
\hline Participants & \multicolumn{2}{|c|}{$\begin{array}{l}\text { Setting: outpatient } \\
\text { Country: United Kingdom } \\
\text { Chronic disease: insulin dependent diabetes (management) } \\
\text { Type of participants: clients }(\mathrm{n}=40) \\
\text { Mean age: intervention group } 1(31.6 \pm 8.3) \text {, intervention group } 2(36.5 \pm 15.3) \text {, usual care (35.6 } \\
\pm 10.4) \\
\text { Sex: intervention group 1 (F: } 38.5 \%, \text { M: } 61.5 \%) \text {, intervention group } 2 \text { (F: } 46.2 \%, \text { M: } 53.8 \%) \text { and } \\
\text { usual care (F: } 42.9 \%, \text { M: } 57.1 \%) \\
\text { Ethnicity: not known }\end{array}$} \\
\hline Interventions & \multicolumn{2}{|c|}{$\begin{array}{l}\text { Group 1: single intervention: modelling (nutritional tools); } 6 \text { months; }(\mathrm{n}=13) \\
\text { Clients had individual assessment, dietary pamphlet containing } 10 \mathrm{~g} \text { carbohydrate exchange lists } \\
\text { and were asked to come three times to the hospital canteen in groups of four or five where they } \\
\text { had lunch with both dietitian and doctor. Participants were asked to help themselves to a variety of } \\
\text { hot and cold dishes and to make up their carbohydrate allowance to what had been prescribed for } \\
\text { them previously. After lunch they were shown a display of other items of food so that they could } \\
\text { see and feel exactly how much of each item did in fact contain } 10 \mathrm{~g} \text { carbohydrate. } \\
\text { Group 2: single intervention: education (education tools - video); } 6 \text { months; }(\mathrm{n}=13) \\
\text { Clients had individual assessment and a dietary pamphlet containing } 10 \mathrm{~g} \text { carbohydrate exchange } \\
\text { lists and viewed a } 24 \text { minutes videotape. This was viewed on three separate occasions while sitting }\end{array}$} \\
\hline
\end{tabular}

Cochrane Database Syst Rev. Author manuscript; available in PMC 2016 June 09. 


\begin{tabular}{|c|c|c|}
\hline & \multicolumn{2}{|c|}{$\begin{array}{l}\text { in an armchair in a quiet room, and without dietitian or doctor being present. The videotape began } \\
\text { with an explanation of the importance of eating a balanced diet and maintaining a consistent } \\
\text { carbohydrate profile. It then took the viewer through a day in the life of two insulin treated patients } \\
\text { with very different dietary requirements and lifestyles. It ended by suggesting that the viewer } \\
\text { should try to work out his or her own carbohydrate profile with the dietitian's help. } \\
\text { Group 3: usual care: no lunchtime nor video; } 6 \text { months; }(\mathrm{n}=14) \\
\text { Clients were assessed by a dietitian and received individual instructions about what carbohydrate } \\
\text { distribution would be appropriate for them. In addition to a pamphlet containing } 10 \mathrm{~g} \text { exchange } \\
\text { lists they were given simple menus to emphasize the carbohydrate profile they should stick to from } \\
\text { day to day. Clients were seen for dietary instruction three times }\end{array}$} \\
\hline Outcomes & \multicolumn{2}{|c|}{$\begin{array}{l}\text { Measurement of diet adherence: adherence to day to day consistency in carbohydrate intake } \\
\text { assessed by a seven-day food record (baseline, } 6 \text { months) }\end{array}$} \\
\hline Notes & \multicolumn{2}{|c|}{$\begin{array}{l}\text { Dietary advice: an appropriate total daily intake of carbohydrate was determined jointly by the } \\
\text { client and dietitian. This was then broken down into } 10 \mathrm{~g} \text { carbohydrate exchanges. } \\
\text { Clients were asked to keep to an agreed distribution of carbohydrate exchanges in the form of } \\
\text { three main meals and three snacks } \\
\text { Drop-out rate: not known } \\
\text { Providers: dietitian and doctor }\end{array}$} \\
\hline \multicolumn{3}{|l|}{ Risk of bias } \\
\hline Bias & Authors' judgement & Support for judgement \\
\hline $\begin{array}{l}\text { Random } \\
\text { sequence } \\
\text { generation } \\
\text { (selection bias) }\end{array}$ & Unclear risk & $\begin{array}{l}\text { Sequence generation is not described explicitly in } \\
\text { the paper }\end{array}$ \\
\hline $\begin{array}{l}\text { Allocation } \\
\text { concealment } \\
\text { (selection bias) }\end{array}$ & Unclear risk & $\begin{array}{l}\text { Allocation concealment is not described explicitly in } \\
\text { the paper }\end{array}$ \\
\hline $\begin{array}{l}\text { Blinding } \\
\text { (performance } \\
\text { bias and } \\
\text { detection bias) } \\
\text { Participants }\end{array}$ & Unclear risk & This study did not assess this item. \\
\hline $\begin{array}{l}\text { Blinding } \\
\text { (performance } \\
\text { bias and } \\
\text { detection bias) } \\
\text { Providers }\end{array}$ & Unclear risk & This study did not assess this item. \\
\hline $\begin{array}{l}\text { Blinding } \\
\text { (performance } \\
\text { bias and } \\
\text { detection bias) } \\
\text { Outcome } \\
\text { assessors }\end{array}$ & Unclear risk & This study did not assess this item. \\
\hline $\begin{array}{l}\text { Incomplete } \\
\text { outcome data } \\
\text { (attrition bias) } \\
\text { All outcomes }\end{array}$ & Low risk & $\begin{array}{l}\text { Missing outcome data balanced in numbers across } \\
\text { intervention groups, with similar reasons for missing } \\
\text { data across groups }\end{array}$ \\
\hline $\begin{array}{l}\text { Selective } \\
\text { reporting } \\
\text { (reporting bias) }\end{array}$ & Unclear risk & No protocol. \\
\hline Other bias & Unclear risk & $\begin{array}{l}\text { Baseline balance between groups. Diet adherence is } \\
\text { assessed by self-reported measure. Validation and } \\
\text { reliability of self-reported diet adherence are not } \\
\text { reported }\end{array}$ \\
\hline \multicolumn{3}{|l|}{ Meland 1994} \\
\hline Methods & \multicolumn{2}{|c|}{ Study design: randomized controlled trial with one intervention group and one control group } \\
\hline Participants & \multicolumn{2}{|c|}{$\begin{array}{l}\text { Setting: outpatient } \\
\text { Country: Norway } \\
\text { Chronic disease: hypertension (management) } \\
\text { Type of participants: clients ( }=34) \\
\text { Mean age: intervention (53), control (52) } \\
\text { Sex: intervention (F: } 37 \%, \text { M: } 63 \% \text { ) and control (F: 47\%, M: 53\%) }\end{array}$} \\
\hline
\end{tabular}

Cochrane Database Syst Rev. Author manuscript; available in PMC 2016 June 09. 


\begin{tabular}{|c|c|c|}
\hline & \multicolumn{2}{|c|}{ Ethnicity: intervention and control groups: $100 \%$ Caucasian } \\
\hline Interventions & \multicolumn{2}{|c|}{$\begin{array}{l}\text { Group 1: single intervention: training (feedback); } 12 \text { weeks; }(n=15) \\
\text { Clients measured their fasting morning chloride concentration on six different occasions during } \\
\text { the trial. A recommendation of } 30 \text { to } 50 \% \text { reduction of urine chloride concentration compared with } \\
\text { the initial value at the inclusion visit was set. } \\
\text { Group 2: control (no self-monitoring); } 1 \text { month: }(n=19)\end{array}$} \\
\hline Outcomes & \multicolumn{2}{|c|}{$\begin{array}{l}\text { Measurement of diet adherence: adherence to sodium-restricted diet assessed by urine sodium } \\
\text { excretion (baseline, } 1 \text { month, } 3 \text { months) }\end{array}$} \\
\hline Notes & \multicolumn{2}{|c|}{$\begin{array}{l}\text { Dietary advice: fresh fish and meat should be preferred for dinner (canned, salted or smoked food } \\
\text { is only rarely allowed), fruit and vegetables should be used plentifully, boil potatoes without salt, } \\
\text { salt should not be used during food processing, spices and herbs should be used plentifully, lemon } \\
\text { juice adds flavour to your food, roasting your food in the oven or microwave conserves its natural } \\
\text { flavours, when frying, use oil instead of butter, ask for salt-reduced soups or sauces, for baking } \\
\text { bread, use } 1 \text { teaspoon salt/litre of liquid } \\
\text { Drop-out rate: } 0 \% \\
\text { Provider: general practitioner }\end{array}$} \\
\hline \multicolumn{3}{|l|}{ Risk of bias } \\
\hline Bias & Authors' judgement & Support for judgement \\
\hline $\begin{array}{l}\text { Random } \\
\text { sequence } \\
\text { generation } \\
\text { (selection bias) }\end{array}$ & Low risk & $\begin{array}{l}\text { Sequence generation referring to a random number } \\
\text { table. }\end{array}$ \\
\hline $\begin{array}{l}\text { Allocation } \\
\text { concealment } \\
\text { (selection bias) }\end{array}$ & Low risk & $\begin{array}{l}\text { Allocation concealment using sequentially } \\
\text { numbered, opaque, sealed envelopes }\end{array}$ \\
\hline $\begin{array}{l}\text { Blinding } \\
\text { (performance } \\
\text { bias and } \\
\text { detection bias) } \\
\text { Participants }\end{array}$ & Unclear risk & This study did not assess this item. \\
\hline $\begin{array}{l}\text { Blinding } \\
\text { (performance } \\
\text { bias and } \\
\text { detection bias) } \\
\text { Providers }\end{array}$ & Unclear risk & This study did not assess this item. \\
\hline $\begin{array}{l}\text { Blinding } \\
\text { (performance } \\
\text { bias and } \\
\text { detection bias) } \\
\text { Outcome } \\
\text { assessors }\end{array}$ & Unclear risk & This study did not assess this item. \\
\hline $\begin{array}{l}\text { Incomplete } \\
\text { outcome data } \\
\text { (attrition bias) } \\
\text { All outcomes }\end{array}$ & Low risk & No missing data. \\
\hline $\begin{array}{l}\text { Selective } \\
\text { reporting } \\
\text { (reporting bias) }\end{array}$ & High risk & $\begin{array}{l}\text { No protocol. Some outcomes of interest are reported } \\
\text { incompletely (weight and HDL-cholesterol) }\end{array}$ \\
\hline Other bias & Unclear risk & $\begin{array}{l}\text { Baseline comparisons between groups are not } \\
\text { reported. Diet adherence is assessed by objective } \\
\text { measure }\end{array}$ \\
\hline \multicolumn{3}{|l|}{ Micco 2007} \\
\hline Methods & \multicolumn{2}{|c|}{ Study design: randomized controlled trial with one intervention group and one control group } \\
\hline Participants & \multicolumn{2}{|c|}{$\begin{array}{l}\text { Setting: research center } \\
\text { Country: United States } \\
\text { Chronic disease: overweight and obesity (prevention and management) } \\
\text { Type of participants: clients }(\mathrm{n}=123) \\
\text { Mean age: intervention }(47.1 \pm 11.1) \text {, control }(46.5 \pm 10.7) \\
\text { Sex: intervention (F: } 89 \%, \mathrm{M}: 12 \%) \text { and control (F: } 77 \%, \mathrm{M}: 23 \%) \\
\text { Ethnicity: intervention(100\% White, } 0 \% \text { Black), control (98\% White, } 2 \% \text { Black) }\end{array}$} \\
\hline Interventions & \multicolumn{2}{|c|}{ Group 1: single intervention: education (individual session with a dietitian); 12 months; $(\mathrm{n}=61)$} \\
\hline
\end{tabular}

Cochrane Database Syst Rev. Author manuscript; available in PMC 2016 June 09. 


\begin{tabular}{|c|c|c|}
\hline & \multicolumn{2}{|c|}{$\begin{array}{l}\text { Monthly, clients attended an in-person meeting in place of an online chat. } \\
\text { Group 2: control (online chat without in-person meeting); } 12 \text { months; }(n=62)\end{array}$} \\
\hline Outcomes & \multicolumn{2}{|c|}{$\begin{array}{l}\text { Measurement of diet adherence: adherence to energy intake assessed by the Block } 98.2 \text { food } \\
\text { frequency questionnaire (baseline, } 6 \text { months, } 12 \text { months) }\end{array}$} \\
\hline Notes & \multicolumn{2}{|c|}{$\begin{array}{l}\text { Dietary advice: } 1200 \text { to } 2100 \text { calorie diet based on baseline body weight, eating a diet abundant in } \\
\text { fruit, vegetables and whole grains and moderate in fat, sugar, salt, and alcohol } \\
\text { Drop-out rate: } 21 \% \\
\text { Providers: dietitian and master's level graduate student }\end{array}$} \\
\hline \multicolumn{3}{|l|}{ Risk of bias } \\
\hline Bias & Authors' judgement & Support for judgement \\
\hline $\begin{array}{l}\text { Random } \\
\text { sequence } \\
\text { generation } \\
\text { (selection bias) }\end{array}$ & Unclear risk & $\begin{array}{l}\text { Sequence generation is not described explicitly in } \\
\text { the paper }\end{array}$ \\
\hline $\begin{array}{l}\text { Allocation } \\
\text { concealment } \\
\text { (selection bias) }\end{array}$ & Unclear risk & $\begin{array}{l}\text { Allocation concealment is not described explicitly in } \\
\text { the paper }\end{array}$ \\
\hline $\begin{array}{l}\text { Blinding } \\
\text { (performance } \\
\text { bias and } \\
\text { detection bias) } \\
\text { Participants }\end{array}$ & Unclear risk & This study did not assess this item. \\
\hline $\begin{array}{l}\text { Blinding } \\
\text { (performance } \\
\text { bias and } \\
\text { detection bias) } \\
\text { Providers }\end{array}$ & Unclear risk & This study did not assess this item. \\
\hline $\begin{array}{l}\text { Blinding } \\
\text { (performance } \\
\text { bias and } \\
\text { detection bias) } \\
\text { Outcome } \\
\text { assessors }\end{array}$ & Unclear risk & This study did not assess this item. \\
\hline $\begin{array}{l}\text { Incomplete } \\
\text { outcome data } \\
\text { (attrition bias) } \\
\text { All outcomes }\end{array}$ & Unclear risk & $\begin{array}{l}\text { Insufficient reporting of attrition to permit } \\
\text { judgement. }\end{array}$ \\
\hline $\begin{array}{l}\text { Selective } \\
\text { reporting } \\
\text { (reporting bias) }\end{array}$ & High risk & $\begin{array}{l}\text { No protocol. Weekly goals met (calories) is reported } \\
\text { incompletely }\end{array}$ \\
\hline Other bias & Unclear risk & $\begin{array}{l}\text { Baseline imbalance between groups (body weight) } \\
\text { but repeated measures analysis of covariance was } \\
\text { performed to control for baseline weight differences. } \\
\text { Diet adherence is assessed by self-reported measure. } \\
\text { Validation and reliability of self-reported diet } \\
\text { adherence are not reported }\end{array}$ \\
\hline \multicolumn{3}{|l|}{ Miller 1988} \\
\hline Methods & \multicolumn{2}{|c|}{ Study design: randomized controlled trial with one intervention group and one control group } \\
\hline Participants & \multicolumn{2}{|c|}{$\begin{array}{l}\text { Setting: outpatient } \\
\text { Country: United States } \\
\text { Chronic disease: myocardial infarction (management) } \\
\text { Type of participants: clients ( }=115) \\
\text { Mean age: intervention and control groups: } 54 \\
\text { Sex: intervention (F: } 27 \%, \text { M: } 73 \% \text { ) and control (F: } 11 \%, \text { M: } 89 \%) \\
\text { Ethnicity: intervention (98\% White, } 2 \% \text { Black), control (87\% White, } 13 \% \text { Black) }\end{array}$} \\
\hline Interventions & \multicolumn{2}{|c|}{$\begin{array}{l}\text { Group 1: multiple intervention: individual session with nurse }+ \text { barrier identification/problem } \\
\text { solving, goal setting; } 60 \text { days; }(\mathrm{n}=58) \\
\text { Clients completed a cardiac rehabilitation program during hospitalization and were visited at home } \\
30 \text { days after discharge. The intervention included a discussion of assessment data, identification } \\
\text { of problems and establishment of goals. } \\
\text { Group 2: control (no nurse intervention); duration: not known; }(\mathrm{n}=57)\end{array}$} \\
\hline
\end{tabular}

Cochrane Database Syst Rev. Author manuscript; available in PMC 2016 June 09. 


\begin{tabular}{|c|c|c|}
\hline Outcomes & \multicolumn{2}{|c|}{$\begin{array}{l}\text { Measurement of diet adherence: adherence to diet assessed by the Health Behavior scale } \\
\text { (Baseline, } 30 \text { days, } 60 \text { days, } 1 \text { year, } 2 \text { years) }\end{array}$} \\
\hline Notes & \multicolumn{2}{|c|}{$\begin{array}{l}\text { Dietary advice: not known } \\
\text { Drop-out rate: } 55.7 \% \text { (calculated) } \\
\text { Providers: cardiovascular nurses }\end{array}$} \\
\hline \multicolumn{3}{|l|}{ Risk of bias } \\
\hline Bias & Authors' judgement & Support for judgement \\
\hline $\begin{array}{l}\text { Random } \\
\text { sequence } \\
\text { generation } \\
\text { (selection bias) }\end{array}$ & Unclear risk & $\begin{array}{l}\text { Sequence generation is not described explicitly in } \\
\text { the paper }\end{array}$ \\
\hline $\begin{array}{l}\text { Allocation } \\
\text { concealment } \\
\text { (selection bias) }\end{array}$ & High risk & $\begin{array}{l}\text { "During hospitalization, } 115 \text { subjects were } \\
\text { alternately assigned to an experimental }(\mathrm{n}=58) \text { or } \\
\text { control group }(\mathrm{n}=57) . "\end{array}$ \\
\hline $\begin{array}{l}\text { Blinding } \\
\text { (performance } \\
\text { bias and } \\
\text { detection bias) } \\
\text { Participants }\end{array}$ & Unclear risk & This study did not assess this item. \\
\hline $\begin{array}{l}\text { Blinding } \\
\text { (performance } \\
\text { bias and } \\
\text { detection bias) } \\
\text { Providers }\end{array}$ & Unclear risk & This study did not assess this item. \\
\hline $\begin{array}{l}\text { Blinding } \\
\text { (performance } \\
\text { bias and } \\
\text { detection bias) } \\
\text { Outcome } \\
\text { assessors }\end{array}$ & Unclear risk & This study did not assess this item. \\
\hline $\begin{array}{l}\text { Incomplete } \\
\text { outcome data } \\
\text { (attrition bias) } \\
\text { All outcomes }\end{array}$ & High risk & $\begin{array}{l}\text { Plausible effect size among missing outcomes } \\
\text { enough to have a clinically-relevant impact on } \\
\text { observed effect size }\end{array}$ \\
\hline $\begin{array}{l}\text { Selective } \\
\text { reporting } \\
\text { (reporting bias) }\end{array}$ & High risk & $\begin{array}{l}\text { No protocol. Some outcomes of interest in the } \\
\text { review are reported incompletely (weight, blood } \\
\text { pressure) }\end{array}$ \\
\hline Other bias & Low risk & $\begin{array}{l}\text { Baseline balance between groups. Diet adherence is } \\
\text { assessed by self-reported measure (validated Health } \\
\text { Behavior scale) }\end{array}$ \\
\hline \multicolumn{3}{|l|}{ Morey 2008} \\
\hline Methods & \multicolumn{2}{|c|}{ Study design: randomized controlled trial with one intervention group and one control group } \\
\hline Participants & \multicolumn{2}{|c|}{$\begin{array}{l}\text { Setting: outpatient } \\
\text { Country: United Kingdom } \\
\text { Chronic disease: end-stage kidney failure (management) } \\
\text { Type of participants: clients }(\mathrm{n}=67) \\
\text { Mean age: intervention }(60.4 \pm 15.6) \text {, control }(54.9 \pm 15.9) \\
\text { Sex: intervention (F: } 26.5 \%, \mathrm{M}: 73.5 \%) \text { and control (F: } 48.5 \% \text {, M: } 51.5 \%) \\
\text { Ethnicity: intervention (52.9\% White, 20.6\% Indo-Asian, } 14.7 \% \text { Black, } 11.8 \% \text { Other), control } \\
\text { (48.5\% White, } 15.2 \% \text { Asian, 30.3\% Black, } 6.1 \% \text { Other) }\end{array}$} \\
\hline Interventions & \multicolumn{2}{|c|}{$\begin{array}{l}\text { Group 1: multiple intervention: individual session with dietitian + educational tools-booklet + } \\
\text { reminder + motivational interviewing; } 6 \text { months; }(\mathrm{n}=34) \\
\text { Clients received a monthly dietetic consultation. A variety of strategies were employed to } \\
\text { encourage dietary modification including motivational counseling, negotiation, behaviour } \\
\text { modification therapy, reminders, reinforcement, supportive care and written and verbal education } \\
\text { Group 2: control (no dietetic consultation); once; }(\mathrm{n}=33)\end{array}$} \\
\hline Outcomes & \multicolumn{2}{|c|}{$\begin{array}{l}\text { Measurement of diet adherence: adherence to phosphate-restricted diet assessed by serum } \\
\text { phosphate concentrations (baseline, } 3 \text { months, } 6 \text { months, } 12 \text { months) }\end{array}$} \\
\hline Notes & \multicolumn{2}{|c|}{$\begin{array}{l}\text { Dietary advice: phosphate-restricted diet } \\
\text { Drop-out rate: } 1.5 \% \text { (calculated) }\end{array}$} \\
\hline
\end{tabular}

Cochrane Database Syst Rev. Author manuscript; available in PMC 2016 June 09. 


\begin{tabular}{|c|c|c|}
\hline & \multicolumn{2}{|l|}{ Provider: dietitian } \\
\hline \multicolumn{3}{|l|}{ Risk of bias } \\
\hline Bias & Authors' judgement & Support for judgement \\
\hline $\begin{array}{l}\text { Random } \\
\text { sequence } \\
\text { generation } \\
\text { (selection bias) }\end{array}$ & Low risk & "Random number generation". \\
\hline $\begin{array}{l}\text { Allocation } \\
\text { concealment } \\
\text { (selection bias) }\end{array}$ & Unclear risk & $\begin{array}{l}\text { Allocation concealment is not described explicitly in } \\
\text { the paper }\end{array}$ \\
\hline $\begin{array}{l}\text { Blinding } \\
\text { (performance } \\
\text { bias and } \\
\text { detection bias) } \\
\text { Participants }\end{array}$ & Unclear risk & This study did not assess this item. \\
\hline $\begin{array}{l}\text { Blinding } \\
\text { (performance } \\
\text { bias and } \\
\text { detection bias) } \\
\text { Providers }\end{array}$ & Unclear risk & This study did not assess this item. \\
\hline $\begin{array}{l}\text { Blinding } \\
\text { (performance } \\
\text { bias and } \\
\text { detection bias) } \\
\text { Outcome } \\
\text { assessors }\end{array}$ & Unclear risk & This study did not assess this item. \\
\hline $\begin{array}{l}\text { Incomplete } \\
\text { outcome data } \\
\text { (attrition bias) } \\
\text { All outcomes }\end{array}$ & Low risk & $\begin{array}{l}\text { Missing outcomes are balanced between groups and } \\
\text { the proportion of missing outcomes compared with } \\
\text { observed event risk not enough to have a clinically- } \\
\text { relevant impact on the intervention effect estimate }\end{array}$ \\
\hline $\begin{array}{l}\text { Selective } \\
\text { reporting } \\
\text { (reporting bias) }\end{array}$ & High risk & $\begin{array}{l}\text { No protocol. Achieving target phosphate (at } 6 \\
\text { months) is reported incompletely }\end{array}$ \\
\hline Other bias & Low risk & $\begin{array}{l}\text { Baseline balance between groups. Diet adherence is } \\
\text { assessed by objective measure }\end{array}$ \\
\hline \multicolumn{3}{|l|}{ Racelis 1998} \\
\hline Methods & \multicolumn{2}{|c|}{ Study design: randomized controlled trial with one intervention group and one control group } \\
\hline Participants & \multicolumn{2}{|c|}{$\begin{array}{l}\text { Setting: outpatient } \\
\text { Country: United States } \\
\text { Chronic disease: peripheral artery disease (management) } \\
\text { Type of participants: clients }(\mathrm{n}=21) \\
\text { Mean age: intervention (53), control (49) } \\
\text { Sex: intervention (F: } 27.3 \%, \text { M: } 72.7 \%) \text { and control (F: } 20 \%, \text { M: } 80 \%) \\
\text { Ethnicity: not known }\end{array}$} \\
\hline Interventions & \multicolumn{2}{|c|}{$\begin{array}{l}\text { Group 1: single intervention: education (telephone follow-up); } 12 \text { months; }(\mathrm{n}=11) \\
\text { Clients received quarterly a telephone call to reinforce smoking cessation and diet information } \\
\text { Group 2: control (no telephone follow-up); once; }(\mathrm{n}=10)\end{array}$} \\
\hline Outcomes & \multicolumn{2}{|c|}{ Measurement of diet adherence: adherence assessment not known } \\
\hline Notes & \multicolumn{2}{|c|}{$\begin{array}{l}\text { Dietary advice: not known } \\
\text { Drop-out rate: } 0 \% \text { (calculated) } \\
\text { Providers: advanced practice nurses and physicians }\end{array}$} \\
\hline \multicolumn{3}{|l|}{ Risk of bias } \\
\hline Bias & Authors' judgement & Support for judgement \\
\hline $\begin{array}{l}\text { Random } \\
\text { sequence } \\
\text { generation } \\
\text { (selection bias) }\end{array}$ & Unclear risk & $\begin{array}{l}\text { Sequence generation is not described explicitly in } \\
\text { the paper }\end{array}$ \\
\hline
\end{tabular}

Cochrane Database Syst Rev. Author manuscript; available in PMC 2016 June 09. 


\begin{tabular}{|c|c|c|}
\hline $\begin{array}{l}\text { Allocation } \\
\text { concealment } \\
\text { (selection bias) }\end{array}$ & Unclear risk & $\begin{array}{l}\text { Allocation concealment is not described explicitly in } \\
\text { the paper }\end{array}$ \\
\hline $\begin{array}{l}\text { Blinding } \\
\text { (performance } \\
\text { bias and } \\
\text { detection bias) } \\
\text { Participants }\end{array}$ & Unclear risk & This study did not assess this item. \\
\hline $\begin{array}{l}\text { Blinding } \\
\text { (performance } \\
\text { bias and } \\
\text { detection bias) } \\
\text { Providers }\end{array}$ & Unclear risk & This study did not assess this item. \\
\hline $\begin{array}{l}\text { Blinding } \\
\text { (performance } \\
\text { bias and } \\
\text { detection bias) } \\
\text { Outcome } \\
\text { assessors }\end{array}$ & Unclear risk & This study did not assess this item. \\
\hline $\begin{array}{l}\text { Incomplete } \\
\text { outcome data } \\
\text { (attrition bias) } \\
\text { All outcomes }\end{array}$ & Low risk & $\begin{array}{l}\text { Only one missing data. The reason for this missing } \\
\text { data not likely related to true outcome }\end{array}$ \\
\hline $\begin{array}{l}\text { Selective } \\
\text { reporting } \\
\text { (reporting bias) }\end{array}$ & High risk & $\begin{array}{l}\text { No protocol. Diet adherence is reported } \\
\text { incompletely. }\end{array}$ \\
\hline Other bias & Unclear risk & $\begin{array}{l}\text { Baseline comparisons between groups are not } \\
\text { reported. Diet adherence is not clearly defined }\end{array}$ \\
\hline \multicolumn{3}{|l|}{ Ryan 2002} \\
\hline Methods & \multicolumn{2}{|c|}{ Study design: randomized controlled trial with two intervention groups and one control group } \\
\hline Participants & \multicolumn{2}{|c|}{$\begin{array}{l}\text { Setting: outpatient } \\
\text { Country: Canada } \\
\text { Chronic disease: type II diabetes (management) } \\
\text { Type of participants: clients ( }=75 \text { ) } \\
\text { Mean age: intervention group } 1(56.6 \pm 8.0 \text { ), intervention group } 2 \text { ( } 57.5 \pm 10.7) \text {, control (54.7 } \\
\pm 14.1 \text { ) } \\
\text { Sex: intervention group 1 (F: } 50 \%, \text { M: } 50 \% \text { ), intervention group } 2 \text { (F: } 45.8 \%, \text { M: } 54.2 \% \text { ) and } \\
\text { control (F: } 63.4 \%, \text { M: } 36.6 \%) \\
\text { Ethnicity: not known }\end{array}$} \\
\hline Interventions & \multicolumn{2}{|c|}{$\begin{array}{l}\text { Group 1: single intervention: persuasion (reminder); } 6 \text { months; }(\mathrm{n}=18) \\
\text { Knowledge and self-care practice, which serve as a reminder, were assessed at } 2 \text { weeks, } 3 \text { months } \\
\text { and } 6 \text { months. } \\
\text { Group 2: single intervention: persuasion (reminder); } 6 \text { months; }(n=24) \\
\text { Knowledge and self-care practice, which serve as a reminder, were assessed at } 3 \text { months and } 6 \\
\text { months. } \\
\text { Group 3: control (no reminder); } 6 \text { months; }(n=33)\end{array}$} \\
\hline Outcomes & \multicolumn{2}{|c|}{$\begin{array}{l}\text { Measurement of diet adherence: adherence to frequency of meals and snacks assessed by a simple } \\
\text { question of frequency of meals and snacks (Baseline, } 4 \text { days, } 2 \text { weeks, } 3 \text { months, } 6 \text { months) }\end{array}$} \\
\hline Notes & \multicolumn{2}{|c|}{$\begin{array}{l}\text { Dietary advice: eating } 3 \text { meals and } 3 \text { snacks/day } \\
\text { Drop-out rate: } 0 \% \\
\text { Providers: nurses, dietitians, physicians, exercise physiologist, podiatrist, ophthalmologist A } \\
\text { second control group was included in this study. Since this control group was not randomized, this } \\
\text { group was not described in the Cochrane review }\end{array}$} \\
\hline \multicolumn{3}{|l|}{ Risk of bias } \\
\hline Bias & Authors' judgement & Support for judgement \\
\hline $\begin{array}{l}\text { Random } \\
\text { sequence } \\
\text { generation } \\
\text { (selection bias) }\end{array}$ & Low risk & Sequence generated by shuffling cards or envelopes. \\
\hline
\end{tabular}

Cochrane Database Syst Rev. Author manuscript; available in PMC 2016 June 09. 


\begin{tabular}{|c|c|c|}
\hline $\begin{array}{l}\text { Allocation } \\
\text { concealment } \\
\text { (selection bias) }\end{array}$ & Unclear risk & $\begin{array}{l}\text { Allocation concealment is not described explicitly in } \\
\text { the paper }\end{array}$ \\
\hline $\begin{array}{l}\text { Blinding } \\
\text { (performance } \\
\text { bias and } \\
\text { detection bias) } \\
\text { Participants }\end{array}$ & Unclear risk & This study did not assess this item. \\
\hline $\begin{array}{l}\text { Blinding } \\
\text { (performance } \\
\text { bias and } \\
\text { detection bias) } \\
\text { Providers }\end{array}$ & Unclear risk & This study did not assess this item. \\
\hline $\begin{array}{l}\text { Blinding } \\
\text { (performance } \\
\text { bias and } \\
\text { detection bias) } \\
\text { Outcome } \\
\text { assessors }\end{array}$ & Unclear risk & This study did not assess this item. \\
\hline $\begin{array}{l}\text { Incomplete } \\
\text { outcome data } \\
\text { (attrition bias) } \\
\text { All outcomes }\end{array}$ & Low risk & No missing data. \\
\hline $\begin{array}{l}\text { Selective } \\
\text { reporting } \\
\text { (reporting bias) }\end{array}$ & High risk & $\begin{array}{l}\text { No protocol. Some outcomes of interest in the } \\
\text { review are reported incompletely (diet adherence, } \\
\text { exercise, glucose monitoring and weight) }\end{array}$ \\
\hline Other bias & High risk & $\begin{array}{l}\text { Baseline imbalance between groups (percentage of } \\
\text { males, body mass index). Diet adherence is assessed } \\
\text { by self-reported measure. Validation and reliability } \\
\text { of self-reported diet adherence are not reported. } \\
\text { Some patients attending the program gave kind } \\
\text { donation }\end{array}$ \\
\hline \multicolumn{3}{|c|}{ Scisney-Matlock 2006} \\
\hline Methods & \multicolumn{2}{|c|}{ Study design: randomized controlled trial with one intervention group and one control group } \\
\hline Participants & \multicolumn{2}{|c|}{$\begin{array}{l}\text { Setting: outpatient } \\
\text { Country: United States } \\
\text { Chronic disease: hypertension (management) } \\
\text { Type of participants: clients ( } \mathrm{n}=27) \\
\text { Mean age: not described } \\
\text { Sex: intervention and control groups (F: 100\%) } \\
\text { Ethnicity: intervention (7 Caucasian, } 6 \text { Minority), control (7 Caucasian, } 7 \text { Minority) }\end{array}$} \\
\hline Interventions & \multicolumn{2}{|c|}{$\begin{array}{l}\text { Group 1: single intervention: modelling (nutritional tools); } 30 \text { days; }(\mathrm{n}=13) \\
\text { Clients were exposed to a Cognitive Representations of the Dietary Approaches to Stop } \\
\text { Hypertension (DASH) diet program consisting in three separate paper wheels (knowledge } \\
\text { dimension, attitude dimension and skill dimension) and a bar chart displaying their baseline } \\
\text { Cognitive Representations of the DASH diet. All three wheels contained the same set of } 18 \text { goals. } \\
\text { For each goal, each wheel contained one message framed to support that goal in the information } \\
\text { dimension of that wheel. Clients were instructed to do the following every morning for a 30-day } \\
\text { period: review an unhealthy Cognitive Representations of the DASH diet from her bar chart, use } \\
\text { the wheels to view the three messages for that goal, and record in the notebook the feelings and } \\
\text { thoughts she has about the goal she selected. } \\
\text { Group 2: control (no wheel nor bar chart); } 30 \text { days; }(\mathrm{n}=14)\end{array}$} \\
\hline Outcomes & \multicolumn{2}{|c|}{$\begin{array}{l}\text { Measurement of diet adherence: adherence to DASH diet assessed by the Health Promotion } \\
\text { Lifestyle Profile survey (baseline, } 30 \text { days, } 60 \text { days, } 90 \text { days) }\end{array}$} \\
\hline Notes & \multicolumn{2}{|c|}{$\begin{array}{l}\text { Dietary advice: DASH diet } \\
\text { Drop-out rate: not known } \\
\text { Providers: not known } \\
\text { Two control groups were included in this study. Since patients in these control groups did not } \\
\text { follow the DASH diet, these control groups were not described in the Cochrane review }\end{array}$} \\
\hline \multicolumn{3}{|l|}{ Risk of bias } \\
\hline Bias & Authors' judgement & Support for judgement \\
\hline
\end{tabular}

Cochrane Database Syst Rev. Author manuscript; available in PMC 2016 June 09. 


\begin{tabular}{|c|c|c|}
\hline $\begin{array}{l}\text { Random } \\
\text { sequence } \\
\text { generation } \\
\text { (selection bias) }\end{array}$ & Low risk & $\begin{array}{l}\text { "Then, researchers used a computer program to } \\
\text { randomise participants" }\end{array}$ \\
\hline $\begin{array}{l}\text { Allocation } \\
\text { concealment } \\
\text { (selection bias) }\end{array}$ & Unclear risk & $\begin{array}{l}\text { "Group assignment was determined in numerical } \\
\text { sequence from } 48 \text { numbered envelopes matching the } \\
\text { stratified sampling criteria representative of a } \\
\text { Salomon Four-Group Design." }\end{array}$ \\
\hline $\begin{array}{l}\text { Blinding } \\
\text { (performance } \\
\text { bias and } \\
\text { detection bias) } \\
\text { Participants }\end{array}$ & Low risk & $\begin{array}{l}\text { "(...) study participants were unaware of their group } \\
\text { assignments" }\end{array}$ \\
\hline $\begin{array}{l}\text { Blinding } \\
\text { (performance } \\
\text { bias and } \\
\text { detection bias) } \\
\text { Providers }\end{array}$ & High risk & $\begin{array}{l}\text { "Because researchers provided one of the } \\
\text { experimental groups, but not either control group, } \\
\text { (...) the study was not blinded to the researchers" }\end{array}$ \\
\hline $\begin{array}{l}\text { Blinding } \\
\text { (performance } \\
\text { bias and } \\
\text { detection bias) } \\
\text { Outcome } \\
\text { assessors }\end{array}$ & Unclear risk & This study did not assess this item. \\
\hline $\begin{array}{l}\text { Incomplete } \\
\text { outcome data } \\
\text { (attrition bias) } \\
\text { All outcomes }\end{array}$ & Unclear risk & $\begin{array}{l}\text { Insufficient reporting of attrition to permit } \\
\text { judgement }\end{array}$ \\
\hline $\begin{array}{l}\text { Selective } \\
\text { reporting } \\
\text { (reporting bias) }\end{array}$ & Unclear risk & No protocol. \\
\hline Other bias & Low risk & $\begin{array}{l}\text { Baseline balance between groups. Diet adherence is } \\
\text { assessed by self-reported measure (Health } \\
\text { Promotion Lifestyle Profile survey). Internal } \\
\text { consistency of Health Promotion Lifestyle Profile } \\
\text { survey described }\end{array}$ \\
\hline \multicolumn{3}{|l|}{ Stewart 2005} \\
\hline Methods & \multicolumn{2}{|c|}{ Study design: randomized controlled trial with one intervention group and one control group } \\
\hline Participants & \multicolumn{2}{|c|}{$\begin{array}{l}\text { Setting: outpatient } \\
\text { Country: South Africa } \\
\text { Chronic disease: hypertension (management) } \\
\text { Type of participants: clients }(\mathrm{n}=83) \\
\text { Mean age: intervention }(56.3 \pm 11.5) \text {, control }(58.6 \pm 11.2) \\
\text { Sex: intervention (F: } 70.7 \%, \mathrm{M}: 29.3 \%) \text { and control (F: } 66.7 \% \text {, M: } 33.3 \%) \\
\text { Ethnicity: intervention }(26.8 \% \text { Black, } 41.5 \% \text { Coloured-mixed, } 14.6 \% \text { Indians, } 17.1 \% \text { White), } \\
\text { control (14.3\% Black, } 54.8 \% \text { Coloured-mixed, 23.8\% Indians, } 7.1 \% \text { White }\end{array}$} \\
\hline Interventions & \multicolumn{2}{|c|}{$\begin{array}{l}\text { Group 1: single intervention: education (telephone follow-up); } 24 \text { weeks; }(n=41) \\
\text { Clients received monthly a telephone call to provide support. } \\
\text { Group 2: control (no telephone follow-up); } 24 \text { weeks; }(n=42)\end{array}$} \\
\hline Outcomes & \multicolumn{2}{|c|}{$\begin{array}{l}\text { Measurement of diet adherence: non-adherence to alcohol intake and adherence to sodium- } \\
\text { restricted diet assessed by a yes/no question (baseline, } 24 \text { weeks, } 36 \text { weeks) }\end{array}$} \\
\hline Notes & \multicolumn{2}{|c|}{$\begin{array}{l}\text { Dietary advice: prudent diet } \\
\text { Drop-out rate: } 63.9 \% \text { (calculated) } \\
\text { Provider: physiotherapist }\end{array}$} \\
\hline \multicolumn{3}{|l|}{ Risk of bias } \\
\hline Bias & Authors' judgement & Support for judgement \\
\hline $\begin{array}{l}\text { Random } \\
\text { sequence } \\
\text { generation } \\
\text { (selection bias) }\end{array}$ & Low risk & $\begin{array}{l}\text { Sequence generated by drawing of lots (clear or } \\
\text { colored balls from a closed bag) }\end{array}$ \\
\hline
\end{tabular}

Cochrane Database Syst Rev. Author manuscript; available in PMC 2016 June 09. 


\begin{tabular}{|c|c|c|}
\hline $\begin{array}{l}\text { Allocation } \\
\text { concealment } \\
\text { (selection bias) }\end{array}$ & Low risk & Allocation concealment using central allocation. \\
\hline $\begin{array}{l}\text { Blinding } \\
\text { (performance } \\
\text { bias and } \\
\text { detection bias) } \\
\text { Participants }\end{array}$ & Unclear risk & This study did not assess this item. \\
\hline $\begin{array}{l}\text { Blinding } \\
\text { (performance } \\
\text { bias and } \\
\text { detection bias) } \\
\text { Providers }\end{array}$ & Unclear risk & This study did not assess this item. \\
\hline $\begin{array}{l}\text { Blinding } \\
\text { (performance } \\
\text { bias and } \\
\text { detection bias) } \\
\text { Outcome } \\
\text { assessors }\end{array}$ & Low risk & $\begin{array}{l}\text { "The first author and a research assistant undertook } \\
\text { all reassessments. Neither the first author nor the } \\
\text { research assistant had been involved in the } \\
\text { intervention and they were blinded to the data } \\
\text { obtained at base-line and to which groups the } \\
\text { patients be-longed." }\end{array}$ \\
\hline $\begin{array}{l}\text { Incomplete } \\
\text { outcome data } \\
\text { (attrition bias) } \\
\text { All outcomes }\end{array}$ & High risk & $\begin{array}{l}\text { The proportion of missing outcomes compared with } \\
\text { observed risk enough to induce clinically-relevant } \\
\text { bias in intervention effect estimate }\end{array}$ \\
\hline $\begin{array}{l}\text { Selective } \\
\text { reporting } \\
\text { (reporting bias) }\end{array}$ & High risk & $\begin{array}{l}\text { No protocol. Blood pressure is reported in- } \\
\text { completely. }\end{array}$ \\
\hline Other bias & High risk & $\begin{array}{l}\text { Baseline imbalance between groups (alcohol } \\
\text { adherence). Diet adherence is assessed by self- } \\
\text { reported measures. Validation and reliability of self- } \\
\text { reported diet adherence are not reported }\end{array}$ \\
\hline \multicolumn{3}{|l|}{ Tsay 2003} \\
\hline Methods & \multicolumn{2}{|c|}{ Study design: randomized controlled trial with one intervention group and one usual care group } \\
\hline Participants & \multicolumn{2}{|c|}{$\begin{array}{l}\text { Setting: outpatient } \\
\text { Country: Taiwan } \\
\text { Chronic disease: end-stage renal disease (management) } \\
\text { Type of participants: clients }(\mathrm{n}=64) \\
\text { Mean age: intervention }(57.51 \pm 11.41) \text {, usual care }(57.94 \pm 11.62) \\
\text { Sex: intervention and usual care groups (F: } 58.1 \%, \text { M: } 41.9 \%) \\
\text { Ethnicity: not known }\end{array}$} \\
\hline Interventions & \multicolumn{2}{|c|}{$\begin{array}{l}\text { Group 1: multiple intervention: stress management, goal setting }+ \text { feedback; } 4 \text { weeks; }(\mathrm{n}=32) \\
\text { The program consisted of } 12 \text { sessions conducted three times per week while clients were receiving } \\
\text { dialysis. Clients learned to relax muscles through listening to audiotaped instructions. Clients were } \\
\text { encouraged to set attainable objectives such as 'decreasing a cup of tea or water a day'. If the goals } \\
\text { were achieved, praise and recognition rewards were given. Individual counselling sessions were } \\
\text { offered stressing physical and emotional adjustment to the chronic illness. Clients recorded their } \\
\text { food and liquid intake daily, and these records were reviewed during each treatment. } \\
\text { Group 2: usual care; duration: not known; }(\mathrm{n}=32)\end{array}$} \\
\hline Outcomes & \multicolumn{2}{|c|}{$\begin{array}{l}\text { Measurement of diet adherence: adherence to fluid-restricted diet assessed by mean weight gains } \\
\text { between dialysis sessions (baseline, } 1 \text { month, } 3 \text { months, } 6 \text { months) }\end{array}$} \\
\hline Notes & \multicolumn{2}{|c|}{$\begin{array}{l}\text { Dietary advice: fluid-restricted diet } \\
\text { Drop-out rate: } 3.1 \% \text { (calculated) } \\
\text { Providers: nephrology nurse specialists, physicians, dietitians, social workers }\end{array}$} \\
\hline \multicolumn{3}{|l|}{ Risk of bias } \\
\hline Bias & Authors' judgement & Support for judgement \\
\hline $\begin{array}{l}\text { Random } \\
\text { sequence } \\
\text { generation } \\
\text { (selection bias) }\end{array}$ & Unclear risk & $\begin{array}{l}\text { Sequence generation is not described explicitly in } \\
\text { the paper }\end{array}$ \\
\hline $\begin{array}{l}\text { Allocation } \\
\text { concealment } \\
\text { (selection bias) }\end{array}$ & Unclear risk & $\begin{array}{l}\text { Allocation concealment is not described explicitly in } \\
\text { the paper }\end{array}$ \\
\hline
\end{tabular}

Cochrane Database Syst Rev. Author manuscript; available in PMC 2016 June 09. 


\begin{tabular}{|c|c|c|}
\hline $\begin{array}{l}\text { Blinding } \\
\text { (performance } \\
\text { bias and } \\
\text { detection bias) } \\
\text { Participants }\end{array}$ & Unclear risk & This study did not assess this item. \\
\hline $\begin{array}{l}\text { Blinding } \\
\text { (performance } \\
\text { bias and } \\
\text { detection bias) } \\
\text { Providers }\end{array}$ & Low risk & $\begin{array}{l}\text { "Only the researcher knew which treatment patients } \\
\text { were receiving, and care providers were not } \\
\text { informed of participant's treatment group." }\end{array}$ \\
\hline $\begin{array}{l}\text { Blinding } \\
\text { (performance } \\
\text { bias and } \\
\text { detection bias) } \\
\text { Outcome } \\
\text { assessors }\end{array}$ & Unclear risk & This study did not assess this item. \\
\hline $\begin{array}{l}\text { Incomplete } \\
\text { outcome data } \\
\text { (attrition bias) } \\
\text { All outcomes }\end{array}$ & Low risk & $\begin{array}{l}\text { Plausible effect size among missing outcomes not } \\
\text { enough to have a clinically-relevant impact on } \\
\text { observed effect size }\end{array}$ \\
\hline $\begin{array}{l}\text { Selective } \\
\text { reporting } \\
\text { (reporting bias) }\end{array}$ & Unclear risk & No protocol. \\
\hline Other bias & Low risk & $\begin{array}{l}\text { Baseline imbalance for body weight change but } \\
\text { baseline differences in weight gain between groups } \\
\text { were taken into account in the repeated-measured } \\
\text { analysis by using the baseline values as a covariate. } \\
\text { Diet adherence is assessed by objective measure }\end{array}$ \\
\hline \multicolumn{3}{|l|}{ Wong 2010} \\
\hline Methods & \multicolumn{2}{|c|}{ Study design: randomized controlled trial with one intervention group and one control group } \\
\hline Participants & \multicolumn{2}{|c|}{$\begin{array}{l}\text { Setting: outpatient } \\
\text { Country: China } \\
\text { Chronic disease: renal failure (management) } \\
\text { Type of participants: clients }(\mathrm{n}=120) \\
\text { Mean age: intervention and control groups }(62.4) \\
\text { Sex: intervention and control groups (F: } 46.9 \%, \text { M: } 53.1 \%) \\
\text { Ethnicity: not known }\end{array}$} \\
\hline Interventions & \multicolumn{2}{|c|}{$\begin{array}{l}\text { Group 1: multiple intervention: telephone follow-up + goal setting; } 6 \text { weeks; }(n=60) \\
\text { Clients received a weekly telephone call consisting to monitoring changes from the specific health } \\
\text { concerns identified in the previous interaction, monitoring progress, providing health advice, } \\
\text { reinforcing health self-management behaviours, and assessing need for referral and reviewing the } \\
\text { health goals with the patient and setting mutual goals } \\
\text { Group 2: control (no telephone follow-up); duration: not known; }(n=60)\end{array}$} \\
\hline Outcomes & \multicolumn{2}{|c|}{$\begin{array}{l}\text { Measurement of diet adherence: non-adherence to diet and fluid-restricted diet assessed by dialysis } \\
\text { diet and fluid non-adherence questionnaire (baseline, } 7 \text { weeks, } 13 \text { weeks) }\end{array}$} \\
\hline Notes & \multicolumn{2}{|c|}{$\begin{array}{l}\text { Dietary advice: dialysis diet and fluid-restricted diet } \\
\text { Drop-out rate: } 18.3 \% \text { (calculated) } \\
\text { Providers: renal nurses and general nurses }\end{array}$} \\
\hline \multicolumn{3}{|l|}{ Risk of bias } \\
\hline Bias & Authors' judgement & Support for judgement \\
\hline $\begin{array}{l}\text { Random } \\
\text { sequence } \\
\text { generation } \\
\text { (selection bias) }\end{array}$ & Low risk & $\begin{array}{l}\text { "120 sets of computer-generated random numbers } \\
\text { were used, and patients who fitted the criteria were } \\
\text { randomised to the study or control group." }\end{array}$ \\
\hline $\begin{array}{l}\text { Allocation } \\
\text { concealment } \\
\text { (selection bias) }\end{array}$ & Unclear risk & $\begin{array}{l}\text { Allocation concealment is not described explicitly in } \\
\text { the paper }\end{array}$ \\
\hline $\begin{array}{l}\text { Blinding } \\
\text { (performance } \\
\text { bias and } \\
\text { detection bias) }\end{array}$ & Unclear risk & This study did not assess this item. \\
\hline
\end{tabular}

Cochrane Database Syst Rev. Author manuscript; available in PMC 2016 June 09. 


\begin{tabular}{|c|c|c|c|}
\hline \multicolumn{4}{|l|}{ Participants } \\
\hline $\begin{array}{l}\text { Blinding } \\
\text { (performance } \\
\text { bias and } \\
\text { detection bias) } \\
\text { Providers }\end{array}$ & \multicolumn{2}{|c|}{ Unclear risk } & This study did not assess this item. \\
\hline $\begin{array}{l}\text { Blinding } \\
\text { (performance } \\
\text { bias and } \\
\text { detection bias) } \\
\text { Outcome } \\
\text { assessors }\end{array}$ & \multicolumn{2}{|c|}{ Unclear risk } & This study did not assess this item. \\
\hline $\begin{array}{l}\text { Incomplete } \\
\text { outcome data } \\
\text { (attrition bias) } \\
\text { All outcomes }\end{array}$ & \multicolumn{2}{|l|}{ High risk } & $\begin{array}{l}\text { Plausible effect size among missing outcomes } \\
\text { enough to have a clinically-relevant impact on } \\
\text { observed effect size }\end{array}$ \\
\hline $\begin{array}{l}\text { Selective } \\
\text { reporting } \\
\text { (reporting bias) }\end{array}$ & \multicolumn{2}{|l|}{ High risk } & $\begin{array}{l}\text { No protocol. Some outcomes of interest in the } \\
\text { review are reported incompletely (blood glucose, } \\
\text { HDL-cholesterol, triglyceride) }\end{array}$ \\
\hline Other bias & \multicolumn{2}{|l|}{ Low risk } & $\begin{array}{l}\text { Baseline balance between groups. Diet adherence is } \\
\text { assessed by self-reported measure (validated } \\
\text { questionnaire) }\end{array}$ \\
\hline \multicolumn{4}{|l|}{ Wood 2008} \\
\hline Methods & \multicolumn{3}{|c|}{$\begin{array}{l}\text { Study design: cluster-randomized controlled trial with two populations including one intervention } \\
\text { group and one usual care group each } \\
\text { Two populations were studied in this study: clients with coronary heart disease (population 1) and } \\
\text { clients at high risk of cardiovascular disease (population 2) }\end{array}$} \\
\hline Participants & $\begin{array}{c}\text { Setting: } \\
\bullet \\
\text { Country: } \\
\bullet \\
\text { Chronic d } \\
\bullet \\
\text { • } \\
\text { Type of p } \\
\bullet \\
\text { Mean age } \\
\bullet \\
\bullet \\
\text { Sex: } \\
\bullet \\
\bullet\end{array}$ & $\begin{array}{l}\text { Population 1: outpatient } \\
\text { Population 2: outpatient } \\
\text { Population 1: France, Italy, } \mathrm{I} \\
\text { Population2: Denmark, Italy } \\
\text { se: } \\
\text { Population 1: coronary hear } \\
\text { Population 2: high risk of cc } \\
\text { cipants: } \\
\text { Population 1: clients (n = 30 } \\
\text { Population 2: clients (n = 23 } \\
\text { Population 1: intervention ( } \\
\text { Population 2: intervention ( } \\
\text { Population 1: intervention (l } \\
\text { Population 2: intervention (l } \\
\text { Ethnicity: not known }\end{array}$ & $\begin{array}{l}\text { and, Spain, Sweden, United Kingdom } \\
\text { oland, Spain, Netherlands, United Kingdom } \\
\text { isease (management) } \\
\text { nary heart disease (prevention) } \\
5 \pm 9.9 \text { ), usual care (63.0 } \pm 9.6) \\
0 \pm 7.6 \text { ), usual care (62.8 } \pm 7.3 \text { ) } \\
30 \%, \text { M: } 70 \% \text { ) and usual care (F: } 30 \%, \text { M: } 70 \% \text { ) } \\
50 \%, \text { M: } 50 \% \text { ) and usual care (F: } 43 \%, \text { M: } 57 \% \text { ) }\end{array}$ \\
\hline Interventions & \multicolumn{3}{|c|}{$\begin{array}{l}\text { Population 1: } \\
\text { Group 1: multiple intervention: individual session with nurse + motivational interviewing; }(\mathrm{n}= \\
\text { 1589) } \\
\text { Clients and their partners attended at least eight weekly sessions with multidisciplinary team using } \\
\text { stages of change and motivational interviews. Clients were provided with a personal record card } \\
\text { for lifestyle and risk factor targets. Nurses also coordinated a rolling program of eight weekly } \\
\text { workshops for coronary heart disease, cardiovascular risk (lifestyle and risk factors control), } \\
\text { cardioprotective medication and return to work and leisure. }\end{array}$} \\
\hline
\end{tabular}

Cochrane Database Syst Rev. Author manuscript; available in PMC 2016 June 09. 


\begin{tabular}{|c|c|c|}
\hline & \multicolumn{2}{|c|}{$\begin{array}{l}\text { Group 2: usual care; duration: not known; }(\mathrm{n}=1499) \\
\text { Population 2: } \\
\text { Group 1: multiple intervention: individual session with nurse + motivational interviewing; }(\mathrm{n}= \\
\text { 1189) } \\
\text { Clients and their partners attended at least eight weekly sessions with nurse and the family doctor } \\
\text { using stages of changes and motivational interviews. Clients were provided with a personal record } \\
\text { card for lifestyle and risk factor targets. Nurses also coordinated a rolling program of eight weekly } \\
\text { workshops for lifestyle and risk factors. } \\
\text { Group 2: usual care; duration: not known; }(n=1128)\end{array}$} \\
\hline Outcomes & \multicolumn{2}{|c|}{$\begin{array}{l}\text { Measurement of diet adherence: adherence to saturated fat, oily fish, fish, and fruit and vegetables } \\
\text { intake assessed by a food-habit questionnaire (baseline, } 1 \text { year) }\end{array}$} \\
\hline Notes & \multicolumn{2}{|c|}{$\begin{array}{l}\text { Dietary advice: }<10 \% \text { of energy from saturated fat, }>400 \mathrm{~g} / \text { day of fruit and vegetables, }>20 \\
\mathrm{~g} / \text { day of fish, }>3 \text { times/week of oily fish, }<30 \mathrm{~g} / \text { day of alcohol } \\
\text { Drop-out rate: not known } \\
\text { Providers: } \\
\begin{array}{l}\text { - } \\
\text { Population 1: nurses, dietitians, physiotherapists, cardiologists } \\
\quad \text { Population 2: nurses, family doctors }\end{array}\end{array}$} \\
\hline \multicolumn{3}{|l|}{ Risk of bias } \\
\hline Bias & Authors' judgement & Support for judgement \\
\hline $\begin{array}{l}\text { Random } \\
\text { sequence } \\
\text { generation } \\
\text { (selection bias) }\end{array}$ & Unclear risk & $\begin{array}{l}\text { Sequence generation is not described explicitly in } \\
\text { the paper }\end{array}$ \\
\hline $\begin{array}{l}\text { Allocation } \\
\text { concealment } \\
\text { (selection bias) }\end{array}$ & Unclear risk & $\begin{array}{l}\text { Allocation concealment is not described explicitly in } \\
\text { the paper }\end{array}$ \\
\hline $\begin{array}{l}\text { Blinding } \\
\text { (performance } \\
\text { bias and } \\
\text { detection bias) } \\
\text { Participants }\end{array}$ & Unclear risk & This study did not assess this item. \\
\hline $\begin{array}{l}\text { Blinding } \\
\text { (performance } \\
\text { bias and } \\
\text { detection bias) } \\
\text { Providers }\end{array}$ & Unclear risk & This study did not assess this item. \\
\hline $\begin{array}{l}\text { Blinding } \\
\text { (performance } \\
\text { bias and } \\
\text { detection bias) } \\
\text { Outcome } \\
\text { assessors }\end{array}$ & Unclear risk & This study did not assess this item. \\
\hline $\begin{array}{l}\text { Incomplete } \\
\text { outcome data } \\
\text { (attrition bias) } \\
\text { All outcomes }\end{array}$ & High risk & $\begin{array}{l}\text { The proportion of missing outcomes compared with } \\
\text { observed risk enough to induce clinically-relevant } \\
\text { bias in intervention effect estimate }\end{array}$ \\
\hline $\begin{array}{l}\text { Selective } \\
\text { reporting } \\
\text { (reporting bias) }\end{array}$ & High risk & $\begin{array}{l}\text { No protocol. Some outcomes of interest in the } \\
\text { review are reported incompletely (HDL-cholesterol, } \\
\text { triglyceride) }\end{array}$ \\
\hline Other bias & Unclear risk & $\begin{array}{l}\text { Baseline comparisons between groups are not } \\
\text { reported. Diet adherence is assessed by self-reported } \\
\text { measure (validated food habit questionnaire) }\end{array}$ \\
\hline \multicolumn{3}{|l|}{ Zhao 2004} \\
\hline Methods & \multicolumn{2}{|c|}{ Study design: randomized controlled trial with one intervention group and one usual care group } \\
\hline Participants & \multicolumn{2}{|c|}{$\begin{array}{l}\text { Setting: outpatient } \\
\text { Country: China } \\
\text { Chronic disease: coronary heart disease (management) } \\
\text { Type of participants: clients }(\mathrm{n}=220) \\
\text { Mean age: intervention }(72.9 \pm 6.4) \text {, usual care }(71.6 \pm 4.1) \\
\text { Sex: intervention (F: } 49 \%, \mathrm{M}: 51 \%) \text { and usual care (F: } 53 \%, \mathrm{M}: 47 \%)\end{array}$} \\
\hline
\end{tabular}

Cochrane Database Syst Rev. Author manuscript; available in PMC 2016 June 09. 


\begin{tabular}{|c|c|c|}
\hline & \multicolumn{2}{|l|}{ Ethnicity: not known } \\
\hline Interventions & \multicolumn{2}{|c|}{$\begin{array}{l}\text { Group 1: multiple intervention: telephone follow-up + individual session with a nurse + goal } \\
\text { setting; } 4 \text { weeks; }(\mathrm{n}=107) \\
\text { Nurse provided one home visit on the second day after discharge and another in the third week and } \\
\text { made two telephone calls in the second and fourth weeks. Nurse set goals with the clients and } \\
\text { assessed whether the clients achieved them. } \\
\text { Group 2: usual care (no visit nor telephone follow-up) ; duration: not known; }(\mathrm{n}=113)\end{array}$} \\
\hline Outcomes & \multicolumn{2}{|c|}{$\begin{array}{l}\text { Measurement of diet adherence: adherence to diet assessed by a seven-day recall questionnaire } \\
\text { (baseline, } 4 \text { weeks, } 12 \text { weeks) }\end{array}$} \\
\hline Notes & \multicolumn{2}{|c|}{$\begin{array}{l}\text { Dietary advice: not known } \\
\text { Drop-out rate: } 9.1 \% \text { (calculated) } \\
\text { Providers: nurses }\end{array}$} \\
\hline \multicolumn{3}{|l|}{ Risk of bias } \\
\hline Bias & Authors' judgement & Support for judgement \\
\hline $\begin{array}{l}\text { Random } \\
\text { sequence } \\
\text { generation } \\
\text { (selection bias) }\end{array}$ & Low risk & $\begin{array}{l}\text { "The patients who agreed to participate would be } \\
\text { assigned to the study or control group using a } \\
\text { computer-generated randomised table, with a } \\
\text { computer number "0" belonged to the control group } \\
\text { and "1"the study group." }\end{array}$ \\
\hline $\begin{array}{l}\text { Allocation } \\
\text { concealment } \\
\text { (selection bias) }\end{array}$ & Low risk & $\begin{array}{l}\text { "...the head nurse asked the eligible patients to draw } \\
\text { sealed envelop that contained a slip indicating the } \\
\text { group the patient be entered..." }\end{array}$ \\
\hline $\begin{array}{l}\text { Blinding } \\
\text { (performance } \\
\text { bias and } \\
\text { detection bias) } \\
\text { Participants }\end{array}$ & Unclear risk & This study did not assess this item. \\
\hline $\begin{array}{l}\text { Blinding } \\
\text { (performance } \\
\text { bias and } \\
\text { detection bias) } \\
\text { Providers }\end{array}$ & Unclear risk & This study did not assess this item. \\
\hline $\begin{array}{l}\text { Blinding } \\
\text { (performance } \\
\text { bias and } \\
\text { detection bias) } \\
\text { Outcome } \\
\text { assessors }\end{array}$ & Low risk & $\begin{array}{l}\text { "The measurement team was blinded of which group } \\
\text { the subjects were in." }\end{array}$ \\
\hline $\begin{array}{l}\text { Incomplete } \\
\text { outcome data } \\
\text { (attrition bias) } \\
\text { All outcomes }\end{array}$ & Low risk & $\begin{array}{l}\text { Missing outcome data balanced in numbers across } \\
\text { intervention groups, with similar reasons for missing } \\
\text { data across groups }\end{array}$ \\
\hline $\begin{array}{l}\text { Selective } \\
\text { reporting } \\
\text { (reporting bias) }\end{array}$ & Unclear risk & No protocol. \\
\hline Other bias & High risk & $\begin{array}{l}\text { Baseline imbalance between groups (number of } \\
\text { chronic diseases). Diet adherence is assessed by self- } \\
\text { reported measure (validated 7-day recall } \\
\text { questionnaire) }\end{array}$ \\
\hline
\end{tabular}

\section{Characteristics of excluded studies [ordered by study ID]}

\begin{tabular}{|l|l|}
\hline Study & Reason for exclusion \\
\hline Abramson 1980 & No measure of adherence outcome. \\
\hline Agras 1996 & Provision of meals, food items or dietary supplements. \\
\hline Ammerman 2003 & No measure of adherence outcome. \\
\hline
\end{tabular}

Cochrane Database Syst Rev. Author manuscript; available in PMC 2016 June 09. 


\begin{tabular}{|c|c|}
\hline Study & Reason for exclusion \\
\hline Arnaud-Battandier 1999 & Provision of meals, food items or dietary supplements. \\
\hline Ashurst 2003 & Interventions had not the same dietary advice component \\
\hline Atwood 1992 & Interventions had not the same dietary advice component \\
\hline Babamoto 2009 & No measure of adherence outcome. \\
\hline Basler 1982 & No measure of adherence outcome. \\
\hline Baum 1991 & No measure of adherence outcome. \\
\hline Befort 2008 & No measure of adherence outcome. \\
\hline Berra 2007 & No measure of adherence outcome. \\
\hline Berteus 2008 & Interventions had not the same dietary advice component \\
\hline Bertram 1990 & Intervention not intended to improve diet adherence. \\
\hline Boeka 2010 & No measure of adherence outcome. \\
\hline Borg 2002 & No measure of adherence outcome. \\
\hline Bosworth 2008 & No measure of adherence outcome. \\
\hline Brekke 2003 & No measure of adherence outcome. \\
\hline Brekke 2005a & No measure of adherence outcome. \\
\hline Brekke 2005b & No measure of adherence outcome. \\
\hline Brekke 2009 & No measure of adherence outcome. \\
\hline Broekhuizen 2010 & No measure of adherence outcome. \\
\hline Bruckert 2008 & Interventions had not the same dietary advice component \\
\hline Burke 2005 & Interventions had not the same dietary advice component \\
\hline Burke 2006a & No measure of adherence outcome. \\
\hline Burke 2006b & No measure of adherence outcome. \\
\hline Burke 2007 & No measure of adherence outcome. \\
\hline Burke 2008 & No measure of adherence outcome. \\
\hline Burke 2010 & No measure of adherence outcome. \\
\hline Burkett 1990 & No measure of adherence outcome. \\
\hline Campbell 1984 & No measure of adherence outcome. \\
\hline Campbell 1990 & Interventions had not the same dietary advice component \\
\hline Campbell 1998 & Interventions had not the same dietary advice component \\
\hline Cangiano 1991 & Provision of meals, food items or dietary supplements. \\
\hline Cangiano 1992 & Provision of meals, food items or dietary supplements. \\
\hline Cangiano 1998 & Provision of meals, food items or dietary supplements. \\
\hline Carels 2005 & Interventions had not the same dietary advice component \\
\hline Carels 2005a & Interventions had not the same dietary advice component \\
\hline Carson 1988 & No measure of adherence outcome. \\
\hline Casebeer 1999 & No measure of adherence outcome. \\
\hline Cegala 2000 & No measure of adherence outcome. \\
\hline Chang 2009 & No measure of adherence outcome. \\
\hline Cheyette 2007 & No measure of adherence outcome. \\
\hline
\end{tabular}

Cochrane Database Syst Rev. Author manuscript; available in PMC 2016 June 09. 


\begin{tabular}{|c|c|}
\hline Study & Reason for exclusion \\
\hline Chlebowski 1993 & Interventions had not the same dietary advice component \\
\hline Costa 2008 & No measure of adherence outcome. \\
\hline Darlington 1986 & No measure of adherence outcome. \\
\hline Davidson 1996 & Provision of meals, food items or dietary supplements. \\
\hline De Zwaan 2005 & Provision of meals, food items or dietary supplements. \\
\hline Dechamps 2009 & No measure of adherence outcome. \\
\hline Del 2009 & Provision of meals, food items or dietary supplements. \\
\hline Demark-Wahnefried 2006 & Interventions had not the same dietary advice component \\
\hline Dennis 2001 & No measure of adherence outcome. \\
\hline Digenio 2009 & Interventions had not the same dietary advice component \\
\hline Domenech 1995 & Interventions had not the same dietary advice component \\
\hline Donnelly 2003 & Provision of meals, food items or dietary supplements. \\
\hline Dyson 1997 & No measure of adherence outcome. \\
\hline Eriksson 2009 & No measure of adherence outcome. \\
\hline Evers 1987 & Interventions had not the same dietary advice component \\
\hline Farmer 2009 & No measure of adherence outcome. \\
\hline Fehily 1991 & Interventions had not the same dietary advice component \\
\hline Ferrante 2010 & Interventions had not the same dietary advice component \\
\hline Fitzgibbon 2005 & No measure of adherence outcome. \\
\hline Forget 1990 & Provision of meals, food items or dietary supplements. \\
\hline Forli 2001 & Provision of meals, food items or dietary supplements. \\
\hline Forrester 2010 & Interventions had not the same dietary advice component \\
\hline Fox 1996 & No measure of adherence outcome. \\
\hline Frohling 1990 & Provision of meals, food items or dietary supplements. \\
\hline Frost 2007 & Interventions had not the same dietary advice component \\
\hline Fuchs 1993 & No measure of adherence outcome. \\
\hline Glasgow 2003 & No measure of adherence outcome. \\
\hline Gorin 2010 & No measure of adherence outcome. \\
\hline Grancelli 2003 & Interventions had not the same dietary advice component \\
\hline Greene 1977 & No measure of adherence outcome. \\
\hline Hakala 1993 & Provision of meals, food items or dietary supplements. \\
\hline Hartwell 1986 & No measure of adherence outcome. \\
\hline Harvey-Berino 2004 & No measure of adherence outcome. \\
\hline Harvey-Berino 2009 & No measure of adherence outcome. \\
\hline Hebert 2001 & Interventions had not the same dietary advice component \\
\hline Henkin 2000 & Interventions had not the same dietary advice component \\
\hline Heraief 1985 & Provision of meals, food items or dietary supplements. \\
\hline Hyman 1998 & No measure of adherence outcome. \\
\hline Jolly 1998 & No measure of adherence outcome. \\
\hline
\end{tabular}

Cochrane Database Syst Rev. Author manuscript; available in PMC 2016 June 09. 


\begin{tabular}{|c|c|}
\hline Study & Reason for exclusion \\
\hline Jolly 2007 & No measure of adherence outcome. \\
\hline Jones 2003 & No measure of adherence outcome. \\
\hline Jula 1990 & Interventions had not the same dietary advice component. \\
\hline Kaiman 2000 & Provision of meals, food items or dietary supplements. \\
\hline Kalodner 1991 & Interventions had not the same dietary advice component. \\
\hline Kalter-Leibovici 2010 & No measure of adherence outcome. \\
\hline Kattelmann 2009 & Interventions had not the same dietary advice component. \\
\hline Khoo 2007 & Provision of meals, food items or dietary supplements. \\
\hline Kim 2006 & No measure of adherence outcome. \\
\hline Kirkman 1994 & Interventions had not the same dietary advice component. \\
\hline Koelewijn-van Loon 2009 & Interventions had not the same dietary advice component. \\
\hline Korhonen 1983 & No measure of adherence outcome. \\
\hline Korhonen 2003 & No measure of adherence outcome. \\
\hline Krier 1999 & Interventions had not the same dietary advice component. \\
\hline Kumanyika 1993 & Interventions had not the same dietary advice component. \\
\hline Lampman 1977 & Interventions had not the same dietary advice component. \\
\hline Laws 2004 & No measure of adherence outcome. \\
\hline Leermakers 1999 & Intervention not intended to improve diet adherence \\
\hline Lesley 2007 & No measure of adherence outcome. \\
\hline Lindahl 2009 & Not a real-life setting. \\
\hline Locatelli 1990 & Interventions had not the same dietary advice component. \\
\hline Lopez 2006 & No measure of adherence outcome. \\
\hline Manchanda 2000 & Interventions had not the same dietary advice component. \\
\hline Mathus-Vliegen 1993 & Intervention not intended to improve diet adherence \\
\hline McCarron 1998 & Provision of meals, food items or dietary supplements. \\
\hline McConnon 2007 & No measure of adherence outcome. \\
\hline McConnon 2009 & No measure of adherence outcome. \\
\hline Melchionda 2006 & No measure of adherence outcome. \\
\hline Melin 2003 & Not a real-life setting. \\
\hline Metz 1997 & Provision of meals, food items or dietary supplements. \\
\hline Metz 2000 & Provision of meals, food items or dietary supplements. \\
\hline Mhurchu 1998 & No measure of adherence outcome. \\
\hline Milas 1995 & Interventions had not the same dietary advice component. \\
\hline Miller 2009 & Interventions had not the same dietary advice component. \\
\hline Morgan 2009 & No measure of adherence outcome. \\
\hline Nir 2004 & Interventions had not the same dietary advice component. \\
\hline Nugent 1984 & No measure of adherence outcome. \\
\hline Oldroyd 2006 & Interventions had not the same dietary advice component. \\
\hline Ornish 1998 & Interventions had not the same dietary advice component. \\
\hline
\end{tabular}

Cochrane Database Syst Rev. Author manuscript; available in PMC 2016 June 09. 


\begin{tabular}{|c|c|}
\hline Study & Reason for exclusion \\
\hline Pater 2000 & No measure of adherence outcome. \\
\hline Pettman 2008 & No measure of adherence outcome. \\
\hline Pierce 1997 & Interventions had not the same dietary advice component. \\
\hline Pierce 2002 & Interventions had not the same dietary advice component. \\
\hline Pierce 2007 & Interventions had not the same dietary advice component. \\
\hline Pijls 2000 & Interventions had not the same dietary advice component. \\
\hline Pringle 1993 & No measure of adherence outcome. \\
\hline Rabkin 1983 & No measure of adherence outcome. \\
\hline Racette 1995 & Interventions had not the same dietary advice component. \\
\hline Rallidis 2009 & Provision of meals, food items or dietary supplements. \\
\hline Rhew 2007 & Study did not involve a nutritional intervention \\
\hline Rimmer 2000 & No measure of adherence outcome. \\
\hline Robertson 1992 & No measure of adherence outcome. \\
\hline Rosman 1989 & Interventions had not the same dietary advice component. \\
\hline Rosman 1990 & Interventions had not the same dietary advice component. \\
\hline Roumen 2008 & No measure of adherence outcome. \\
\hline Sadur 1999 & No measure of adherence outcome. \\
\hline Sartorio 2003 & No measure of adherence outcome. \\
\hline Schapira 1991 & No measure of adherence outcome. \\
\hline Sevick 2008 & Interventions had not the same dietary advice component. \\
\hline Shaw-Stuart 2000 & No measure of adherence outcome. \\
\hline Singh 1991 & Interventions had not the same dietary advice component. \\
\hline Singh 1992 & Interventions had not the same dietary advice component. \\
\hline Sisk 2006 & No measure of adherence outcome. \\
\hline Smith 1997 & No measure of adherence outcome. \\
\hline Sone 2010 & No measure of adherence outcome. \\
\hline Southard 2003 & No measure of adherence outcome. \\
\hline Sperduto 1986 & No measure of adherence outcome. \\
\hline Thoolen 2009 & No measure of adherence outcome. \\
\hline Tilley 1997 & No measure of adherence outcome. \\
\hline Toobert 1998 & Interventions had not the same dietary advice component. \\
\hline Toobert 2000 & Interventions had not the same dietary advice component. \\
\hline Torgerson 1999 & Provision of meals, food items or dietary supplements. \\
\hline Tsang 2001 & No measure of adherence outcome. \\
\hline Vale 2003 & Interventions had not the same dietary advice component. \\
\hline van der Weijden 1998 & Interventions had not the same dietary advice component. \\
\hline van Gool 2006 & Interventions had not the same dietary advice component. \\
\hline Verges 1998 & No measure of adherence outcome. \\
\hline Voils 2009 & No measure of adherence outcome. \\
\hline
\end{tabular}

Cochrane Database Syst Rev. Author manuscript; available in PMC 2016 June 09. 


\begin{tabular}{|l|l|}
\hline Study & Reason for exclusion \\
\hline von Gruenigen 2008 & No measure of adherence outcome. \\
\hline Wadden 1997 & No measure of adherence outcome. \\
\hline Wadden 2009 & Provision of meals, food items or dietary supplements. \\
\hline Webber 2010 & No measure of adherence outcome. \\
\hline Wing 1986 & No measure of adherence outcome. \\
\hline Wing 1996 & No measure of adherence outcome. \\
\hline Wing 1999 & No measure of adherence outcome. \\
\hline Wing 2003 & Intervention not intended to improve diet adherence. \\
\hline Witmer 2004 & No measure of adherence outcome. \\
\hline Wright 1981 & No measure of adherence outcome. \\
\hline Zismer 1982 & No measure of adherence outcome. \\
\hline
\end{tabular}

Characteristics of studies awaiting assessment [ordered by study ID]

\begin{tabular}{|c|c|}
\hline \multicolumn{2}{|l|}{ Aldous 2009} \\
\hline Methods & Study design: not known \\
\hline Participants & $\begin{array}{l}\text { Setting: not known } \\
\text { Country: Canada } \\
\text { Chronic disease: not known } \\
\text { Type of participants: clients }\end{array}$ \\
\hline Interventions & $\begin{array}{l}\text { The intervention Community Cardiovascular Hearts in Motion is a multidisciplinary, multi-vascular } \\
\text { program combining nutrition intervention, weekly exercise, and risk factor management including } \\
\text { motivational interviewing and behaviour change techniques }\end{array}$ \\
\hline Outcomes & Measurement of diet adherence: not known \\
\hline Notes & $\begin{array}{l}\text { Dietary advice: not known } \\
\text { Provider: dietitian } \\
\text { No response to attempted contact with author. }\end{array}$ \\
\hline \multicolumn{2}{|l|}{ Amato 1990} \\
\hline Methods & Study design: randomized controlled trial with one intervention group and one usual care group \\
\hline Participants & $\begin{array}{l}\text { Setting: not known } \\
\text { Country: Italy } \\
\text { Chronic disease: obesity (management) } \\
\text { Type of participants: clients }\end{array}$ \\
\hline Interventions & $\begin{array}{l}\text { The study compared an intervention using a psychological therapy combined with the usual diet } \\
\text { treatment with an usual care group receiving only the usual diet }\end{array}$ \\
\hline Outcomes & Measurement of diet adherence: adherence to diet \\
\hline Notes & $\begin{array}{l}\text { Dietary advice: not known } \\
\text { Provider: not known } \\
\text { The study was published in Italian and only the abstract was available in English }\end{array}$ \\
\hline \multicolumn{2}{|l|}{ Clark 2004} \\
\hline Methods & Study design: randomized controlled trial with one intervention group and one usual care group \\
\hline Participants & $\begin{array}{l}\text { Setting: outpatient } \\
\text { Country: United Kingdom } \\
\text { Chronic disease: type II diabetes (management) } \\
\text { Type of participants: clients }\end{array}$ \\
\hline Interventions & $\begin{array}{l}\text { A brief, tailored lifestyle self-management intervention including assessment, clients' participation in } \\
\text { goal setting, selection of personalized strategies to overcome barriers }\end{array}$ \\
\hline
\end{tabular}

Cochrane Database Syst Rev. Author manuscript; available in PMC 2016 June 09. 


\begin{tabular}{|c|c|}
\hline Outcomes & $\begin{array}{l}\text { Measurement of diet adherence: adherence to fat restriction assessed by the Kristal Food Habits } \\
\text { Questionnaire and the Block Fat Screener }\end{array}$ \\
\hline Notes & $\begin{array}{l}\text { Dietary advice: not known } \\
\text { Provider: not known } \\
\text { The corresponding author was contacted in order to have more information about the dietary advice } \\
\text { provided in both groups. However, no response to attempted contact with author }\end{array}$ \\
\hline \multicolumn{2}{|l|}{ Contel 1993} \\
\hline Methods & Study design: not known \\
\hline Participants & $\begin{array}{l}\text { Setting: not known } \\
\text { Country: not known } \\
\text { Chronic disease: not known } \\
\text { Type of participants: not known }\end{array}$ \\
\hline Interventions & Not known \\
\hline Outcomes & Measurement of diet adherence: not known \\
\hline Notes & $\begin{array}{l}\text { Diet: not known } \\
\text { Provider: not known } \\
\text { Abstract unobtainable. }\end{array}$ \\
\hline \multicolumn{2}{|l|}{ Duncan 2001} \\
\hline Methods & Study design: randomized controlled trial with one intervention group and one control group \\
\hline Participants & $\begin{array}{l}\text { Setting: not known } \\
\text { Country: United States } \\
\text { Chronic disease: congestive heart failure (management) } \\
\text { Type of participants: clients }\end{array}$ \\
\hline Interventions & $\begin{array}{l}\text { A behavioural intervention consisting of feedback on the three-day sodium intake of the clients and a } \\
\text { discussion of problem-solving strategies to reduce future sodium intake was compared to a control } \\
\text { group. Both groups received the usual dietary education class }\end{array}$ \\
\hline Outcomes & $\begin{array}{l}\text { Measurement of diet adherence: adherence to dietary sodium advice assessed by a three-day dietary } \\
\text { intake log }\end{array}$ \\
\hline Notes & $\begin{array}{l}\text { Dietary advice: sodium-restricted diet } \\
\text { Provider: not known } \\
\text { Contact with author: data no longer available. Therefore, the inclusion criteria of use of provision of } \\
\text { meals, food items or dietary supplements could not be assessed }\end{array}$ \\
\hline \multicolumn{2}{|c|}{ Fernández López 2007} \\
\hline Methods & Study design: randomized controlled trial with two intervention groups and one control group \\
\hline Participants & $\begin{array}{l}\text { Setting: outpatient } \\
\text { Country: Spain } \\
\text { Chronic disease: hypertension (management) } \\
\text { Type of participants: clients }\end{array}$ \\
\hline Interventions & $\begin{array}{l}\text { The study compared an educative sessions intervention and an intervention consisting to provide } \\
\text { written information to clients with a control group }\end{array}$ \\
\hline Outcomes & Measurement of diet adherence: not known \\
\hline Notes & $\begin{array}{l}\text { Dietary advice: not known } \\
\text { Providers: nurses } \\
\text { No response to attempted contact with author(s). }\end{array}$ \\
\hline \multicolumn{2}{|l|}{ Firth 2009} \\
\hline Methods & Study design: not known \\
\hline Participants & $\begin{array}{l}\text { Setting: not known } \\
\text { Country: Canada } \\
\text { Chronic disease: not known } \\
\text { Type of participants: clients }\end{array}$ \\
\hline Interventions & The intervention was a web-based, self-monitoring wellness program \\
\hline Outcomes & Measurement of diet adherence: not known \\
\hline Notes & $\begin{array}{l}\text { Dietary advice: not known } \\
\text { Provider: not known }\end{array}$ \\
\hline
\end{tabular}

Cochrane Database Syst Rev. Author manuscript; available in PMC 2016 June 09. 


\begin{tabular}{|c|c|}
\hline \multicolumn{2}{|l|}{ González 1987} \\
\hline Methods & Study design: not known \\
\hline Participants & $\begin{array}{l}\text { Setting: not known } \\
\text { Country: not known } \\
\text { Chronic disease: not known } \\
\text { Type of participants: not known }\end{array}$ \\
\hline Interventions & Not known \\
\hline Outcomes & Measurement of diet adherence: not known \\
\hline Notes & $\begin{array}{l}\text { Dietary advice: not known } \\
\text { Provider: not known } \\
\text { Abstract unobtainable. }\end{array}$ \\
\hline \multicolumn{2}{|l|}{ Hauner 2006} \\
\hline Methods & Study design: randomized controlled trial with one intervention group and one usual care group \\
\hline Participants & $\begin{array}{l}\text { Setting: not known } \\
\text { Country: Germany } \\
\text { Chronic disease: type II diabetes (management) } \\
\text { Type of participants: clients }\end{array}$ \\
\hline Interventions & $\begin{array}{l}\text { The study compared an intense nutritional training program (diet, knowledge about diabetes, physical } \\
\text { activities and other lifestyle factors) with an usual care group }\end{array}$ \\
\hline Outcomes & Measurement of diet adherence: not known \\
\hline Notes & $\begin{array}{l}\text { Dietary advice: not known } \\
\text { Provider: not known } \\
\text { No response to attempted contact with author. }\end{array}$ \\
\hline \multicolumn{2}{|l|}{ Kim 2003} \\
\hline Methods & Study design: randomized controlled trial with one intervention group and one control group \\
\hline Participants & $\begin{array}{l}\text { Setting: outpatient } \\
\text { Country: Korea } \\
\text { Chronic disease: type II diabetes (management) } \\
\text { Type of participants: clients }\end{array}$ \\
\hline Interventions & $\begin{array}{l}\text { The study compared a telephone follow-up intervention including self-monitoring blood glucose levels, } \\
\text { diet and exercise, feedback from a dietitian and an informative booklet with a control group }\end{array}$ \\
\hline Outcomes & Measurement of diet adherence: adherence to diet assessed by a self-reported adherence questionnaire \\
\hline Notes & $\begin{array}{l}\text { Dietary advice: not known } \\
\text { Providers: nurse, dietitian } \\
\text { The corresponding authors were contacted in order to have more information about the dietary advice } \\
\text { provided in both groups. However, no response to attempted contact with authors }\end{array}$ \\
\hline \multicolumn{2}{|l|}{ Koprucki 2010} \\
\hline Methods & Study design: randomized controlled trial with one intervention group and one control group \\
\hline Participants & $\begin{array}{l}\text { Setting: not known } \\
\text { Country: United States } \\
\text { Chronic disease: chronic kidney disease (management) } \\
\text { Type of participants: clients }\end{array}$ \\
\hline Interventions & $\begin{array}{l}\text { The study compared an intervention group in which clients monitored dietary intake with a personal } \\
\text { digital assistant (PDA) programmed with their dietary prescription and received PDA feedback } \\
\text { regarding \% of daily targets consumed and counselling based on Social Cognitive Theory with a } \\
\text { control group }\end{array}$ \\
\hline Outcomes & Measurement of diet adherence: not known \\
\hline Notes & $\begin{array}{l}\text { Dietary advice: sodium-restricted diet } \\
\text { Provider: not known } \\
\text { Contact with author(s): information provided does not allow including or excluding the study }\end{array}$ \\
\hline \multicolumn{2}{|l|}{ Lin 2007} \\
\hline Methods & Study design: randomized controlled trial with three intervention groups \\
\hline
\end{tabular}

Cochrane Database Syst Rev. Author manuscript; available in PMC 2016 June 09. 


\begin{tabular}{|c|c|}
\hline Participants & $\begin{array}{l}\text { Setting: community } \\
\text { Country: Taiwan } \\
\text { Chronic disease: overweight and obesity (prevention/management) } \\
\text { Type of participants: clients }\end{array}$ \\
\hline Interventions & $\begin{array}{l}\text { The study compared: 1) an individualized weight control education, 2) a group weight control } \\
\text { education and 3) a mail-delivered weight control education }\end{array}$ \\
\hline Outcomes & Measurement of diet adherence: not known \\
\hline Notes & $\begin{array}{l}\text { Dietary advice: not known } \\
\text { Provider: not known } \\
\text { No response to attempted contact with authors. }\end{array}$ \\
\hline \multicolumn{2}{|c|}{ Martínez-Marcos 1999} \\
\hline Methods & Study design: not known \\
\hline Participants & $\begin{array}{l}\text { Setting: not known } \\
\text { Country: not known } \\
\text { Chronic disease: not known } \\
\text { Type of participants: not known }\end{array}$ \\
\hline Interventions & Not known \\
\hline Outcomes & Measurement of diet adherence: not known \\
\hline Notes & $\begin{array}{l}\text { Dietary advice: not known } \\
\text { Provider: not known } \\
\text { Abstract unobtainable. }\end{array}$ \\
\hline \multicolumn{2}{|l|}{ Mayeux 2004} \\
\hline Methods & Study design: not known \\
\hline Participants & $\begin{array}{l}\text { Setting: not known } \\
\text { Country: United States } \\
\text { Chronic disease: not known } \\
\text { Type of participants: clients }\end{array}$ \\
\hline Interventions & $\begin{array}{l}\text { The study compared an Aramark Nutrition Concepts } \odot \text { Survival Skills diet education using a condensed } \\
\text { one-page handout with a traditional diet education using in-depth material }\end{array}$ \\
\hline Outcomes & Measurement of diet adherence: adherence to diet assessed by a telephone survey \\
\hline Notes & $\begin{array}{l}\text { Dietary advice: not known } \\
\text { Provider: dietitian } \\
\text { Address for authors correspondence not found. }\end{array}$ \\
\hline \multicolumn{2}{|l|}{ Mensink 2003} \\
\hline Methods & Study design: randomized controlled trial with one intervention group and one control group \\
\hline Participants & $\begin{array}{l}\text { Setting: not known } \\
\text { Country: Netherlands } \\
\text { Chronic disease: glucose intolerance (prevention) } \\
\text { Type of participants: clients }\end{array}$ \\
\hline Interventions & $\begin{array}{l}\text { The study compared an intensive intervention aiming to stimulate the dietary change and the physical } \\
\text { activity with a control group }\end{array}$ \\
\hline Outcomes & Measurement of diet adherence: adherence to diet assessed by a three-day food record \\
\hline Notes & $\begin{array}{l}\text { Dietary advice: Dutch guidelines for a healthy diet (Dutch Nutrition Council) } \\
\text { Providers: dietitians and trainers } \\
\text { The author was contacted in order to obtain more information about the dietary advice provided in both } \\
\text { groups. } \\
\text { However, there was no response to our attempted contact with author }\end{array}$ \\
\hline \multicolumn{2}{|l|}{ Paisey 2005} \\
\hline Methods & Study design: randomized controlled trial with one intervention group and one control group \\
\hline Participants & $\begin{array}{l}\text { Setting: not known } \\
\text { Country: United Kingdom } \\
\text { Health problem: type II diabetes (management) } \\
\text { Type of participants: clients }\end{array}$ \\
\hline
\end{tabular}

Cochrane Database Syst Rev. Author manuscript; available in PMC 2016 June 09. 


\begin{tabular}{|c|c|}
\hline Interventions & $\begin{array}{l}\text { The study compared an intensive group using self-monitoring of food intake and feedback with a } \\
\text { control group }\end{array}$ \\
\hline Outcomes & Measurement of diet adherence: not known \\
\hline Notes & $\begin{array}{l}\text { Dietary advice: diabetes United Kingdom guidelines on low fat and complex carbohydrate/no sugar. } \\
\text { Providers: dietitians and nurses } \\
\text { Contact with author: information do not allow including or excluding the study }\end{array}$ \\
\hline \multicolumn{2}{|l|}{ Simpson 2010} \\
\hline Methods & Study design: randomized controlled trial with two intervention groups \\
\hline Participants & $\begin{array}{l}\text { Setting: not known } \\
\text { Country: United Kingdom } \\
\text { Chronic disease: obesity (management) } \\
\text { Type of participants: clients }\end{array}$ \\
\hline Interventions & $\begin{array}{l}\text { The study compared an intense intervention using motivational interviewing with a less intense } \\
\text { intervention }\end{array}$ \\
\hline Outcomes & Measurement of diet adherence: not known \\
\hline Notes & $\begin{array}{l}\text { Dietary advice: not known } \\
\text { Provider: not known } \\
\text { Contact with author: information do not allow including or excluding the study }\end{array}$ \\
\hline \multicolumn{2}{|l|}{ Song 2009} \\
\hline Methods & Study design: randomized controlled trial with one intervention group and one control group \\
\hline Participants & $\begin{array}{l}\text { Setting: outpatient } \\
\text { Country: Korea } \\
\text { Chronic disease: type II diabetes (management) } \\
\text { Type of participants: clients }\end{array}$ \\
\hline Interventions & $\begin{array}{l}\text { The study compared a diabetes outpatient intensive management program including multidisciplinary } \\
\text { diabetes education, complication monitoring and telephone counseling with a control group }\end{array}$ \\
\hline Outcomes & Measurement of diet adherence: adherence to diet assessed by a self-report questionnaire on adherence \\
\hline Notes & $\begin{array}{l}\text { Dietary advice: not known } \\
\text { Providers: endocrinologist, diabetes education nurse, family physician, rehabilitation therapist, } \\
\text { dermatologist, psychologist, dietitian, pharmacist, ophthalmologist and physiotherapist } \\
\text { The corresponding author was contacted in order to obtain more information about the dietary advice } \\
\text { provided in both groups. However, there was no response to attempted contact with author }\end{array}$ \\
\hline \multicolumn{2}{|l|}{ Stollar 1993} \\
\hline Methods & Study design: not known \\
\hline Participants & $\begin{array}{l}\text { Setting: not known } \\
\text { Country: not known } \\
\text { Chronic disease: not known } \\
\text { Type of participants: not known }\end{array}$ \\
\hline Interventions & Not known \\
\hline Outcomes & Measurement of diet adherence: not known \\
\hline Notes & $\begin{array}{l}\text { Dietary advice: not known } \\
\text { Provider: not known } \\
\text { Abstract unobtainable. }\end{array}$ \\
\hline \multicolumn{2}{|l|}{ Wedman 1987} \\
\hline Methods & Study design: not known \\
\hline Participants & $\begin{array}{l}\text { Setting: outpatient } \\
\text { Country: United States } \\
\text { Chronic disease: diabetes (management) } \\
\text { Type of participants: clients }\end{array}$ \\
\hline Interventions & The study compared an intervention using graphic teaching aids with a control group \\
\hline Outcomes & $\begin{array}{l}\text { Measurement of diet adherence: adherence to diet assessed by dietitian's appointment log and by } \\
\text { information obtained during each visit of every client }\end{array}$ \\
\hline
\end{tabular}


Notes

Dietary advice: decreasing fat consumption, eating meals at regular intervals and controlling portion size

Provider: dietitian

Address for authors correspondence not found.

\section{Characteristics of ongoing studies [ordered by study ID]}

\begin{tabular}{|c|c|}
\hline \multicolumn{2}{|l|}{ Feldman 2009} \\
\hline Trial name or title & Home Based Blood Pressure Intervention for Blacks \\
\hline Methods & $\begin{array}{l}\text { Study design: cluster-randomized controlled trial with two intervention groups and one usual } \\
\text { care group }\end{array}$ \\
\hline Participants & $\begin{array}{l}\text { Setting: outpatient } \\
\text { Country: United States } \\
\text { Chronic disease: hypertension (management) } \\
\text { Type of participants: clients }\end{array}$ \\
\hline Interventions & $\begin{array}{l}\text { Two interventions will be tested and compared to a usual care group: 1) a "basic" intervention } \\
\text { delivering key evidence-based reminders to home care nurses and patients while the patient is } \\
\text { receiving traditional postacute home health care, 2) an "augmented" intervention that includes } \\
\text { that same as the basic intervention plus transition to an ongoing hypertension home support } \\
\text { program that extends support for } 12 \text { months }\end{array}$ \\
\hline Outcomes & Measurement of diet adherence: adherence to healthy diet \\
\hline Starting date & Not described \\
\hline Contact information & Dr Penny H. Feldman: pfeldman@ vnsny.org \\
\hline Notes & $\begin{array}{l}\text { Dietary advice: Dietary Approaches to Stop Hypertension (DASH) recommendations } \\
\text { Providers: nurses }\end{array}$ \\
\hline \multicolumn{2}{|l|}{ Griva 2010} \\
\hline Trial name or title & $\begin{array}{l}\text { The effectiveness of a self-management intervention to improve outcomes in prevalent } \\
\text { haemodialysis patients: a randomised controlled trial }\end{array}$ \\
\hline Methods & Study design: randomized controlled trial with one intervention group and one usual care group \\
\hline Participants & $\begin{array}{l}\text { Setting: outpatient } \\
\text { Country: Singapore } \\
\text { Chronic disease: end-stage renal disease (management) } \\
\text { Type of participants: clients }\end{array}$ \\
\hline Interventions & $\begin{array}{l}\text { One intervention will be tested and compared to an usual care group: a group-based self- } \\
\text { management intervention including address of misconceptions, group discussion of possible } \\
\text { coping strategies, identification of barriers to change, training in specific management } \\
\text { strategies, identification of individual goals to be achieved, formulation of actions plans to } \\
\text { achieve these goals and review previously set goals }\end{array}$ \\
\hline Outcomes & $\begin{array}{l}\text { Measurement of diet adherence: adherence to dietary restrictions assessed by values of blood } \\
\text { phosphate, calcium phosphate and potassium levels and gain between dialysis sessions }\end{array}$ \\
\hline Starting date & August 2010 \\
\hline Contact information & $\begin{array}{l}\text { Dr Konstadina Griva: Department of Psychology, Faculty of Arts and Social Sciences, National } \\
\text { University of Singapore, Block AS4 \#02-28, } 9 \text { arts link }\end{array}$ \\
\hline Notes & $\begin{array}{l}\text { Dietary advice: not described } \\
\text { Providers: psychologist, dietitian and nurse }\end{array}$ \\
\hline \multicolumn{2}{|l|}{ Jansink 2006} \\
\hline Trial name or title & $\begin{array}{l}\text { Title: Nurse-led motivational interviewing to change the lifestyle of patients with type II } \\
\text { diabetes (MILD-project): protocol for a cluster, randomized, controlled trial on implementing } \\
\text { lifestyle recommendations }\end{array}$ \\
\hline Methods & $\begin{array}{l}\text { Study design: cluster-randomized controlled trial with one intervention group and one control } \\
\text { group }\end{array}$ \\
\hline Participants & $\begin{array}{l}\text { Setting: outpatient } \\
\text { Country: Netherlands }\end{array}$ \\
\hline
\end{tabular}

Cochrane Database Syst Rev. Author manuscript; available in PMC 2016 June 09. 


\begin{tabular}{|c|c|}
\hline & $\begin{array}{l}\text { Chronic disease: type II diabetes (management) } \\
\text { Type of participants: clients }\end{array}$ \\
\hline Interventions & $\begin{array}{l}\text { One intervention will be tested and compared to a control group: the clients will receive an } \\
\text { intervention using motivational interviewing. The primary care nurse who will provide the } \\
\text { intervention will receive training in an implementation strategy with motivational interviewing } \\
\text { as the core component. Other components of this strategy will be adaptation of the diabetes } \\
\text { protocol to local circumstances, introduction of a social map for lifestyle support, and } \\
\text { educational and supportive tools for sustaining motivational interviewing }\end{array}$ \\
\hline Outcomes & Measurement of diet adherence: adherence to diet assessed by a self-reported questionnaire \\
\hline Starting date & March 2007 \\
\hline Contact information & Dr Renate Jansink: r.jansink@iq.umcn.nl \\
\hline Notes & $\begin{array}{l}\text { Dietary advice: Dutch guidelines norms } \\
\text { Providers: nurses }\end{array}$ \\
\hline \multicolumn{2}{|l|}{ Ma 2009} \\
\hline Trial name or title & $\begin{array}{l}\text { Evaluation of lifestyle interventions to treat elevated cardiometabolic risk in primary care (E- } \\
\text { LITE): a randomised controlled trial }\end{array}$ \\
\hline Methods & Study design: randomized controlled trial with two intervention groups and an usual care group \\
\hline Participants & $\begin{array}{l}\text { Setting: outpatient } \\
\text { Country: United States } \\
\text { Chronic disease: overweight and obesity with pre-diabetes and/or metabolic syndrome } \\
\text { (prevention and management) } \\
\text { Type of participants: clients }\end{array}$ \\
\hline Interventions & $\begin{array}{l}\text { Two interventions will be tested and compared to an usual care group: 1) information } \\
\text { technology-assisted self-management, 2) information technology-assisted self-management } \\
\text { combined with care management }\end{array}$ \\
\hline Outcomes & Measurement of diet adherence: adherence to diet assessed by a three-day food record \\
\hline Starting date & Not described \\
\hline Contact information & Dr Jun Ma: maj@pamfri.org \\
\hline Notes & $\begin{array}{l}\text { Dietary advice: total fat reduction (to } 25 \% \text { of energy), energy balance and restriction (with a } \\
\text { goal of a } 500 \text { - to } 1000 \text {-calorie reduction diet), saturated fat intake (to < } 10 \% \text { of energy), } \\
\text { cholesterol intake (to < } 300 \mathrm{mg} / \text { day), consumption of a high plant-based diet that includes a } \\
\text { variety of fruit and vegetables, whole grains, and low-fat dairy products and reduction of high } \\
\text { glycemic index carbohydrates } \\
\text { Providers: dietitian and exercise physiologist }\end{array}$ \\
\hline \multicolumn{2}{|l|}{ Sher 2002} \\
\hline Trial name or title & Partners for life: a theoretical approach to developing an intervention for cardiac risk reduction \\
\hline Methods & Study design: randomized controlled trial with one intervention group and one control group \\
\hline Participants & $\begin{array}{l}\text { Setting: outpatient } \\
\text { Country: United States } \\
\text { Chronic disease: coronary artery disease(management) } \\
\text { Type of participants: clients }\end{array}$ \\
\hline Interventions & $\begin{array}{l}\text { A standard behavioral treatment group including a couples intervention will be compared to a } \\
\text { standard behavioral treatment (control) }\end{array}$ \\
\hline Outcomes & Measurement of diet adherence: adherence to dietary recommendations \\
\hline Starting date & Not described \\
\hline Contact information & Dr Tamara Goldman Sher: t-sher@ northwestern.edu \\
\hline Notes & $\begin{array}{l}\text { Dietary advice: weight loss or dietary modification based on current American Heart } \\
\text { Association recommendations } \\
\text { Providers: therapist }\end{array}$ \\
\hline
\end{tabular}

Cochrane Database Syst Rev. Author manuscript; available in PMC 2016 June 09. 
DATA AND ANALYSES

Comparison 1. Nutritional tools versus control in diet adherence

\begin{tabular}{|c|c|c|c|c|}
\hline $\begin{array}{l}\text { Outcome or subgroup } \\
\text { title }\end{array}$ & No. of studies & No. of participants & Statistical method & Effect size \\
\hline 1 Continuous data & 2 & & $\begin{array}{l}\text { Std. Mean Difference (IV, } \\
\text { Random, 95\% CI) }\end{array}$ & Totals not selected \\
\hline $\begin{array}{l}1.1 \text { Adherence to energy } \\
\text { intake at } 6 \text { months }\end{array}$ & 1 & & $\begin{array}{l}\text { Std. Mean Difference (IV, } \\
\text { Random, 95\% CI) }\end{array}$ & $0.0[0.0,0.0]$ \\
\hline $\begin{array}{l}1.2 \text { Adherence to protein } \\
\text { intake at } 6 \text { months }\end{array}$ & 1 & & $\begin{array}{l}\text { Std. Mean Difference (IV, } \\
\text { Random, 95\% CI) }\end{array}$ & $0.0[0.0,0.0]$ \\
\hline $\begin{array}{l}1.3 \text { Adherence to fat } \\
\text { intake at } 6 \text { months }\end{array}$ & 1 & & $\begin{array}{l}\text { Std. Mean Difference (IV, } \\
\text { Random, 95\% CI) }\end{array}$ & $0.0[0.0,0.0]$ \\
\hline $\begin{array}{l}\text { 1.4 Adherence to } \\
\text { carbohydrate intake at } 6 \\
\text { months }\end{array}$ & 1 & & $\begin{array}{l}\text { Std. Mean Difference (IV, } \\
\text { Random, 95\% CI) }\end{array}$ & $0.0[0.0,0.0]$ \\
\hline $\begin{array}{l}1.5 \text { Adherence to } \\
\text { cholesterol intake at } 6 \\
\text { months }\end{array}$ & 1 & & $\begin{array}{l}\text { Std. Mean Difference (IV, } \\
\text { Random, 95\% CI) }\end{array}$ & $0.0[0.0,0.0]$ \\
\hline $\begin{array}{l}\text { 1.6 Adherence to fiber } \\
\text { intake at } 6 \text { months }\end{array}$ & 1 & & $\begin{array}{l}\text { Std. Mean Difference (IV, } \\
\text { Random, 95\% CI) }\end{array}$ & $0.0[0.0,0.0]$ \\
\hline $\begin{array}{l}1.7 \text { Adherence to } \\
\text { sodium intake at } 6 \text { months }\end{array}$ & 1 & & $\begin{array}{l}\text { Std. Mean Difference (IV, } \\
\text { Random, 95\% CI) }\end{array}$ & $0.0[0.0,0.0]$ \\
\hline $\begin{array}{l}1.8 \text { Adherence to fruit } \\
\text { intake at } 6 \text { months }\end{array}$ & 1 & & $\begin{array}{l}\text { Std. Mean Difference (IV, } \\
\text { Random, 95\% CI) }\end{array}$ & $0.0[0.0,0.0]$ \\
\hline $\begin{array}{l}1.9 \text { Adherence to } \\
\text { vegetable intake at } 6 \\
\text { months }\end{array}$ & 1 & & $\begin{array}{l}\text { Std. Mean Difference (IV, } \\
\text { Random, 95\% CI) }\end{array}$ & $0.0[0.0,0.0]$ \\
\hline $\begin{array}{l}1.10 \text { Adherence to sweet } \\
\text { food intake at } 6 \text { months }\end{array}$ & 1 & & $\begin{array}{l}\text { Std. Mean Difference (IV, } \\
\text { Random, 95\% CI) }\end{array}$ & $0.0[0.0,0.0]$ \\
\hline $\begin{array}{l}1.11 \text { Adherence to } \\
\text { energy intake at } 12 \text { weeks }\end{array}$ & 1 & & $\begin{array}{l}\text { Std. Mean Difference (IV, } \\
\text { Random, 95\% CI) }\end{array}$ & $0.0[0.0,0.0]$ \\
\hline $\begin{array}{l}1.12 \text { Adherence to fat } \\
\text { intake at } 12 \text { weeks }\end{array}$ & 1 & & $\begin{array}{l}\text { Std. Mean Difference (IV, } \\
\text { Random, 95\% CI) }\end{array}$ & $0.0[0.0,0.0]$ \\
\hline
\end{tabular}

Comparison 2. Multiple interventions versus control in diet adherence

\begin{tabular}{|c|c|c|c|c|}
\hline Outcome or subgroup title & No. of studies & No. of participants & Statistical method & Effect size \\
\hline 1 Continuous data & 4 & & $\begin{array}{l}\text { Std. Mean Difference } \\
\text { (IV, Random, 95\% CI) }\end{array}$ & Totals not selected \\
\hline $\begin{array}{l}\text { 1.1 Adherence to sodium- } \\
\text { restricted diet at } 3 \text { months }\end{array}$ & 1 & & $\begin{array}{l}\text { Std. Mean Difference } \\
\text { (IV, Random, 95\% CI) }\end{array}$ & $0.0[0.0,0.0]$ \\
\hline $\begin{array}{l}1.2 \text { Adherence to diet at } 3 \\
\text { months }\end{array}$ & 1 & & $\begin{array}{l}\text { Std. Mean Difference } \\
\text { (IV, Random, 95\% CI) }\end{array}$ & $0.0[0.0,0.0]$ \\
\hline $\begin{array}{l}1.3 \text { Adherence to fluid- } \\
\text { restricted diet at } 1 \text { month }\end{array}$ & 1 & & $\begin{array}{l}\text { Std. Mean Difference } \\
\text { (IV, Random, 95\% CI) }\end{array}$ & $0.0[0.0,0.0]$ \\
\hline $\begin{array}{l}\text { 1.4 Adherence to fluid- } \\
\text { restricted diet at } 3 \text { months }\end{array}$ & 1 & & $\begin{array}{l}\text { Std. Mean Difference } \\
\text { (IV, Random, 95\% CI) }\end{array}$ & $0.0[0.0,0.0]$ \\
\hline $\begin{array}{l}\text { 1.5 Adherence to fluid- } \\
\text { restricted diet at } 6 \text { months }\end{array}$ & 1 & & $\begin{array}{l}\text { Std. Mean Difference } \\
\text { (IV, Random, 95\% CI) }\end{array}$ & $0.0[0.0,0.0]$ \\
\hline $\begin{array}{l}1.6 \text { Non-adherence to diet } \\
\text { (days) at } 7 \text { weeks }\end{array}$ & 1 & & $\begin{array}{l}\text { Std. Mean Difference } \\
\text { (IV, Random, 95\% CI) }\end{array}$ & $0.0[0.0,0.0]$ \\
\hline $\begin{array}{l}1.7 \text { Non-adherence to diet } \\
\text { (days) at } 13 \text { weeks }\end{array}$ & 1 & & $\begin{array}{l}\text { Std. Mean Difference } \\
\text { (IV, Random, 95\% CI) }\end{array}$ & $0.0[0.0,0.0]$ \\
\hline
\end{tabular}




\begin{tabular}{|c|c|c|c|c|}
\hline Outcome or subgroup title & No. of studies & No. of participants & Statistical method & Effect size \\
\hline $\begin{array}{l}1.8 \text { Non-adherence to diet } \\
\text { (degree) at } 7 \text { weeks }\end{array}$ & 1 & & $\begin{array}{l}\text { Std. Mean Difference } \\
\text { (IV, Random, 95\% CI) }\end{array}$ & $0.0[0.0,0.0]$ \\
\hline $\begin{array}{l}1.9 \text { Non-adherence to diet } \\
\text { (degree) at } 13 \text { weeks }\end{array}$ & 1 & & $\begin{array}{l}\text { Std. Mean Difference } \\
\text { (IV, Random, 95\% CI) }\end{array}$ & $0.0[0.0,0.0]$ \\
\hline $\begin{array}{l}1.10 \text { Non-adherence to } \\
\text { fluid-restricted diet (days) at } \\
7 \text { weeks }\end{array}$ & 1 & & $\begin{array}{l}\text { Std. Mean Difference } \\
\text { (IV, Random, 95\% CI) }\end{array}$ & $0.0[0.0,0.0]$ \\
\hline $\begin{array}{l}1.11 \text { Non-adherence to } \\
\text { fluid-restricted diet (days) at } \\
13 \text { weeks }\end{array}$ & 1 & & $\begin{array}{l}\text { Std. Mean Difference } \\
\text { (IV, Random, 95\% CI) }\end{array}$ & $0.0[0.0,0.0]$ \\
\hline $\begin{array}{l}1.12 \text { Non-adherence to } \\
\text { fluid-restricted diet (degree) } \\
\text { at } 7 \text { weeks }\end{array}$ & 1 & & $\begin{array}{l}\text { Std. Mean Difference } \\
\text { (IV, Random, 95\% CI) }\end{array}$ & $0.0[0.0,0.0]$ \\
\hline $\begin{array}{l}1.13 \text { Non-adherence to } \\
\text { fluid-restricted diet (degree) } \\
\text { at } 13 \text { weeks }\end{array}$ & 1 & & $\begin{array}{l}\text { Std. Mean Difference } \\
\text { (IV, Random, 95\% CI) }\end{array}$ & $0.0[0.0,0.0]$ \\
\hline 2 Dichotomous data & 5 & & $\begin{array}{l}\text { Risk Ratio (M-H, } \\
\text { Random, 95\% CI) }\end{array}$ & Totals not selected \\
\hline $\begin{array}{l}2.1 \text { Adherence to sodium- } \\
\text { restricted diet at } 18 \text { months }\end{array}$ & 1 & & $\begin{array}{l}\text { Risk Ratio (M-H, } \\
\text { Random, } 95 \% \text { CI) }\end{array}$ & $0.0[0.0,0.0]$ \\
\hline $\begin{array}{l}2.2 \text { Adherence to fat } \\
\text { intake at } 3 \text { months }\end{array}$ & 1 & & $\begin{array}{l}\text { Risk Ratio (M-H, } \\
\text { Random, } 95 \% \text { CI) }\end{array}$ & $0.0[0.0,0.0]$ \\
\hline $\begin{array}{l}2.3 \text { Adherence to } \\
\text { saturated fat intake at } 3 \\
\text { months }\end{array}$ & 1 & & $\begin{array}{l}\text { Risk Ratio (M-H, } \\
\text { Random, } 95 \% \text { CI) }\end{array}$ & $0.0[0.0,0.0]$ \\
\hline $\begin{array}{l}2.4 \text { Adherence to } \\
\text { unsaturated fat intake at } 3 \\
\text { months }\end{array}$ & 1 & & $\begin{array}{l}\text { Risk Ratio (M-H, } \\
\text { Random, 95\% CI) }\end{array}$ & $0.0[0.0,0.0]$ \\
\hline $\begin{array}{l}2.5 \text { Adherence to } \\
\text { carbohydrate intake at } 3 \\
\text { months }\end{array}$ & 1 & & $\begin{array}{l}\text { Risk Ratio (M-H, } \\
\text { Random, 95\% CI) }\end{array}$ & $0.0[0.0,0.0]$ \\
\hline $\begin{array}{l}\text { 2.6 Adherence cholesterol } \\
\text { intake at } 3 \text { months }\end{array}$ & 1 & & $\begin{array}{l}\text { Risk Ratio (M-H, } \\
\text { Random, 95\% CI) }\end{array}$ & $0.0[0.0,0.0]$ \\
\hline $\begin{array}{l}2.7 \text { Adherence to } \\
\text { saturated fat intake at } 15 \\
\text { months }\end{array}$ & 1 & & $\begin{array}{l}\text { Risk Ratio (M-H, } \\
\text { Random, 95\% CI) }\end{array}$ & $0.0[0.0,0.0]$ \\
\hline $\begin{array}{l}2.8 \text { Adherence to fat } \\
\text { intake at } 15 \text { months }\end{array}$ & 1 & & $\begin{array}{l}\text { Risk Ratio (M-H, } \\
\text { Random, 95\% CI) }\end{array}$ & $0.0[0.0,0.0]$ \\
\hline $\begin{array}{l}2.9 \text { Adherence to } \\
\text { unsaturated fat intake at } 15 \\
\text { months }\end{array}$ & 1 & & $\begin{array}{l}\text { Risk Ratio (M-H, } \\
\text { Random, 95\% CI) }\end{array}$ & $0.0[0.0,0.0]$ \\
\hline $\begin{array}{l}2.10 \text { Adherence to } \\
\text { carbohydrate intake at } 15 \\
\text { months }\end{array}$ & 1 & & $\begin{array}{l}\text { Risk Ratio (M-H, } \\
\text { Random, } 95 \% \text { CI) }\end{array}$ & $0.0[0.0,0.0]$ \\
\hline $\begin{array}{l}2.11 \text { Adherence to fiber } \\
\text { intake at } 15 \text { months }\end{array}$ & 1 & & $\begin{array}{l}\text { Risk Ratio (M-H, } \\
\text { Random, 95\% CI) }\end{array}$ & $0.0[0.0,0.0]$ \\
\hline $\begin{array}{l}2.12 \text { Adherence to } \\
\text { cholesterol intake at } 15 \\
\text { months }\end{array}$ & 1 & & $\begin{array}{l}\text { Risk Ratio (M-H, } \\
\text { Random, 95\% CI) }\end{array}$ & $0.0[0.0,0.0]$ \\
\hline $\begin{array}{l}2.13 \text { Adherence to } \\
\text { phosphate-restricted diet at } 3 \\
\text { months }\end{array}$ & 1 & & $\begin{array}{l}\text { Risk Ratio (M-H, } \\
\text { Random, } 95 \% \text { CI) }\end{array}$ & $0.0[0.0,0.0]$ \\
\hline $\begin{array}{l}2.14 \text { Adherence to } \\
\text { saturated fat intake at } 1 \text { year } \\
\text { - CHD patients }\end{array}$ & 1 & & $\begin{array}{l}\text { Risk Ratio (M-H, } \\
\text { Random, 95\% CI) }\end{array}$ & $0.0[0.0,0.0]$ \\
\hline
\end{tabular}

Cochrane Database Syst Rev. Author manuscript; available in PMC 2016 June 09. 


\begin{tabular}{|c|c|c|c|c|}
\hline Outcome or subgroup title & No. of studies & No. of participants & Statistical method & Effect size \\
\hline $\begin{array}{l}2.15 \text { Adherence to oily } \\
\text { fish intake at } 1 \text { year - CHD } \\
\text { patients }\end{array}$ & 1 & & $\begin{array}{l}\text { Risk Ratio (M-H, } \\
\text { Random, 95\% CI) }\end{array}$ & $0.0[0.0,0.0]$ \\
\hline $\begin{array}{l}2.16 \text { Adherence to fish } \\
\text { intake at } 1 \text { year - CHD } \\
\text { patients }\end{array}$ & 1 & & $\begin{array}{l}\text { Risk Ratio (M-H, } \\
\text { Random, 95\% CI) }\end{array}$ & $0.0[0.0,0.0]$ \\
\hline $\begin{array}{l}2.17 \text { Adherence to fruit } \\
\text { and vegetable intake at } 1 \\
\text { year - CHD patients }\end{array}$ & 1 & & $\begin{array}{l}\text { Risk Ratio (M-H, } \\
\text { Random, 95\% CI) }\end{array}$ & $0.0[0.0,0.0]$ \\
\hline $\begin{array}{l}2.18 \text { Adherence to oily } \\
\text { fish intake at } 1 \text { year - high } \\
\text { risk CHD patients }\end{array}$ & 1 & & $\begin{array}{l}\text { Risk Ratio (M-H, } \\
\text { Random, 95\% CI) }\end{array}$ & $0.0[0.0,0.0]$ \\
\hline $\begin{array}{l}2.19 \text { Adherence to fish } \\
\text { intake at } 1 \text { year - high-risk } \\
\text { CHD patients }\end{array}$ & 1 & & $\begin{array}{l}\text { Risk Ratio (M-H, } \\
\text { Random, 95\% CI) }\end{array}$ & $0.0[0.0,0.0]$ \\
\hline $\begin{array}{l}2.20 \text { Adherence to fruit } \\
\text { and vegetable intake at } 1 \\
\text { year - high-risk CHD } \\
\text { patients }\end{array}$ & 1 & & $\begin{array}{l}\text { Risk Ratio (M-H, } \\
\text { Random, 95\% CI) }\end{array}$ & $0.0[0.0,0.0]$ \\
\hline $\begin{array}{l}2.21 \text { Adherence to diet at } \\
4 \text { weeks }\end{array}$ & 1 & & $\begin{array}{l}\text { Risk Ratio (M-H, } \\
\text { Random, 95\% CI) }\end{array}$ & $0.0[0.0,0.0]$ \\
\hline $\begin{array}{l}2.22 \text { Adherence to diet at } \\
12 \text { weeks }\end{array}$ & 1 & & $\begin{array}{l}\text { Risk Ratio (M-H, } \\
\text { Random, 95\% CI) }\end{array}$ & $0.0[0.0,0.0]$ \\
\hline
\end{tabular}

Cochrane Database Syst Rev. Author manuscript; available in PMC 2016 June 09. 


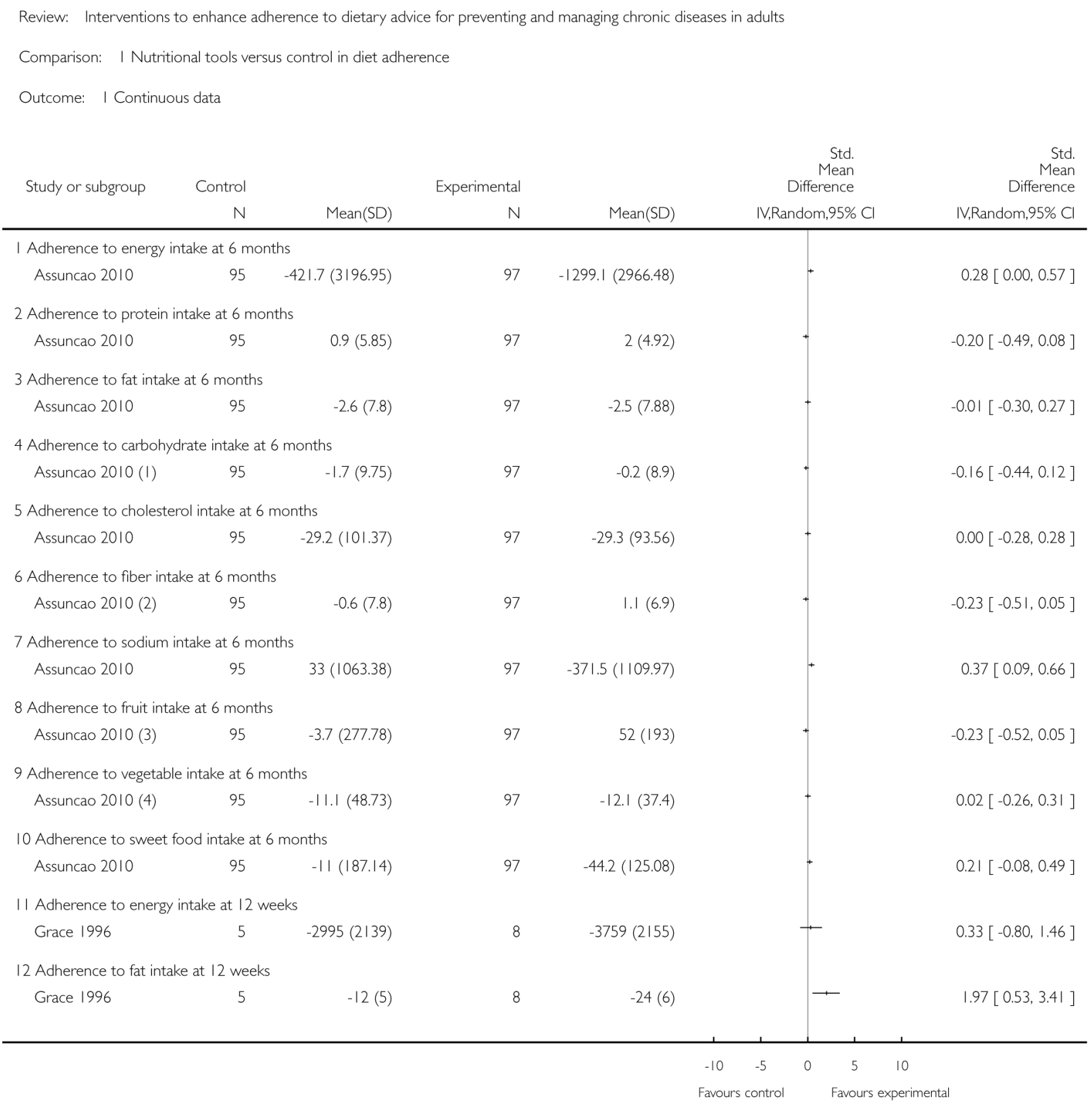

\section{Analysis 1.1.}

Comparison 1 Nutritional tools versus control in diet adherence, Outcome 1 Continuous data.

Cochrane Database Syst Rev. Author manuscript; available in PMC 2016 June 09. 


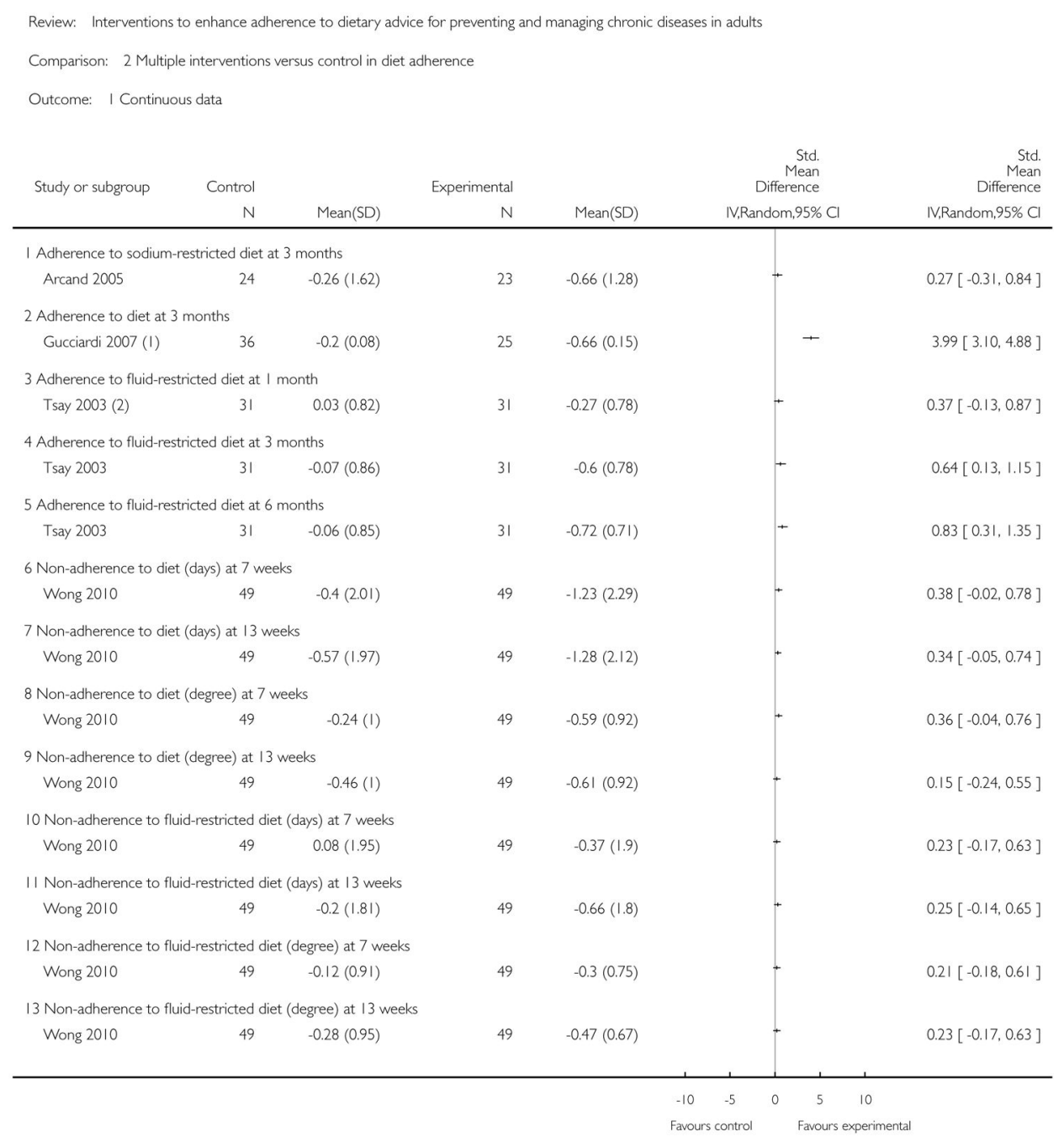

\section{Analysis 2.1.}

Comparison 2 Multiple interventions versus control in diet adherence, Outcome 1 Continuous data. 


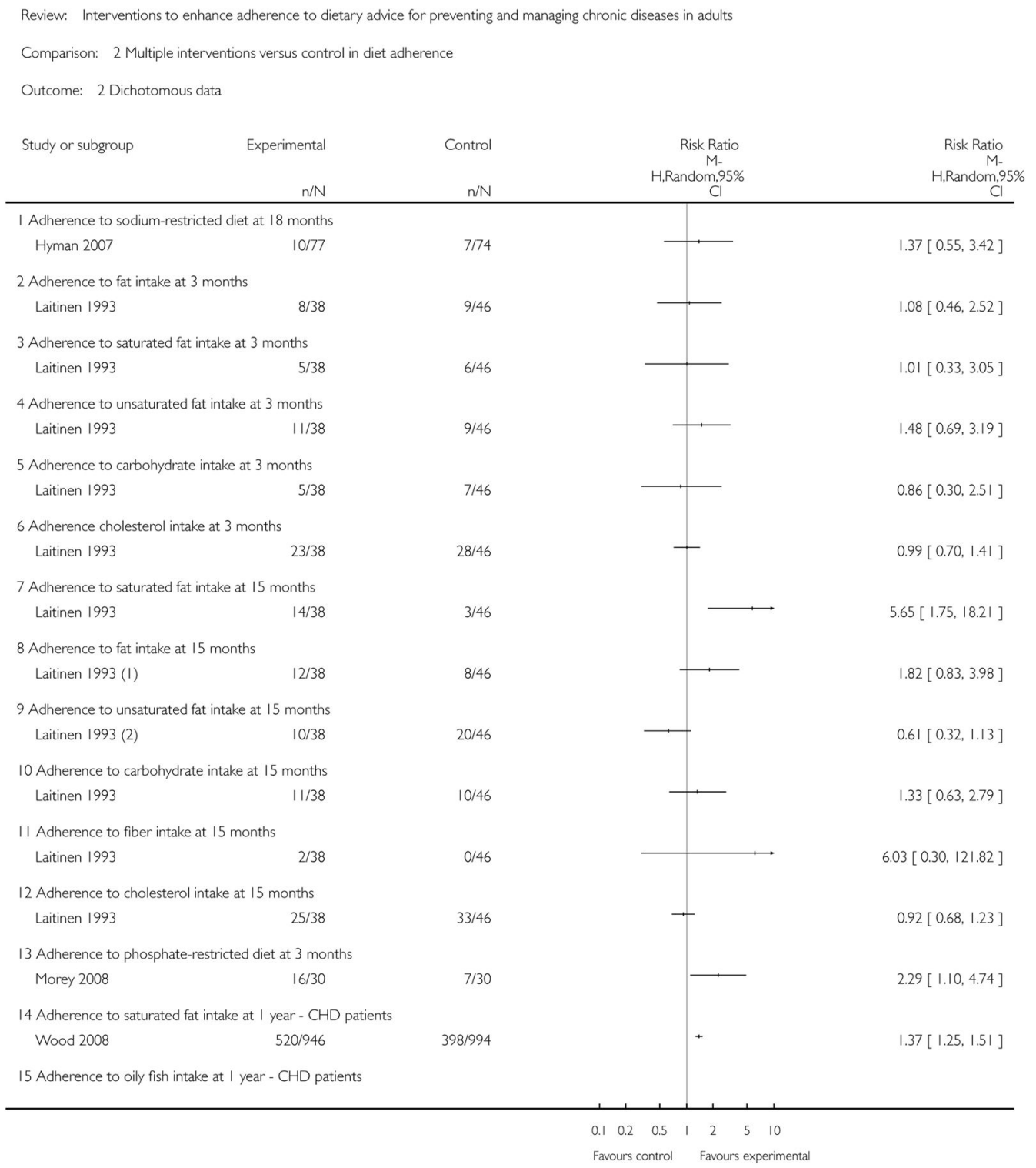




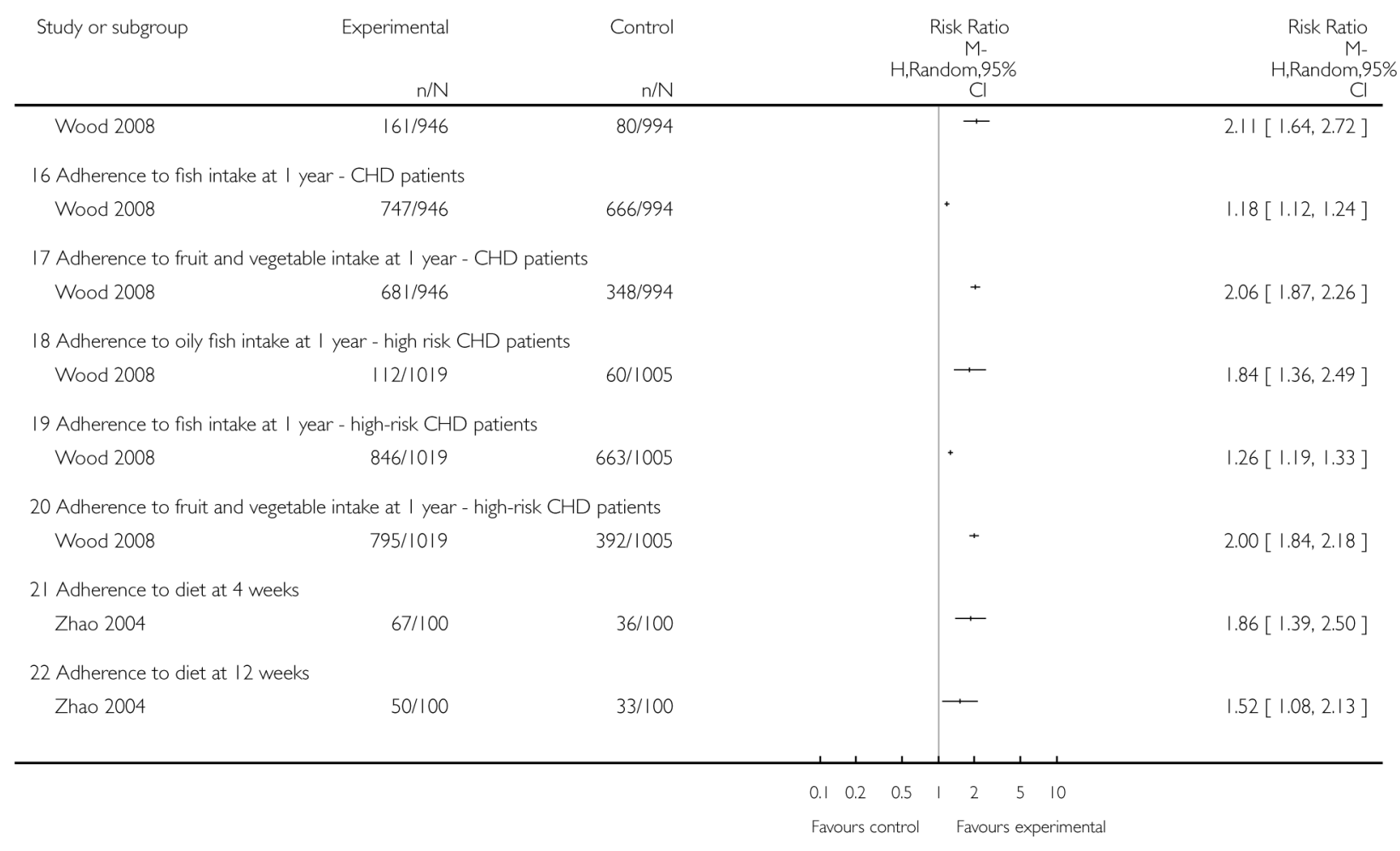

Analysis 2.2.

Comparison 2 Multiple interventions versus control in diet adherence, Outcome 2

Dichotomous data. 


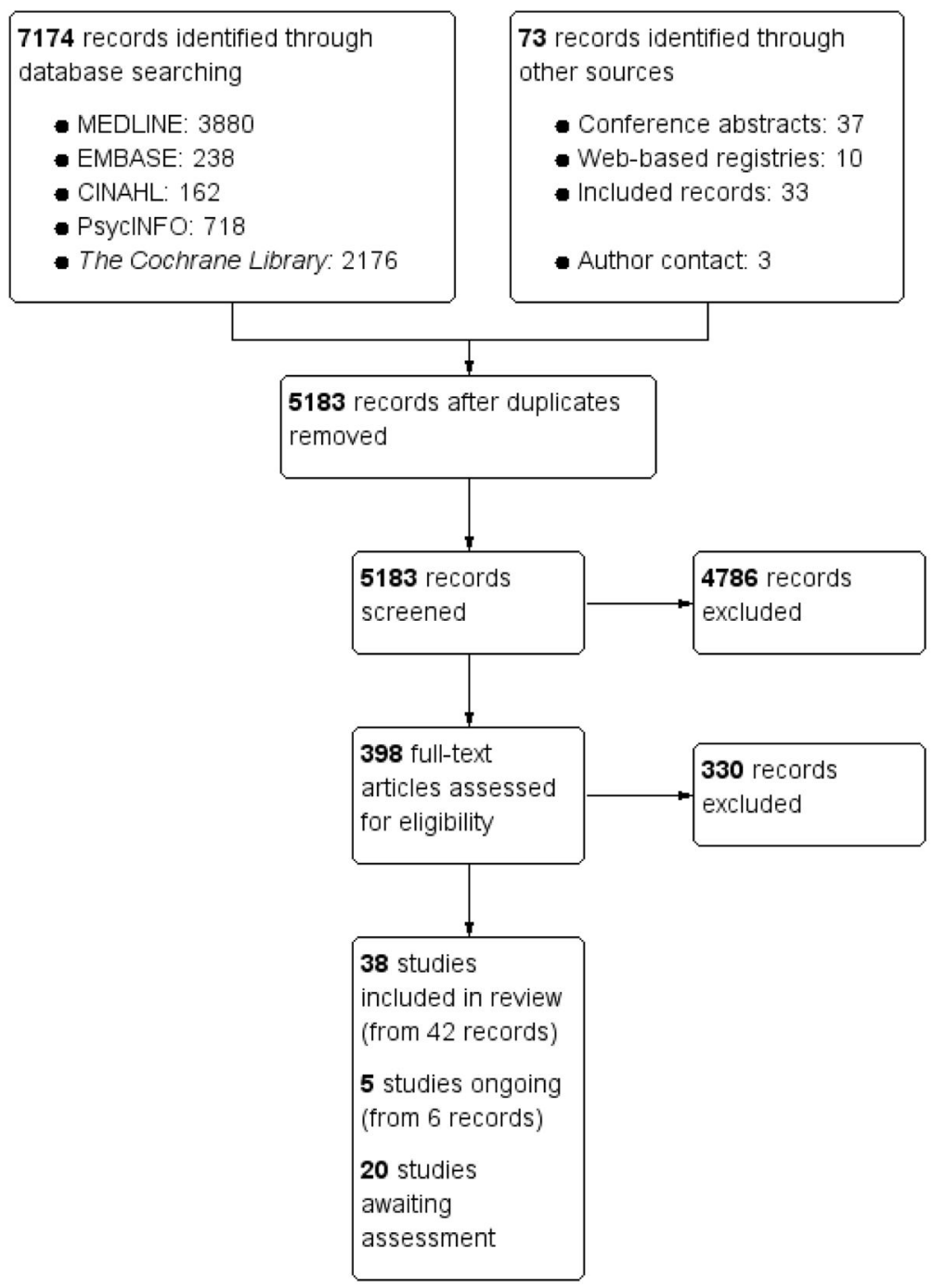

Figure 1.

Study flow diagram. 


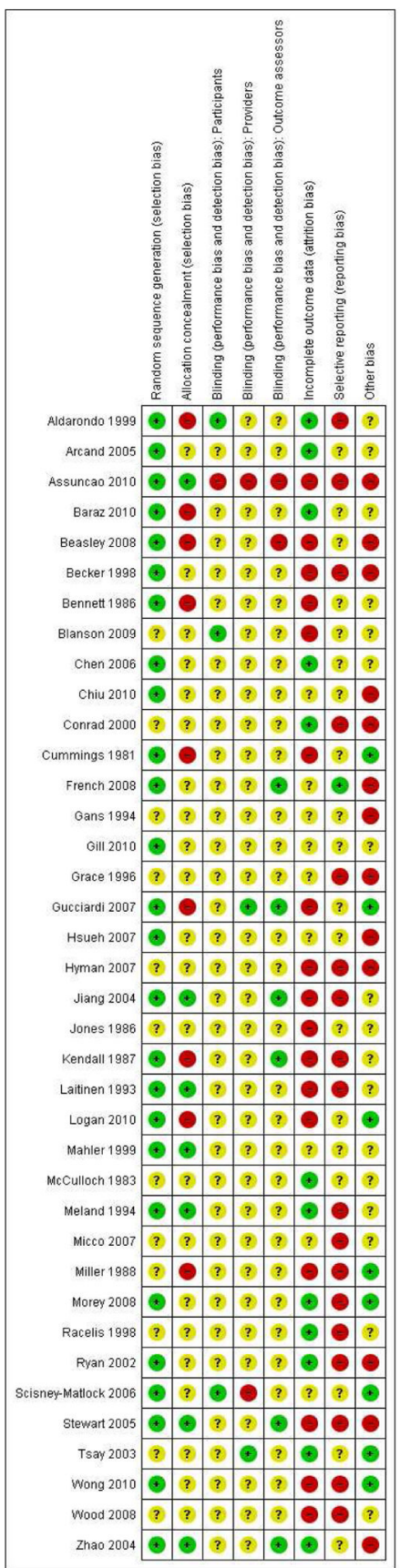

Figure 2.

Risk of bias summary: review authors' judgements about each risk of bias item for each included study. 


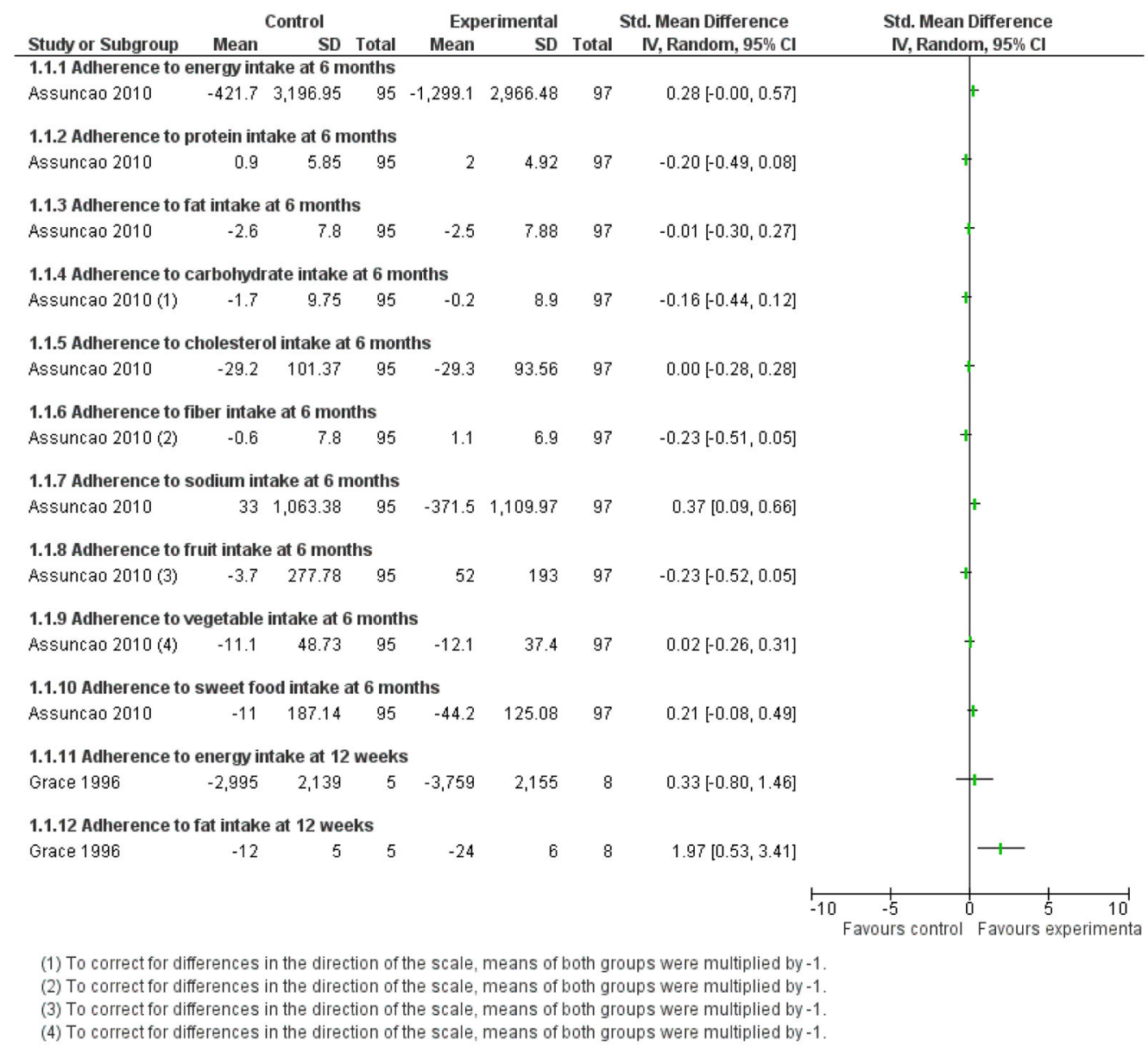

Figure 3.

Forest plot of comparison: 6 Nutritional tools versus control in diet adherence, outcome: 6.1 Continuous data. *Means represent the difference between pre-and post- intervention. 


\begin{tabular}{|c|c|c|c|c|c|c|c|c|c|}
\hline \multirow[b]{2}{*}{ Study or Subgroup } & \multicolumn{3}{|c|}{ Control } & \multicolumn{3}{|c|}{ Experimental } & \multirow{2}{*}{$\begin{array}{l}\text { Std. Mean Difference } \\
\text { IV, Random, } 95 \% \mathrm{Cl}\end{array}$} & \multirow{2}{*}{\multicolumn{2}{|c|}{$\begin{array}{l}\text { Std. Mean Difference } \\
\text { V, Random, } 95 \% \mathrm{Cl}\end{array}$}} \\
\hline & Mean & SD & Total & Mean & SD & Total & & & \\
\hline \multicolumn{10}{|c|}{ 2.1.1 Adherence to sodium-restricted diet at 3 months } \\
\hline Arcand 2005 & -0.26 & 1.62 & 24 & -0.66 & 1.28 & 23 & $0.27[-0.31,0.84]$ & & - \\
\hline \multicolumn{10}{|c|}{ 2.1.2 Adherence to diet at 3 months } \\
\hline Gucciardi 2007 (1) & -0.2 & 0.08 & 36 & -0.66 & 0.15 & 25 & $3.99[3.10,4.88]$ & & + \\
\hline \multicolumn{10}{|c|}{ 2.1.3 Adherence to fluid-restricted diet at 1 month } \\
\hline Tsay 2003 (2) & 0.03 & 0.82 & 31 & -0.27 & 0.78 & 31 & $0.37[-0.13,0.87]$ & & t \\
\hline \multicolumn{10}{|c|}{ 2.1.4 Adherence to fluid-restricted diet at 3 months } \\
\hline Tsay 2003 & -0.07 & 0.86 & 31 & -0.6 & 0.78 & 31 & $0.64[0.13,1.15]$ & & + \\
\hline \multicolumn{10}{|c|}{ 2.1.5 Adherence to fluid-restricted diet at 6 months } \\
\hline Tsay 2003 & -0.06 & 0.85 & 31 & -0.72 & 0.71 & 31 & $0.83[0.31,1.35]$ & & + \\
\hline \multicolumn{10}{|c|}{ 2.1.6 Non-adherence to diet (days) at 7 weeks } \\
\hline Wong 2010 & -0.4 & 2.01 & 49 & -1.23 & 2.29 & 49 & $0.38[-0.02,0.78]$ & & I \\
\hline \multicolumn{10}{|c|}{ 2.1.7 Non-adherence to diet (days) at 13 weeks } \\
\hline Wang 2010 & -0.57 & 1.97 & 49 & -1.28 & 2.12 & 49 & $0.34[-0.05,0.74]$ & & + \\
\hline \multicolumn{10}{|c|}{ 2.1.8 Non-adherence to diet (degree) at 7 weeks } \\
\hline Wang 2010 & -0.24 & 1 & 49 & -0.59 & 0.92 & 49 & $0.36[-0.04,0.76]$ & & + \\
\hline \multicolumn{10}{|c|}{ 2.1.9 Non-adherence to diet (degree) at 13 weeks } \\
\hline Wong 2010 & -0.46 & 1 & 49 & -0.61 & 0.92 & 49 & $0.15[-0.24,0.55]$ & - & - \\
\hline \multicolumn{10}{|c|}{ 2.1.10 Non-adherence to fluid-restricted diet (days) at 7 weeks } \\
\hline Wong 2010 & 0.08 & 1.95 & 49 & -0.37 & 1.9 & 49 & $0.23[-0.17,0.63]$ & + & $r$ \\
\hline \multicolumn{10}{|c|}{ 2.1.11 Non-adherence to fluid-restricted diet (days) at 13 weeks } \\
\hline Wang 2010 & -0.2 & 1.81 & 49 & -0.66 & 1.8 & 49 & $0.25[-0.14,0.65]$ & t & 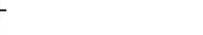 \\
\hline \multicolumn{10}{|c|}{ 2.1.12 Non-adherence to fluid-restricted diet (degree) at 7 weeks } \\
\hline Wong 2010 & -0.12 & 0.91 & 49 & -0.3 & 0.75 & 49 & $0.21[-0.18,0.61]$ & t- & $r$ \\
\hline \multicolumn{10}{|c|}{ 2.1.13 Non-adherence to fluid-restricted diet (degree) at 13 weeks } \\
\hline Wong 2010 & -0.28 & 0.95 & 49 & -0.47 & 0.67 & 49 & $0.23[-0.17,0.63]$ & t- & 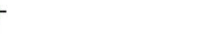 \\
\hline & & & & & & & & $\begin{array}{ccc}-10 & -5 & 0 \\
& \text { Favours control } & \\
\end{array}$ & $\begin{array}{c}5 \\
\text { Favours experimenta }\end{array}$ \\
\hline
\end{tabular}

Figure 4.

Forest plot of comparison: 8 Multiple interventions versus control in diet adherence, outcome: 8.1 Continuous data. *Means represent the difference between pre-and postintervention. 


\begin{tabular}{|c|c|c|c|c|c|c|c|}
\hline \multirow{2}{*}{ Study or Subgroup } & \multicolumn{2}{|c|}{ Experimental } & \multicolumn{2}{|c|}{ Control } & \multirow{2}{*}{$\begin{array}{c}\text { Risk Ratio } \\
\text { M-H, Random, } 95 \% \mathrm{Cl}\end{array}$} & \multirow{2}{*}{\multicolumn{2}{|c|}{$\begin{array}{c}\text { Risk Ratio } \\
\text { M-H, Random, } 95 \% \mathrm{Cl}\end{array}$}} \\
\hline \multirow{2}{*}{\multicolumn{6}{|c|}{ 2.2.1 Adherence to sodium-restricted diet at 18 months }} & & \\
\hline & & & & & & & \\
\hline Hyman 2007 & 10 & 77 & 7 & 74 & $1.37[0.55,3.42]$ & & + \\
\hline \multicolumn{6}{|c|}{ 2.2.2 Adherence to fat intake at 3 months } & & \\
\hline Laitinen 1993 & 8 & 38 & 9 & 46 & $1.08[0.46,2.52]$ & & \\
\hline \multicolumn{6}{|c|}{ 2.2.3 Adherence to saturated fat intake at 3 months } & & \\
\hline Laitinen 1993 & 5 & 38 & 6 & 46 & $1.01[0.33,3.05]$ & & \\
\hline \multicolumn{6}{|c|}{ 2.2.4 Adherence to unsaturated fat intake at 3 months } & & \\
\hline Laitinen 1993 & 11 & 38 & 9 & 46 & $1.48[0.69,3.19]$ & & 1 \\
\hline \multicolumn{6}{|c|}{ 2.2.5 Adherence to carbohydrate intake at 3 months } & & \\
\hline Laitinen 1993 & 5 & 38 & 7 & 46 & $0.86[0.30,2.51]$ & & \\
\hline \multicolumn{6}{|c|}{ 2.2.6 Adherence cholesterol intake at 3 months } & & \\
\hline Laitinen 1993 & 23 & 38 & 28 & 46 & $0.99[0.70,1.41]$ & & - \\
\hline \multicolumn{6}{|c|}{ 2.2.7 Adherence to saturated fat intake at $\mathbf{1 5}$ months } & & \\
\hline Laitinen 1993 & 14 & 38 & 3 & 46 & $5.65[1.75,18.21]$ & & $\longmapsto$ \\
\hline \multicolumn{6}{|c|}{ 2.2.8 Adherence to fat intake at 15 months } & & \\
\hline Laitinen 1993 (1) & 12 & 38 & 8 & 46 & $1.82[0.83,3.98]$ & & + \\
\hline \multicolumn{6}{|c|}{ 2.2.9 Adherence to unsaturated fat intake at 15 months } & & \\
\hline Laitinen 1993 (2) & 10 & 38 & 20 & 46 & $0.61[0.32,1.13]$ & + & - \\
\hline \multicolumn{6}{|c|}{ 2.2.10 Adherence to carbohydrate intake at 15 months } & & \\
\hline Laitinen 1993 & 11 & 38 & 10 & 46 & $1.33[0.63,2.79]$ & & \\
\hline \multicolumn{6}{|c|}{ 2.2.11 Adherence to fiber intake at 15 months } & & \\
\hline Laitinen 1993 & 2 & 38 & 0 & 46 & $6.03[0.30,121.82]$ & & $\longrightarrow$ \\
\hline \multicolumn{6}{|c|}{ 2.2.12 Adherence to cholesterol intake at 15 months } & & \\
\hline Laitinen 1993 & 25 & 38 & 33 & 46 & $0.92[0.68,1.23]$ & - & - \\
\hline \multicolumn{6}{|c|}{ 2.2.13 Adherence to phosphate-restricted diet at 3 months } & & \\
\hline Marey 2008 & 16 & 30 & 7 & 30 & $2.29[1.10,4.74]$ & & 1 \\
\hline \multicolumn{6}{|c|}{ 2.2.14 Adherence to saturated fat intake at 1 year - CHD patients } & & \\
\hline Wood 2008 & 520 & 946 & 398 & 994 & $1.37[1.25,1.51]$ & & + \\
\hline \multicolumn{7}{|c|}{ 2.2.15 Adherence to oily fish intake at 1 year - CHD patients } & \\
\hline Wood 2008 & 161 & 946 & 80 & 994 & $2.11[1.64,2.72]$ & & $十$ \\
\hline \multicolumn{7}{|c|}{ 2.2.16 Adherence to fish intake at 1 year - CHD patients } & \\
\hline Wood 2008 & 747 & 946 & 666 & 994 & $1.18[1.12,1.24]$ & & + \\
\hline \multicolumn{7}{|c|}{ 2.2.17 Adherence to fruit and vegetable intake at 1 year - CHD patients } & \\
\hline Wood 2008 & 681 & 946 & 348 & 994 & $2.06[1.87,2.26]$ & & + \\
\hline 2.2.18 Adherence $t$ & illy fish in & ake at 1 & 1 year $-h$ & high rist & K CHD patients & & \\
\hline Wood 2008 & 112 & 1019 & 60 & 1005 & $1.84[1.36,2.49]$ & & 十 \\
\hline 2.2.19 Adherence $t$ & ish intak & at 1 yea & ar - high- & -risk CH & HD patients & & \\
\hline Wood 2008 & 846 & 1019 & 663 & 1005 & $1.26[1.19,1.33]$ & & + \\
\hline 2.2.20 Adherence t & ruit and $\mathrm{v}$ & egetable & e intake a & at 1 yea & ar - high-risk CHD patier & & \\
\hline Wood 2008 & 795 & 1019 & 392 & 1005 & $2.00[1.84,2.18]$ & & + \\
\hline 2.2.21 Adherence t & liet at $4 \mathrm{n}$ & eeks & & & & & \\
\hline Zhao 2004 & 67 & 100 & 36 & 100 & $1.86[1.39,2.50]$ & & 十 \\
\hline 2.2.22 Adherence $t$ & liet at 12 & Neeks & & & & & \\
\hline Zhao 2004 & 50 & 100 & 33 & 100 & $1.52[1.08,2.13]$ & & 十 \\
\hline & & & & & & 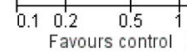 & \begin{tabular}{ccc|}
1 & 1 & 1 \\
2 & 5 & 10 \\
Favours experimenta
\end{tabular} \\
\hline
\end{tabular}

Figure 5.

Forest plot of comparison: 8 Multiple interventions versus control in diet adherence, outcome: 8.2 Dichotomous data. *Means represent the difference between pre-and postintervention.

Cochrane Database Syst Rev. Author manuscript; available in PMC 2016 June 09. 


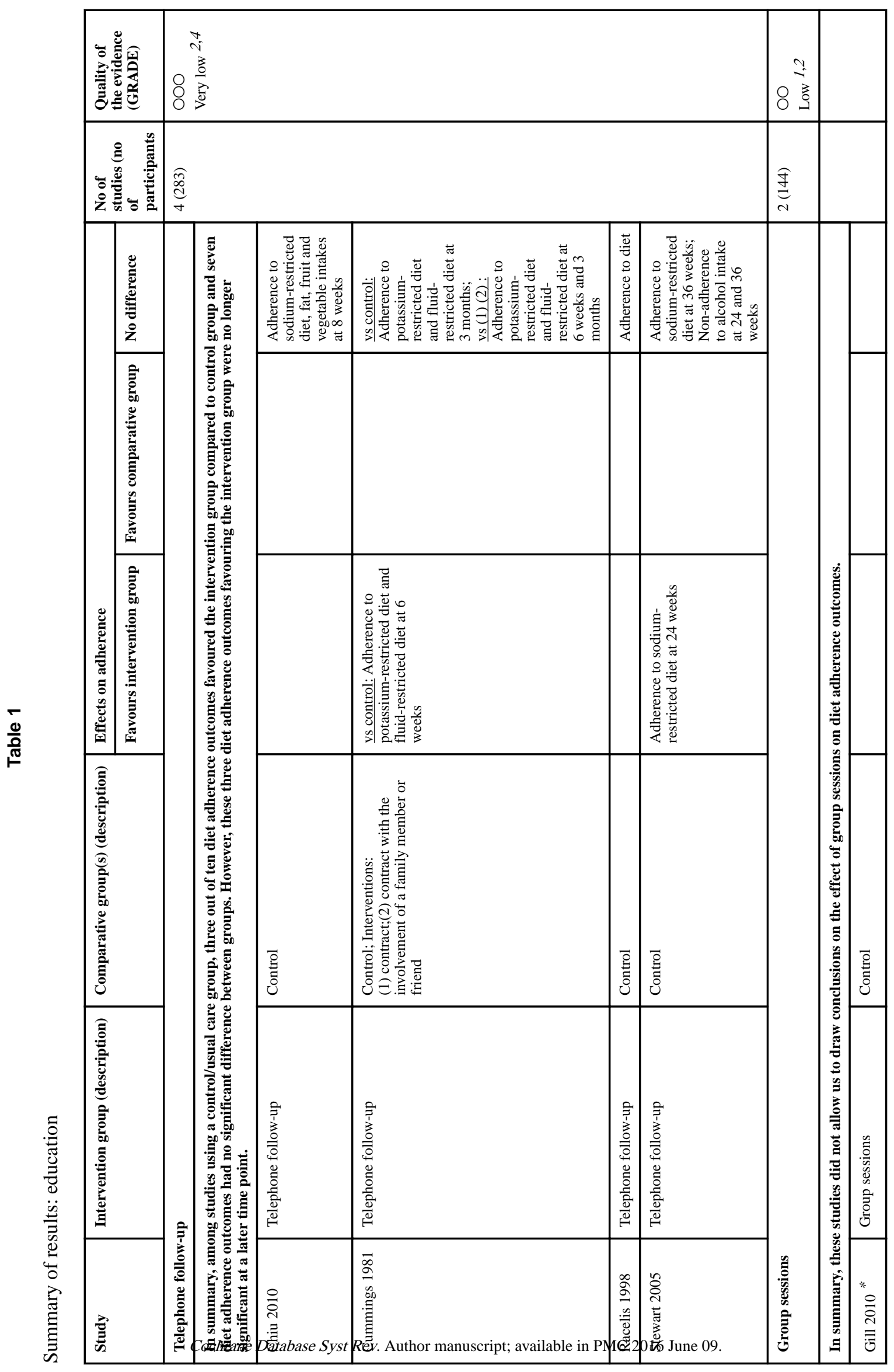




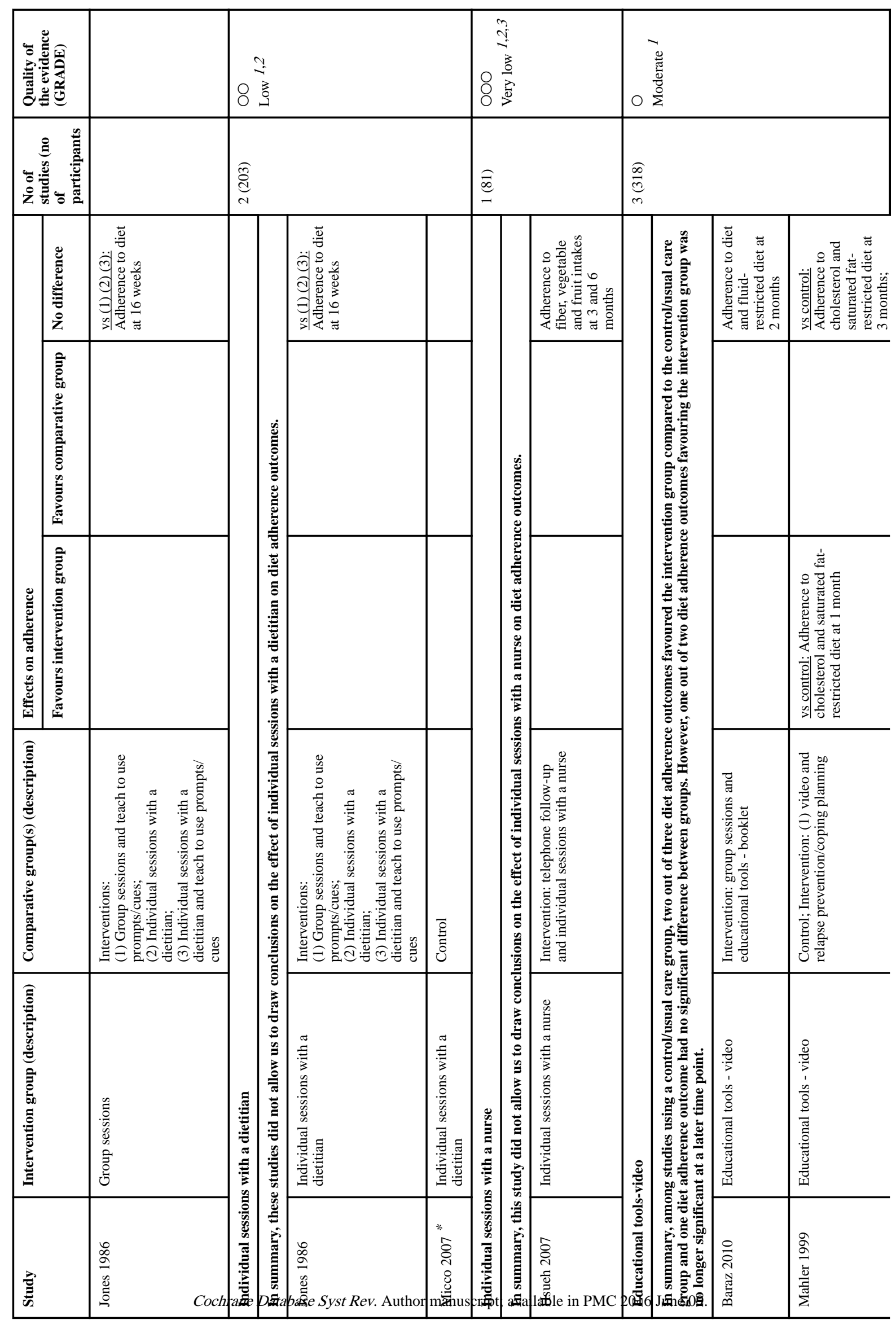




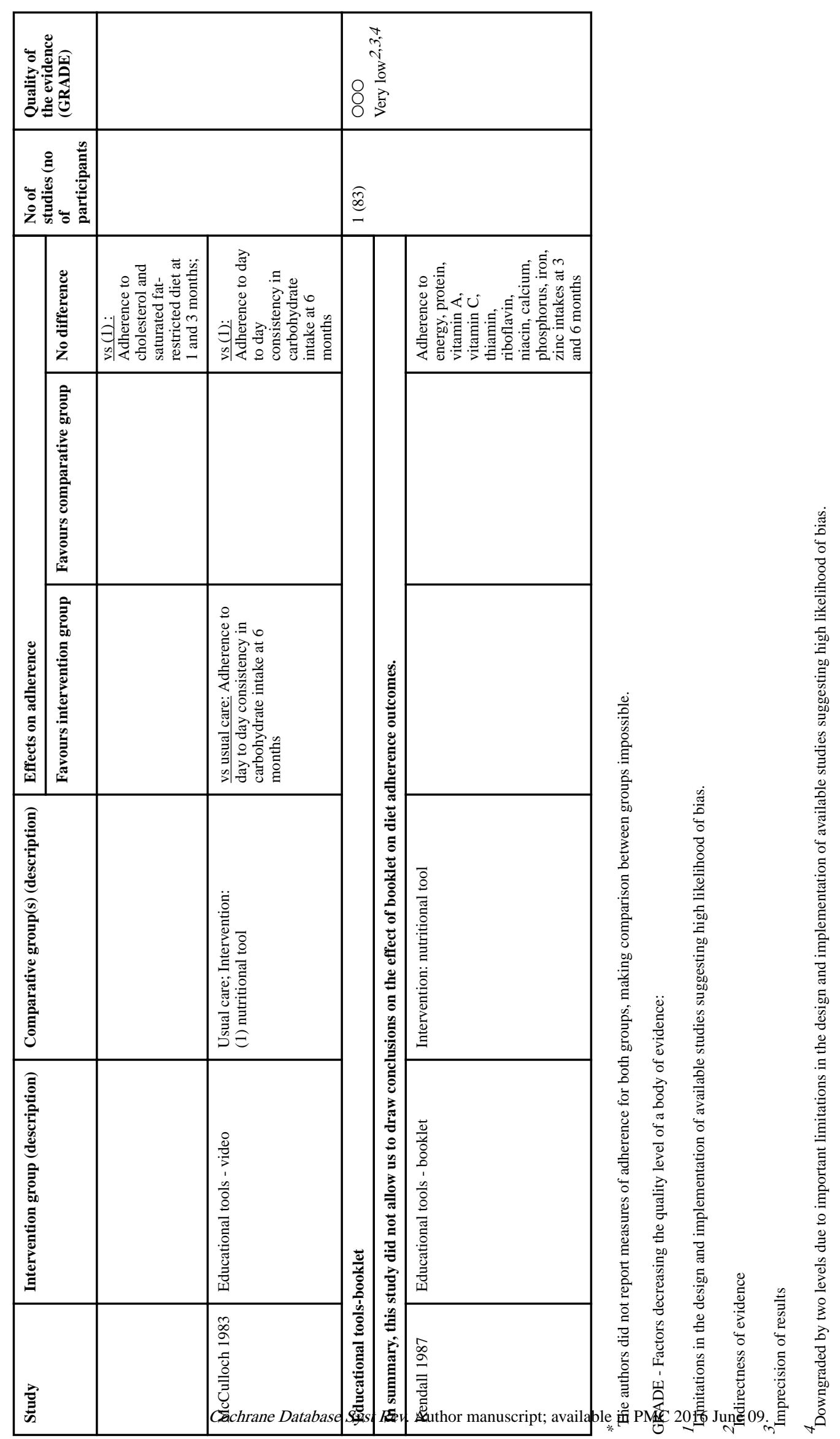




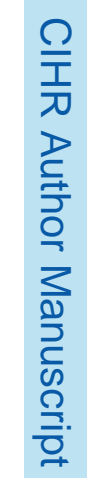

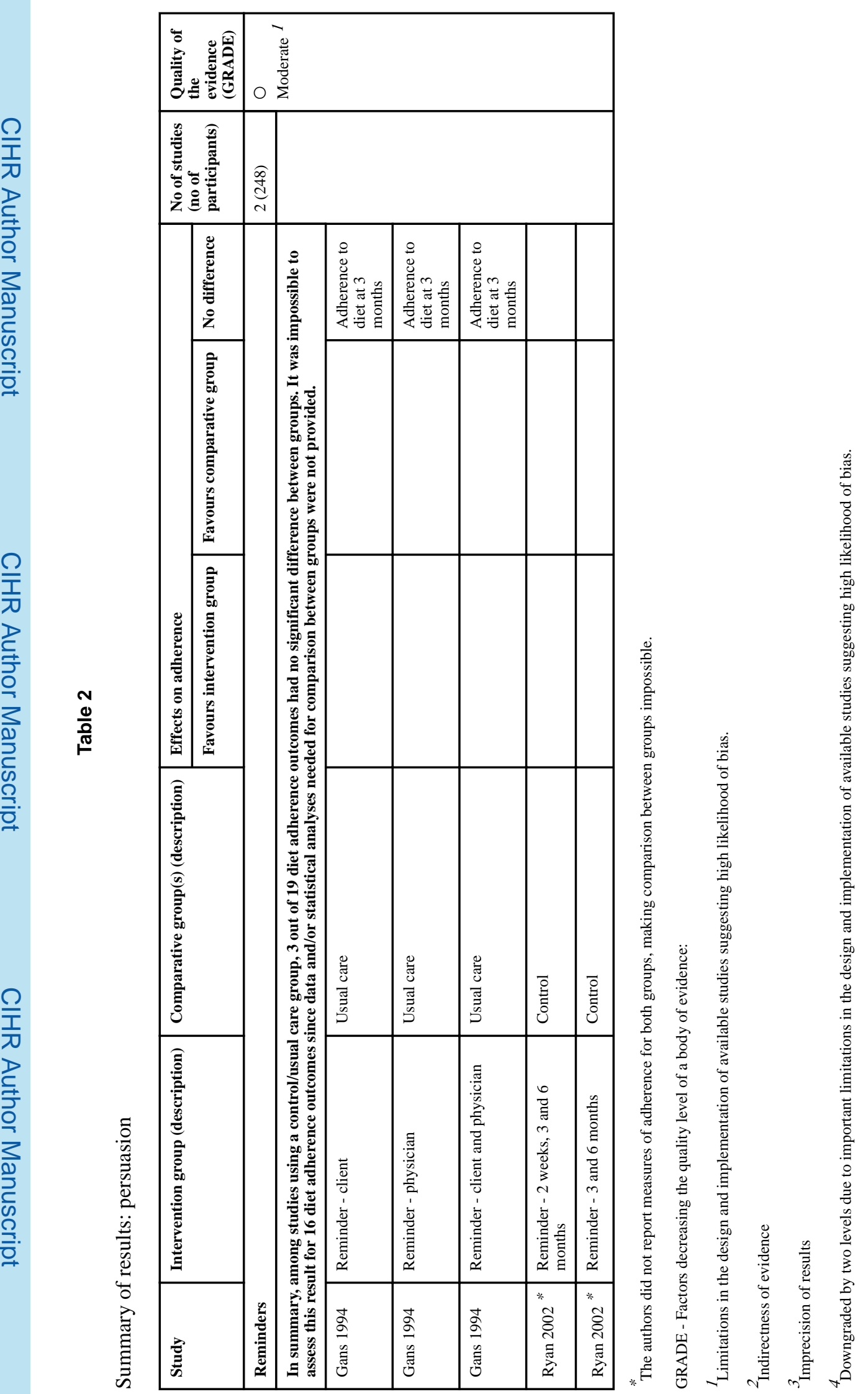

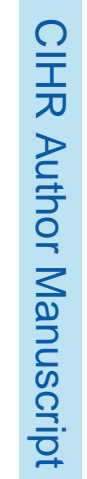

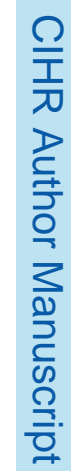

Cochrane Database Syst Rev. Author manuscript; available in PMC 2016 June 09. 


$$
\text { int }
$$




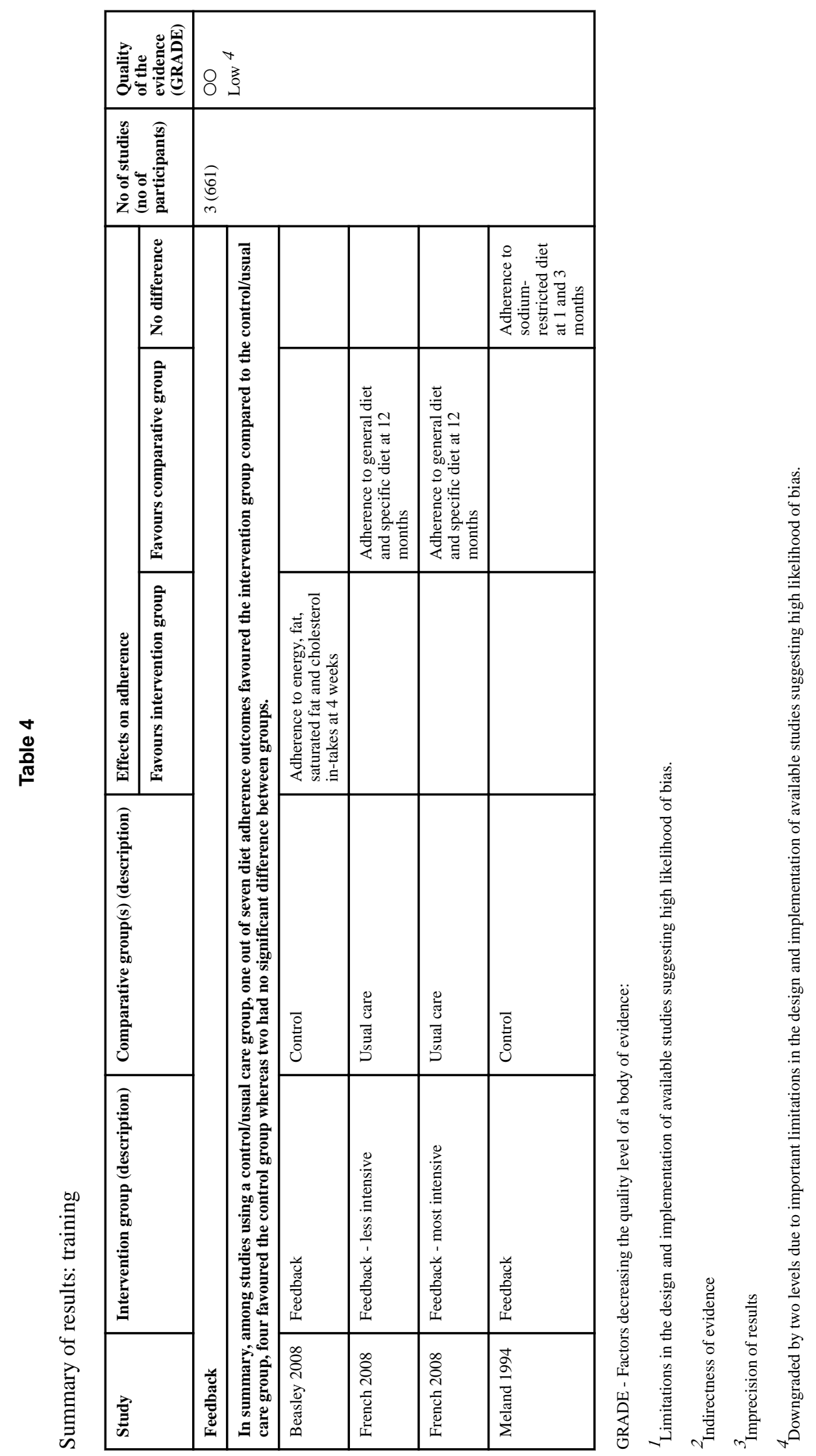

Cochrane Database Syst Rev. Author manuscript; available in PMC 2016 June 09. 


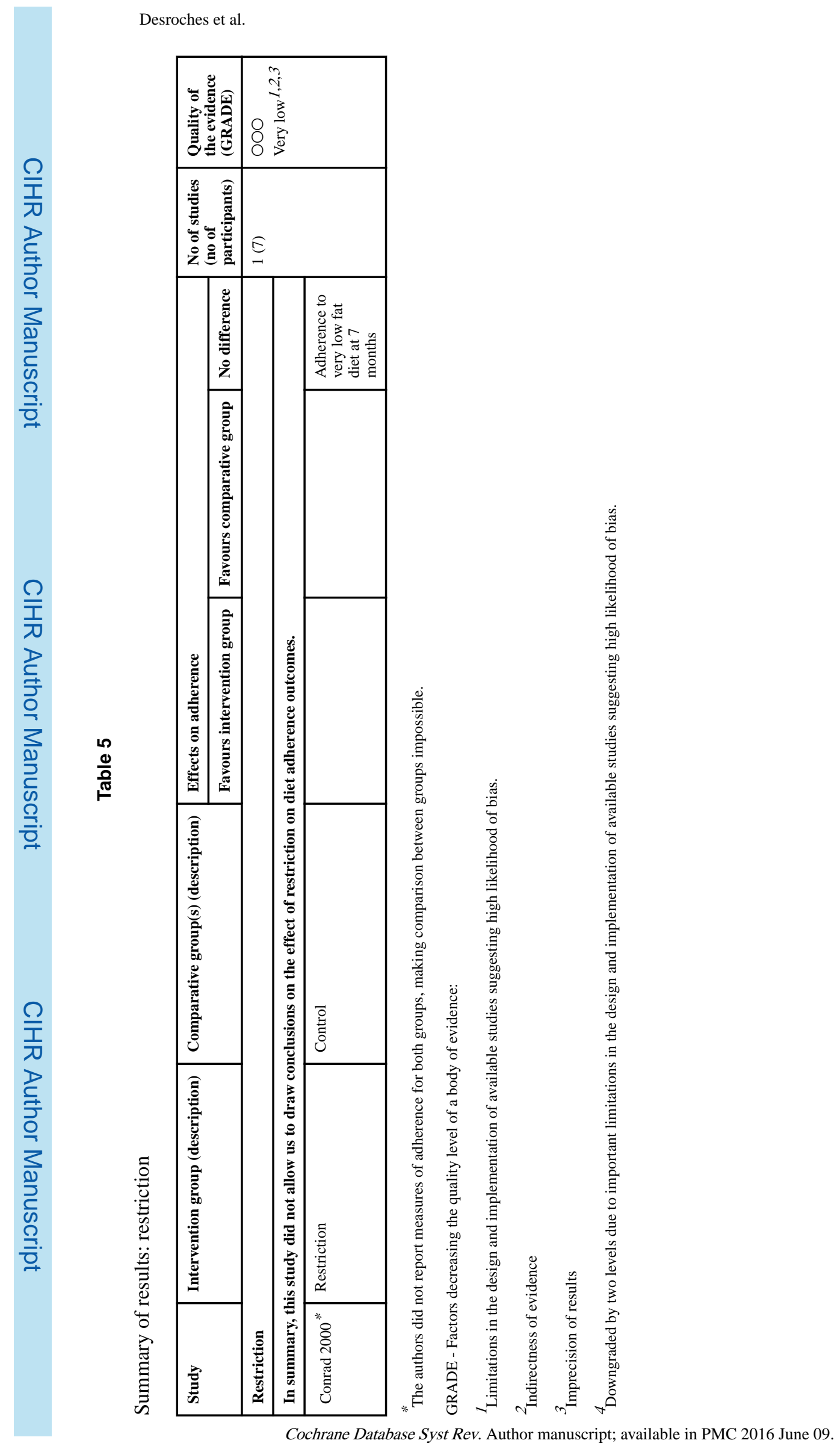

Page 126 


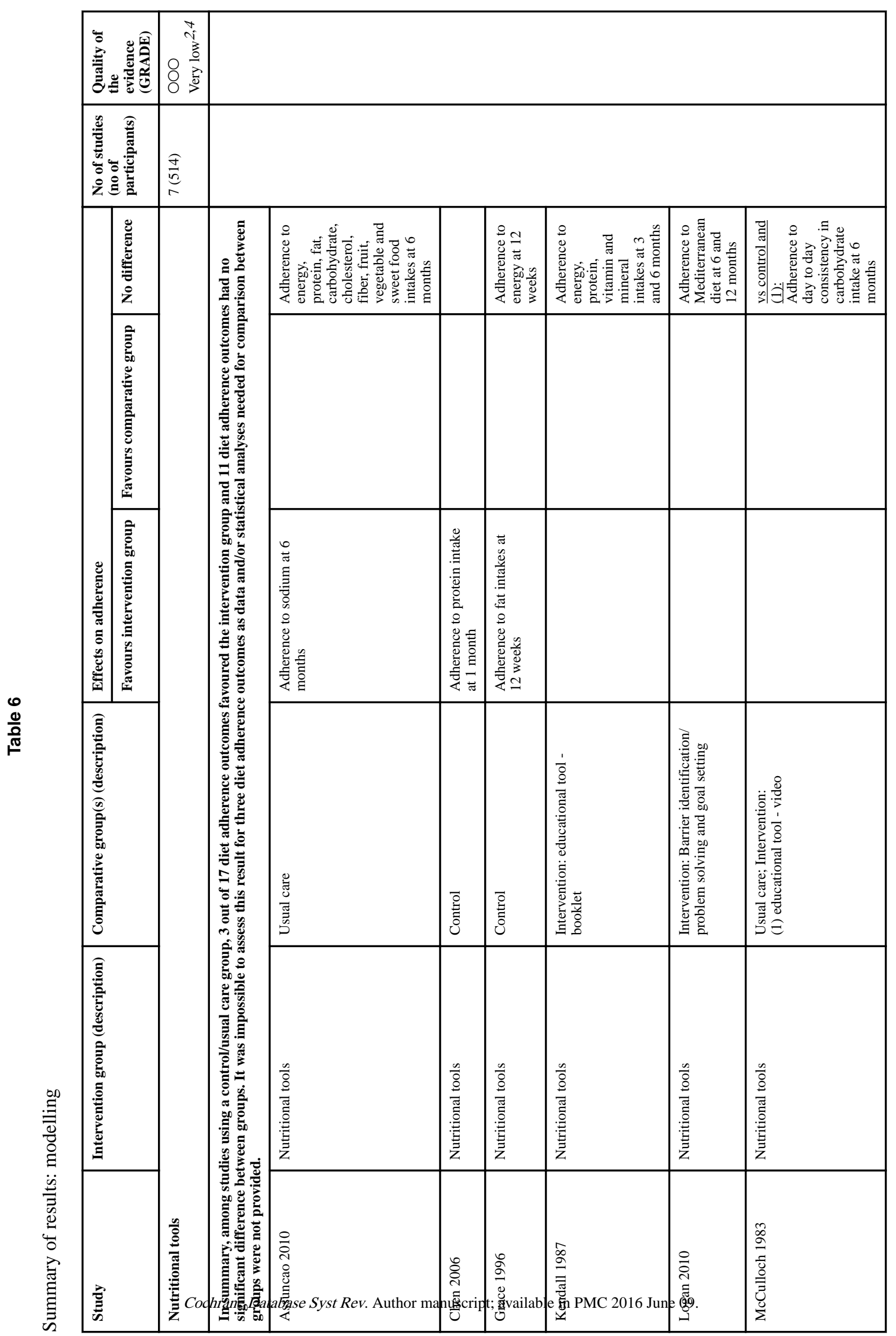



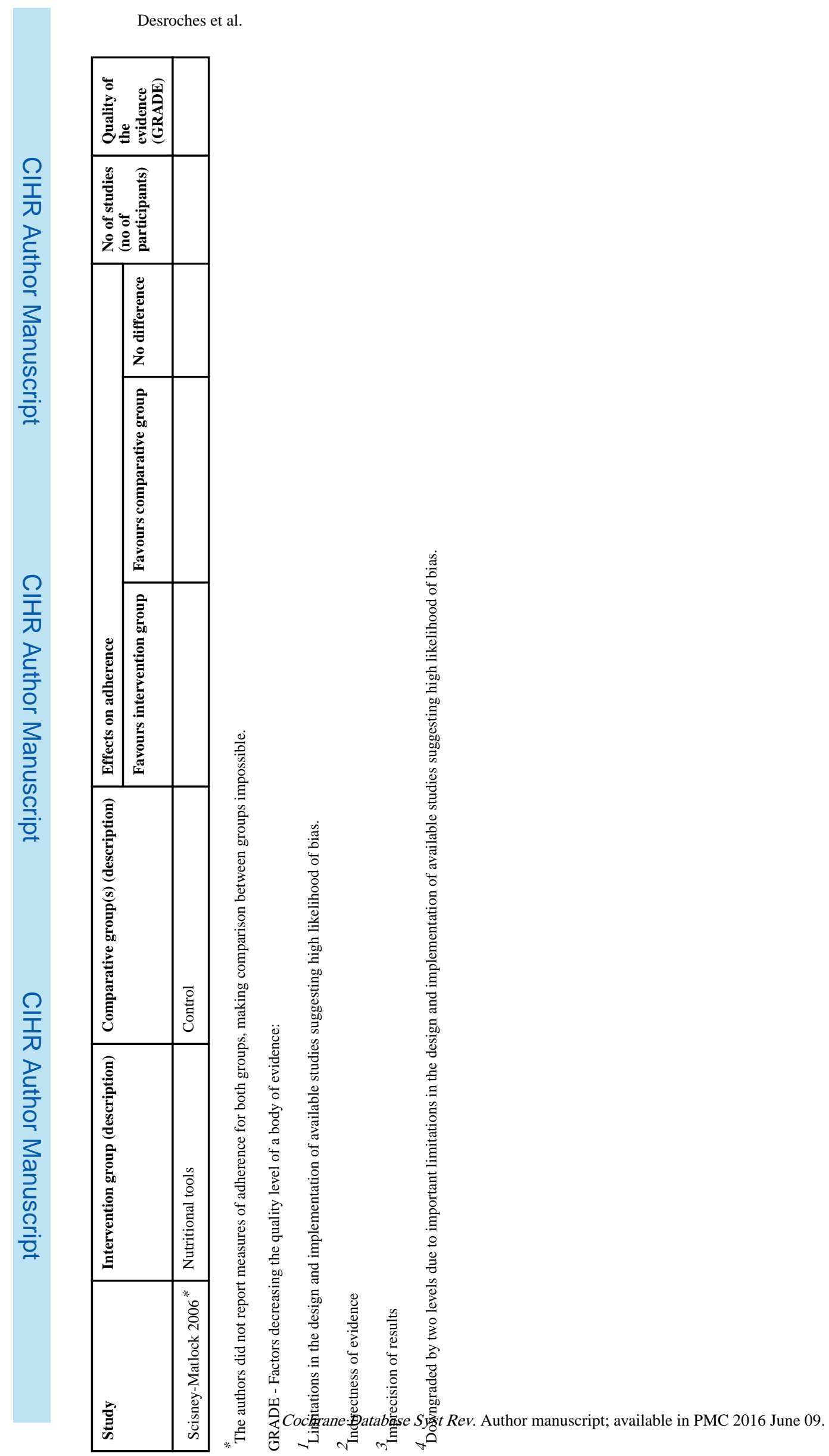


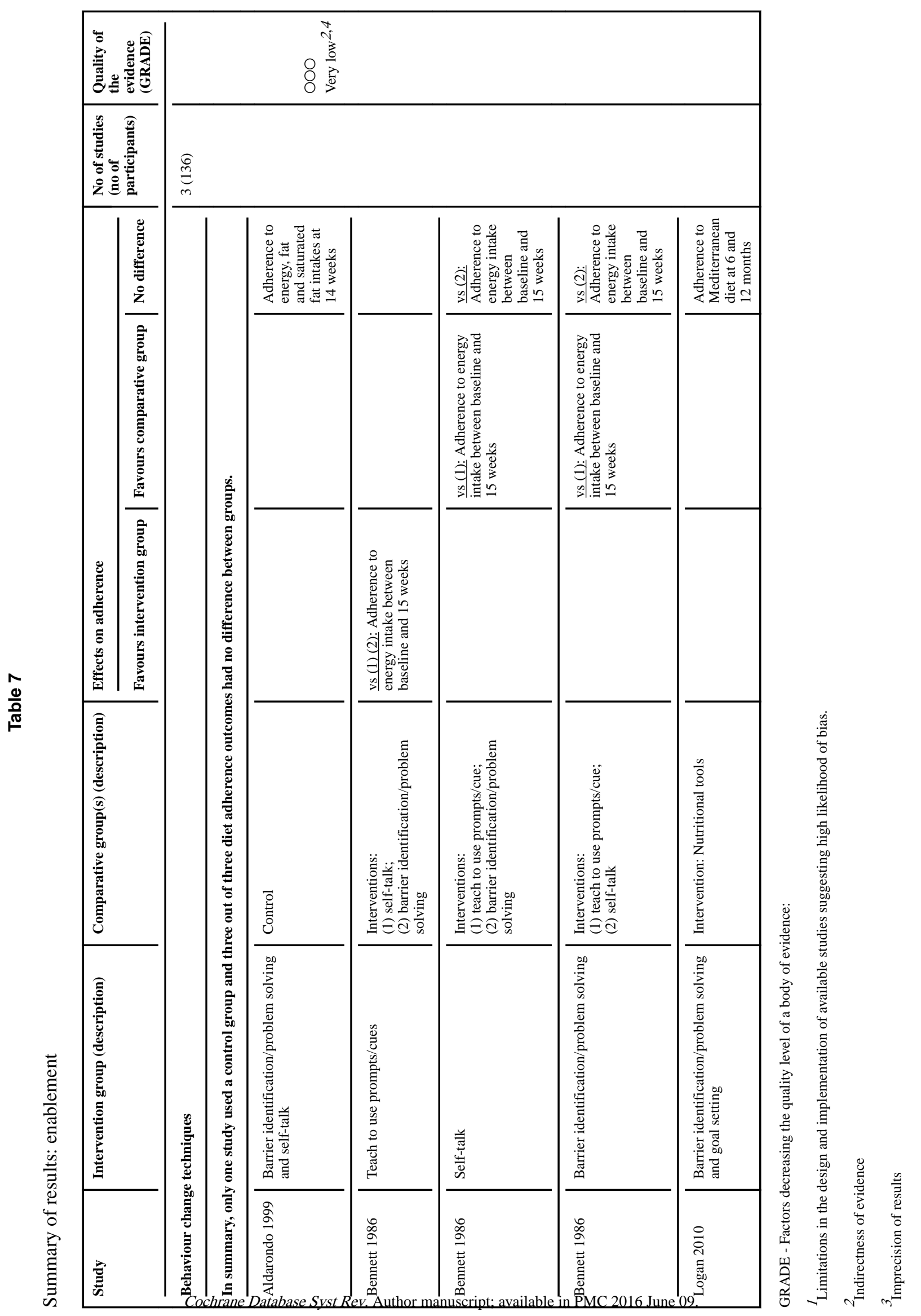




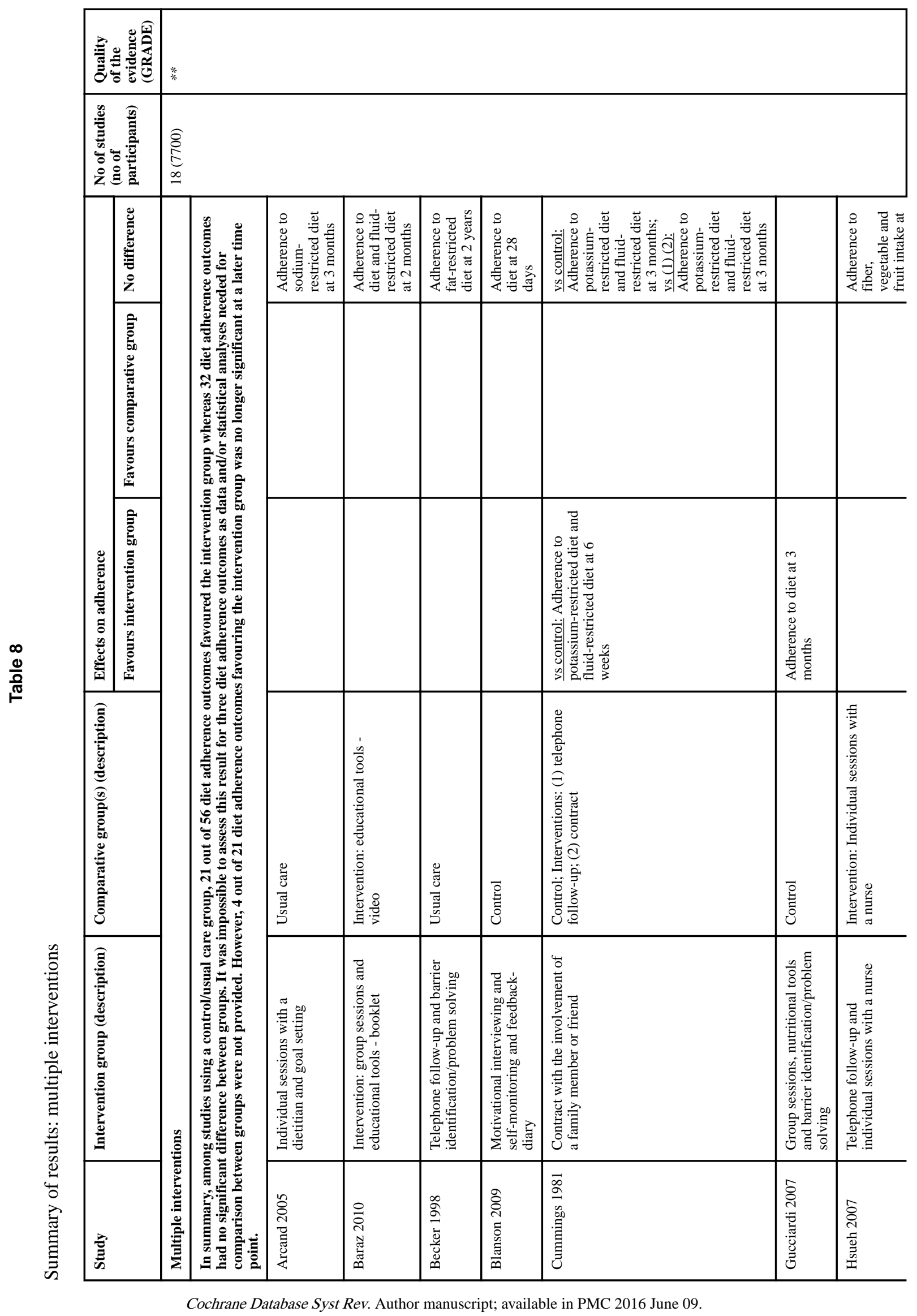




\begin{tabular}{|c|c|c|c|c|c|c|c|c|}
\hline \multicolumn{2}{|c|}{ 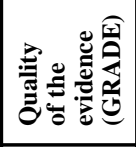 } & & & & & & & \\
\hline \multicolumn{9}{|c|}{ 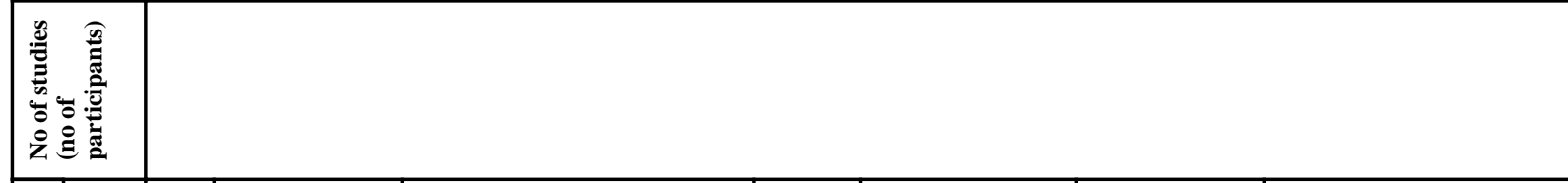 } \\
\hline \multirow{2}{*}{\multicolumn{2}{|c|}{ 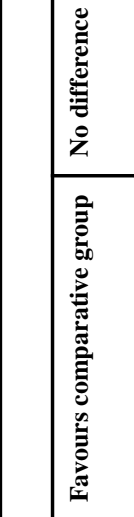 }} & 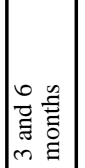 & 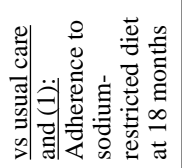 & 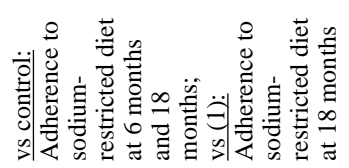 & & 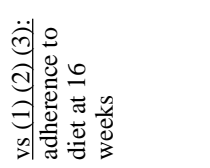 & 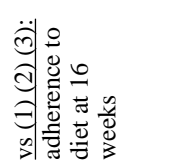 & 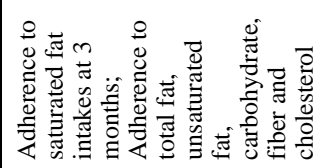 \\
\hline & & & & 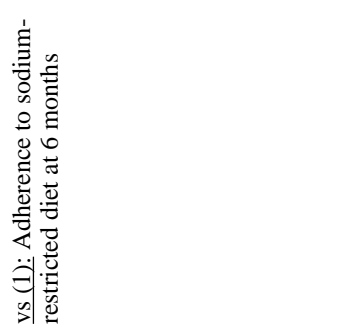 & & & & \\
\hline 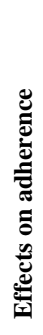 & 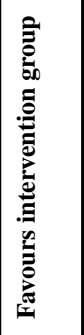 & & 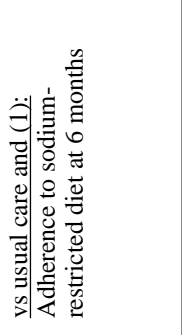 & & 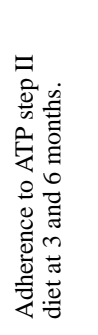 & & & 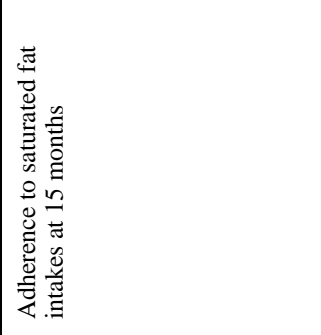 \\
\hline \multicolumn{2}{|c|}{ 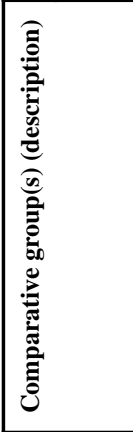 } & & 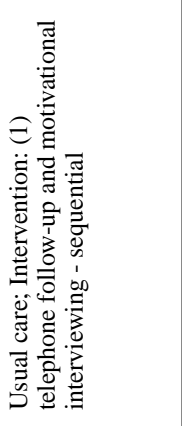 & 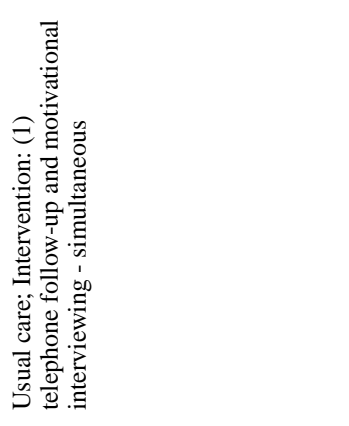 & 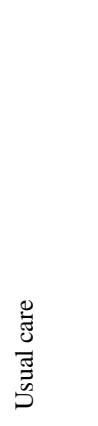 & 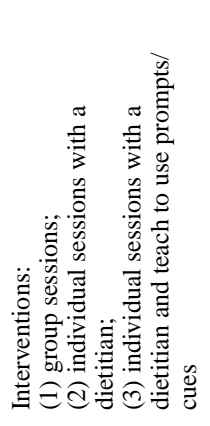 & 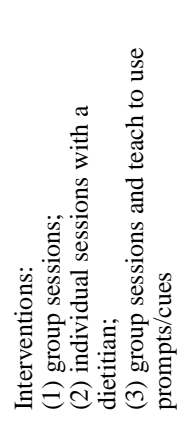 & 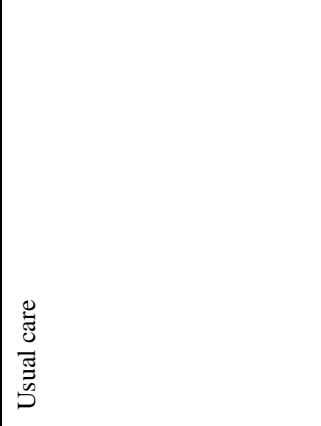 \\
\hline \multicolumn{2}{|c|}{ 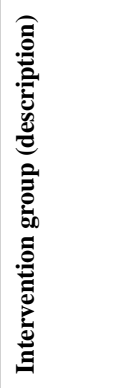 } & & 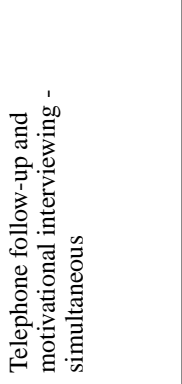 & 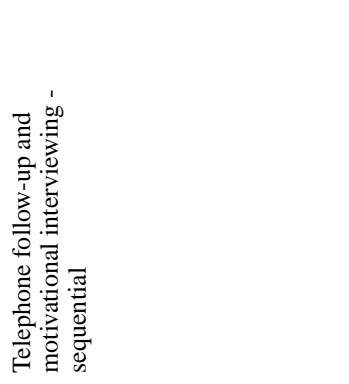 & 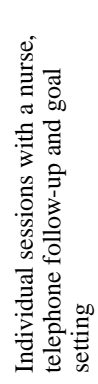 & 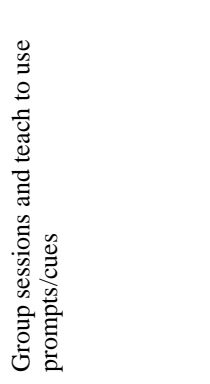 & 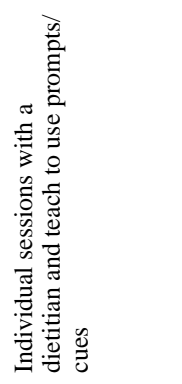 & 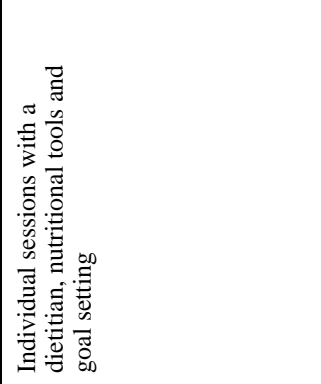 \\
\hline \multicolumn{2}{|c|}{ 竞 } & & 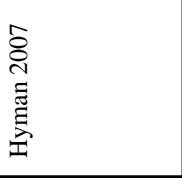 & 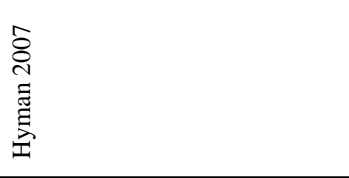 & 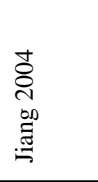 & 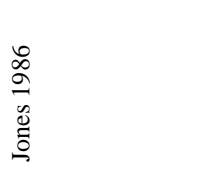 & 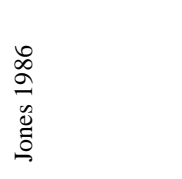 & 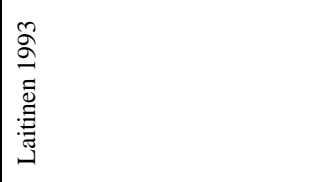 \\
\hline
\end{tabular}

Cochrane Database Syst Rev. Author manuscript; available in PMC 2016 June 09. 


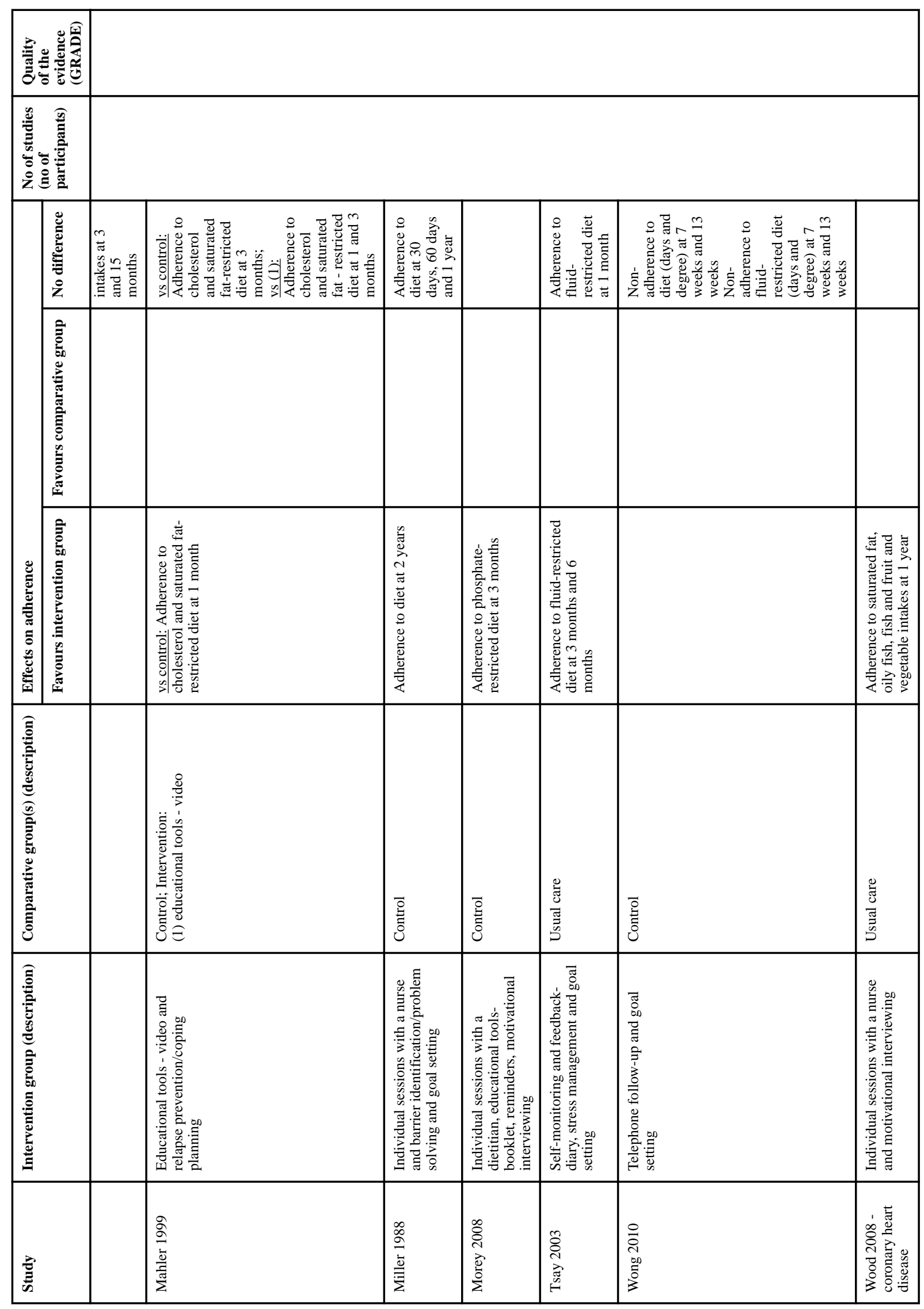

Cochrane Database Syst Rev. Author manuscript; available in PMC 2016 June 09. 


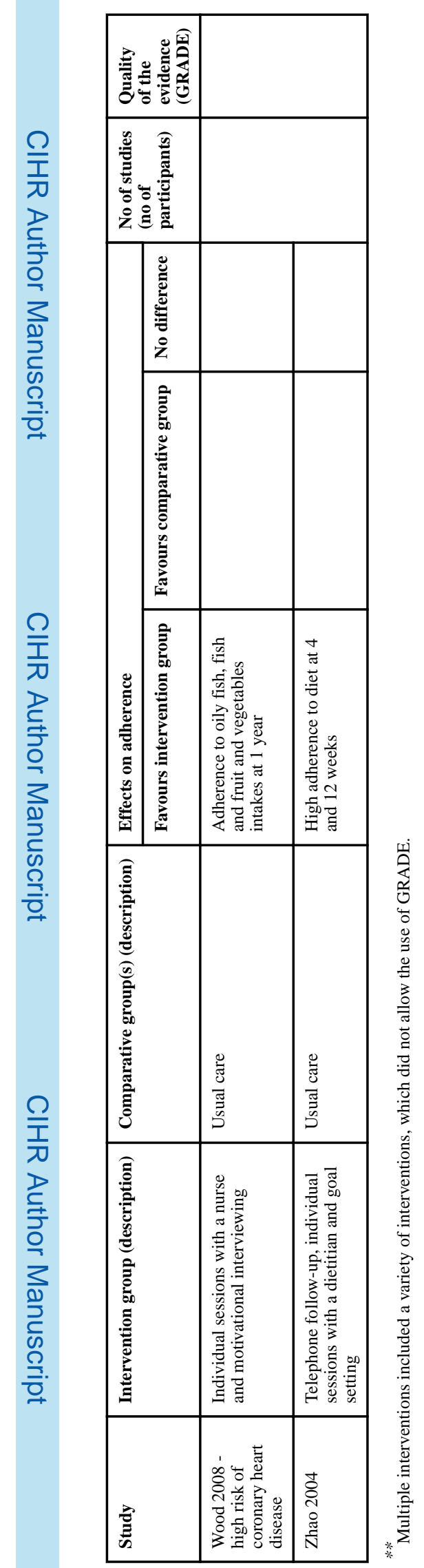

Cochrane Database Syst Rev. Author manuscript; available in PMC 2016 June 09. 